1224

\title{
INSECTES ET PARASITES NUISIBLES AUX ANIMAUX DOMESTIQUES AU CANADA
}
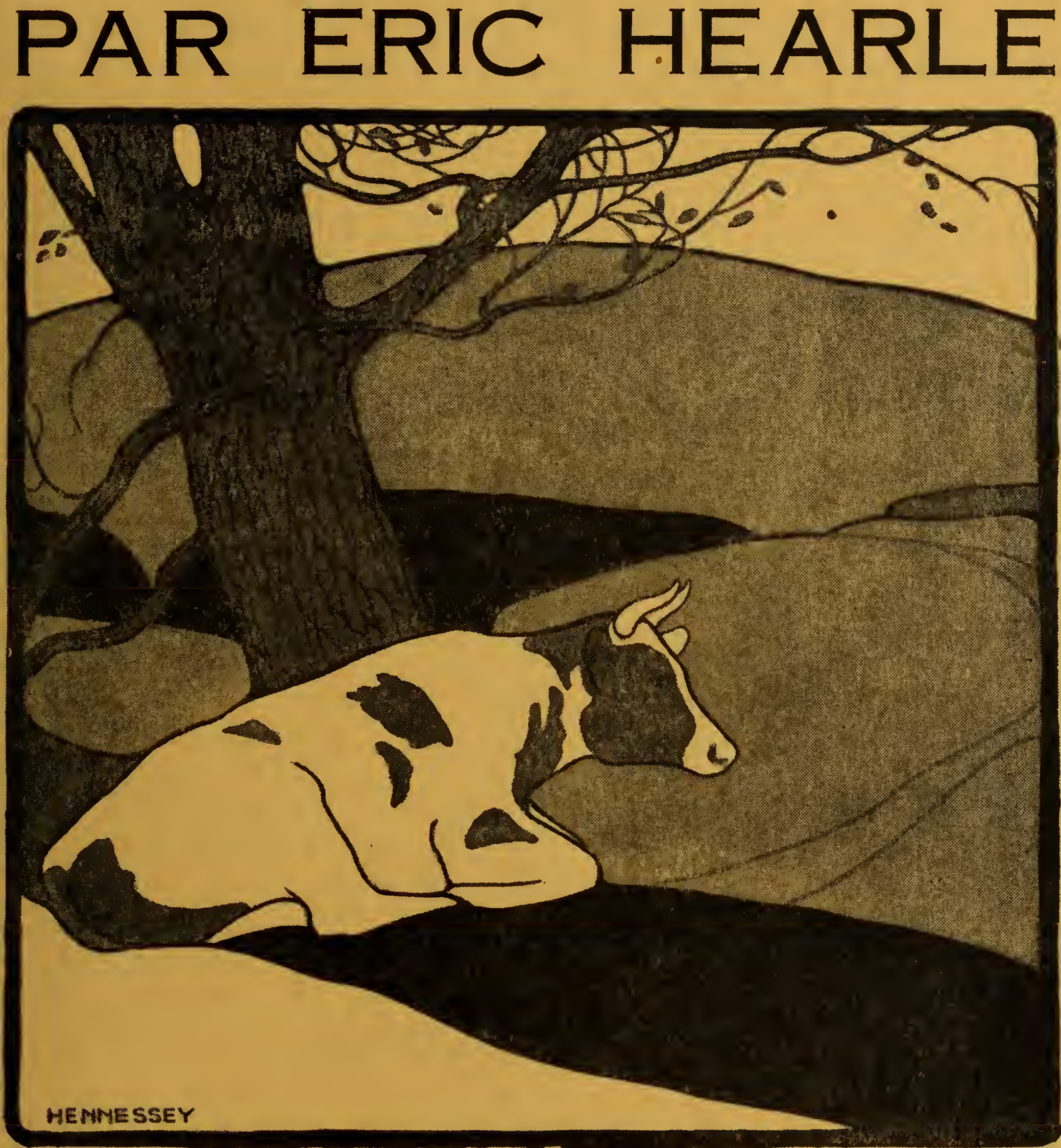

DOMINION DU CANADA

MINISTĖRE DE L'AGRICULTURE PUBLICATION 604

Iblié par ordre de l'Honorable James G. Gardiner, Ministre de l'Agriculture Ottawa, mars 1938 


\section{DIVISION DE L'ENTOMOLOGIE}

Entomologiste du Dominion et chef de la Division..... Arthur Gibson

Chef, Service des insectes nuisibles aux forêts........... J. J. de Gryse

Chef, Service de la suppression des fléaux étrangers...... L. S. McLaine

Chef, Service de l'entomologie systématique........... . H. McDunnough

Chef, Service des insectes nuisibles aux récoltes des champs et des jardins..................... G. Crawford

\section{LABORATOIRES}

Annapolis Royal, N.-E... Recherches sur les insecticides: Arthur Kelsall, préposé.

Fredericton, N.-B..... Recherches sur les insectes nuisibles aux forêts: R. E. Balch, préposé.

Recherches sur les insectes nuisibles aux récoltes des champs: R. P. Gorham, préposé.

Recherches sur les insecticides: C. W. Maxwell, préposé.

Berthierville, Qué....... Recherches sur les insectes nuisibles aux forêts: I.. Daviault, préposé.

Hemmingford, Qué..... Recherches sur les insectes nuisibles aux fruits: C. E. Petch, préposé.

Ottawa, Ont.......... Recherches sur les insectes nuisibles aux forêts: E. B. Watson, préposé.

Recherches sur les insectes nuisibles aux légumes: A. G. Dustan, préposé.

Enquête sur les insectes destructeurs: C. R. Twinn, préposé.

Recherches sur les insectes nuisibles aux produits entreposés: H. E. Gray, préposé.

Belleville, Ont......... Recherches sur les parasites: A. B. Baird, préposé.

Station de Vineland, Ont. Recherches sur les insectes nuisibles aux fruits: W. A. Ross, préposé.

Simcoe, Ont........... Recherches sur les insectes nuisibles aux fruits: J. A. Hall, préposé.

Strathroy, Ont.......... Recherches sur les insectes nuisibles aux récoltes des champs: A. A. Wood, préposé suppléant.

Chatham, Ont......... Recherches sur les insectes nuisibles aux récoltes des champs: G. M. Stirrett, préposé.

Brandon, Man......... Recherches sur les insectes nuisibles aux récoltes des champs: R. D. Bird, préposé.

Winnipeg, Man........ Recherches sur les insectes nuisibles aux forêts: H. A. Richmond, préposé.

Indian Head, Sask..... . Recherches sur les insectes nuisibles aux forêts et aux arbres d'ombrage: K. E. Stewart, préposé.

Saskatoon, Sask........Recherches sur les insectes nuisibles aux récoltes des champs: K. M. King, préposé.

Lethbridge, Alta........ Recherches sur les insectes nuisibles aux récoltes des champs: H. L. Seamans, préposé.

Agassiz, C.-B ......... Recherches sur les insectes nuisibles aux récoltes des champs et aux fruits: R. Glendenning, préposé.

Kamloops, C.-B.

Vancouver, C.-B

Victoria, C.-B. .

Vernon, C.-B.

Recherches sur les insectes nuisibles aux bestiaux: G. A. Mail, préposé.

Recherches sur les insectes nuisibles aux forêts: W. G. Mathers, préposé.

Recherches sur les insectes nuisibles aux fruits: W. Downes, préposé.

Recherches sur les insectes nuisibles aux forêts: R. Hopping, préposé.

Recherches sur les insectes nuisibles aux fruits et aux récoltes des champs: E. R. Buckell, préposé.

\section{STATIONS D'INSPECTION DES VÉGÉTAUX}

Halifax, N.-E

Saint John, N.-B.

Québec, Qué.

Montréal, Qué....

Toronto, Ont.

Niagara Falls, Ont.

Windsor, Ont

Winnipeg, Man.

Estevan, Sask

Vancouver, C.-B

Victoria, C.-B
A. K. Gibson, préposé. A. Finnamore, préposé. L. R. Gagnon, préposé. W. St. G. Ryan, préposé. W. A. Fowler, préposé. R. W. Sheppard, préposé. W. R. Lapp, préposé. C. A. S. Smith, préposé. P. C. Brown, préposé. H. F. Olds, préposé. J. Noble, préposé. 
DOMINION DU CANADA-MINISTĖRE DE L'AGRICULTURE

INSECTES ET PARASITES

NUISIBLES AUX

ANIMAUX DOMESTIQUES

AU CANADA

Par ERIC HEARLE

DIVISION DE

L'ENTOMOLOGIE

Publié par ordre de l'Honorable James G. Gardiner, Ministre de l'Agriculture Ottawa, mars 1938 
Version française par C.-E. Mortureux, B.S.A. 


\section{AVANT - PROPOS}

Le manuscrit original de ce bulletin, préparé par le regretté Eric Hearle, mort prématurément le 17 avril 1934, était basé en grande partie sur les études et les recherches entrep'ises par lui ou sous sa direction, alors qu'il était attaché aux laboratoires entomologiques d'Indian Head, Sask. (1926-28) et de Kamloops, C.-B. (1928-34), et chargé des recherches sur les insectes nuisibles aux bestiaux.

Ce bulletin, qui embrasse les derniers progrès enregistrés dans la connaissance de ce sujet, est destiné à remplacer le bulletin $n^{\circ} 29$ de la nouvelle série, écrit par le Dr Hadwen (aujourd'hui Directeur de science vétérinaire à la Fondation de recherches de l'Ontario), publié par le Ministère en 1923 et dont l'édition est épuisée depuis quelque temps. M. Hearle a fait l'éloge du Dr Hadwen dans les termes que voici: "Les recherches entreprises par le Dr Hadwen sur les insectes nuisibles aux bestiaux sont si importantes et si complètes qu'elles doivent nécessairement former la base de toute publication sur ces fléaux. J'ai moi-même largement puisé dans les résultats publiés de ces recherches pour. écrire ce bulletin.» M. Hearle exprimait également sa reconnaissance au Dr R. A. Cooley et au Dr R. R. Parker, du laboratoire des tiques du Service de la santé publique des Etats-Unis, Hamilton, Montana, pour conseils utiles et corrections apportées au chapitre sur les tiques; à R. K. Helmer, ex-directeur des fermes d'élevage de Nicola Lake, qui a examiné les manuscrits du point de vue d'un éleveur pratique; à T. P. McKenzie, ex-commissaire provincial des herbages pour la Colombie-Britannique, et à G. Challenger, souscommissaire provincial de l'industrie animale de la Colombie-Britannique, pour renseignements fournis au sujet des pratiques de paissance des bovins et des moutons sur les grands herbages; au Bureau d'entomologie et de quarantaine des plantes, Washington, D.C.; au Service entomologique du collège d'agriculture de l'Ontario, et au Dr E. A. Bruce, du Service fédéral sanitaire des animaux, qui ont prêté certains spécimens employés dans la préparation des illustrations.

M. Hearle s'était tout spécialement distingué dans l'étude des différents groupes d'insectes et d'arthropodes suceurs de sang qui attaquent l'homme et les animaux, et ses connaissances étaient tenues en haute estime par les éleveurs de l'Ouest du Canada. Les recherches sur lesquelles ce bulletin est basé ont été conduites principalement dans les provinces de l'Ouest, mais M. Hearle a consulté également un grand nombre de publications ad hoc de différentes provenances, car il voulait que cet ouvrage fût utile pour les propriétaires de bestiaux sur tous les points du Canada. Ce travail est sans conteste une contribution des plus précieuses pour l'industrie animale.

Le manuscrit laissé par M. Hearle a été revisé et préparé pour la publication par C. R. Twinn, de la Division de l'entomologie à Ottawa, qui a aussi incorporé un certain nombre de recommandations utiles émanant du professeur G. J. Spencer, du Service biologique de l'université de la Colombie-Britannique, chargé temporairement du laboratoire de Kamloops pendant les étés de 1934-1936, et de T. K. Moilliet, ex-membre du personnel de M. Hearle, qui, tous deux, ont lu attentivement le manuscrit. L'excellente série d'illustrations a été préparée par Frank Hennessey, artiste de la Division de l'entomologie, Ottawa. La version française de ce bulletin est l'œuvre de M. C.-E. Mortureux.

ARTHUR GIBSON,

Entomologiste du Dominion. 


\section{TABLE DES MATIÈRES}

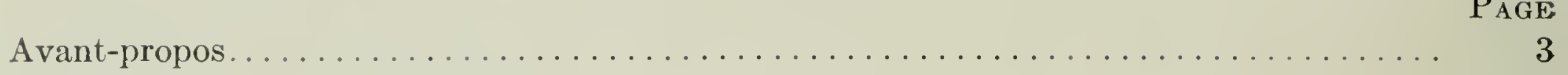

Introduction. . . . . . . . . . . . . . . . . . . . . . . . . . . . . 5

Comment les insectes nuisent aux bestiaux. . . . . . . . . . . . . . . . . . . 5

Moyens répressifs employés contre les insectes nuisibles. . . . . . . . . . . . . . . 6

Protection des animaux à l'époque des mouches. . . . . . . . . . . . . . . . . . . . 9

Soins et traitement $\mathrm{du}$ fumier. . . . . . . . . . . . . . . . . . . . . . . . . . 10

Parasites et maladies des animaux transportés par le fumier . . . . . . . . . . . . . . 12

Vers portés par les bousiers. . . . . . . . . . . . . . . . . . . . . . . . . . 13

Mouches diptères nuisibles aux animaux. . . . . . . . . . . . . . . . . . . . . 13

Mouches qui se multiplient dans le fumier. . . . . . . . . . . . . . . . . . 13

Mouches piquantes qui se multiplient dans les marais, les fondrières et les cours d'eau. 21

Mouches piquantes de moindre importance. . . . . . . . . . . . . . . . . . . . . . . 32

Estres et hypodermes. . . . . . . . . . . . . . . . . . . . . . . . . . . 34

Mouches à viande. . . . . . . . . . . . . . . . . . . . . . . . . . . . 60

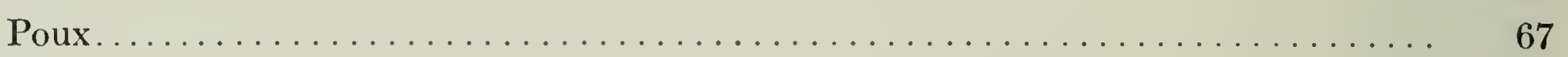

Puces........................................... 71

Punaises communes ennemies des volailles. . . . . . . . . . . . . . . . . . . . . 73

Poux des animaux domestiques et des volailles. . . . . . . . . . . . . . . . . . . . 74

Poux suceurs.................................... 74

Poux broyeurs.................................. 78

Mites des animaux domestiques et des volailles..................... 85

Acares ou mites à gale. . . . . . . . . . . . . . . . . . . . . . . . . . . . 85

Mites des volailles ou dermanysse des poulaillers. . . . . . . . . . . . . . . . . . 97

Autres espèces de mites des volailles. . . . . . . . . . . . . . . . . . . . . . . . 98

Tiques............................................... 98

Programme mensuel pour la suppression des insectes et des arthropodes qui nuisent aux bestiaux...................................... 110 


\title{
Insectes et parasites nuisibles aux animaux domestiques au Canada
}

\author{
Par Eric Hearle
}

INTRODUCTION

Les insectes qui affectent les animaux sont, dans bien des districts, le plus grand obstacle à l'élevage, et ils peuvent même parfois en déterminer le succès ou l'échec; c'est donc une question dont aucun éleveur ne peut se désintéresser. Il n'est pas exagéré de dire que peu de gens, même parmi ceux qui ont les rapports les plus intimes avec l'industrie animale, se rendent compte de l'énorme tribut que prélèvent les insectes et les autres parasites des animaux domestiques. Par exemple, aux Etats-Unis la perte annuelle causée par les seuls hypodermes est estimée à 50 millions de dollars. Hadwen estimait en 1923 que $27 \cdot 5$ pour cent des peaux canadiennes sont ("varronnées», c'est-à-dire trouées par les larves de ce parasite et l'auteur de ces pages estimait en 1929 que la perte annuelle causée par les hypodermes en Colombie-Britannique dépassait un quart de million de dollars; c'est là une évaluation des plus modérées. Le Dr L. Stevenson évalue à cinq millions de dollars la perte annuelle causée par les hypodermes dans la seule province de l'Ontario. Dans un rapport qu'il adressait en 1930 au Conseil national de recherches au sujet d'une enquête sur les dommages causés par les hypodermes, le Docteur W. E. Graham déclare que "plus de 50 pour cent des bovins canadiens étaient infestés en 1930.") Il estime que 95 pour cent des peaux portaient des tumeurs ouvertes ou guéries, causant une dépréciation de $\$ 700,000$ dans la valeur des peaux canadiennes.

Il y a plus de 200 espèces d'insectes connues qui attaquent les bestiaux, sans compter les acares, mites et tiques. Les pages suivantes traitent des métamorphoses, du cycle de la vie et des mœurs des espèces les plus importantes. Ces connaissances sont indispensables; sans elles, il serait impossible aux éleveurs de combattre ces fléaux d'une manière efficace.

\section{COMMENT LES INSECTES NUISENT AUX BESTIAUX}

Les insectes et les espèces apparentées nuisent aux bestiaux de plusieurs façons, dont les principales sont les suivantes:

(1) Irritation et perte de sang causées par les insectes et arthropodes suceurs, comme les moustiques, simulies ou mouches noires, taons, mouches piquantes des étables, mouches des cornes, poux suceurs, barbins ou mélophages du mouton, tiques et autres.

(2) Amaigrissement des animaux affectés et diminution de la production du lait chez les vaches laitières, résultant de la présence des larves parasitaires de différentes mouches, qui se développent dans le corps de l'animal, notamment les "varrons" ou larves de l'hypoderme, les œstres du cheval, du mouton, et différentes mouches à viande.

(3) Affaiblissement résultant des tourments et de l'incommodité causés par les attaques des insectes du premier groupe qui sucent le sang, et plus particulièrement de ceux du deuxième groupe, qui pondent leurs œufs. Les animaux, constamment harcelés et obligés de combattre leurs ennemis, ne peuvent paître paisiblement ni faire un bon travail et ils sont souvent très difficiles à conduire. 
(4) Irritation et amaigrissement causés par la perte de sommeil résultant du nombre immense de mouches communes qui infestent les écuries et les étables, et importunent constamment les animaux en se promenant sur eux et sur leur nourriture.

(5) Irritation et amaigrissement, et même maladies graves, causés par les attaques d'acares minuscules, comme les mites à gale.

(6) Pertes causées par la transmission mécanique des maladies par certains insectes comme la mouche commune, qui peuvent porter des bactéries infectieuses. Le charbon est souvent transmis par des mouches qui piquent comme la mouche des étables ou les taons; la façon intermittente dont ces derniers se nourrissent les dispose tout spécialement à transmettre la maladie. Les mouches qui piquent sont les hôtes intermédiaires de certaines maladies; une espèce commune de mouche noire sert de véhicule à une maladie importante du sang chez les canards. Les tiques et certaines mouches piquantes, spécialement la mouche du chevreuil, transmettent la tularémie qui affecte les moutons et quelques autres animaux. Enfin les mouches communes et beaucoup d'autres insectes peuvent aussi jouer le rôle d'hôtes intermédiaires de différents vers parasitaires, qu'ils transmettent aux animaux domestiques.

\section{MOYENS DE LUTTE CONTRE LES INSECTES QUI NUISENT AUX BESTIAUX DOMESTIQUES}

Les pertes causées par la plupart des insectes qui nuisent aux bestiaux peuvent être grandement réduites par la bonne application des connaissances actuelles, et il est possible, au moins dans certaines régions, de supprimer complètement quelques-unes des espèces les plus nuisibles.

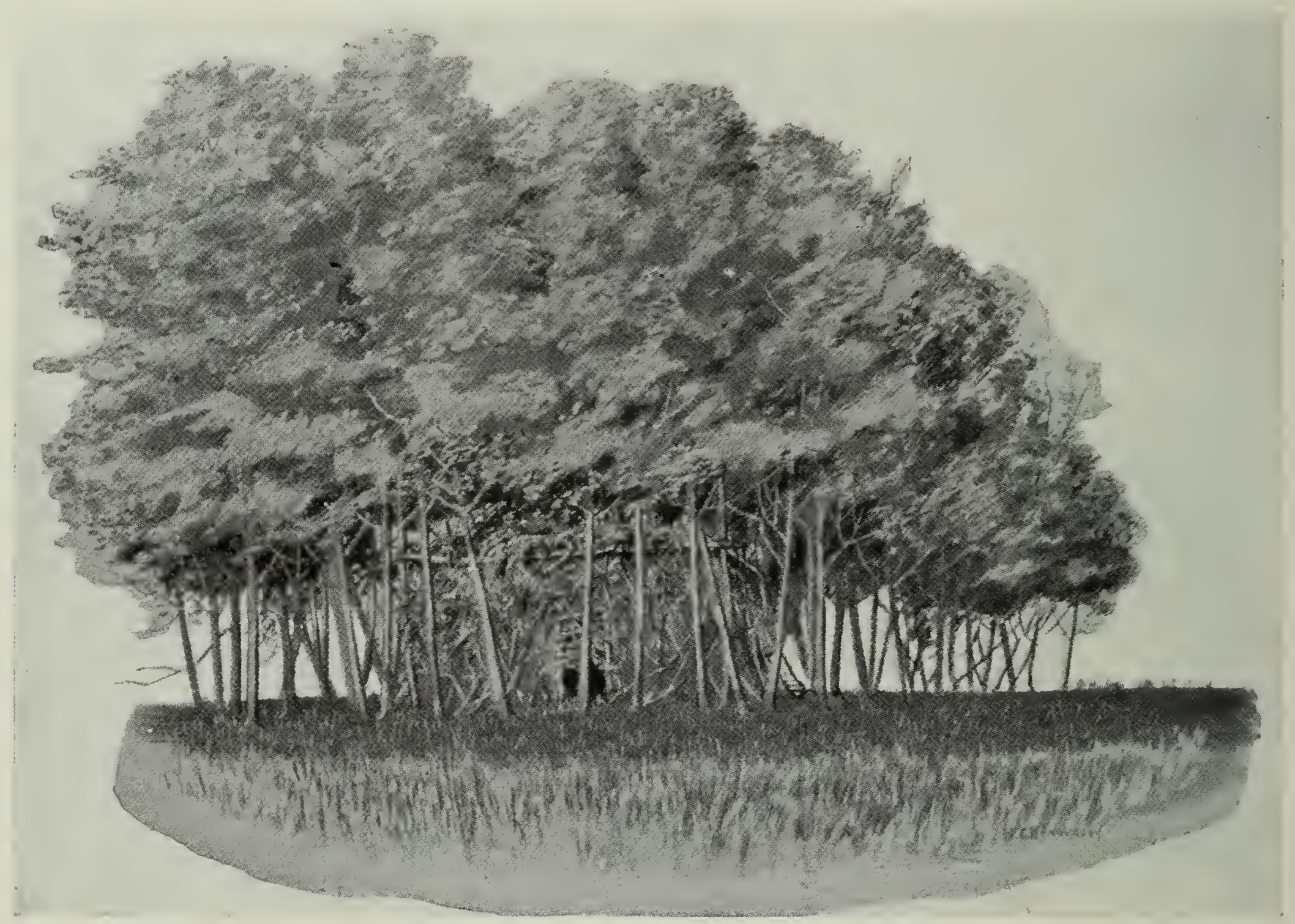

Fig. 1-Bosquet d'arbres contenant un refuge à bestiaux, contre les mouches (d'après Hadwen). 
Voici, résumés sommairement, les moyèns d'obtenir ces résultats:

(1) Pratiques générales de culture, mesures sanitaires et bon traitement du fumier.-On peut par ces moyens supprimer en partie les foyers de propagation des mouches communes et des mouches piquantes.

En supprimant tous les déchets et les charognes pour empêcher les mouches bleues (mouches à viande) de s'y multiplier, on préviendra dans une grande mesure la transmission des larves de ces mouches aux moutons et aux autres animaux. On peut se protéger contre les hypodermes et toutes les mouches piquantes, en utilisant des pâturages pourvus de refuges obscurs où les animaux peuvent se réfugier ou de bosquets épais d'arbres qui peuvent servir de refuges. On peut aussi très souvent protéger les animaux contre les mouches en les retenant à l'étable le jour et en les laissant paître et prendre leurs ébats la nuit. Enfin, le bon égouttement, le remplissage des trous et des endroits bas dans les champs, au cours des travaux de culture, peuvent faire disparaître les foyers de propagation des moustiques et des escargots, qui sont les hôtes intermédiaires de la douve chez les moutons. Dans les troupeaux où les brebis agnèlent de bonne heure et où les moutons sont débarrassés de leurs crottins, les mouches à viande ne causent que peu de dégâts.

L'isolation temporaire de tous les nouveaux animaux amenés sur la ferme est une pratique excellente, qui permet de réduire grandement le risque de l'introduction de parasites et de maladies aux autres animaux du troupeau.

(2) L'emploi de substances chimiques repoussantes ou de protecteurs mécaniques.-L'emploi de substances repoussantes ou de préparations anti-mouches pour protéger les animaux est très répandu au Canada, et cependant la plupart de' ces préparations n'ont pas beaucoup d'effet et quelques-unes même peuvent faire plus de mal que de bien. Elles peuvent être utiles cependant dans certaines conditions; par exemple, on peut protéger les plaies ou blessures accidentelles ou chirurgicales chez les animaux contre les mouches bleues en appliquant certaines substances comme l'huile de goudron; on protège les moutons contre l'ostre en goudronnant leur's naseaux; on prévient l'invasion des tiques en appliquant des enduits d'huile et de goudron sur la base de la crinière chez les chevaux, et on peut apaiser les vaches laitières à l'heure de la traite quand les moustiques et les autres mouches piquantes pullulent en les pulvérisant. L'emploi de substances repoussantes peut aussi être nécessaire lorsque les chevaux de travail ou de selle et les autres animaux sont attaqués par un grand nombre de mouches noires.

En général, l'emploi de pulvérisations contre les mouches n'est pas très utile; on n'a pas encore trouvé la substance idéale qui puisse conférer une protection utile pendant un long temps, quoique des centaines de matériaux aient été mis à l'essai par un grand nombre d'investigateurs compétents. Il convient de mentionner ici l'emploi de certains sels brevetés dont il s'est fait une grande vente dans ce pays et aux Etats-Unis parce que les fabricants prétendent que les animaux nourris de ces sels émettent des exhalations qui les immunisent contre les attaques des mouches. Il a été démontré par des essais soigneux que ces prétendus avantages ne reposent sur aucun fondement.

Parmi les protecteurs mécaniques, nous pouvons mentionner les gardes du nez et de la gorge généralement employés aujourd'hui pour protéger les chevaux contre les attaques des ostres, de même que les sacs de toile pour les oreilles dont on se ser't pour protéger les chevaux de travail contre les mouches noires, dont certaines espèces s'insinuent dans les oreilles lorsque les chevaux mangent. On recouvre parfois les chevaux de filets pour les protéger contre les morsures des mouches. Dans certains endroits des Etats-Unis où les mouches d'étable se montrent particulièrement nuisibles, on se sert de couvertures de toile et même de pantalons de toile pour protéger les animaux 
contre leurs attaques. Parfois aussi, on recouvre la tête et l'encolure des chevaux de capuchons de grosse toile pour les protéger contre certaines mouches qui recherchent ces endroits lorsque les chevaux mangent leurs repas.

(3) L'emploi d'insecticides, de bains, etc., pour la destruction des insectes et des parasites sur les animaux infestés.-Il y aurait à mentionner parmi les substances de ce genre le lavage au savon derris pour tuer les larves d'hypodermes (varrons) tandis qu'elles sont dans la peau des bêtes à corne; le bisulfure de carbone et le tétrachlorure de carbone pour débarrasser les chevaux des larves d'œstres attachées à leur estomac; le benzol pour tuer les larves chez les moutons; les solutions d'arsenic et d'autres ingrédients pour détruire les barbins (mélophages) des moutons, les mites à gale et les tiques; l'huile de lin crue et certaines huiles de pétrole brevetées pour tuer les poux sur les chevaux et les bêtes à corne; et le fluorure de sodium et les poudres de pyrèthre et de der'ris qui servent également à cet emploi, ainsi qu'à détruire d'autres parasites externes des animaux domestiques et des volailles.

(4) Méthodes spéciales de fumigation.-Deux méthodes intéressantes reposent sul l'emploi de vapeurs qui se dégagent de certaines substances et qui ont un effet stupéfiant. (a) On peut faire la pulvérisation en mélangeant de une demi-livre à une livre de poudre de pyrèthre, ou son équivalent d'extrait de pyrèthre, dans un gallon d'huile de charbon (pétrole); lor'squ'elle est pulvérisée dans l'air d'une chambre ou d'une écurie fermée, cette solution tue ou stupéfie les mouches qui tombent alors sur le plancher et peuvent être ramassées au balai et détruites. Il y a aussi les pulvérisations commerciales que l'on emploie de la même façon. On se sert d'autres pulvérisations pour détruire les mouches des cornes et les mouches des étables lorsque celles-ci se posent sur les animaux pour se repaître. (b) Le sulfate de nicotine (solution à 40 pour cent) enduit en couche légère sur les juchoirs des poulaillers débarrasse fort bien les oiseaux de leurs poux et des autres parasites externes. La valeur des boucanes pour stupéfier les insectes et protéger les animaux contre leurs attaques est bien connue dans certaines régions.

(5) L'emploi d'ingrédients chimiques pour détruire les insectes dans leurs foyers de multiplication.-Les moyens suivants sont employés: épandage d'huile sur les marais stagnants où les moustiques se multiplient; emploi d'huile miscible pour détruire les larves des mouches noires dans les cours d'eau; emploi d'ellébore, de borax et de fluosilicate de soude sur les tas de fumier pour détruire les larves de la mouche commune; et emploi de sulfate de cuivre en poussière ou en solution pour détruire les escargots qui servent d'hôtes intermédiaires pour la douve du mouton.

(6) Suppression des foyers de multiplication ou moyens d'empêcher que les insectes nuisibles ne s'y reproduisent.-On peut obtenir ce résultat en drainant les endroits bas où l'eau se rassemble et dans lesquels les moustiques se multiplient, et qui offrent également un milieu favorable aux escargots, lesquels sont essentiels au cycle évolutif de la douve; en endiguant pour empêcher l'inondation des endroits bas et prévenir ainsi le développement des moustiques et des escargots; en empilant le fumier en tas carrés et compacts pour réduire les conditions favorables à la multiplication des mouches; en brûlant les meules de paille et en labourant les bords extérieurs de ces meules pour réduire la production des mouches des étables; enfin, en détruisant les carcasses ou les charognes pour empêcher la multiplication des mouches bleues de la viande. Il y a des tiques très nuisibles qui se nourrissent sur des petits animaux rongeur's pendant leurs premières phases et l'on peut, par conséquent, détruire les tiques en supprimant ces petits animaux par différents moyens.

(7) L'emploi de pièges et de poison. - Les mouches communes, de même que les mouches bleues de la viande dont les larves infestent parfois les moutons et les autres animaux domestiques, peuvent être détruites en grand nom- 
bre par l'emploi de pièges spéciaux, appâtés de certaines substances. On sait, par exemple, que l'on peut réduire beaucoup le nombre de taons qui attaquent les chevaux en se servant de grandes cages à piège qui offrent un refuge sombre, très recherché par ces mouches. On peut aussi se servir de formaline et de lait pour empoisonner les mouches communes. Enfin, on a eu recours avec succès à la pulvérisation des carcasses avec des poisons à base d'arsenic pour réduire les mouches bleues de la viande.

(8) Liemploi de parasites pour combattre les insectes nuisibles aux bestiaux.Beaucoup d'insectes ont des parasites qui les attaquent et dont on peut se servir pour faire la guerre à ces insectes. On a cherché dans le Montana à prévenir les tiques qui causent la paralysie en élevant et en implantant un grand nombre de parasites importés. On dit que les mêmes parasites se sont montrés utiles pour réduire les tiques du chien dans certaines parties de l'Est des Etats-Unis. De même, en Australie, on cherche à détruire la mouche bleue au moyen de parasites.

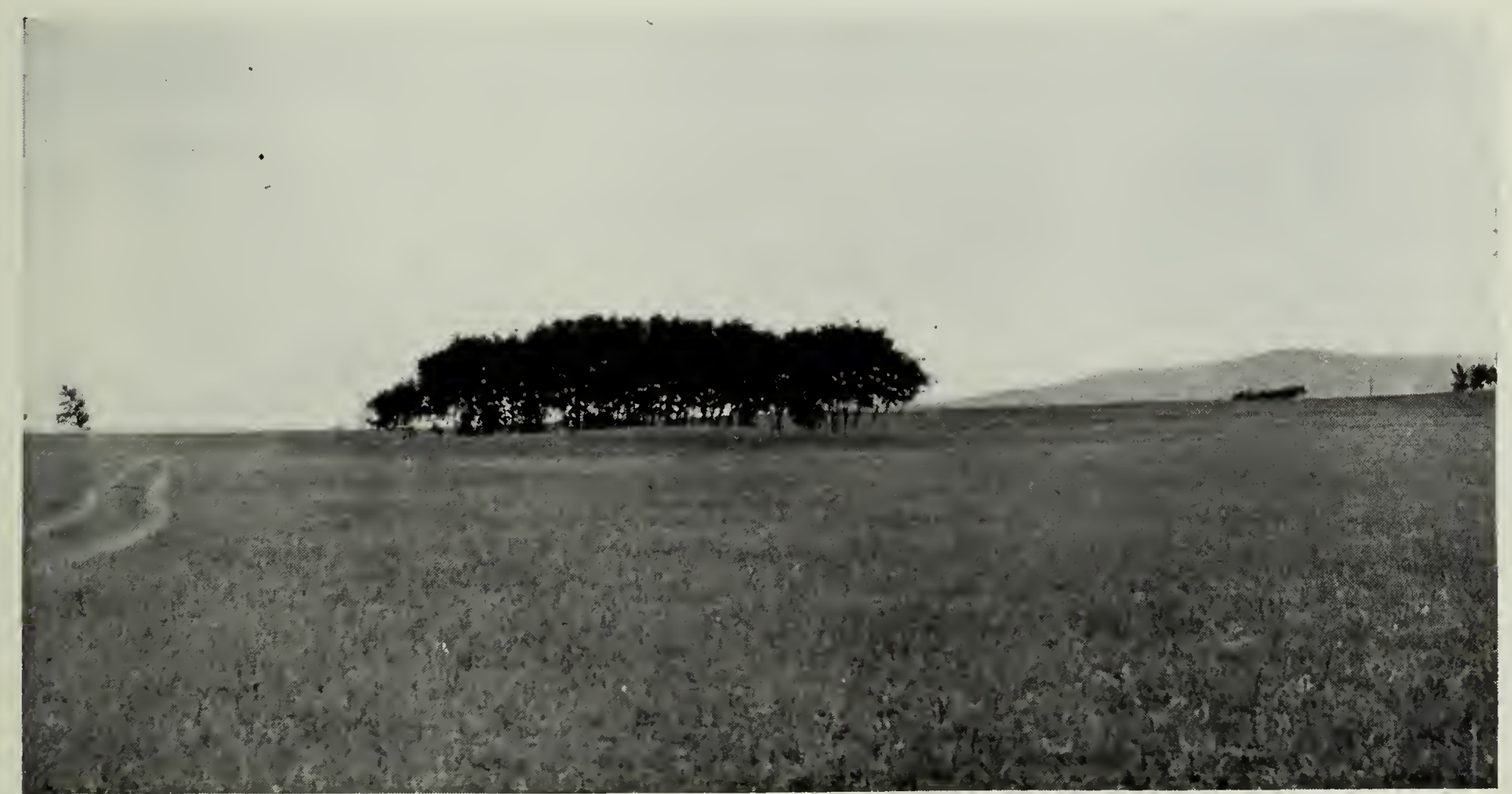

Fig. 2-Touffe naturelle d'arbres servant de refuge contre les mouches (originale).

(9) Importance de la coopération pour combattre les insectes nuisibles aux bestiaux.-On ne saurait trop insister sur l'importance de l'union des efforts pour combattre ces insectes nuisibles. La coopération entre cultivateurs est essentielle dans la lutte contre un grand nombre d'insectes qui attaquent les animaux de la ferme, et notamment, les hypodermes, les oestres, les mouches communes et certaines autres espèces.

\section{LA PROTECTION DES ANIMAUX À L'ÉPOQUE DES MOUCHES}

Pendant la saison où différentes espèces de mouches pullulent, les animaux de la ferme sont généralement laissés dehors, où ils endurent ces insectes du mieux qu'ils peuvent. Les cultivateurs emploient souvent toutes sortes de substances et d'applications repoussantes, mais les effets bienfaisants de ces substances, lorsqu'elles en ont, durent trop peu de temps pour être réellement satisfaisants. Un meilleur moyen de protéger les animaux est de fournir un refuge ou un abri pendant la journée. Les vaches laitières, les chevaux de travail et les autres bestiaux, qui sont généralement à proximité des bâtiments de la ferme, peuvent être mis à l'étable ou à l'écurie. Un abri de ce genre est 
même essentiel pour le maintien de la production du lait chez les vaches. Pour les chevaux, les bovins et les moutons qui paissent sur pâturage loin des bâtiments de la ferme, des refuges obscurs avec un rideau tendu devant la porte fournissent une bonne protection. Dans les pâturages où il y a des arbres ou des broussailles, on peut facilement construire des refuges obscurs en attachant des perches aux arbres pour former un toit de broussailles et en épaississant un peu les côtés. Les refuges de broussailles sont utiles dans les endroits boisés, car les animaux cherchent la protection des bois lorsque les mouches sont gênantes. On voit à la figure 2 un bosquet d arbres qui ferait un excellent abri si les sous-broussailles étaient éclaircies au centre, et si l'on y ajoutait un toit et des côtés.

L'emploi de boucane est un autre moyen de protéger les bestiaux. La fumée a un effet stupéfiant sur les insectes et elle peut être très utile lorsque

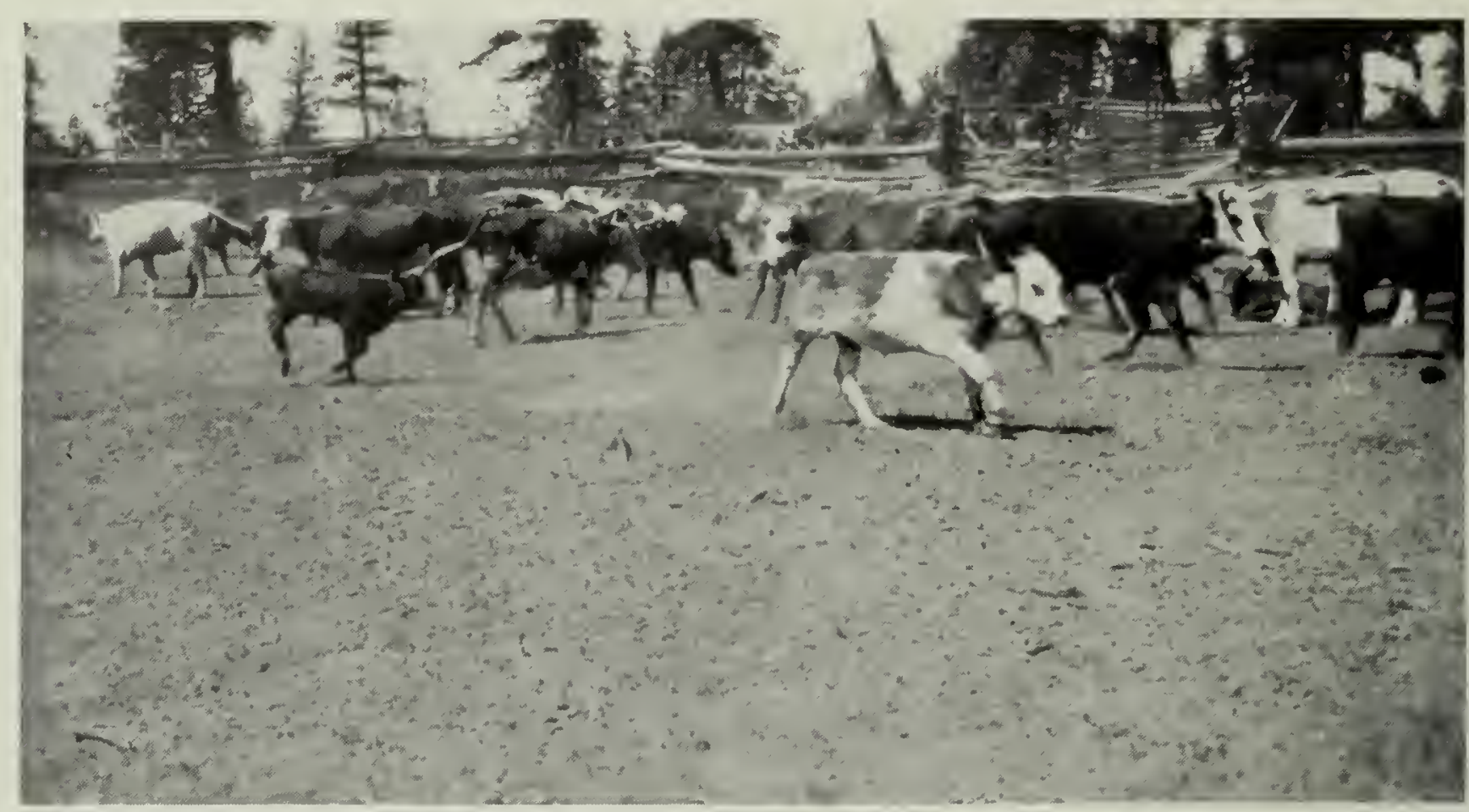

Fig. 3-Animaux pourchassés par l'hypoderme (d'après Hadwen).

les moustiques et les mouches noires abondent. Les lacs et les cours d'eau sont utiles également lorsque les bêtes à cornes sont exposées aux attaques des hypodermes, car ces animaux se protègent en se tenant dans l'eau. Il ne faut pas conduire les animaux tenus sur les grands herbages dans des corrals quand les mouches abondent et spécialement s'il y a des hypodermes. Les grands rassemblements d'animaux doivent être faits avant ou après la saison des mouches. Les recommandations qui précèdent sont d'ordre général; on trouvera des recommandations plus détaillées dans les autres chapitres de ce bulletin traitant de différentes espèces de mouches.

\section{LE SOIN ET LE TRAITEMENT DU FUMIER}

Le fumier est une grande richesse pour les cultivateurs, car il est essentiel pour maintenir la fertilité du sol, mais c'est aussi une source prolifique de mouches-mouches communes, mouches des étables, mouches des cornes, etc., et un intermédiaire par lequel un grand nombre de parasites et de maladies sont portés d'un animal à l'autre. On peut fort heureusement restreindre la propagation des mouches et les dangers de la transmission des parasites et des maladies au moyen de certaines mesures simples, peu coûteuses, qui aident également à conserver le fumier. Les cours des bâtiments et les étables 
elles-mêmes devraient toujours être tenues propres, sans trous, et bien égouttées. Il faut ramasser les déjections des animaux deux fois par semaine lorsqu'il fait chaud et les mettre sur le tas de fumier, lequel devrait être séparé du reste de la cour par une clôture ou empilé en dehors de la cour pour empêcher les animaux de manger la litière ou de la piétiner. Il est préférable de construire le tas de fumier sur une surface dure ou en béton, pour empêcher les larves des mouches d'avoir accès à la terre dans laquelle elles se transforment en nymphes. Les côtés du tas doivent être taillés d'équerre, presque verticaux, mais inclinés légèrement vers le centre. A mesure que l'on ajoute du fumier frais au tas, il faut le tasser fortement au moyen d'une pelle. La chaleur engendrée par la fermentation est utile pour détruire tous les oufs des mouches, les larves et les nymphes, sauf peut-être ceux qui sont près de la surface de la couche supérieure.

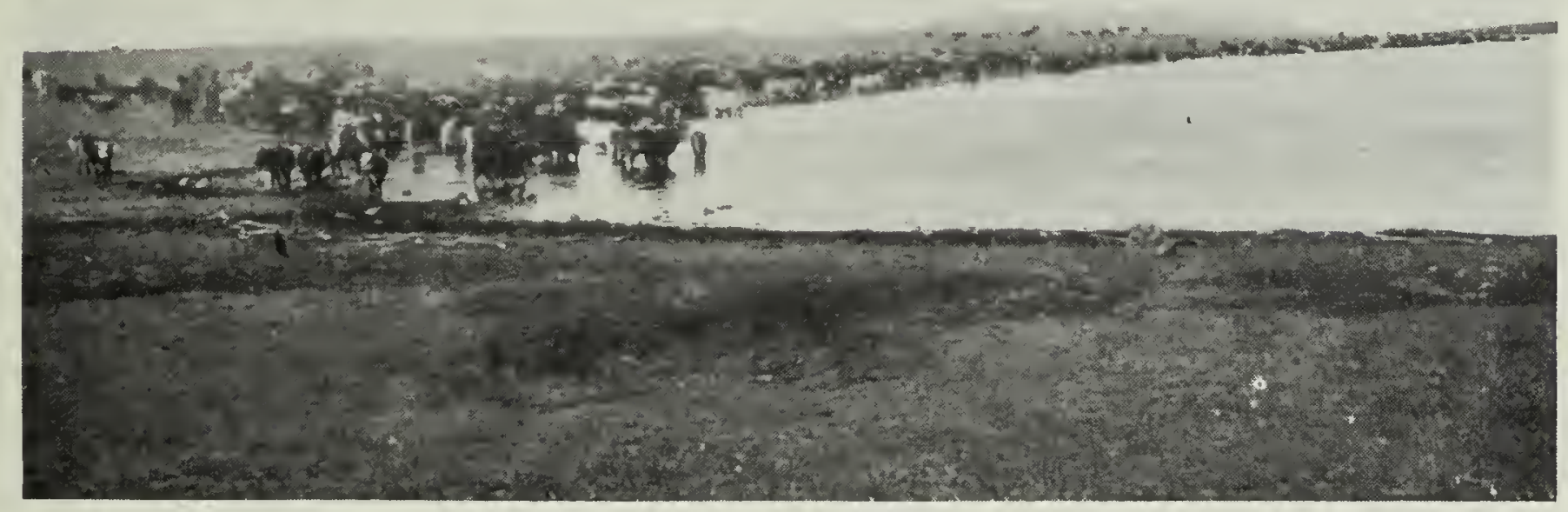

Fig. 4-Animaux se tenant dans l'eau pour éviter l'attaque de l'hypoderme (d'après Hadwen).

Si la quantité de fumier est petite, on peut la traiter au moyen d'ingrédients chimiques pour empêcher les mouches de s'y multiplier. Une demilivre d'ellébore dans dix gallons d'eau, ou une livi'e de fluosilicate de soude mélangé dans quinze gallons d'eau et qu'on laisse reposer pendant 24 heures suffisent pour traiter dix pieds cubes ou huit boisseaux de fumier. Ces ingrédients chimiques sont un poison et il faut empêcher les animaux d'en boire. On peut s'en servir pour traiter la couche supérieure du tas de fumier. Le borax a plus d'action comme larvicide, mais il peut diminuer la valeur fertilisante du fumier.

Un autre moyen d'empêcher les mouches de se multiplier et qui est recommandé aux Etats-Unis, est de se servir d'un piège à larves consistant en un bassin peu profond, en béton, légèrement incliné et relié à une citerne au moyen d'un drain muni d'une cheville. On construit sur ce bassin une plate-forme en bois au moyen de baguettes de bois clouées sur un cadre d'un pied de hauteur et placées à environ un pouce et demi d'espacement. On empile le fumier sur cette plate-forme. On tient toujours de l'eau dans le bassin et les larves qui émigrent en quête de terre pour se transformer en nymphes tombent dans l'eau et se noient. On peut faire écouler l'eau qui se trouve dans la citerne en enlevant la cheville de temps à autre. Il ne faut pas laisser le bassin se remplir de fumier. La construction de ce piège est représentée à la figure 5 


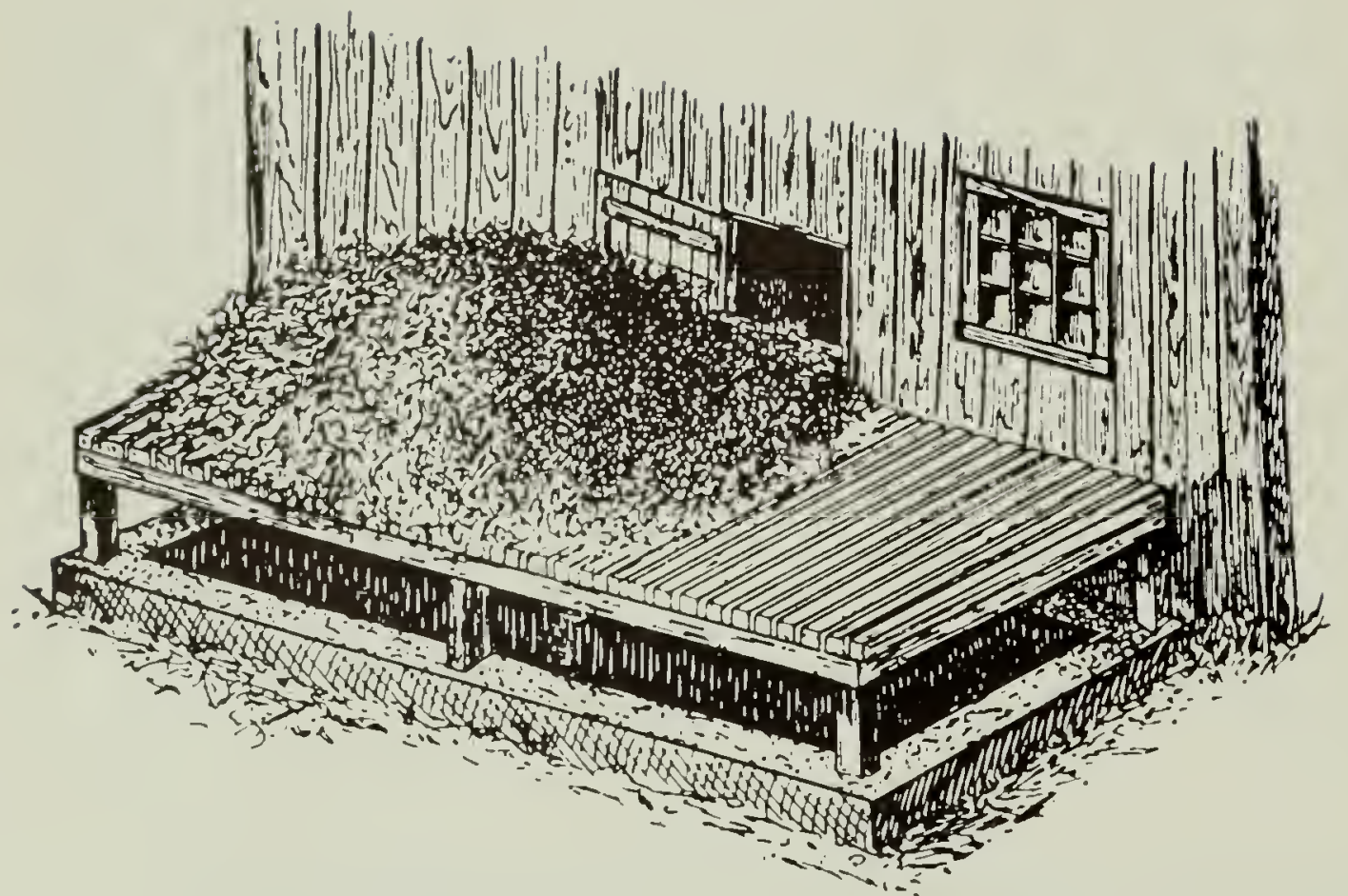

Fig. 5-Un piège à larves (d'après Brittain).

Pendant la saison des mouches c'est une excellente pratique que de transporter le fumier aux champs à fréquents intervalles, au moins deux fois par semaine lorsqu'il fait chaud, et de l'épandre en couche mince au moyen d'une épandeuse à fumier. Dans ces conditions, l'effet desséchant du soleil et du vent empêche les mouches de se reproduire. Il faut aussi éparpiller fréquemment pendant l'été, au moyen d'une herse à chaînons ou d'un autre instrument de ce genre, les déjections des animaux qui sont tenus dans de petits enclos ou dans des champs près des bâtiments de la ferme. Enfin, il faut avoir soin d'enlever et d'épandre le fumier qui s'accumule autour des hangars et des refuges construits dans les champs pour protéger les animaux contre les mouches; les animaux se tiennent ainsi propres et les mouches ne peuvent plus se multiplier.

On ne devrait jamais permettre aux bestiaux, et spécialement aux pores, de se réfugier sous les étables et les autres bâtiments; on fera bien de poser des planches pour les empêcher d'y aller. C'est une bonne pratique que d'épandre de la chaux sur la cour de la ferme après l'avoir nettoyée et de bêcher ou de labourer le sol qui a été imprégné de fumier.

Les campagnes de nettoyage en commun sont celles qui donnent les meilleur's résultats dans la guerre aux mouches et il est vivement à désirer qu'elles soient entreprises partout où les fermes sont suffisamment rapprochées pour que ces efforts coopératifs puissent être mis en œuvre.

\section{LE RÔLE DU FUMIER DANS LA TRANSMISSION DES PARA- SITES ET DES MALADIES}

On comprend mieux à quel point il importe de bien soigner et de bien utiliser le fumier quand on sait qu'un certain nombre de maladies et de parasites sont transmis d'un animal à l'autre par l'intermédiaire du fumier. Il y a plusieurs maladies bactériennes comme la fièvre charbonneuse, le charbon symptomatique, le choléra des porcs et la tuberculose, qui sont transmises de cette façon. Il en est spécialement ainsi de la tuberculose, car les bactéries de cette maladie se rencontrent souvent dans le fumier provenant de bêtes tuberculeuses. Beaucoup des hommes chargés du soin des bestiaux ont l'habitude déplorable d'employer les étables comme lieux d'aisances et les

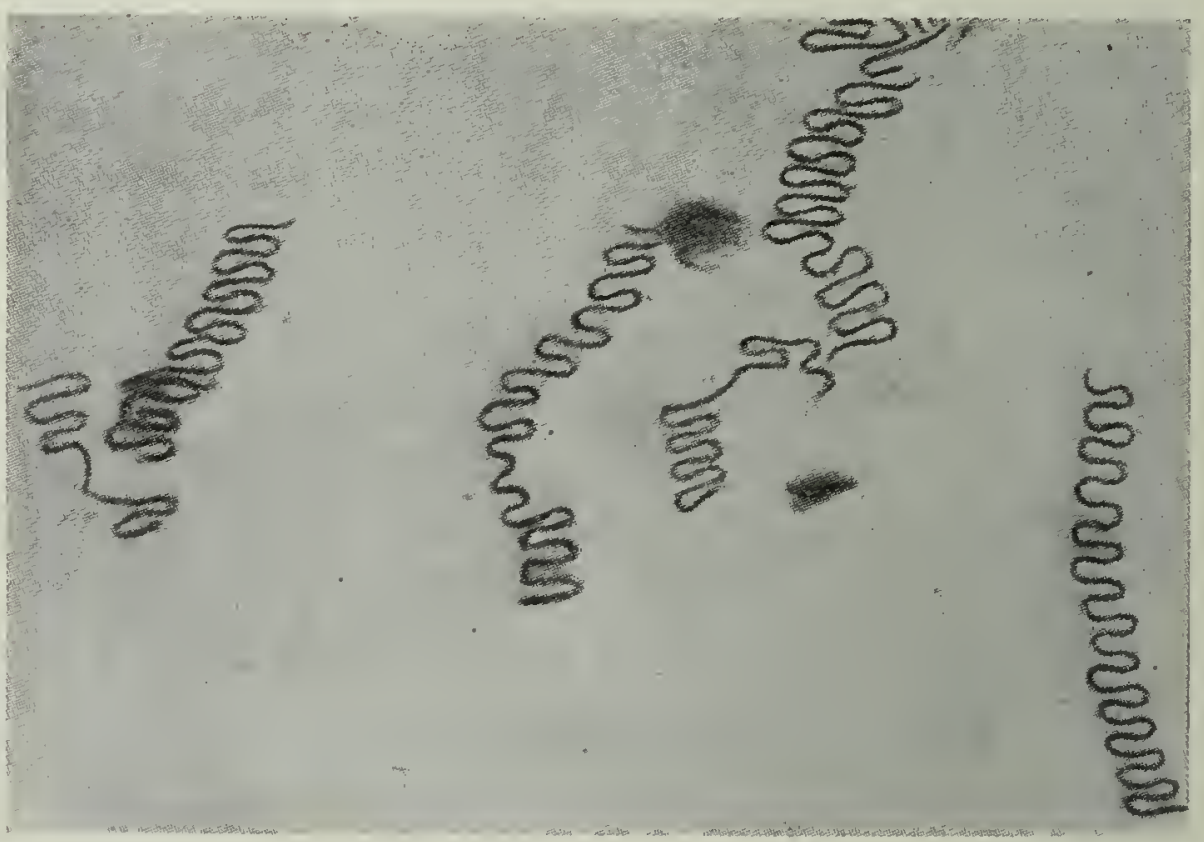

Fig. 6-Un ver rond, Gongylonema scutatum, généralement trouvé dans l'oesophage du bœuf, du mouton et du cheval (d'après Hadwen). 
excréments humains sont souvent jetés sur le tas de fumier. On ne devrait jamais, pour ces raisons, permettre aux bêtes à cornes, aux cochons ou aux autres bestiaux de se nourrir sur le tas de fumier. La rougeole, une maladie des por'cs et des vaches, causée par la présence de larves du ténia dans le corps, peut être contractée par les animaux qui mangent des oufs ou des parties de ténia évacués par l'homme. En outre, le fumier de presque tous les animaux de la ferme contient des œufs de vers parasitaires et il peut être avalé par les bestiaux lorsque ceux-ci mangent des fourrages contaminés par le fumier. Les parcs ou enclos et les champs rarement cultivés sont une source de danger sous ce rapport, d'autant plus que ces endroits sont généralement infestés de bousiers qui servent d'hôtes secondaires pour les vers, c'est-à-dire de porteurs de vers. On trouvera dans le chapitre suivant des renseignements plus complets sur ce point.

\section{LES BOUSIERS COMME PORTEURS DE VERS}

L'entomologiste Ransom a récapitulé les connaissances que nous possédons sur les insectes en tant que porteurs de vers. Parmi les vers les plus importants qui passent certaines de leurs phases dans les insectes coprophages ou "bousiers" il y a les suivants:

Gongylonema scutatum (Leuckart 1873), un ver rond qui vit dans l'œsophage ou le gosier du bœuf, du mouton et du cheval. Les œufs des vers qui sont évacués par les animaux sont mangés par les bousiers dont plusieurs espèces jouent le rôle d'hôtes intermédiaires. Les bousiers sont avalés par les animaux qui paissent.

Vers de l'estomac des porcs, Arduenna strongylina Rudolphi et Physocephalus sexalatus (Molin 1860), Diesing 1861. Ce sont là deux espèces de vers de l'estomac des porcs qui sont très nuisibles aux porcs. Ils passent certaines phases de leur cycle évolutif dans les coléoptères, tels que les scarabées et d'autres espèces.

Le ver géant à tête épineuse des porcs, Macracanthorhynchus hirudinaceus (Pallas 1781) Travossos 1916. C'est un gros ver blanc qui vit sur le petit intestin du porc et provoque l'apparition de gros ulcères ou plaies sur les parois. Les œufs évacués par les porcs sont avalés par les larves des bousiers (larves blanches). Les oufs éclosent et se développent dans ces larves, ils sont à leur tour mangés par leur hôte, le porc, dans lequel ils arrivent à maturité.

Moyens préventifs.-Les bousiers, comme leur nom l'indique, vivent dans le fumier, et les recommandations que nous avons faites au sujet de la façon de combattre la mouche des cornes s'appliquent également à eux (voir page 21); l'important est de charrier le fumier au champ à fréquents intervalles ou de l'éparpiller en couche mince et de le laisser se dessécher. Les pares permanents à cochons sur terrain nu sont bientôt infestés de toutes sortes de parasites et c'est

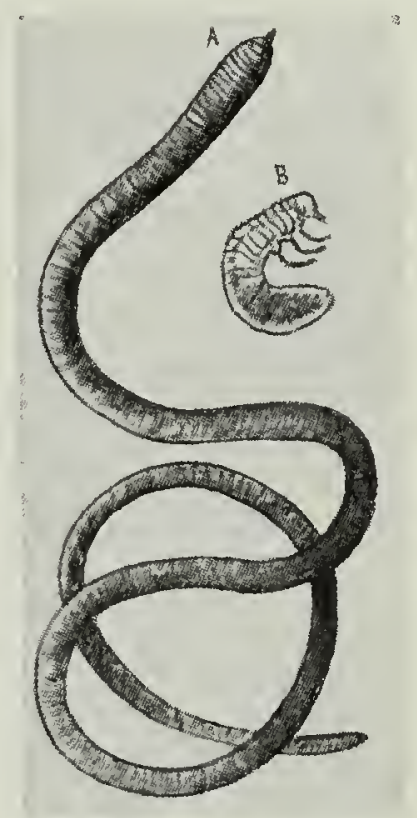

Fig. 7-(A) Le ver géant à tête d'épine du porc, Macracanthorhynchus hirudinaceus; (B) Ver blanc (d'après Hegner, Root et Augustins). spécialement dans ces endroits que les cochons ramassent ces insectes. C'est une bonne précaution que de retourner à la bêche ou à la charrue le sol de surface, mais il ne faut pas répéter souvent cette opération, car les oufs de certaines espèces de vers sont très résistants et peuvent encore éclore lorsqu'ils sont ramenés à la surface par un deuxième labour.

\section{MOUCHES DIPTĖRES NUISIBLES AUX BESTIAUX Mouches qui naissent dans le fumier LA MOUCHE COMMUNE (Musca domestica L.)}

Description et cycle évolutif.-La mouche commune est si bien connue qu'il peut paraître superflu d'en faire une description; et, cependant, on la confond 
souvent avec d'autres mouches, comme la mouche piquante des étables ou "mouche charbonneuse" et la pollénie. De couleur cendrée, la mouche commune mesure environ un quart de pouce de longueur. Elle porte sur le thorax quatre raies foncées, et sur l'abdomen une région centrale de couleur foncée;

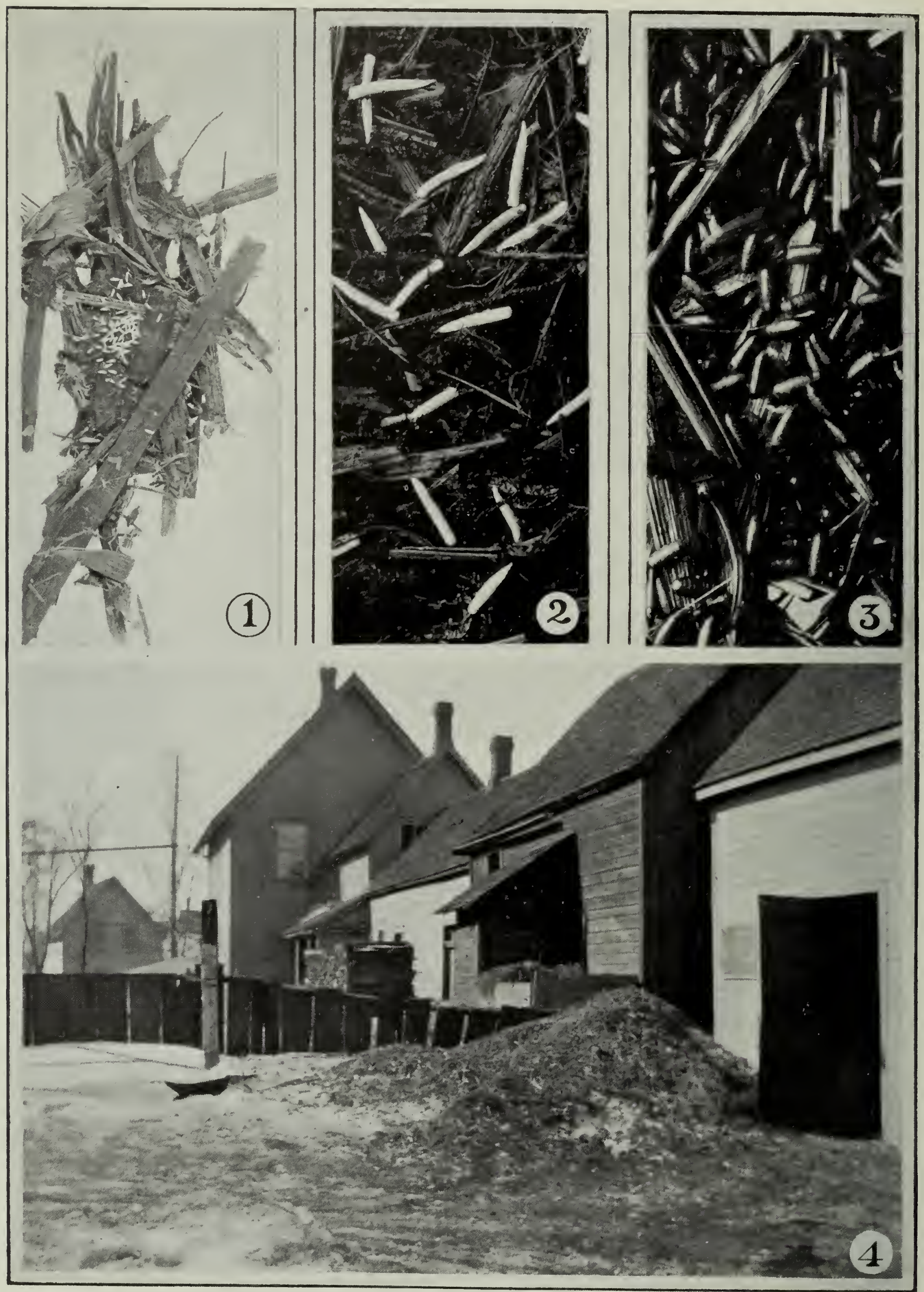

Fig. 8-La mouche commune; 1, œufs; 2, larves; 3, nymphes ou pupes; tous de grosseur naturelle; 4 , tas de fumier-foyer typique de multiplication (d'après Gibson et Twinn). 
les côtés sont plus pâles. Les parties de la bouche ne sont pas aussi pointues que chez la mouche des étables; elles sont en forme de coussinet aux extrémités. Ces parties buccales régurgitent et rejettent constamment de petites gouttelettes d'humidité qui contiennent souvent des bactéries nuisibles, et l'infection peut être propagée de cette façon.

La mouche commune passe par les quatre métamorphoses habituelles aux insectes: l'œuf, la larve, la pupe ou nymphe, et la mouche adulte ailée. Une femelle peut pondre de 600 à 2,000 oufs d'un blanc luisant, ressemblant à de tout petits grains de riz, et ces œufs sont déposés par petits paquets dans le fumier, les déchets alimentaires et d'autres matières en décomposition. L'incubation peut se faire en une journée, et les petites larves blanches, sans pattes, atteignent leur taille complète, d'un demi-pouce, en moins d'une semaine lor'sque les conditions sont favorables. On a trouvé près de 7,000 de ces lar'ves sur un échantillon de fumier de quatre livres. Her'ms a calculé qu'une tonne de fumier peut contenir 900,000 lar'ves après quatre jours seulement d'exposition à la ponte. Lorsqu'elles ont atteint leur complet développement, les larves émigrent sur les parties les plus sèches de leur habitat et se métamorphosent en nymphes lisses, brun foncé, en for'me de baril, et la mouche adulte peut sortir de la nymphe au bout d'une semaine environ lorsque les conditions sont favorables. Les générations se succèdent tout l'été et il en résulte une nombreuse population à l'automne.

La mouche commune comme porteur de maladies et de parasites. - La part que prend la mouche commune à la transmission des maladies de l'homme est bien connue, mais on connaît moins le rôle qu'elle joue enver's les animaux sous ce rapport. Il est probable cependant qu'un grand nombre de maladies des ar imaux sont transmises par les mouches, d'autant plus que ces insectes trouvent généralement plus facilement accès aux déjections des animaux infectieux ainsi qu'à leur's plaies et blessures qu'à celle de l'homme. Elles incommodent aussi beaucoup les animaux par leur attention persistante, et lorsqu'elles sont très nombreuses, elles peuvent les faire maigrir et en réduire la production.

Trois espèces de vers londs du genre Habronema, qui vivent dans l'estomac des chevaux et se rencontrent parfois dans les plaies qui se produisent sur ces animaux pendant l'été, passent une partie de leur vie dans les mouches

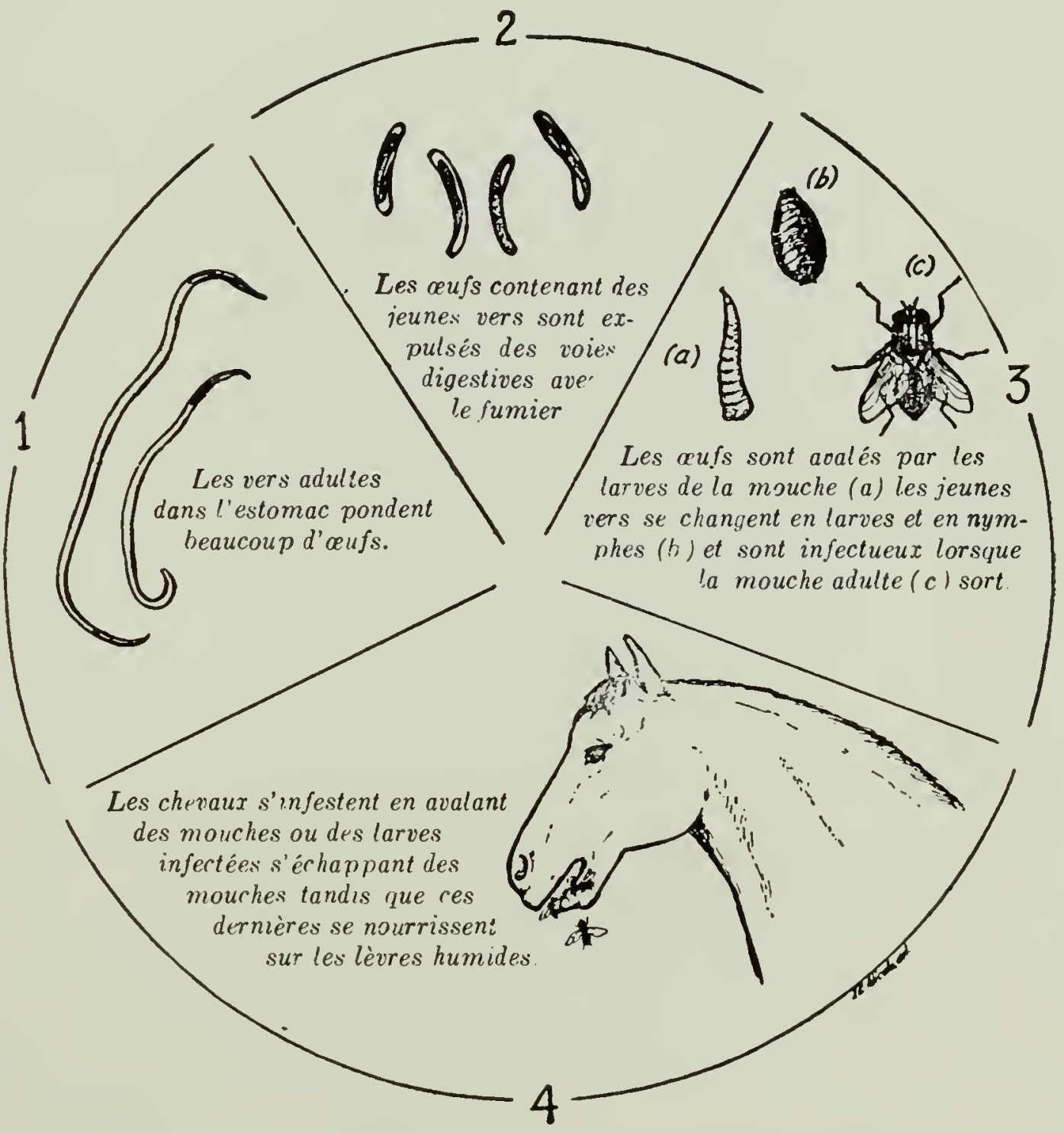

Fig. 9.-Schéma montrant la transmission de Habronema muscae par la mouche commune (d'après Schwartz, Imes et Wright). communes et les mouches des étables, et sont ainsi portées pal' ces insectes d'un cheval à l'autre. Cette transmission se produit comme suit: (voir figure 9):-- Les oufs des ver's sont évacués dans le fumiel des chevaux infectés, et sont ensuite absorbés dans l'intestin des larves des mouches 
qui infestent le fumier. Ces œufs éclosent et les larves des vers ronds restent dans le corps des insectes qui leur donnent asile jusqu'à ce que ces derniers se transforment en mouches adultes. La façon dont les chevaux s'infectent n'est

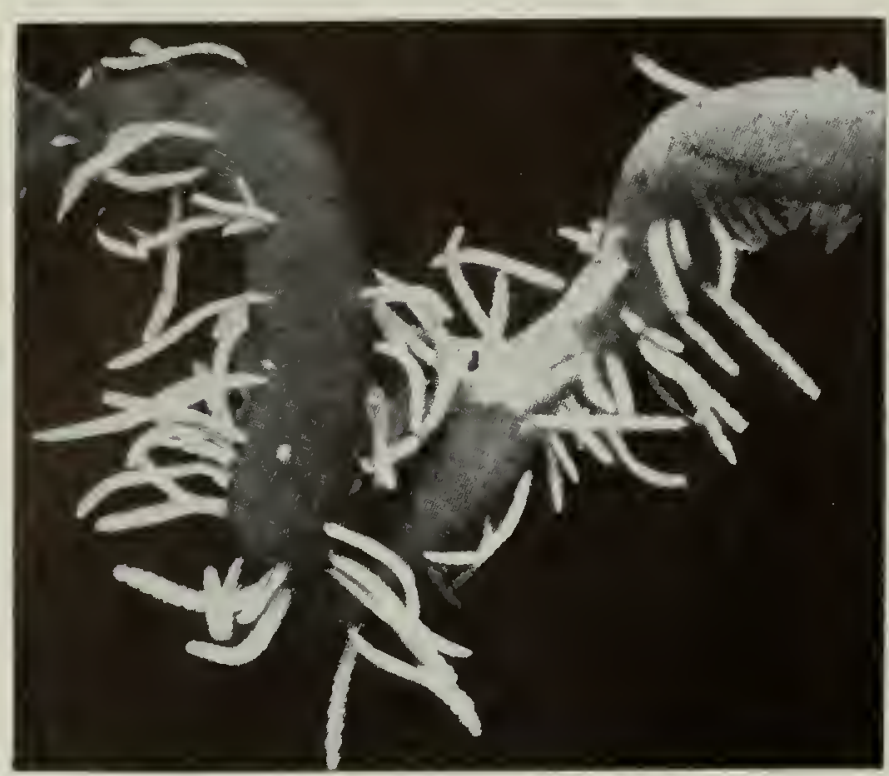

Fig. 10-Intestin de volaille envahi par des ténias, Chaonotamia infundibuliformis (d'après Herms). pas exactement connue; on pense que l'infection a lieu lorsque le cheval avale les mouches qui volent autour de lui; il se peut aussi que les larves des vers ronds passent des mouches au cheval lorsque ces mouches se posent sur les lèvres du cheval. Lorsque les vers arrivent dans l'estomac du cheval, ils y produisent des tumeur's dans lesquelles ils achèvent de se développer. Les ceufs produits par les vers adultes sont évacués avec les déjections du cheval et le cycle est alor's complété. Ces vers ronds, ou nématodes, se rencontrent aussi parfois dans les plaies que peuvent porter les chevaux, en été, où ils sont portés par les mouches, qui recherchent les plaies et blessures non protégées. La présence d'un certain nombre de jeunes vers cause une démangeaison intense; les animaux mordent et rongent leurs plaies, les aggravent et les agrandissent, si bien qu'elles prennent un diamètre de quelques pouces. Parfois, les nématodes larvaires sont portés aux yeux des chevaux par des mouches infectées, et peuvent y engendrer une affection que l'on appelle conjonctivite habronémique.

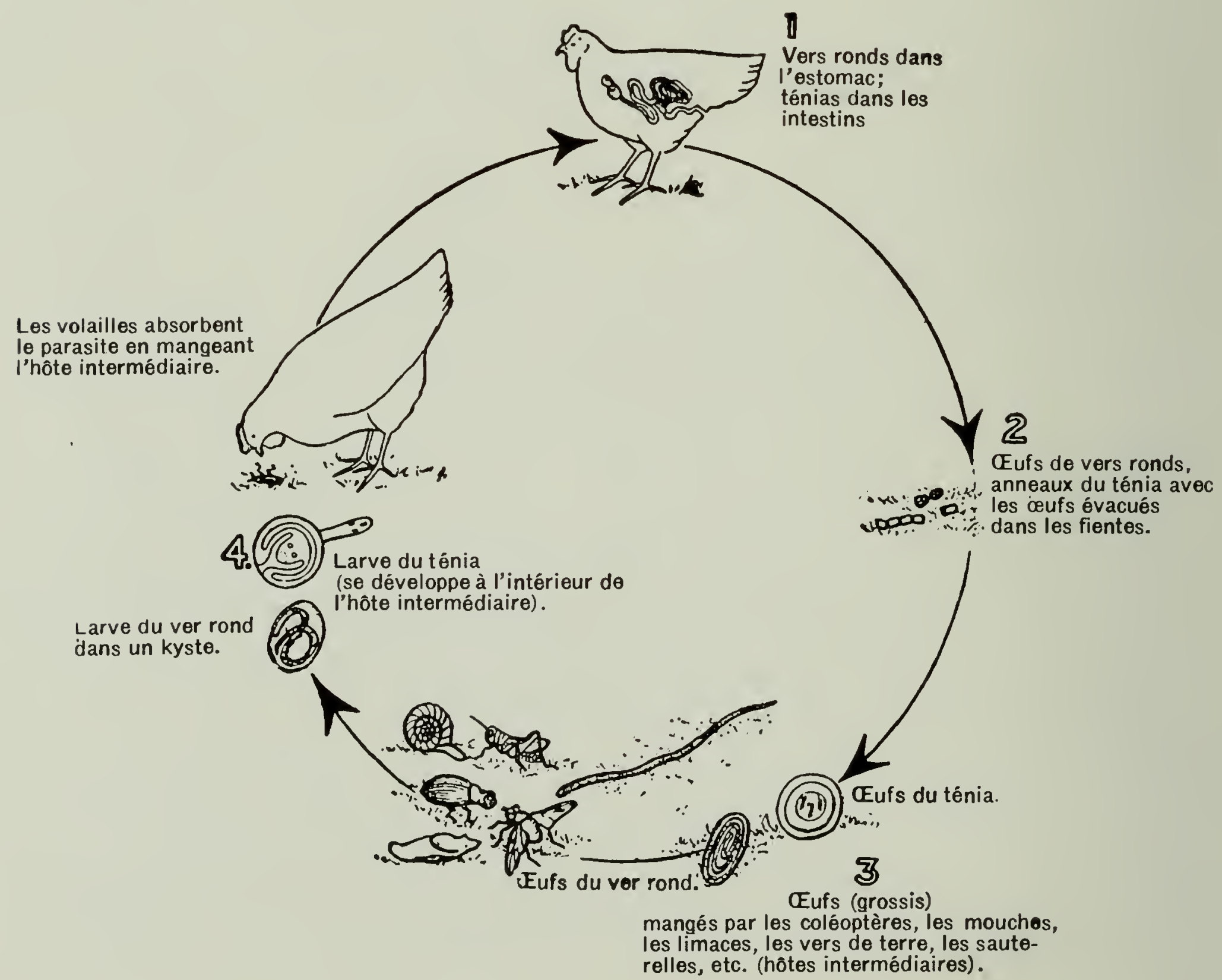

Fig. 11-Schéma montrant comment les volailles s'infestent de ténias et de vers ronds en mangeant des insectes qui leur servent d'hôtes intermédiaires (d'après Buckley, Bunyea et Cram). 
On devrait toujours consulter un vétérinaire pour le traitement des grosses plaies d'été, et de cette conjonctivite. Les moyens préventifs consistent à réduire ou enrayer la multiplication des mouches, et à protéger les écuries par des toiles métalliques (moustiquaires). Il faut assécher et guérir aussi rapidement que possible toutes les blessures, plaies ou coupures en les saupoudrant avec de l'acide borique ou quelque autre poudre antiseptique appropriée; afin qu'elles n'attirent pas les mouches.

$\mathrm{Au}$ moins trois espèces de ténias qui habitent les intestins des volailles, passent leurs phases intermédiaires dans la mouche commune. On peut juger de la gravité de cette infestation des volailles en jetant un coup d'œil sur la gravure ci-jointe (figure 10). Les nombreux œufs minuscules des ténias sont évacués avec les fientes des oiseaux infectés, et il est probable que les mouches qui transmettent les parasites s'infestent dans leur phase larvaire en se multipliant dans ces fientes.

Les bovins souffrent parfois de l'inflammation des yeux au temps des mouches, et cette inflammation peut se répandre dans tout le troupeau; on croit également qu'elle est portée d'un animal à l'autre par les mouches qui sont attirées par les suppurations des yeux. On devrait tenir tous les animaux affectés dans des étables obscures et consulter un vétérinaire.

Destruction de la mouche commune.-Pour détruire la mouche commune le meilleur moyen est de supprimer ou de réduire les foyers de multiplication, en traitant de façon utile ou en enlevant le fumier ou les déchets. Le fumier frais de cheval est une source abondante de mouches; c'est probablement dans le fumier de cheval que naissent la majoirité des mouches dans les districts ruraux.

Dans les villes, où les chevaux ont été largement remplacés par le moteur à combustion interne, les déchets sont un facteur important dans la reproduction des mouches. Les moyens préventifs devraient toujours être organisés en commun, car il suffit d'un tas de fumier négligé ou d'un dépôt de déchets pour infester tout un voisinage. Le soin et l'utilisation du fumier ont été discutés dans un chapitre précédent de ce bulletin. Les déchets organiques, comme les ordures ménagères, devraient être enveloppés dans du papier et déposés dans des poubelles jusqu'à ce que l'on puisse les brûler.

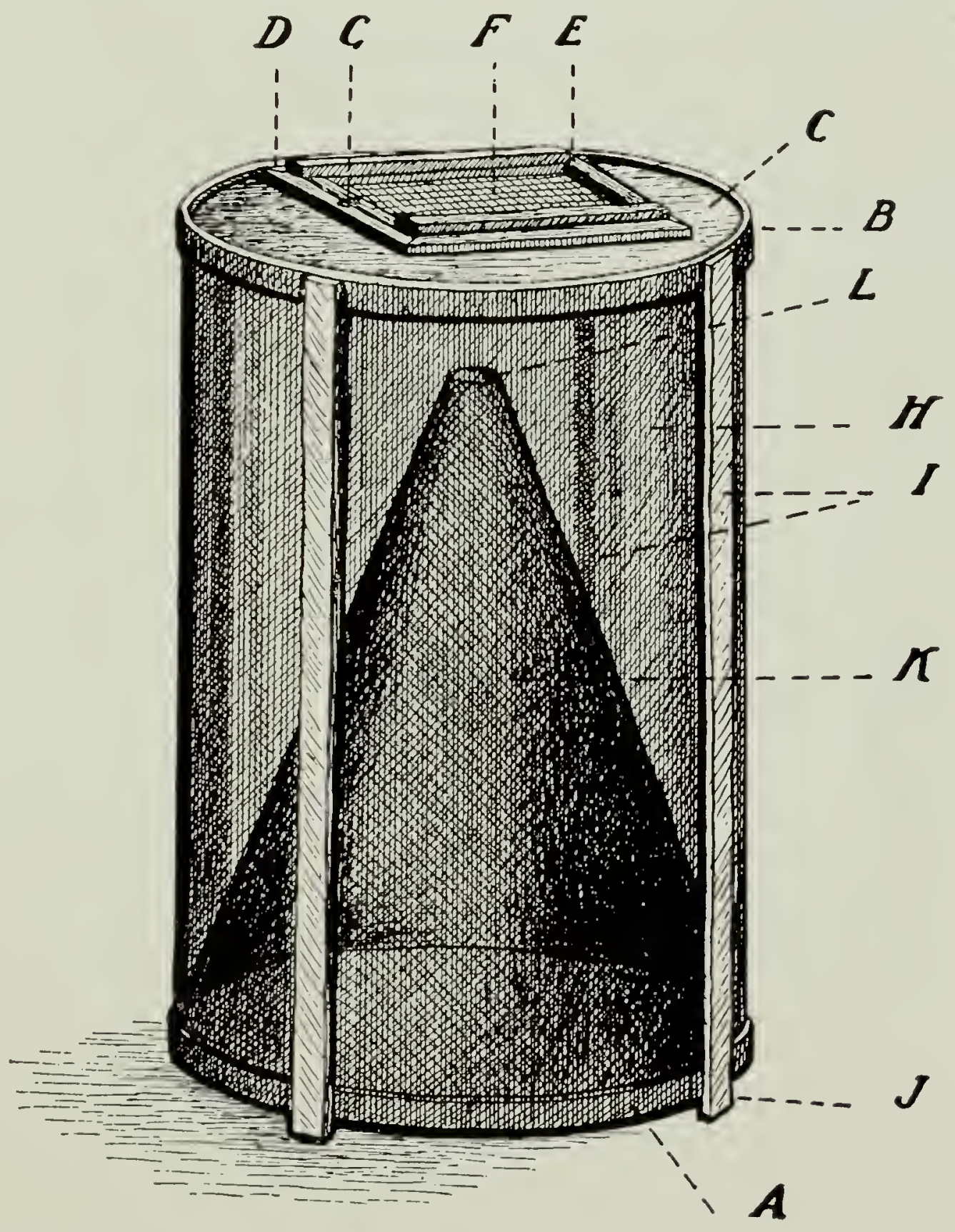

Fig. 12-Piège à mouches de Bishopp: A, cercle formant le cadre au fond; $B$, cercle formant le cadre au sommet; $C$, dessus du piège fait d'un fond de baril; $\mathrm{D}$, bandes autour de la porte; $\mathrm{E}-\mathrm{F}$. porte; $G$, fixateur; $H$, toile métallique sur l'extérieur du piège: $\mathrm{I}$, bandes de chaque côté du piège entre les cercles; J, pointes de ces bandes faisant saillie pour former des jambes; K, cône; L, bords unis de la toile métallique formant un cône (d'après Bishopp). $51767-2$ 
Il faut prendre les mesures nécessaires pour empêcher les mouches de pénétrer dans les habitations et de contaminer la nourriture. Les portes et les fenêtres des maisons et des autres bâtiments devraient être recouvertes de moustiquaires, et l'on détruira toutes les mouches qui s'introduiront à l'intérieur. On peut le faire au moyen de tue-mouches, de papiers collants et de papiers empoisonnés, etc., ou encore en exposant dans des soucoupes de l'appât empoisonné, composé d'une cuillerée à thé de formaline mélangée à une tasse de lait sucré ou d'eau sucrée. On aura soin de tenir cet appât hors de la portée des enfants et des animaux domestiques. Les mouches sont attirées par la lumière, et ces appâts empoisonnés ou ces papiers sont plus utiles quand ils sont placés près des châssis. Jaa figure 12 représente un piège à mouches de construction simple et facile, imaginé par Bishopp, et qui peut être employé utilement dans les bâtiments de ferme. Dix pièges de ce genre sur une grande ferme laitière des Etats-Unis ont pris 86 gallons de mouches représentant un demi-milliard de ces insectes, au cours d'une seule saison. On peut se servir d'appâts composés de lait sur sucré avec de la cassonade, ou de mélasse, une partie pour trois parties d'eau. Ces appâts doivent être souvent renouvelés.

Une pulvérisation de pyrèthre et d'huile de charbon est utile contre les mouches à l'intérieur des habitations. On prépare cette pulvérisation facilement et à peu de frais en faisant tremper pendant deux heures ou plus une demi-livre de poudre de pyrèthre fraîche dans un gallon d'huile de charbon, et en remuant par intervalles. On laisse reposer quelque temps pour que le sédiment se dépose au fond, et on transvase le liquide jaune clair au moyen d'un siphon ou en le filtrant, dans un contenant hermétiquement bouché. On peut obtenir une pulvérisation concentrée en employant une livre de pyrèthre ou son équivalent d'extrait. Cette pulvérisation s'applique sous forme d'une fine vapeur, et c'est lorsque les portes et les châssis sont fermés qu'elle donne les meilleurs résultats. On ramasse au balai les insectes morts ou paralysés pour les détruire. Cette pulvérisation ne fait aucun mal aux bestiaux ou à l'homme. On peut aussi acheter des pulvérisations brevetées de même composition et toutes prêtes à être employées.

\section{LA MOUCHE PIQUANTE DES ÉTABLES OU MOUCHE CHARBONNEUSE}

\section{(Stomoxys calcitrans L.)}

La mouche piquante des étables, que l'on voit souvent dans les endroits ensoleillés sur les murs des étables et des bâtiments de ferme pendant l'été, est souvent appelée "mouche charbonneuse". Elle a à peu près la même grosseur que la mouche commune des maisons, mais elle paraît plus vigoureuse, et sa couleur est gris brun. L'abdomen est gris et porte plusieurs grandes taches, rondes et foncées, lui donnant une apparence bigarrée. On peut toujours la reconnaître par la trompe perçante mince, non pas élargie comme chez la mouche commune, et qui se prolonge en droite ligne devant la face. Elle diffère de sa parente plus petite, la mouche des cornes, par le fait qu'elle n'a pas de préférence, et attaque aussi bien les chevaux, les vaches et les cochons, que l'homme. "Les bêtes à cornes et les chevaux sont mordus principalement sur les jambes, et lorsque les mouches des étables sont nombreuses, les animaux n'ont aucun repos depuis l'aube jusqu'à la tombée de la nuit. Ils frappent du pied et s'agitent constamment. Lorsque les mouches communes et les mouches des cornes se mettent aussi de la partie, les animaux irrités n'ont plus aucun repos."* Les cochons souffrent aussi beaucoup de leurs attaques; lorsque les mouches piquantes sont nombreuses ils s'efforcent de se protéger en se vautrant dans la boue pour se recouvrir d'une couche protectrice, ou ils se couchent dans des trous dans la terre ou se réfugient sous les bâtiments. Les mouches piquantes naissent dans les déjections, et spécialement dans le

\footnotetext{
* Hadwen.
} 
fumier de cheval, lor'squ'il est mélangé de foin ou de paille, mais elles préfèrent les végétaux en décomposition, et se multiplient surtout dans les déchets éparpillés sur les bords des vieilles meules de foin ou de paille. Lorsque ces déchets sont humides et en état de décomposition, elles peuvent se reproduire en nombres prodigieux. Les tas d'herbe tondue qu'on laisse pourrir dans les jardins sont parfois la source de beaucoup de ces mouches. Comme elles préfèrent les végétaux en décomposition pour se multiplier, les mouches piquantes des étables atteignent généralement leur plus grande abondance dans les régions agricoles du Canada où l'on pratique la culture du grain ou la culture mixte.

Cycle évolutif.-Le cycle de la vie et les premières phases sont assez semblables à ceux de la mouche commune; le cycle de l'œuf à l'œuf est complété en deux ou trois semaines. Il se produit un certain nombre de générations, et les mouches font leur apparition en avril dans les régions de la côte de la Colombie-Britannique, et environ un mois plus tard dans les provinces des Prairies. Elles deviennent de plus en plus nombreuses à mesure que l'été s'avance, et elles tourmentent les animaux jusqu'à ce que les froids s'établissent. On a vu des mouches adultes vivre plus de deux mois, et pondre pendant ce tempṣ des couvées successives d'œufs.

Moyens répressifs.-Les soins d'entretien du fumier, déjà mentionnés, sont utiles pour réduire le nombre de mouches piquantes, mais les tas de paille et de foin et d'autres végétaux humides en décomposition, devraient être l'objet d'une attention toute spéciale. On aura soin de faire des meules de foin et de paille bien arrondies, pour que le dessus soit imperméable à la pluie. Les côtés seront aussi nettement découpés que possible, et il ne faudra pas laisser de déchets s'accumuler autour de la base. C'est une bonne pratique que de retourner à la charrue les bords des vieilles meules de paille brûlée.

On a recommandé l'emploi d'une substance repoussante, composée d'un mélange d'huile de poisson, d'huile de goudron et d'huile de pouliot, ajouté à un peu d'huile de charbon, mais ce mélange ne procure qu'un soulagement temporaire contre les attaques des mouches. On emploie aussi parfois en pulvérisation sur les bestiaux un mélange composé d'une partie d'huile de pin pour dix-neuf parties d'huile de charbon ou d'un mélange de pyrèthre-huile de charbon. Les jambières de toile sont utiles et n'ont pas besoin de monter beaucoup plus haut que les genoux ou les jarrets, car les mouches mordent généralement assez bas sur les jambes. Dans les districts où les mouches abondent, on devrait placel des moustiquaires sur les châssis des bâtiments. La mouche piquante ne déploie pas d'activité dans l'obscurité ou le demi-jour, et la construction de refuges assombris est un moyen de défense simple et utile.

\section{LA MOUCHE DES CORNES (Lyperosia irritans L.)}

La mouche des cornes est originaire de l'Europe et s'est répandue assez rapidement après son introduction dans l'Amérique du Nord en 1887. Cette espèce a été notée au Canada pour la première fois on 1892, et elle s'est propagée d'un bout à l'autre du continent pendant les onze années suivantes, causant de t'rès grandes alarmes chez les propriétaires de bestiaux.

La mouche des cornes est beaucoup plus petite que les deux dernières espèces dont nous avons parlé, et sa couleur est gris sombre uniforme. Sa trompe, armée pour transpercer, est moins apparente, plus courte et plus forte que celle de la mouche des étables; on peut aisément distinguer la mouche des cornes de cette dernière sur les animaux, par sa taille plus petite et sa façon de se poser la tête en bas. On voit par la gravure ci-jointe que ces mouches ont une tendance à se r'éunir en essaims. Elles préfèrent le côté de l'animal qui est à l'ombre, et sont souvent plus épaisses sur le garrot, où l'animal peut difficilement les atteindre avec la queue ou la tête Au repos, lorsqu'elles ont 
cessé de se nourrir, elles se posent généralement à la base des cornes, d'où leur nom de mouches des cornes. Lorsqu'elles sont abondantes, elles peuvent recouvrir la base de la corne d'une couche épaisse sur un tiers de sa longueur. Depuis que le décornage est très usité, le nom vulgaire de mouche des cornes ne lui convient plus autant qu'autrefois. Lorsque la mouche se nourrit, ses ailes sont étalées et assez bien séparées, mais lorsqu'elle se repose, les ailes sont serrées près du corps. Un fait intéressant à noter, c'est que ces mouches re se nourrissent qu'une fois par jour. Elles diffèrent également beaucoup des autres mouches piquantes par le fait qu'elles restent constamment sur les animaux, même la nuit. Elles ne paraissent pas les faire souffrir, cependant, lorsque les animaux sont dans l'étable. Elles n'attaquent guère que les bêtes

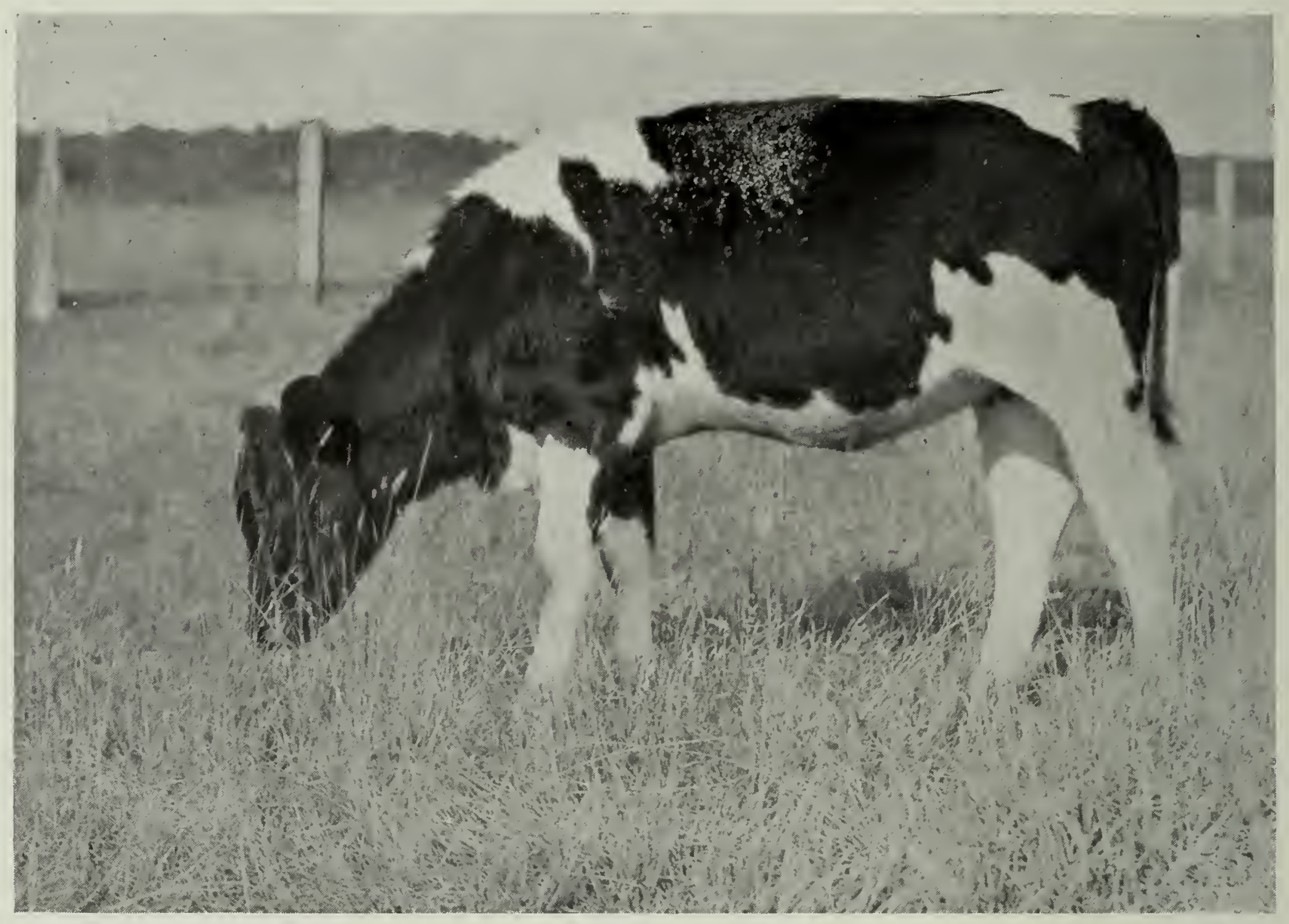

Fig. 13-Mouches des cornes sur une vache (Original).

à cornes (et disons ici qu'elles manifestent une préférence marquée pour les animaux noirs, par opposition aux animaux blancs ou de couleur claire); on les a vues cependant parfois, mais rarement, attaquer des chevaux, des moutons et des chiens. Dans bien des districts du Canada, et spécialement dans les saisons favorables à son développement, la mouche des cornes est la pire espèce de toutes celles qui piquent les vaches. Heureusement, les hivers froids en réduisent considérablement le nombre, et il est rare que l'abondance de ces mouches prenne des proportions sérieuses avant juin, et même plus tard, dans les régions plus froides du Canada. Les mois de juillet et d'août sont les pires pour cette mouche, qui ne commence à diminuer que dans les journées fraîches de septembre.

Cycle évolutif.-La mouche femelle part de l'endroit où elle se repose sur la vache, pour pondre des œufs brun rougeâtre sur les bouses dès que celles-ci sont évacuées, et revient ensuite sur l'animal. Une femelle pond moins de deux douzaines d'œufs pendant sa vie. Les larves, qui sont blanches, s'enfouissent dans le fumier, mais restent assez près de la surfare. Lorsqu'elles sont 
complètement développées, elles émigrent dans la terı'e où elles se changent en nymphes brun foncé, en forme de baril. Le développement est assez rapide, la période entière de temps qui s'écoule de l'œuf à l'adulte n'est que d'environ deux semaines. Les générations se succèdent sans arrêt toute la saison.

Moyens répressifs.-Le meilleur moyen répressif consiste à épandre les bouses de vaches pour les faire sécher. Le fumier frais est indispensable aux larves, qui meurent s'il sèche tandis qu'elles sont encore dans leurs premières phases. A l'époque des chaleurs, le fumier devrait être épandu deux fois par semaine. Cette précaution vaut bien le peu de temps qu'elle exige autour de la cour de la ferme et dans les petits pâturages. On peut se servir pour cela d'un râteau ou d'une pelle. Si on laisse les cochons avec les vaches, ils font ce travail généralement assez bien pour empêcher les œufs des mouches d'éclore. Les substances repoussantes ont peu d'utilité parce qu'elles durent peu de temps, mais on peut beaucoup réduire le nombre de mouches en traitant les vaches au pulvérisateur lorsqu'elles passent par un passage étroit. La pulvérisation pyrèthre-huile de

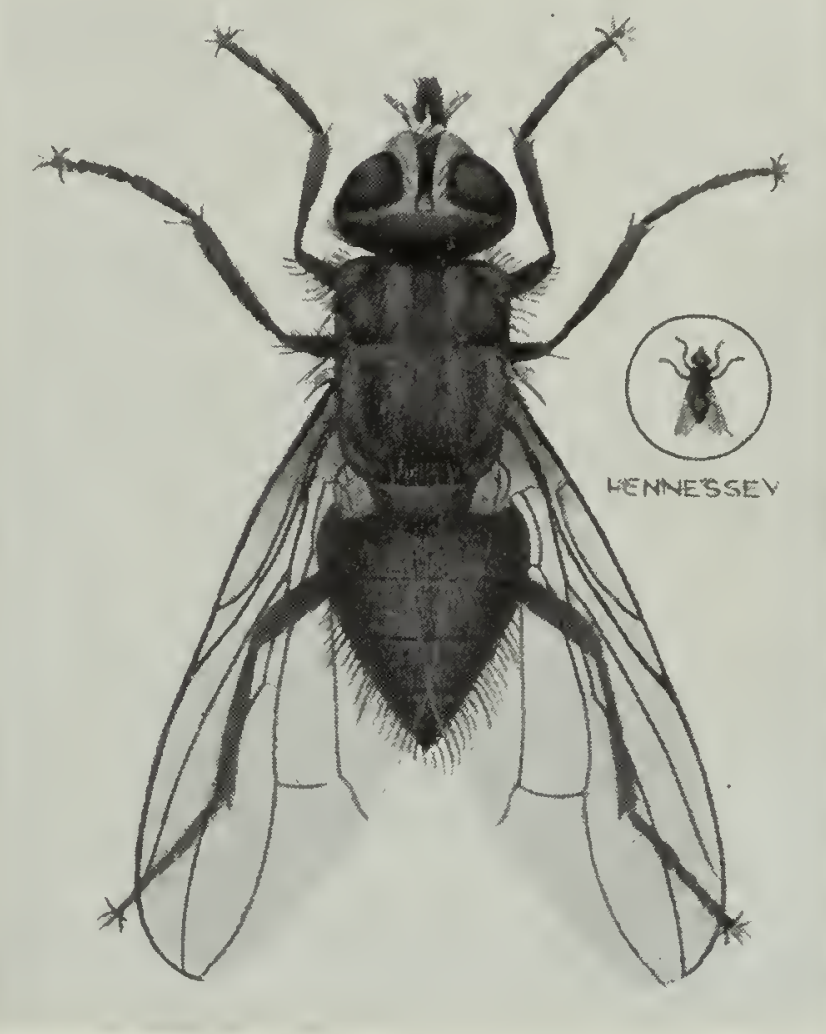

Fig. 14-Mouche des cornes, Lyperosia irritans I., grossie et grosseur naturelle (Original). charbon (voir page 8) à laquelle on ajoute une partie par vingt d'huile de pin peut être employée utilement pour cela. Mais, quand on se sert de cette pulvérisation, comme de toutes celles à base d'huile de charbon, il faut éviter de mouiller la peau des animaux.

\section{Mouches piquantes qui naissent dans les bourbiers, les marais et les cours d'eau}

\section{MOUSTIQUES OU MARINGOUINS-Culicidés: Aedes, Culex, Anopheles, Theobaldia}

Ces insectes grêles, à structure délicate, et qui sucent le sang sont les plus nuisibles de toutes les mouches de ce genre qui affectent les bestiaux dans bien des parties de notre pays. Il s'en rencontre plus de soixante espèces au Canada, dont beaucoup ont des habitudes très différentes. Il est donc très utile de connaître les principales espèces qui habitent un district lorsqu'on veut tenter de les combattre. On confond souvent avec ces insectes les moucherons ou brûlots, les petites tipules et autres espèces de ce genre, mais on peut toujours reconnaître les moustiques par leur longue trompe ou proboscis et la bordure d'écailles autour de la marge de l'aile.

Les pertes que les moustiques occasionnent en tourmentant les bestiaux sont considérables. La production du lait baisse beaucoup chez les vaches laitières au début de la saison des moustiques dans les districts les plus affectés, et les laitiers pratiques prétendent que cette perte peut se monter jusqu'à 40 pour cent. D'autres bestiaux maigrissent par suite de la perte de sang et des tourments qu'ils endurent et l'on a même vu dans des cas extrêmes des animaux mourir, spécialement des veaux et des poulains. Les brebis sont tellement incommodées qu'elles abandonnent parfois leurs agneaux. Aucune catégorie de bestiaux ne peut se soustraire aux attaques des moustiques; même les volailles sont affectées.

Tous les moustiques exigent de l'eau pour le développement de leurs premières phases; il leur est impossible de se développer dans l'herbe humide, la 
rosée sur la végétation, etc., mais différentes espèces manifestent une préférence marquée pour certains lieux. Beaucoup, par exemple, se développent presque entièrement dans des terrains inondés, adjacents aux rivières et aux lacs; d autres, comme les espèces qui habitent les prairies, préfèrent les flaques d'eau peu profondes, résultant de la fonte des neiges au printemps. Enfin, les fossés et les creux remplis d'eau de pluie, et à partir du Manitoba en se dirigeant sur l'Est, les barils et les autres récipients d'eau de pluie sont souvent les endroits d'où naissent une multitude de moustiques gênants.

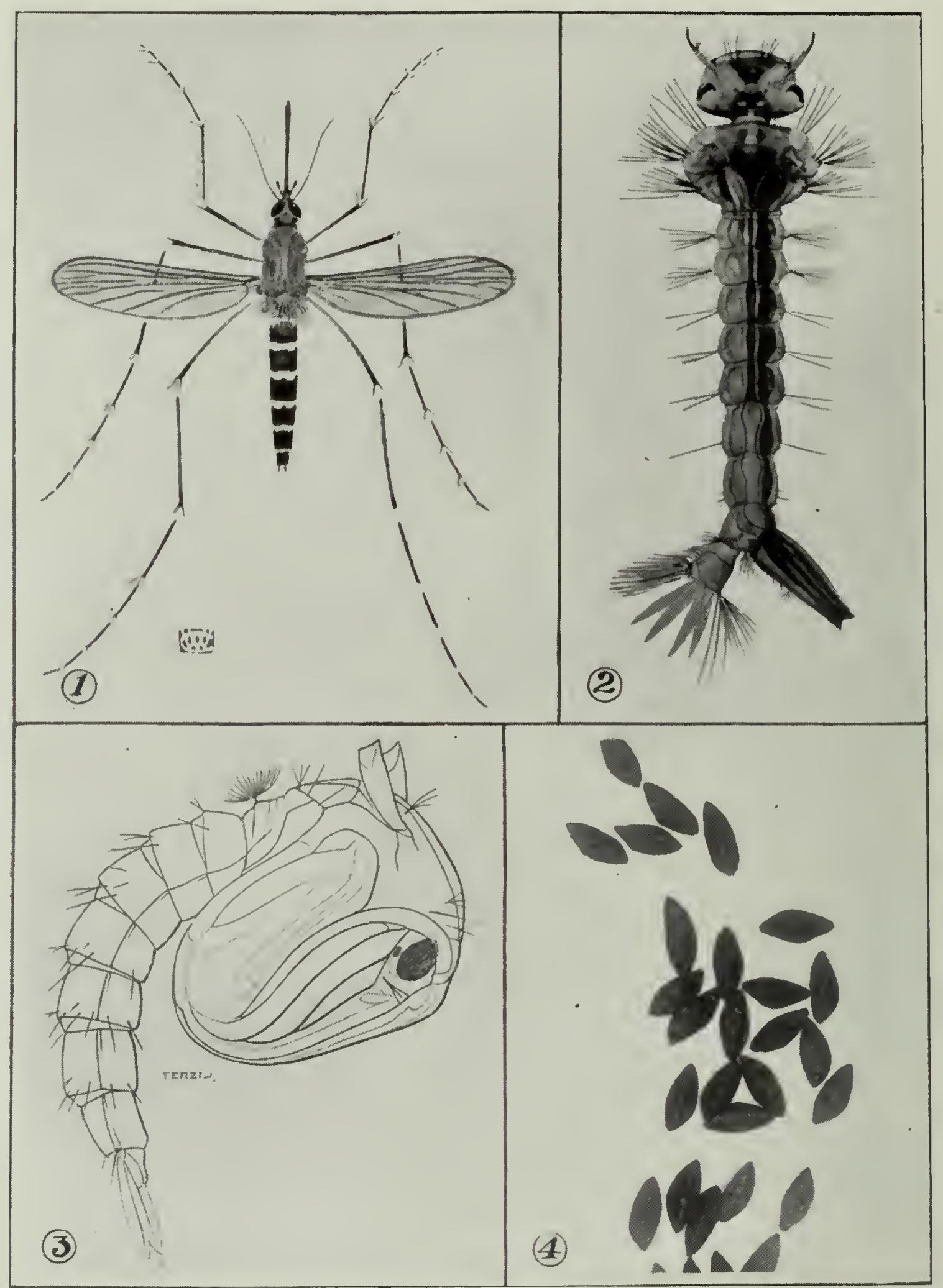

Fig. 15-Métamorphoses d'un moustique; 1, femelle adulte; 2, larve;

3, pupe; 4, oufs; tous du genre Aedes (illustration de l'auteur).

Cycle évolutif.-Au Canada la majorité des moustiques appartient au genre Aedes. Le cycle évolutif d'un moustique typique du genre Aedes naissant dans l'eau des crues est le suivant: l'hiver est passé sous forme d'œuf sur le gazon dans les dépressions des terres d'alluvion. Lorsque ces oufs sont recouverts d'eau pendant les crues printanières ils éclosent en larves actives. Ces larves ont une tête bien marquée et sont pourvues à l'extrémité de leur abdomen d'un tube par lequel elles peuvent respirer lorsqu'elles se reposent à la surface de l'eau. Elles se nourrissent des formes minuscules de vie qui abondent dans l'eau; les parties buccales sont pourvues de brosses spéciales 
qui amènent ces particules dans le gosier. E les utilisent également plus ou moins les substances tenues en solution dans l'eau. Lorsqu'elles atteignent toute leur taille ces larves se changent en nymphes robustes, et celles-ci se fendent au bout de plusieurs jours pour livrer passage à l'insecte adulte qui, s'il est une femelle, passe sa vie, qui peut durer un ou deux mois, à tourmenter les hommes et les bêtes. La femelle pond plusieurs centaines d'œufs qui sont déposés individuellement dans des creux sujets à être recouverts par l'eau. Il n'y a qu'une génération par an dans la plupart des espèces, mais tous les œufs n'éclosent pas dans la première eau qui r'emplit les creux et les inondations successives donnent naissance à plusieurs générations pendant la saison. En ce qui concerne les moustiques des flaques de neige les œufs éclosent au printemps lorsque la neige fond.

Moyens répressifs.-La lutte contre les moustiques a fait des progrès rapides au Canada en ces dernier's dix ans, et le succès des campagnes qui ont été entreprises démontre éloquemment ce que l'on peut accomplir. La plupart de ces

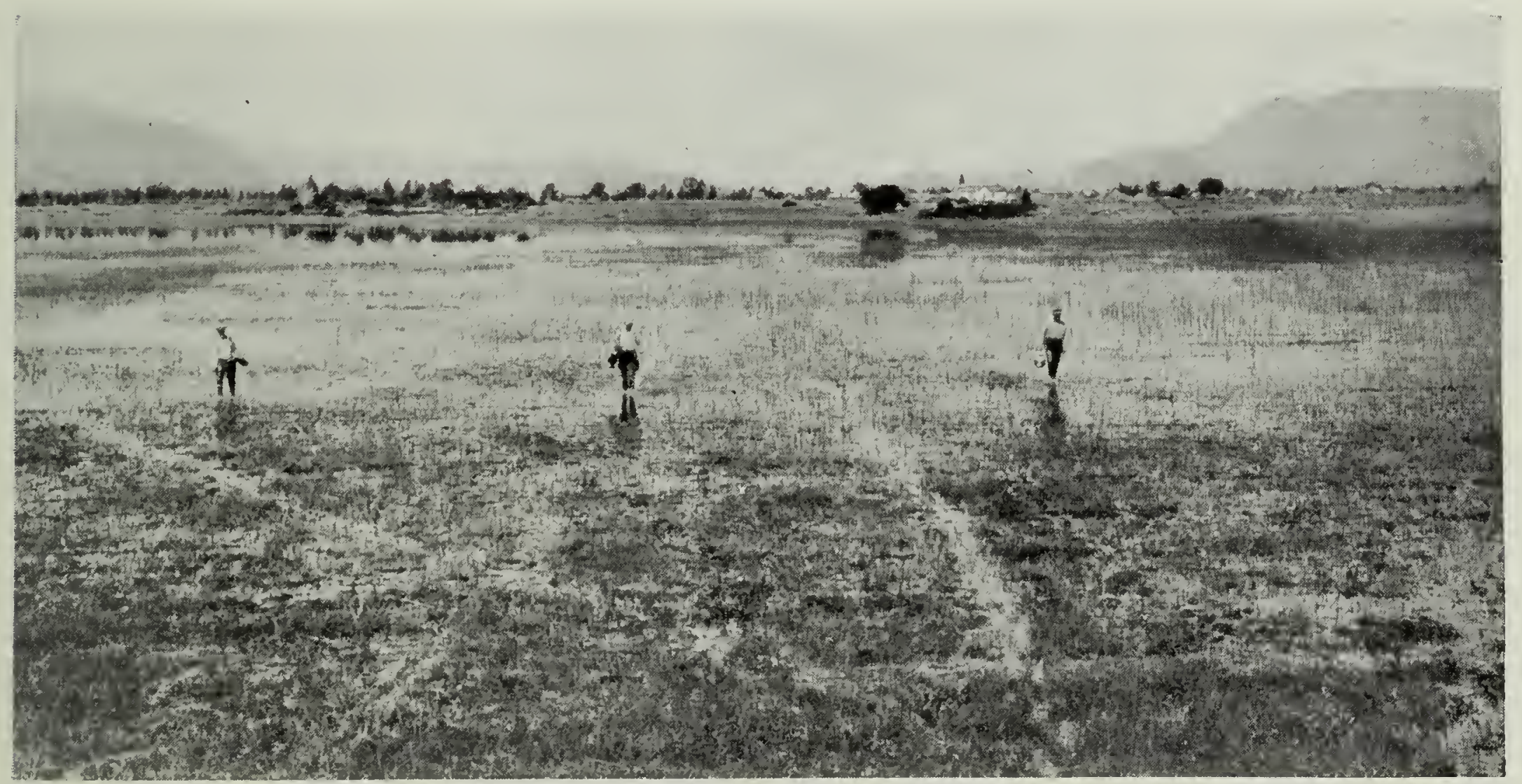

Fig. 16-Eau des crues servant de lieu de multiplication pour les moustiques, et huileur's au travail (Original).

campagnes ont été conduites dans des villes et villages, mais quelques-unes l'ont été également dans les districts ruraux, et il n'y a pas de doute que l'on pourrait arriver à grandement léduire ce fléau et les pertes qu'il cause aux animaux de ferme dans bien des groupements agricoles. L'union des efforts de tous les propriétaires de felmes contiguës est nécessaire pour réussir; la répression des moustiques est essentiellement un problème de groupement.

L'égouttement des étendues d'eau où les moustiques naissent est le moyen idéal de combattre ce fléau, car il supprime permanemment leurs foyers de multiplication. Le remplissage de ces creux est utile lorsque ce moyen peut être employé. Partout où ces mesures ne sont pas pratiques ou désirables, le huilage de la surface de l'eau au moyen d'huile à brûler bon marché est très utile s'il est fait au bon moment. On peut appliquer une mince couche d'huile au moyen d'un arrosoir, mais une pompe à pulvériser portative est plus utile et cause moins de perte.

Il est spécialement difficile de protéger les animaux contre les attaques des moustiques, car ces insectes mordent jour et nuit, et certaines espèces cherchent toujour's à s'introduire dans les bâtiments. L'emploi de substances repoussantes, comme l'huile de poisson, l'huile de pin et la citronnelle, procure 
un soulagement temporaire et apaise les animaux au moment de la traite. La fumée est l'un des moyens de protection les plus simples et les plus efficaces, aussi bien en plein air que dans les bâtiments où les animaux sont attachés. Lorsque les moustiques pullulent on devrait faire une "boucane" continuelle pour protéger les bestiaux. Les étables bien pourvues de moustiquaires sont très nécessaires pour protéger les vaches laitières et les autres animaux d'un grand prix. Même dans ces étables il est parfois nécessaire d'avoir recours à la boucane pour chasser les moustiques après que les animaux sont attachés, car un grand nombre de moustiques pénètrent souvent dans le bâtiment avec le troupeau. Dans les étables et les écuries grossières, on peut grandement réduire le nombre des moustiques qui y entrent en pulvérisant les murs et les plafonds avec de la créosote dont on met deux à quatre gallons par étable. On dit que l'action repoussante de ce traitement dure plusieurs mois.

\section{TAONS DES CHEVAUX-Espèces Tabanus, Chrysops et Hamatopota}

Les mouches robustes et épaisses qui attaquent les chevaux ne le cèdent en importance qu'aux moustiques parmi les insectes suceurs du sang qui nuisent aux animaux de ferme au Canada. L'espèce Tabanus constitue le groupe le plus gros et le plus robuste; on les appelle souvent "mouche bouledogue" en anglais, à cause de leurs attaques persistantes. Le genre Chrysops contient l'espèce plus petite, plus courte, communément appelée "mouches à chevreuil", tandis que les hématopotes appelés en anglais "breeze flies", à ailes bigarrées

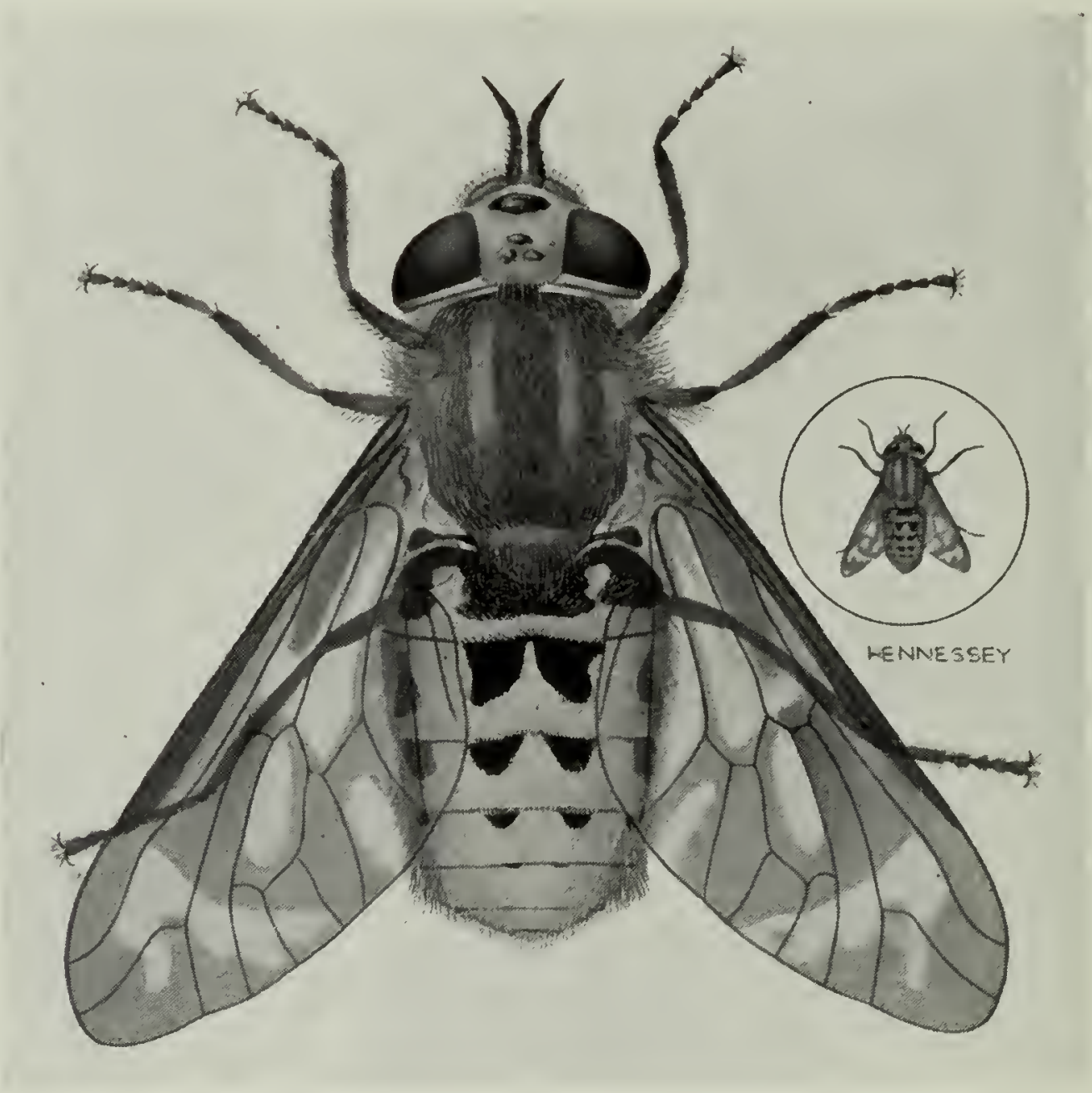

Fig. 17-Un taon typique du chevreuil ou mouche à chevreuil, Chrysops discalis Will., grossie et grosseur naturelle (Original).

et à structure plus délicate appartiennent au genre Homatopota. Un caractère commun à la plupart de ces insectes est l'éclat des yeux, qui reflètent les couleurs de l'arc-en-ciel, en bandes, taches ou raies. Les antennes courtes, épaisses se composent de trois jointures et varient d'une façon caractéristique dans tous les genres. Les taons des chevaux constituent un groupe nombreux; il y en a environ 100 espèces au Canada.

En général, les taons, lorsqu'ils sont en petit nombre, incommodent peu les animaux, pas autant du moins que beaucoup d'autres espèces d'insectes 
suceurs de sang ou que les oestres et les hypodermes, mais lorsqu'ils pullulent, ils affolent les bestiaux. Les bovins, ayant une peau épaisse, sont moins affectés que les chevaux, à peau mince. Les chiens paraissent les redouter tout spécialement. Dans les districts où se rencontrent de grandes régions marécageuses, dans les régions des prairies qui contiennent beaucoup de fondrières ou bourbiers et dans les pâturages alpestres, les taons peuvent devenir un fléau intolérable, spécialement dans l'année qui suit une saison particulièrement humide. Ils sont généralement moins communs dans les districts agricoles depuis longtemps établis et mieux développés, que dans les districts plus récemment colo-

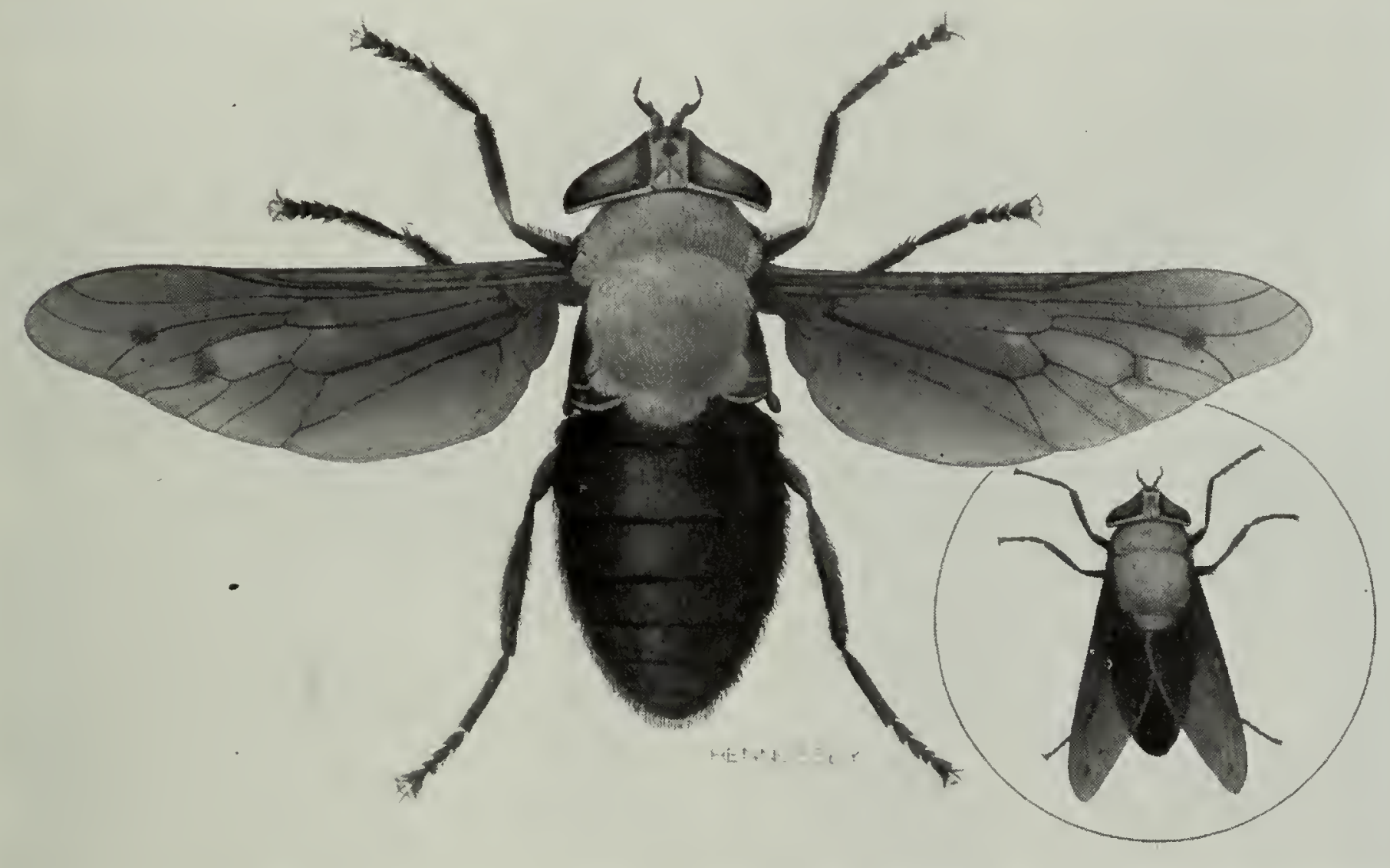

Fig. 18-Femelle du taon bouledogue, Tabanus punctifer O.S., grossie et grosseur naturelle (Original).

nisés. Le fait suivant fera mieux comprendre l'importance de ces mouches: un observateur dans l'un des états du sud-est a estimé que les bœufs d'engrais perdent en moyenne 100 livres de poids à cause des tourments constants que leur cause l'abondance des taons. Parfois, dans quelques-unes des régions des Prairies où les taons pullulent, il est presque impossible de faire travailler les chevaux pendant une bonne partie de la journée, et ils sont nombreux les chevaux qui prennent le mors aux dents pendant la saison des foins. Ce n'est pas tout: la façon intermittente dont les taons se nourrissent les rend spécialement aptes à transmettre le charbon, des animaux infectés aux animaux sains. Il est possible également qu'ils aient une part dans la transmission de la fièvre des marais chez les chevaux. On sait qu'une espèce, Chrysops discalis Will., qui est spécialement commune dans la région sèche de la ColombieBritannique et qui s'étend à l'est jusqu'au Manitoba, transmet la tularémie dans les états de l'Ouest. C'est une maladie des rongeur's, qui peut être contractée par les moutons et les autres animaux, ainsi que par l'homme.

Il n'y a qu'une génération de chaque espèce de taons par an et le cycle évolutif peut se prolonger sur une dizaine de mois, parfois même il peut durer deux ans; on sait, par les observations qui ont été faites pendant un certain nombre de saisons en Colombie-Britannique et en Saskatchewan, que chaque espèce a une période régulière d'abondance et que les espèces se suivent en succession régulière du printemps jusqu'à l'automne. Cependant, la première apparition et l'époque de la plus grande abondance de plusieurs espèces peuvent 
coïncider. C'est en juin, juillet et août que ces mouches causent le plus d'incommodité; en septembre leur nombre a généralement beaucoup diminué. Les différentes espèces varient également par la façon qu'elles ont de mordre; les unes s'attaquent presque exclusivement à l'abdomen, d'autres à la figure et au cou, et ainsi de suite. Contrairement aux moustiques, les taons ne déploient de l'activité que pendant le jour.

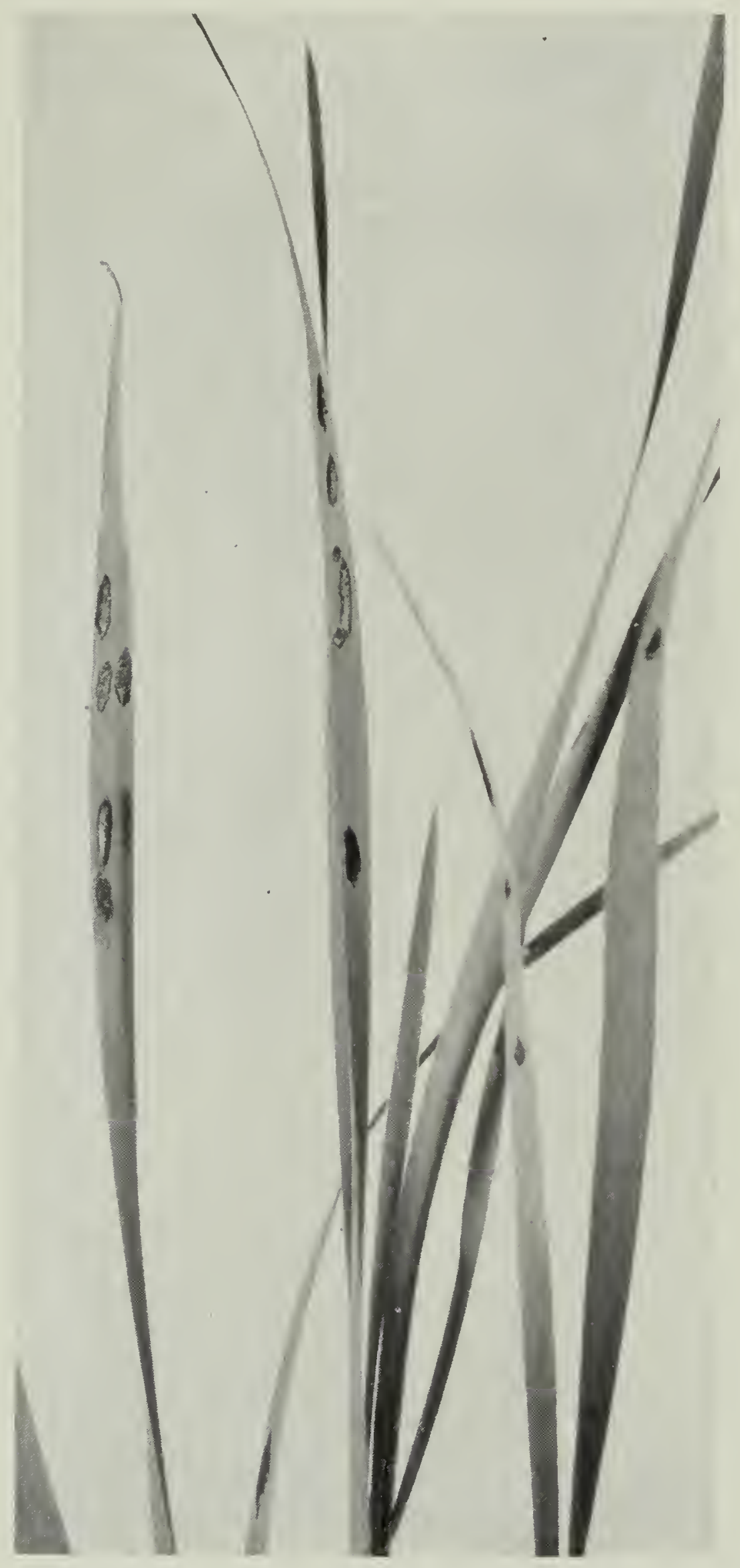

Fig. 19-Masses d'oufs de la mouche à chevreuil, Chrysops moerens Walker (Original).

Cycle évolutif.-Les modes de reproduction et les métamorphoses sont les suivants: les œufs, qui sont pondus en une masse compacte de plusieurs centaines, sont placés sur les feuilles des plantes aquatiques, sur les arbres et les arbustes qui dominent les bourbiers et les marécages, ou, pour certaines espèces, sur les rocs au bord des cours d'eau. On les a vus également sur les fils de fer barbelés qui entourent les conduites d'irrigation. Les masses d'œufs sont généralement d'uine couleur blanche ou grise, elles sont noir de jais chez quelques mouches à chevreuil. L'éclosion se produit au bout d'une semaine environ et les jeunes larves tombent dans l'eau ou sur le terrain humide. Les larves ont une forme allongée, s'effilant brusquement aux deux extrémités, et chaque segment porte des cannelures ou crêtes marquées. L'habitat principal des larves est la boue sur les bords des bourbiers, des marais et des flaques d'eau. Elles se nourrissent de petits organismes à corps mou pendant l'été et l'automne. L'hiver la croissance est à peu près nulle, mais le printemps et l'été suivants la larve entièrement développée se dirige vers de la terre plus sèche où elle se métamorphose en une nymphe allongée, qui donne naissance à la mouche adulte au bout de deux à trois semaines.

Moyens répressifs. - En raison de la nature des foyers de multiplication, il est extrêmement difficile, sinon impossible de détruire les taons dans leur's premières phases; en fait, on n'a pas encore trouvé un moyen de destruction très satisfaisant. Comme les œufs de la plupart des espèces sont pondus au-dessus de l'eau, Hine a prétendu qu'une pellicule d'huile sur la surface de l'eau tuerait les larves lor'sque celles-ci tombent sur l'eau en sortant des œufs. Le même investigateur a recommandé également de recueillir et de détruire les masses d'œufs, mais ce moyen ne paraît avoir qu'une application très limitée, comme par exemple, dans un endroit où les foyers de multiplication ne sont pas trop éparpillés. Parman, écrivant sur les conditions que l'on rencontre au Texas, dit qu'un jeune garçon a pu recueillir neuf chopines de masses d'œufs, soit envi- 
ron 2,000,000 d'œufs en une journée, et un total de 20,000,000 d'œufs a été ramassé de cette façon. Un chercheur russe, Porchinsky, a constaté que les adultes ont l'habitude de survoler certaines flaques d'eau et de tremper leur

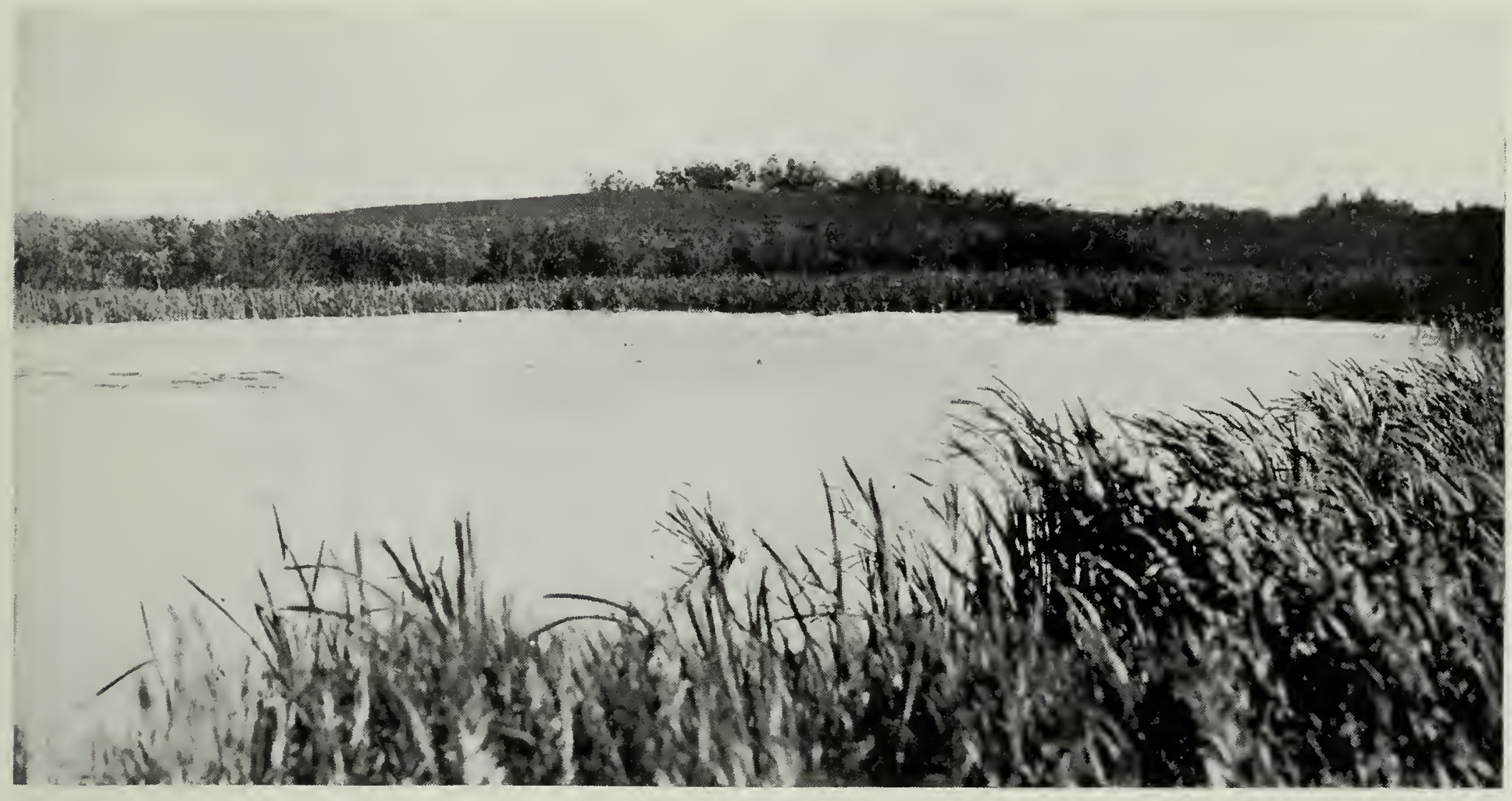

Fig. 20-Endroit typique pour la multiplication du taon des chevreuils (Original).

corps dans l'eau en passant. En versant de l'huile de charbon sur ces flaques, il les a converties en pièges et a réussi à tuer près de 2,000 taons en trois jours dans une flaque d'une verge carrée environ, mais une grande proportion de ces taons étaient des mâles inoffensifs. Les taons adultes ont l'habitude

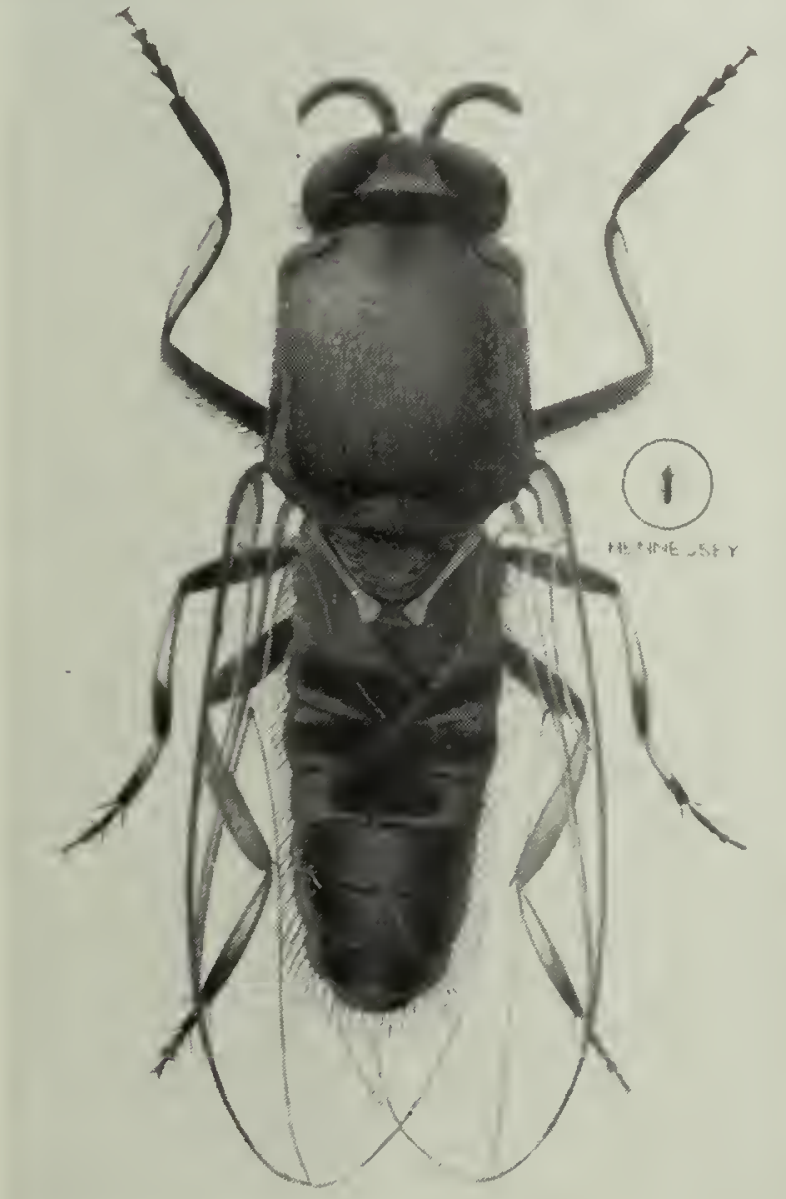

Fig. 22-La simulie ou mouche noire, Simulium venustum Say, femelle, grossie et grosseur naturelle (Original).
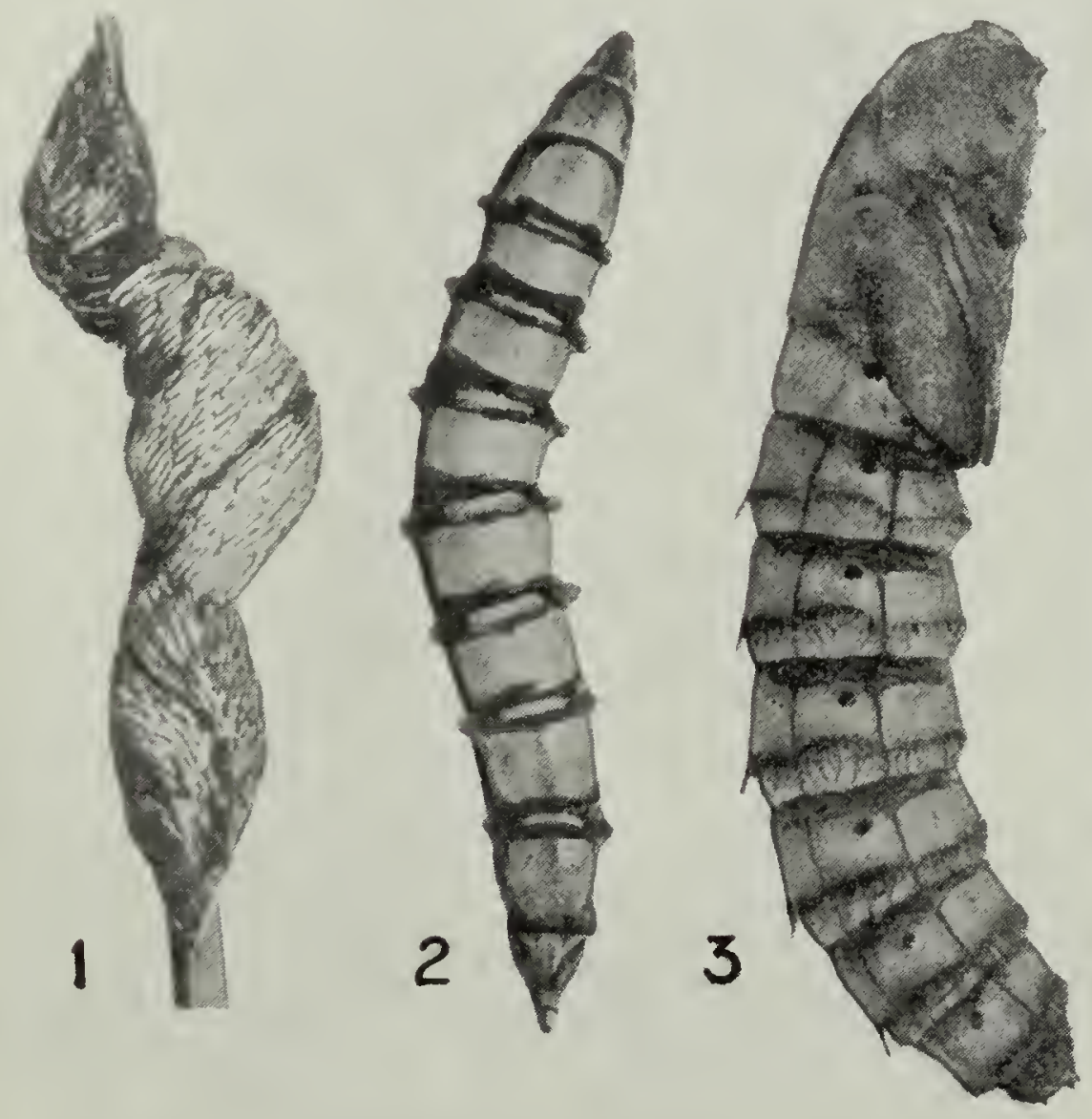

Fig 21-Tabanus punctifer O.S., métamorphoses: 1, masse d'œufs, 2 , larve; 3 , pupe; très grossie (d'ar rès Webb et Wells). 
de pénétrer dans les bâtiments ou d'autres lieux clos. Nous en avons trouvé un grand nombre à l'intérieur d'automobiles. Criddle, au Manitoba, a tiré parti de cette habitude en convertissant un petit bâtiment non employé en un piège, en mettant des rebords de grillage de fil de fer sur les bords des portes. Les taons accompagnant les bêtes à cornes qui avaient été abreuvées près de là cherchaient l'ombrage que ce bâtiment offrait et étaient pris au piège en entrant. Une multitude a été prise de cette façon en quelques jours et il en est résulté une diminution sensible dans le nombre noté plus tard autour des animaux. Les abris obscurs sont utiles mais ils ne sont nécessaires que pendant la chaleur du jour, car les taons ne sont actifs qu'à une heure avancée de la matinée et disparaissent au coucher du soleil. L'emploi de solutions repoussantes n'a que peu de valeur à cause de la persistance des attaques. Les filets à mouches donnent quelque protection aux chevaux de travail. Lorsque les taons sont spécialement abondants, on pourrait fournir des couvertures de toile en tenant spécialement compte des parties du corps qui sont mordues par les différentes espèces. Par exemple, le taon ordinaire à tête verte (Tabanus phaenops O.S.) préfère la tête et l'encolure, et il s'agit donc de recouvrir ces parties. Pour le grand taon noir à thorax gris (Tabanus punctifer O.S.), qui est l'espèce la plus commune dans bien des parties de la région sèche de la Colombie-Britannique, il faut recouvrir le dos et la croupe.

Les larves, les nymphes et les adultes sont attaquées par certains ennemis, mais pas suffisamment pour causer une réduction appréciable dans la population des taons. Les œufs sont souvent fortement parasités par des insectes minuscules, semblables à des guêpes. Nous avons noté parfois un parasitisme intense en Saskatchewan. Il semble peu douteux que ces petits ennemis des taons en réduisent le nombre. La présence de parasites a été notée dans 90 pour cent des masses d'œufs d'une espèce de mouche à chevreuil. Une espèce de ces parasites (Trichogramma minutum Riley) peut être élevée sur un grand nombre d'hôtes, y compris plusieur's ordres d'insectes.

\section{SIMULIES OU MOUCHES NOIRES (Simuliidés)}

Cette famille ne compte que peu d'espèces et les individus sont de petite taille. Trente-huit espèces avaient été notées ou décrites au Canada jusqu'à 1936. Peu d'entre elles mesurent plus d'un quart de pouce de longueur, la majorité n'ont guère que la moitié de cette dimension. Malgré leur petite taille, ce sont des suceurs de sang acharnés et dangereux; dans certains districts, elles constituent un terrible fléau pour l'homme aussi bien que pour les animaux sauvages et domestiques. Heureusement, elles ne sont pas aussi répandues au Canada que les moustiques et les taons. Les simulies ont des ailes courtes, larges, un corps trapu, court, le thorax est proéminent, en bosse; c'est sans doute cette dernière caractéristique qui leur a valu le nom de "moucheron buffalo" (buffalo gnat). La plupart des espèces ont une couleur noire ou foncée; les unes sont grises, d'autres rouges. Leur attaque est caractérisée par un acharnement têtu, féroce, beaucoup plus que chez les moustiques. Lorsqu'elles se posent sur une bête, elles se faufilent à traver's les poils jusqu'à la peau. Sur l'homme, elles se faufilent dans les manches, sous le col, autour du dessus des bottes, et dans tous les autres endroits vulnérables; elles s'attaquent spécialement à la tête, juste au-dessous du rebord du chapeau. Chez les animaux, les naseaux, la poitrine, le ventre sont très attaqués; la poitrine devient souvent une plaie. Beaucoup d'espèces se posent spécialement sur les oreilles pour se nourrir, et lorsque les mouches noires abondent, leurs allées et venues incessantes font penser à l'activité d'une ruche d'abeilles. Le poison qu'elles introduisent par leurs morsures provoque un gonflement et une douleur qui peuvent persister plusieurs jours. Heureusement, ces mouches ne mordent que le jour, mais, de même que les taons, elles peuvent commencer leur travail à l'aube, même s'il fait froid; leur activité n'est nullement restreinte aux par- 
ties les plus chaudes de la journée comme chez les taons. Les mouches noires sont généralement plus abondantes en juin et juillet, mais elles font aussi souvent leur apparition vers la fin d'avril et en mai; elles ont une plus longue saison que la plupart des mouches piquantes, parfois même elles se montrent très gênantes jusqu'à la mi-octobre dans certains districts. Dans certaines régions on en a vu au vol en petit nombre en novembre. Elles volent au loin, de grands essaims parcourant des distances considérables, et l'on a vu des simulies en quantité jusqu'à une quinzaine de milles de tout endroit possible de multiplication.

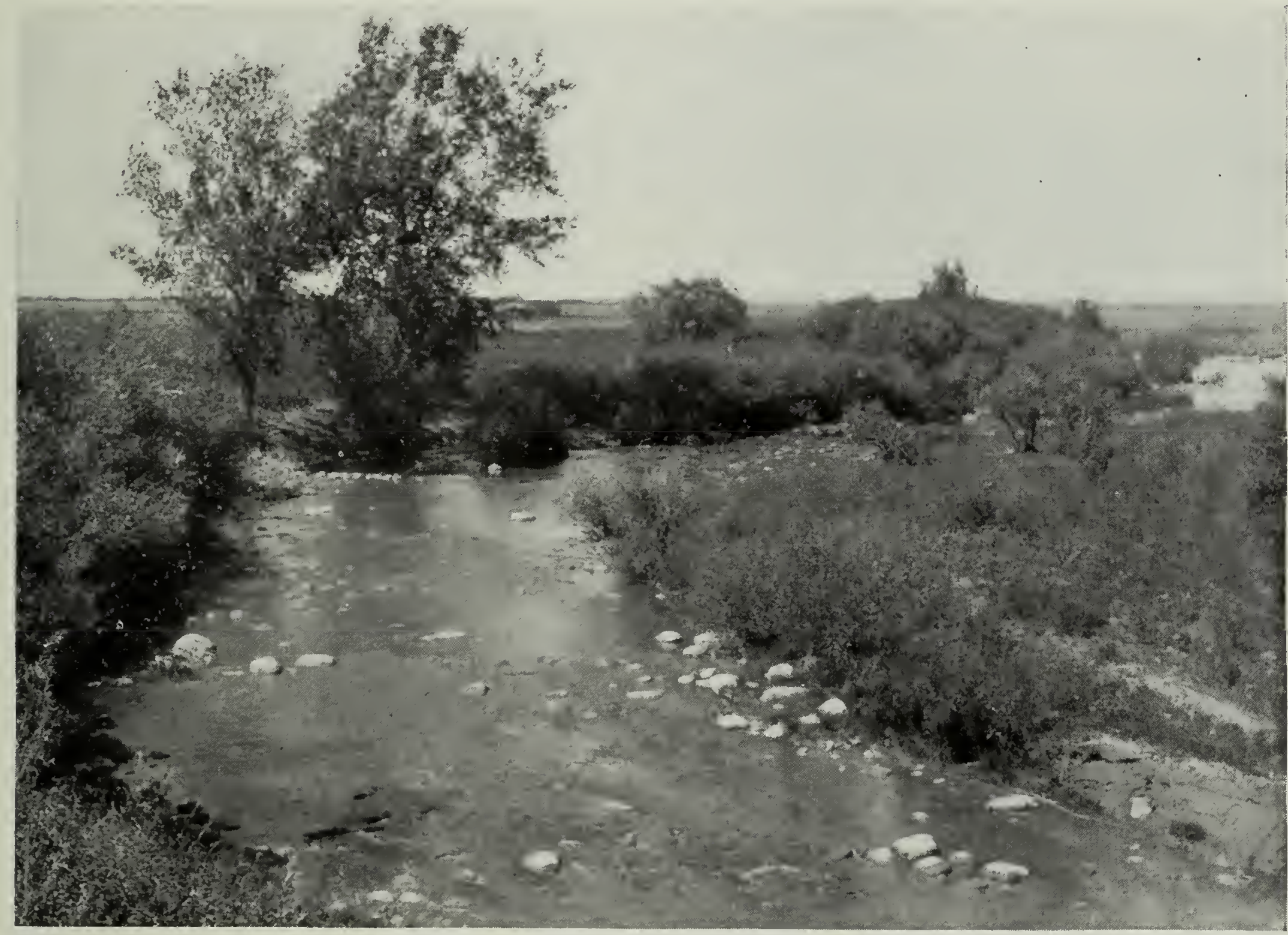

Fig. 23-Un cours d'eau typique à mouches noires (Original).

Ces mouches noires, partout où elles abondent, ont une très grande importance au point de vue économique; on peut en juger par le fait que les pertes causées pendant une seule semaine et dans un seul comté de l'un des EtatsUnis du Sud-Ouest ont été évaluées à un demi-million de dollars. Lorsqu'un nombreux essaim de mouches noires entoure un troupeau de vaches, les effets sont parfois désastreux. L'effet irritant des piqûres autour des naseaux fait que les animaux ronflent et respirent profondément, et ils avalent parfois en ce faisant un tel nombre de mouches qu'ils suffoquent et meurent presque subitement. En Saskatchewan, une forte mortalité chez les bestiaux, qui paraissait au premier abord être causée par l'explosion subite d'une maladie fatale, ${ }^{*}$ était en l'éalité causée de la façon que nous venons d'indiquer par les mouches noires. Quelque 300 bêtes à cornes ont péri dans une localité. La mort peut aussi être provoquée directement par l'effet du poison introduit par la piqûre. Toutes les catégories de bestiaux, de même que les animaux sauvages, les oiseaux et l'homme sont attaqués, mais les différentes espèces de simulies manifestent des préférences marquées sous ce rapport. L'une des espèces les plus répandues au Canada, appelée la simulie à bas blancs (Simulium venustum Say), attaque

* Hadwen. 
surtout l'homme. Cette espèce sert également d'hôte intermédiaire à un parasite protozoaire du sang chez les canards (Leucocytozoon anatis Wickware) qui cause une maladie grave chez les canards sauvages et domestiques.

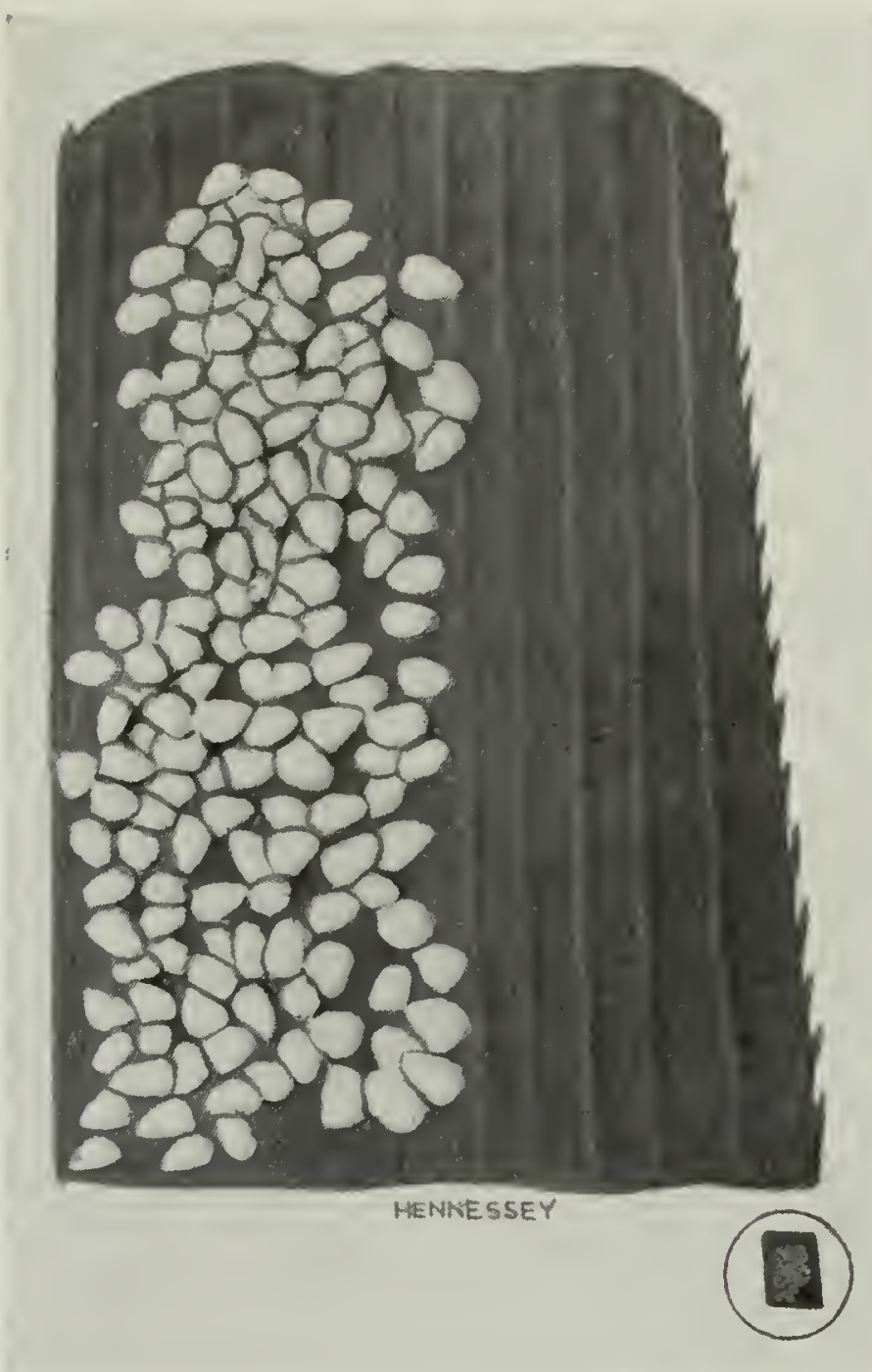

Fig. 24-CEufs de Simulium venustum Siy, sur l'herbe aquatique, grossis et grosseur naturelle (Original).

Cycle évolutif.-Les simulies se multiplient dans l'eau courante, peu profonde, des rivières et des ruisseaux. Le cycle de la vie des différentes espèces paraît être très semblable, mais nous avons noté, de même que chez les taons, que différentes espèces se succèdent d'un bout à l'autre de la saison d'une façon bien marquée dans quelques districts. Le nombre varie aussi beaucoup d'une saison à l'autre. Chez certaines espèces très abondantes qui naissent dans la rivière de la Saskatchewan, Cameron a trouvé que le cycle évolutif dure environ six semaines et qu'il y a quatre générations par an.

Les petits oufs jaune luisant des mouches noires sont pondus en masses compactes sur les pierres et sur la végétation dans les cours d'eau à courant rapide, et ils adhèrent avec ténacité à ces pierres et à ces végétaux au moyen de l'enduit gluant dont ils sont recouverts. Les mouches pénètrent même parfois dans l'eau pour $y$ pondre leurs œufs et on les a vues qui déposaient ces œufs à un pied au-dessous de la surface. Chaque femelle pond environ 500 œufs. Les larves qui éclosent de ces oufs se maintiennent en place, en dépit de la force du courant, au moyen de disques en forme de ventouse et de petits crochets placés à l'extrémité de l'abdomen. Elles ressemblent quelque peu à de petites sangsues par l'apparence et les mouvements, mais elles ont une tête bien définie, portant sur les côtés des brosses hérissées en forme d'éventails, faisant saillie comme de grandes oreilles. Elles se tissent un fil fin qui les fixe en place et les empêche d'être entraînées par l'eau lorsqu'elles se déplacent d'un endroit à l'autre. Elles se nourrissent à peu près de la même façon que les larves des moustiques, au moyen des brosses en forme d'éventails qui entourent la bouche, mais elles se procurent de l'oxygène de l'eau bien aérée dans laquelle elles vivent au moyen de branchies triples à l'extrémité caudale et à travers le tégument du corps. La couleur peut être brun foncé, verte ou pâle; elles se rassemblent en masses épaisses, visqueuses, semblables à de la mousse, sur les pierres et les autres objets dans l'eau comme les troncs d'arbres et les végétaux submergés. Lorsqu'elles sont complètement développées, elles se

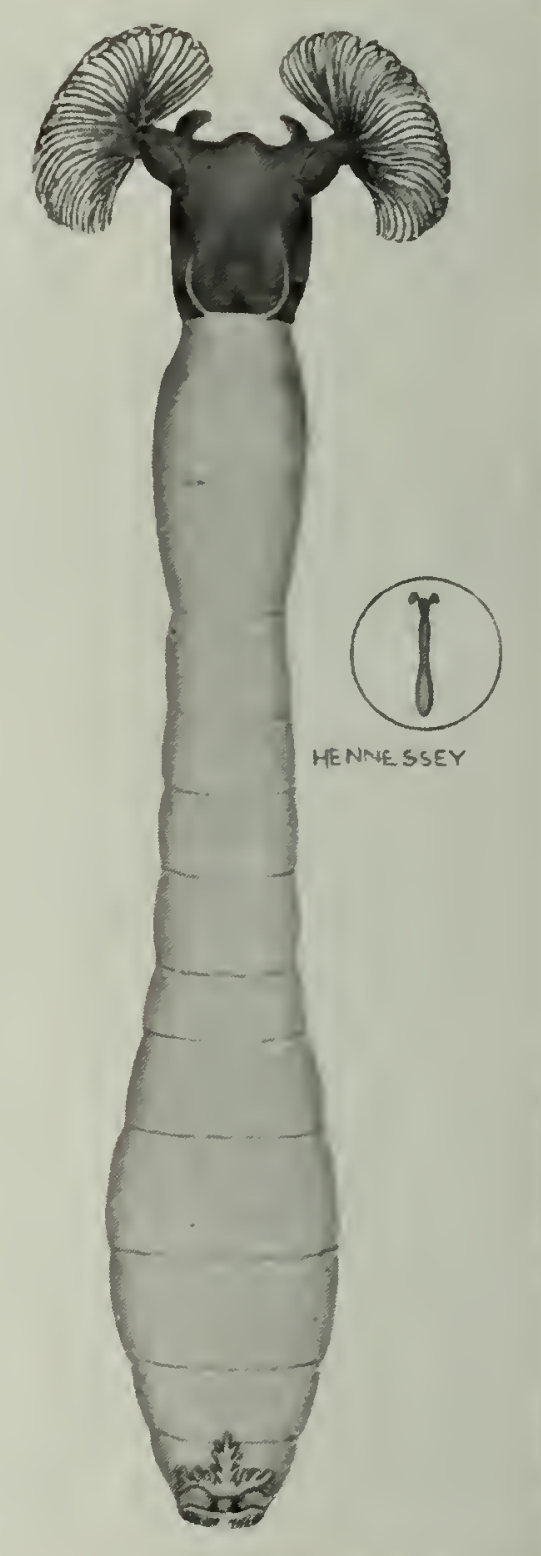

Fig. 25-Vue dorsale d'une larve entièrement développée de Simulium venustum Say, grossie et grosseur naturelle (Original). 
tissent un cocon, ouvert à une extrémité, qui est attaché à différents objets, et s'y transforment en nymphes. La forme et le caractère du cocon varient suivant l'espèce; la plus commune est la forme de pantoufle. La nymphe, qui est trapue, respire au moyen de deux touffes de filaments sur le thorax, dont le nombre et l'arrangement varient également dans les différentes espèces. La mouche adulte qui sort de la nymphe peut prendre son vol lorsqu'elle arrive à la surface de l'eau. Elle vit assez longtemps. Chez beaucoup d'espèces l'hiver se passe sous forme de larve.

Moyens répressifs. - Il n'est pas facile de combattre les mouches noires et les moyens répressifs coûtent généralement assez cher, mais beaucoup de bonnes démonstrations ont indiqué de façon bien nette que l'on peut grandement réduire le nombre de ces mouches en appliquant des huiles bien choisies aux rivières et aux cours d'eau dans lesquels elles se multiplient. Il faut que l'huile employée soit miscible, c'est-à-dire qu'elle se mélange aisé.. ment avec l'eau. Ce type d'huile coûte beaucoup plus cher que les huiles à brûler, de qualité inférieure, qui sont efficaces contre les larves des moustiques. Cette méthode est pratiquée sur des cours d'eau ou des rapides de petite étendue. On applique l'huile de façon à donner à l'eau un aspect laiteux opaque; l'huile doit être en quantité suffisante pour que cette eau laiteuse mette environ trois minutes à passer un certain point. Deux gallons d'huile suffisent pour traiter un petit cours d'eau sur une distance d'environ 300 verges. Malheureusement, il est extrêmement difficile d'obtenir la dilution voulue pour détruire les larves des mouches noires sans faire de mal aux poissons, et de toute façon les nymphes ne sont pas détruites. Comme ces mouches couvrent une assez grande distance au vol, les moyens répressifs doivent être appliqués sur une région assez étendue; c'est essentiellement un problème de groupement.

Il ne semble pas que la mouche adulte ait beaucoup d'ennemis naturels, mais les larves en comptent un grand nombre. En Saskatchewan, Cameron a constaté qu'en été la carpe ordinaire se nourrit principalement des larves et des nymphes des mouches noires, la forme singulière de la bouche de ce poisson est bien adaptée pour cette proie. Les vers parasitaires et les maladies protozoaires en réduisent parfois le nombre, mais malheureusement aucun de ces ennemis ne se prête au développement et à l'emploi d'une façon pratique.

L'emploi de "boucane" - une fumée épaisse est le moyen le plus facile et le plus rapide de protéger les bestiaux contre les attaques des mouches noires. "Il faut agir rapidement pour protéger les bestiaux quand un nombreux essaim de mouches noires arrive, et l'endroit choisi pour engendrer la boucare doit être à une distance commode des bâtiments de la ferme; une personne devrait être spécialement chargée de faire un feu de boucane chaque fois que les bestiaux ont besoin d'être protégés. Lorsque les animaux ont constaté le soulagement que la fumée leur donne, ils reviennent au même endroit dès que les mouches recommencent à les tourmenter."* L'application d'un enduit d'huile sur la robe des chevaux de travail, des chevaux de selle et des vaches laitières fournit quelque protection; il faut donner une attention spéciale à la poitrine, au ventre et à l'intérieur des oreilles. Il ne faut pas appliquer l'huile abondamment (spécialement sur le dos) pendant les jours de grand soleil, car il pourrait en résulter des inconvénients. Heureusement, les mouches manifestent une préférence pour les parties inférieures du corps. L'huile de poisson ou l'huile de lin crue, avec une petite quantité d'huile de goudron, et une émulsion d'huile

* Hadwen. 
de charbon sont parmi les matériaux les plus recommandés. Les petits sacs de coton recouvrant les oreilles des chevaux de travail sont très utiles pour empêcher l'entrée des mouches, car, comme nous l'avons mentionné ci-dessus, quelques espèces, comme le Simulium vittatum Zett attaquent spécialement l'intérieur des oreilles.

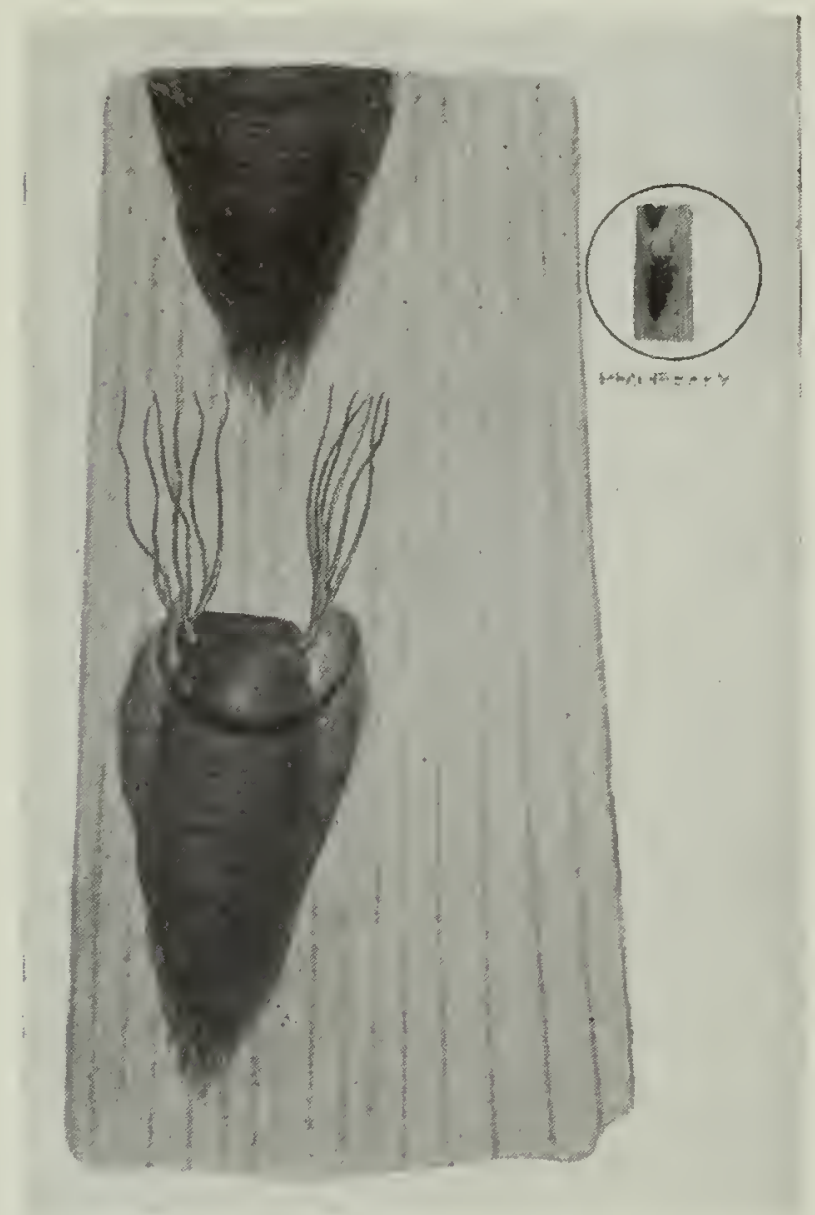

Fig. 26-Nymphe de Simulium venustum Say, dans un cocon sur l'herbe aquatique, grossie et grosseur naturelle (Original).

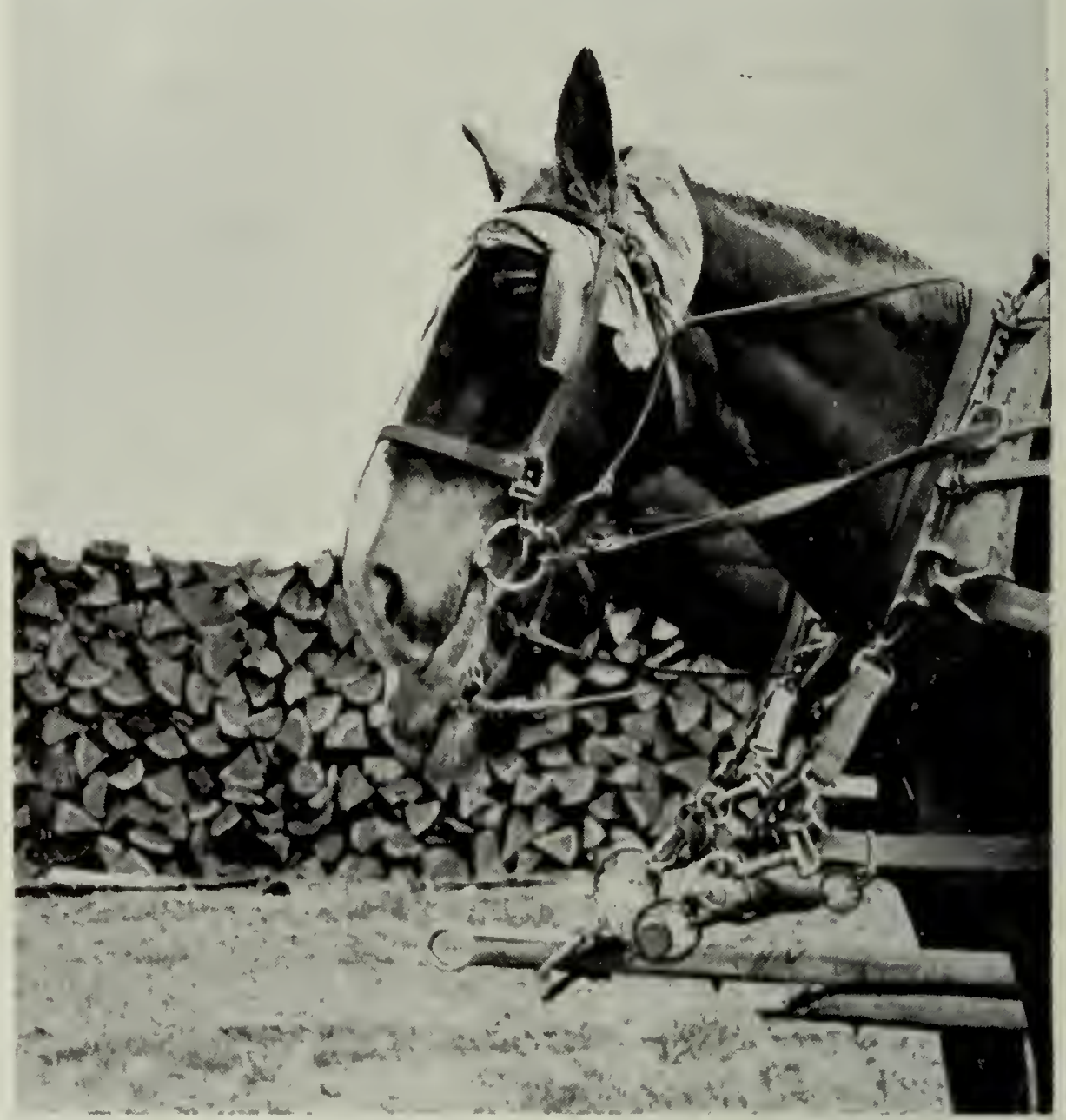

Fig. 27-Cheval de travail portant des sacs aux oreilles pour le protéger contre les attaques des mouches noires dont beaucoup d'espèces se posent sur les oreilles pour les mordre (Original).

\section{Mouches piquantes de moindre importance: brûlots, moucherons, symphoromies}

Les mouches dont il est question dans les paragraphes précédents comptent parmi les espèces les plus communes qui tourmentent les bestiaux, mais il y en a quelques autres, beaucoup moins répandues, cependant, qui causent aussi une grande incommodité à l'homme et aux animaux dans les endroits où elles abondent.

\section{“MOUCHERONS OU BRÛLOTS”, esp. Culicoides}

Ces petites mouches, appelées moucherons, brûlots ou mouches des sables, ressemblent quelque peu à de petits moustiques par leur apparence, mais l'appareil à succion ou "trompe" est très court. Dans la plupart des espèces les ailes et le thorax portent des marques caractéristiques, donnant un effet bigarré. Le nom anglais "no-see-um" (on ne les voit pas) est spécialement descriptif, car ces mouches dépassent rarement un seizième de pouce de longueur, et quelques-unes sont même encore plus petites. On n'en connaît que relativement peu d'espèces au Canada. L'un des plus gros membres du genre, appelé Culicoides obsoletus Mgn., se rencontre en Colombie-Britannique et on l'a trouvé en grand nombre en Alberta où il attaque sauvagement les chevaux. On l'a vu également qui attaquait l'homme et les animaux dans l'Est du Canada. Plusieurs autres espèces ont été notées en Alberta et Saskatchewan. Malgré leur petitesse, elles infligent de grandes souffrances et il faut avoir beaucoup de patience pour essayer de traire les vaches en plein air lorsqu'elles sont nom- 
breuses. Les brûlots évitent le vent, le soleil et la pleine lumière du jour; ils sont spécialement actifs à la tombée de la nuit et assez tôt le matin les jours calmes. Heureusement, ils sont très localisés et ne volent pas au loin. Ils se multiplient dans toutes sortes d'endroits, mais spécialement dans l'eau ou le sable et la terre saturés d'eau. Dans différentes parties du monde on a

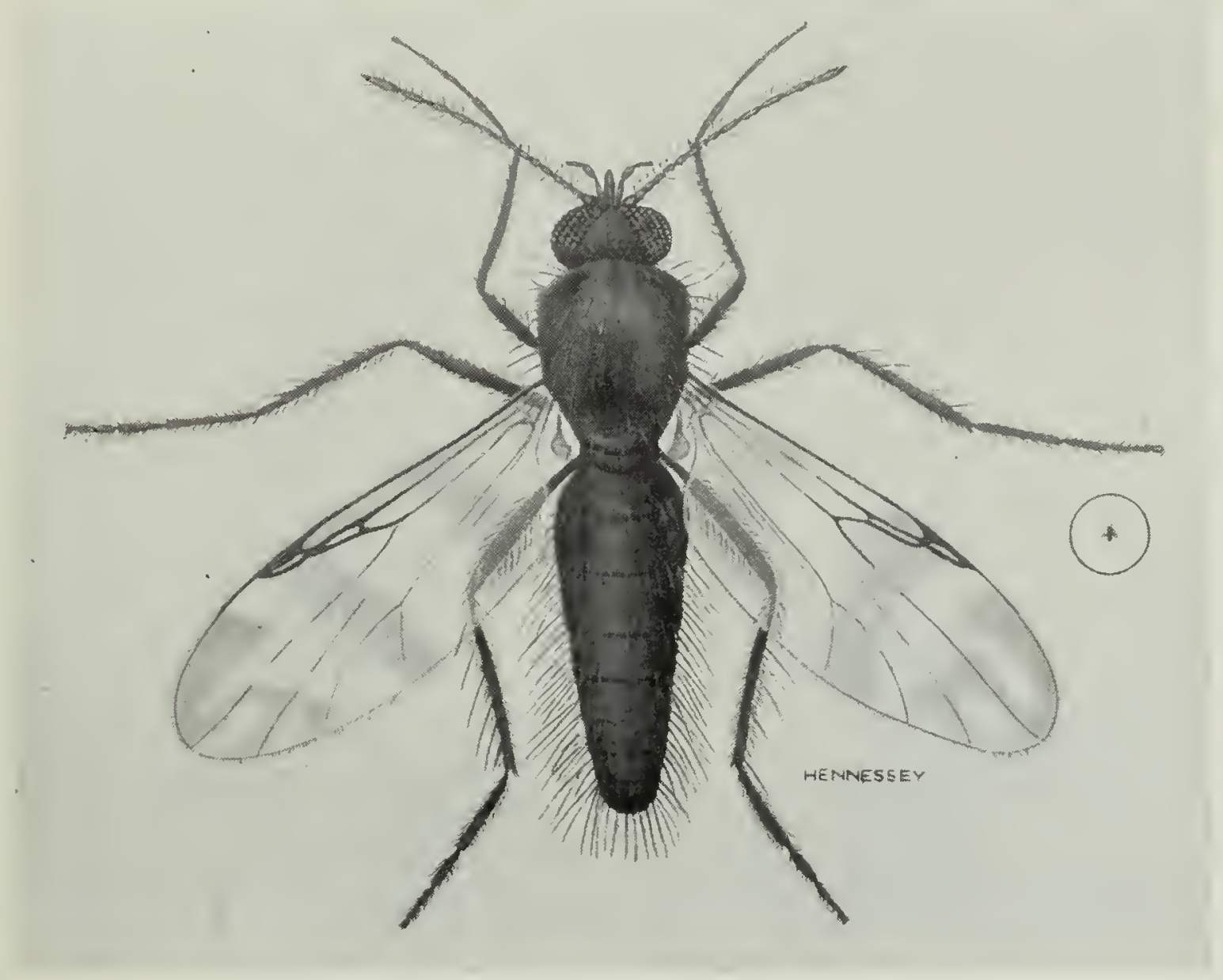

Fig. 28-Fémelle de brûlot, Culicoides obsoletus, Mgn., grossie et grosseur naturelle (Original).

aussi trouvé les premières phases de cet insecte dans les trous d'arbres et dans l'eau qui séjourne dans les souches d'arbres en pourriture, sous les pierres, la mousse, l'écorce, et même dans la sève sortant des arbres. Quelques espèces ont été trouvées dans des bouses de vaches. Les larves sont blanches et très minces; la nymphe brune est mince et elle est pourvue de deux petits tubes de respiration sur le thorax.

Il sera impossible de combattre cette espèce au moyen de larvicides tant que l'on n'aura pas d'indications plus complètes sur les endroits où elle se propage et il faudra avoir recours à la boucane et à des applications repoussantes à base d'huile. La petitesse des brûlots leur permet de pénétrer facilement à travers les moustiquaires, mais on peut les empêcher d'entrer en pulvérisant les moustiquaires avec un mélange repoussant.

\section{SYMPHOROMIES OU MOUCHES MORDANTES, esp. Symphoromyia}

Ces mouches ont une distribution encore plus limitée que les brûlots, mais elles se montrent extrêmement nuisibles dans les districts montagneux, en Colombie-Britannique et en Alberta.

Ce sont des mouches robustes, de grosseur moyenne, un peu plus petites et un peu plus minces que les mouches communes, et l'abdomen est effilé, en forme de cône. La plupart d'entre elles ont une couleur foncée, quelques-unes sont d'un noir luisant, mais d'autres sont brun rougeâtre. On n'en connaît actuellement qu'une demi-douzaine d'espèces au Canada. Pendant une année exceptionnellement pluvieuse, elles étaient extrêmement abondantes dans certaines parties de la Colombie-Britannique et de l'Alberta, et comme leur morsure est très douloureuse, elles causaient de grands tourments aux hommes et 
aux animaux domestiques, et les propriétaires de bestiaux s'en plaignaient beaucoup. Les chevaux de transport et les moutons dans la région des hautes montagnes en souffrent énormément. Un observateur dans l'Etat de Washington a noté jusqu'à 100 de ces mouches suivant un attelage de chevaux et les piquant à la tête, la partie qui est la plus généralement attaquée. Elles déploient le plus d'activité pendant la partie la plus chaude du jour; elles rressemblent sous ce rapport à leur parent, le taon du cheval.

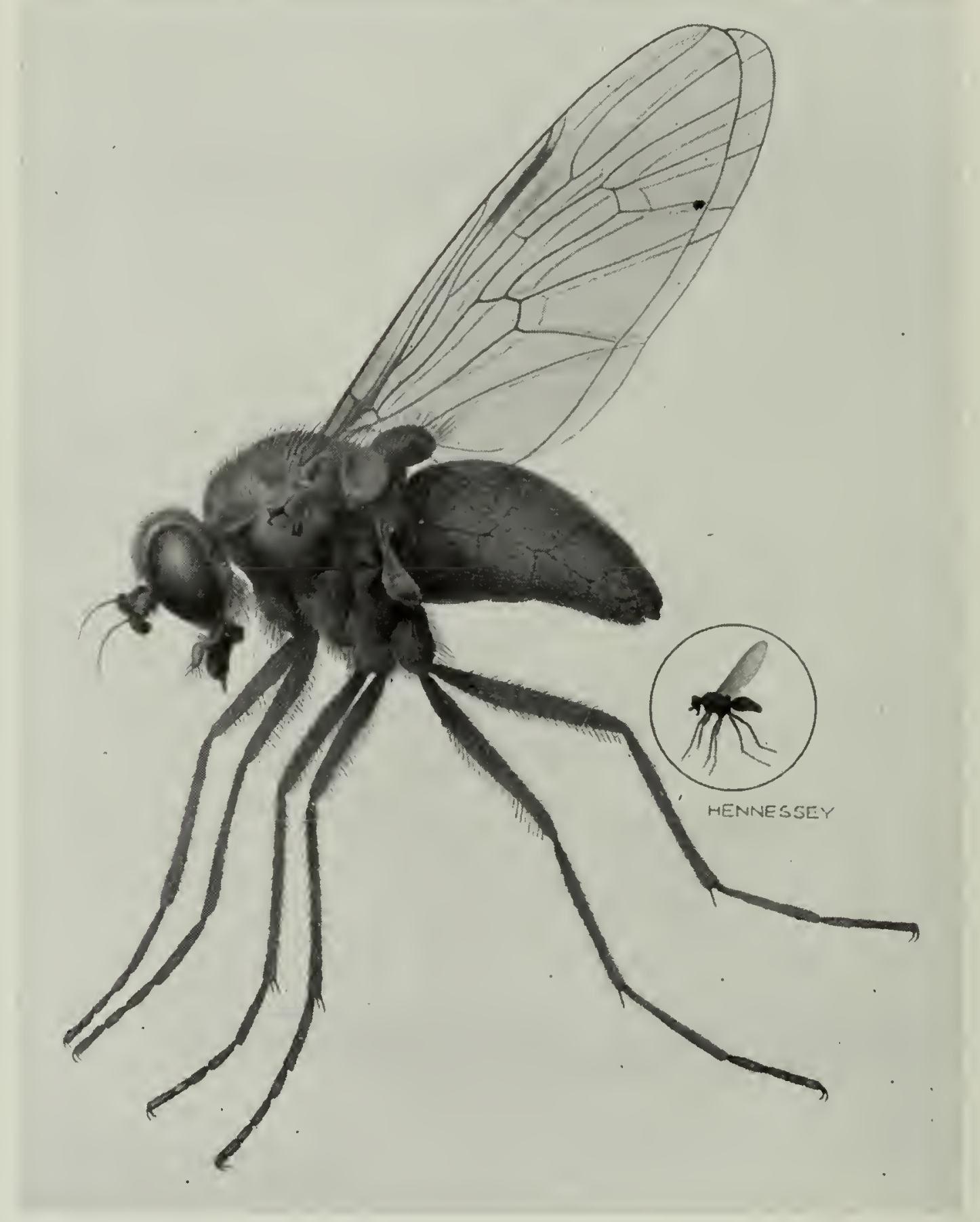

Fig. 29-Mouche mordante, Symphoromyia hirta, Johns, grossie et grosseur naturelle (Original).

On connaît très peu de choses sur les lieux de propagation ou les premières métamorphoses, mais on sait que d'autres membres de la même famille sont. aquatiques ou naissent dans le bois pourri et les végétaux en décomposition. Ce manque de renseignements nous interdit de conseiller des moyens répressifs. On pourrait se servir de substances repoussantes ou de boucane pour protéger les animaux lorsque ces mouches sont particulièrement abondantes.

\section{Estres et hypodermes}

LES OESTRES DU CHEVAL (esp. Gastrophilus)

Il y a trois espèces différentes d'œstres qui attaquent les chevaux au Canada: Gastrophilus haemorrhoidalis L., G. nasalis L., et G. intestinalis De Geer. Aucune de ces espèces n'est indigène au pays, et il est probable qu'elles ont été 
introduites dans l'Amérique du Nord il y a très longtemps. Ce n'est qu'assez récemment qu'elles se sont propagées dans quelques-uns des districts les plus nouvellement colonisés du Canada, et elles s'y sont grandement multipliées en ces vingt dernières années. Les chevaux et les mulets sont les animaux généralement attaqués, mais on a vu aussi des oestres se porter sur des cochons et d'autres animaux et un certain nombre de cas de myiase chez l'homme, provoqués par la larve de l'œstre, ont été notés au Canada et ailleurs. Tous les œestres ont à peu près le même cycle évolutif: tous pondent leurs œufs sur l'animal hôte, et les larves en forme de baril se développent dans l'appareil digestif, mais les différentes espèces ont des habitudes quelque peu différentes, et c'est pourquoi nous avons jugé bon de les présenter séparément par ordre d'importance.

\section{L'CESTRE HÉMORROÏDAL OU CESTRE DU NEZ (Gastrophilus hamorrhoidalis L.)}

Cet œstre, appelé en anglais "mouche du nez" ou "mouche à queue rouge" (nose fly, red tailed bot-fly) est le plus petit des trois, et cependant c'est celui qui cause de beaucoup le plus d'ennuis. Il se rencontre dans les trois provinces de l'Ouest et abonde tout spécialement dans les districts découverts des Prairies et les grands herbages. L'œstre adulte mesure environ un demi-pouce de longueur; il a une queue rouge orange et ressemble quelque peu à un petit bourdon. Le thorax, entre les ailes, ainsi que la partie centrale de l'abdomen, sont traversés d'une bande d'un noir luisant; les parties antérieures de l'abdomen et du thorax sont revêtues de poils gris jaunâtre. C'est l'espèce qui a de beaucoup le vol le plus rapide. Il plane près de terre entre les jambes de devant du cheval, puis se lance brutalement avec une grande force sur les naseaux de l'animal, où il fixe.solidement ses œufs noirs, pourvus d'une tige, à la base des poils courts, sur les lèvres. Ce n'est que pendant la ponte que les chevaux sont tourmentés par ces mouches. La présence d'œstres dans le voisinage ne paraît pas les inquiéter, pas autant, par exemple, que l'hypoderme n'inquiète les bêtes à cor-

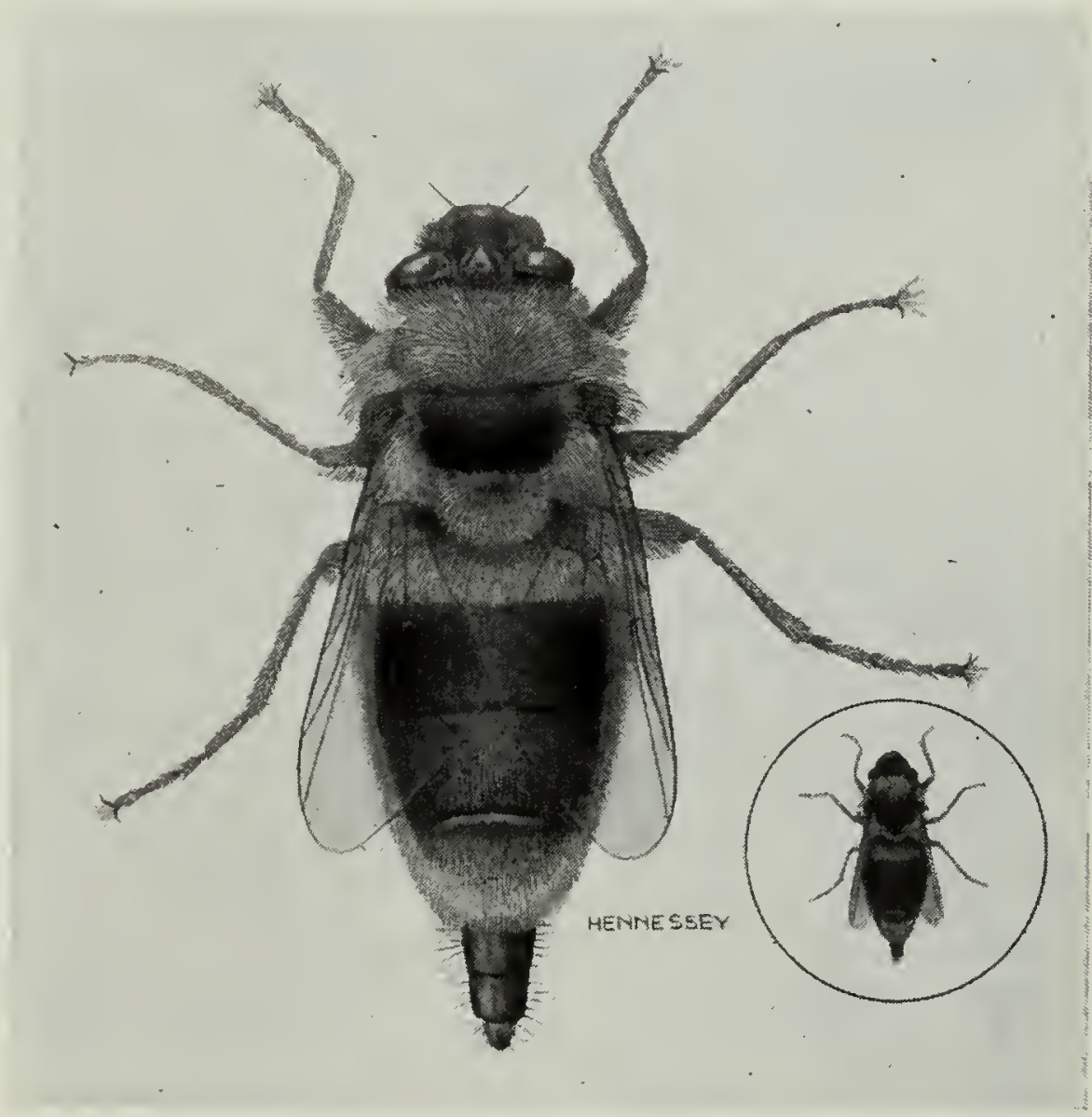

Fig. 30-Femelle adulte de l'œestre hémorroïdal, Gastrophilus haemorrhoidalis L., grossie et grosseur naturelle (Original). nes. Certains auteurs prétendent que la crainte manifestée par les chevaux résulte de la douleur causée par la tige pointue de l'œuf en transperçant la peau, mais la majorité des entomologistes qui ont étudié ces insectes ne partagent pas cette opinion; ils prétendent que la tige de l'œuf n'est jamais enfoncée dans la peau et que la terreur éprouvée par le cheval est due uniquement à la façon brutale dont la mouche frappe la lèvre très sensible. Celle-ci saisit les poils avec ses pattes en pondant ses œufs, et ses attaques répétées terrorisent l'animal. Cependant l'examen du rebord d'un chapeau frappé par un œstre a révélé qu'un œuf y avait été déposé et que la tige avait complètement pénétré dans le feutre.

Dommages causés par l'œstre hémorroüdal.-On considère que cette mouche est l'insecte le plus nuisible de tous ceux qui attaquent les chevaux, quand elle 
est abondante. Elle affole tellement les animaux par sa ponte que ceux-ci ne peuvent paître en paix ni se reposer pendant une bonne partie du jour; l'agitation continuelle dans laquelle elle les tient les fait maigrir. Ils n'ont aucune paix pendant les journées chaudes et ensoleillées et sont dans un état de perpétuelle irritation nerveuse. Les chevaux sous le harnais ne peuvent faire un bon travail lorsque leur attention est constamment attirée par les œstres qui cherchent à les frapper, et trop souvent, ils prennent le mors aux dents. L'irritation provoquée par la ponte et l'éclosion des larves sur les lèvres portent les chevaux à se frotter la bouche sur des surfaces dures, et les plaies qui en résultent les rendent encore plus irritables.

Les larves d'ostres sont nuisibles également en s'attachant à l'estomac et aux autres parties de l'appareil digestif. Plus d'un millier de larves ont été extraites de l'estomac d'un cheval. Il y a quelque divergence d'opinions au sujet de l'importance exacte de ces dommages, mais il est incontestable que la présence d'un grand nombre de ces parasites fait maigrir l'animal et l'affaiblit, et celui-ci peut même mourir d'épuisement pendant les hivers rigoureux lorsque les conditions d'alimentation sont spécialement mauvaises. Cependant, lorsque la nourriture est abondante et que les insectes ne sont pas en grand nombre, les chevaux ne paraissent pas en être grandement incommodés.

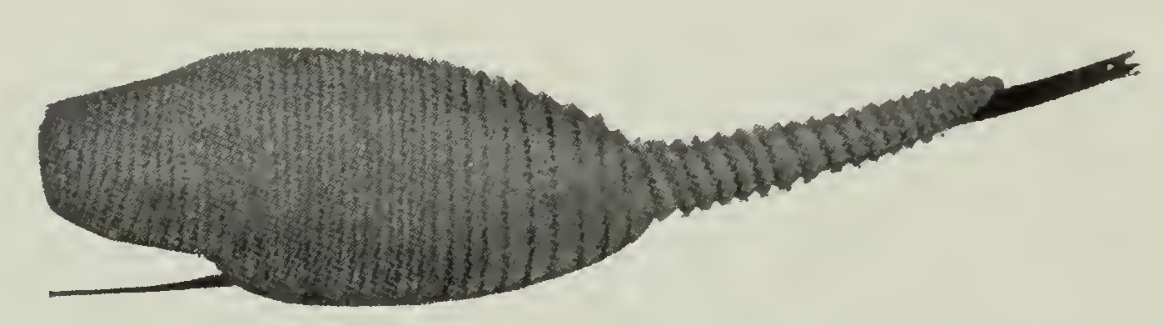

Fig. 31-CEuf de l'oestre hémorroïdal, très grossi (d'après Hadwen et Cameron).

Les larves de ces oestres, et celles des autres espèces d'oestres contiennent une substance qui s'est révélée très toxique pour les chevaux à qui on l'a injectée sous la peau, et il est possible que la maladie appelée "jiggers" (une sorte de paralysie agitante) puisse r'ésulter de l'absorption du poi-

son engendré par les larves dans l'estomac.

Cycle évolutif.-Le cycle évolutif de cet œstre est le suivant: les adultes sont au vol à partir de la fin de juin jusqu'à la fin d'août; c'est en juillet qu'ils déploient ordinairement le plus d'activité. On voit parfois une mouche tardive dans la première semaine de septembre. La ponte ne se fait que pendant les journées claires et ensoleillées; les cstres n'inquiètent que peu les chevaux lorsque le temps est sombre ou que le vent souffle avec violence. La ponte peut commencer le jour où les mouches sortent des coques de nymphes dans la terre, et chaque femelle peut pondre environ 150 oufs pendant sa courte vie, qui se prolonge rarement plus d'une semaine. Les oufs éclosent au bout de huit à quinze jours, l'humidité et la friction ne sont pas aussi essentielles pour cela que pour les oufs de l'œestre ordinaire. Après cela les connaissances que nous possédons des autres phases sont un peu incertaines. Il a été démontré expérimentalement que les larves nouvellement écloses s'enfoncent dans la chair; en fait, de nombreux cas de myiase chez l'homme, causés par la larve de l'œstre, ont été enregistrés. Il est probable que la larve parvient à l'estomac par une voie moins directe que par l'absorption avec la nourriture ou l'eau. Elle s'accroche à la muqueuse de l'estomac, où elle reste jusqu'à la fin de l'hiver ou jusqu'au printemps suivant, puis elle émigre dans la région du rectum, et, après avoir atteint son complet développement, se fixe près de l'anus, où on peut la voir faisant saillie. C'est la seule espèce qui ait cette habitude, et c'est de là qu'elle tire son nom hémorroüdal.

Les larves tombent à terre au bout de deux ou trois jours et s'y enfoncent pour se nymphoser; la phase de nymphe dure de trois à huit semaines. La mouche adulte ne prend aucune nourriture; en fait, les parties buccales sont rudimentaires et ne sont pas disposées pour l'alimentation comme chez les autres membres de cette famille. Les mouches n'ont pas de dard, mais il est parfois bien difficile de persuader de ce fait les propriétaires de chevaux, si 
grande est la terreur que ces insectes inspirent à leurs animaux. Heureusement pour le succès des moyens répressifs entrepris en commun, ces insectes sont incapables de voler au loin, et leur champ d'action dépasse rarement un rayon d'un demi-mille.

Moyens répressifs contre l'œestre hémorroüdal.-Les propriétaires de chevaux qui agissent en commun peuvent largement réduire le nombre des œstres, et même les faire disparaître complètement dans des districts d'une certaine étendue. Comme l'insecte passe l'hiver sous forme de larve dans l'estomac du cheval, le traitement médical de tous les chevaux et mulets dans un district au moyen de substances utiles pour l'expulsion des larves, est la façon la plus logique de combattre ce fléau. La coopération de tous les propriétaires de chevaux dans un district pourrait très bien résulter en l'établissement de districts sans ostres.

Le bisulfure de carbone est la meilleure substance pour extirper les larves d'œestres de l'estomac. Ce liquide, qui produit un gaz, est administré sous forme de capsules de gélatine, et une seule dose de six drachmes est suffisante pour un cheval de mille livres; on réduit la quantité en proportion de la taille chez les animaux plus petits et plus jeunes. On recommande de faire jeûner les animaux de dix-huit à vingt-quatre heures avant d'administrer la drogue, et de ne pas leur donner de nourriture ni d'eau pendant cinq ou six heures après. Il n'est pas nécessaire de donner un purgatif après le traitement. L'administration de cette drogue doit être laissée aux soins d'un vétérinaire qualifié, car l'animal pourrait subir une incommodité très grave si la capsule n'était pas bien avalée. Il pourrait aussi en souffrir s'il n'était pas en état d'être traité, et ce n'est qu'un vétérinaire exercé qui peut être le juge dans les cas de.ce genre. I'époque du traitement a une grande importance; la meilleure époque est le commencement de l'hiver, après que l'activité des oestres a cessé. Tous les chevaux devraient recevoir le traitement avant la mi-décembre.

Il existe plusieurs moyens utiles de protéger les animaux contre les attaques des œestres hémorroïdaux. Pour les animaux de travail, une muselière de bandelettes de cuir encerclant les naseaux, est utile, mais elle doit être faite de façon à ne laisser aucune partie découverte au centre du nez; il faut aussi qu'elle protège parfaitement les parties du dessous, car les mouches frappent par-dessous. Cette illustration représente une muselière de ce genre, bien faite et utile.

Le Bureau entomologique des Etats-Unis recommande un appareil encore plus simple: un morceau de cuir ou de courroie de quatre à six pouces de large est attaché par chaque extrémité aux anneaux du mors au moyen d'une ficelle ou d'une agrafe, de façon

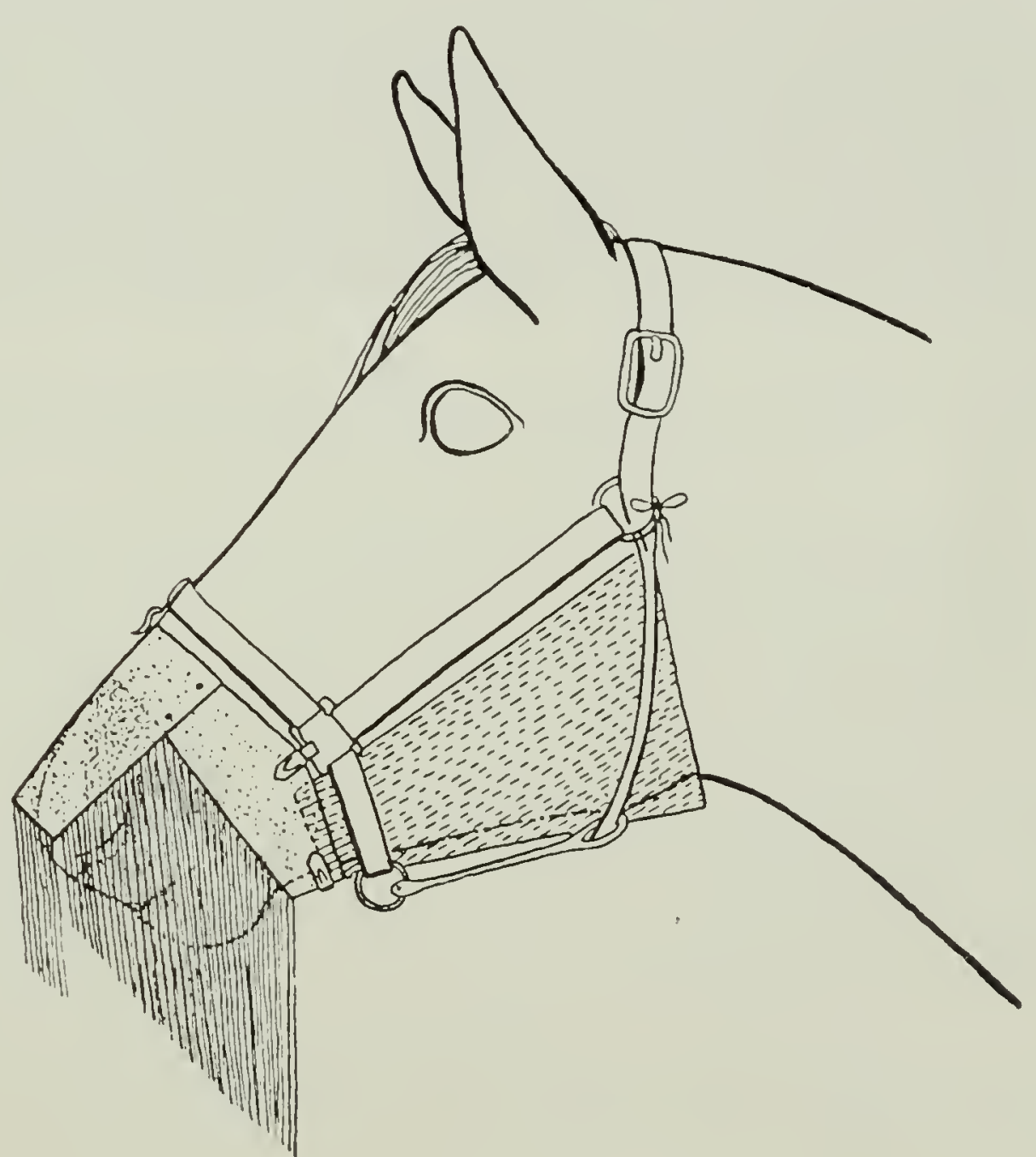

Fig. 32-Frange de cuir améliorée pour protéger les chevaux contre les attaques de l'œestre hémorroïdal; le couvert de toile protège la région entre les mâchoires contre l'œstre de la gorge (d'après Hadwen et Cameron). 
que toute la lèvre, y compris les commissures, soit protégée. Les paniers en fil de fer, généralement employés comme protecteurs, ont plusieurs défauts et sont moins satisfaisants que les muselières de cuir. On a aussi proposé de simples licous pour protéger les chevaux contre les œestres, tout en leur permettant de paître. Ces dispositifs protègent aussi l'animal contre l'œstre commun.
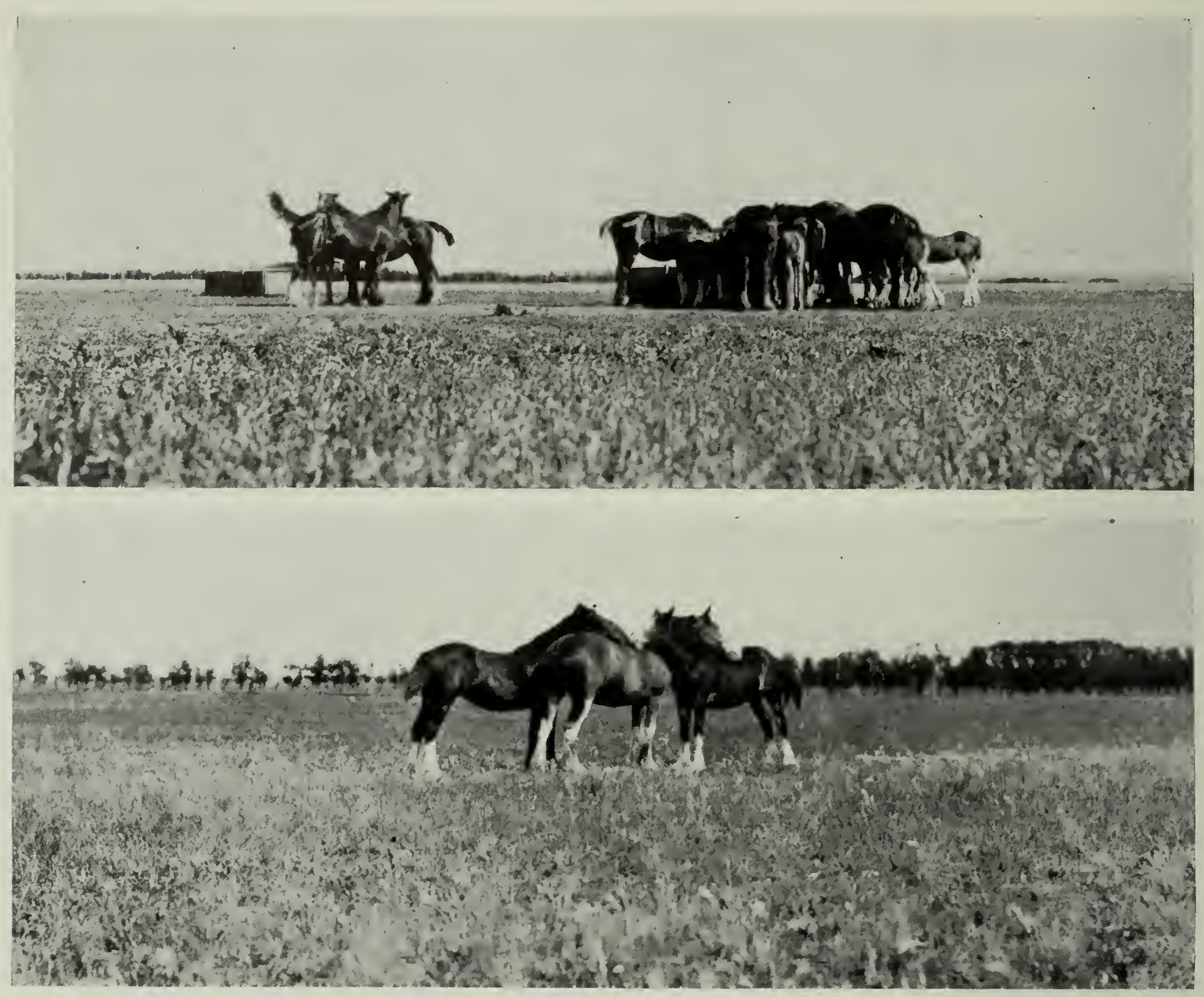

Fig. 33-Au-dessus: chevaux se protégeant contre les attaques de l'œstre; ceux de droite se tiennent la tête sur une auge remplie d'eau; au-dessous: attitude caractéristique des chevaux se protégeant contre les attaques des œestres (Original).

Pour protéger les animaux au pâturage, on devrait établir des refuges obscurs ou des abris de broussailles; ces refuges protègent très bien, car cette espèce d'œstre ne pénètre pas dans les endroits très ombragés. Si les chevaux sont dehors tout le jour, à la merci des œstres, ils sont recouverts d'un grand nombre d'œufs, et les larves sont en nombre correspondant dans l'estomac l'hiver suivant. Il est certain, que de bons refuges réduisent l'infestation et les 'ourments causés par les oestres adultes. Il est souvent possible de tenir les animaux dans l'écurie pendant le jour et de les laisser paître la nuit. Ils sont ainsi protégés contre les œestres, car ni cette espèce ni les autres ne pondent leurs œufs à l'intérieur des bâtiments.

Les chevaux se protègent généralement dans une grande mesure en se tenant dans des flaques d'eau et des bourbiers lorsqu'il y en a dans les pâturages; nous avons constaté qu'en l'absence de bourbiers, les animaux se rassemblent autour d'un abreuvoir, la tête tendue par-dessus l'eau. D'un mouvement rapide de la tête, ils projettent une mouche dans l'eau, et pendant deux jours nous avons vu près de soixante mouches noyées de cette façon. Cinquante d'entre elles étaient des œstres hémorroïdaux et le reste des œstres de la gorge. 
L'CESTRE DE LA GORGE (Gastrophilus nasalis L.)

Cet ostre est un peu plus gros que l'œstre hémorroïdal. Le thorax a une couleur rouge de rouille uniforme, et l'extrémité de l'abdomen n'a pas la couleur rouge caractéristique que l'on trouve chez l'œstre hémorroïdal; il est gris jaunâtre aussi bien par devant que par derrière la bande centrale noire luisante. Les œufs sont pondus presque exclusivement vers la base des longs poils de la partie supérieure de la gorge, entre les mâchoires. De même que l'œstre hémorroïdal, cette mouche plane entre les jambes de devant du cheval et se lance subitement vers le haut pour attacher ses œufs. Dès que l'animal sent la mouche, il retire sa tête dans l'encolure, d'où ce hochement de tête perpétuel que l'on voit chez

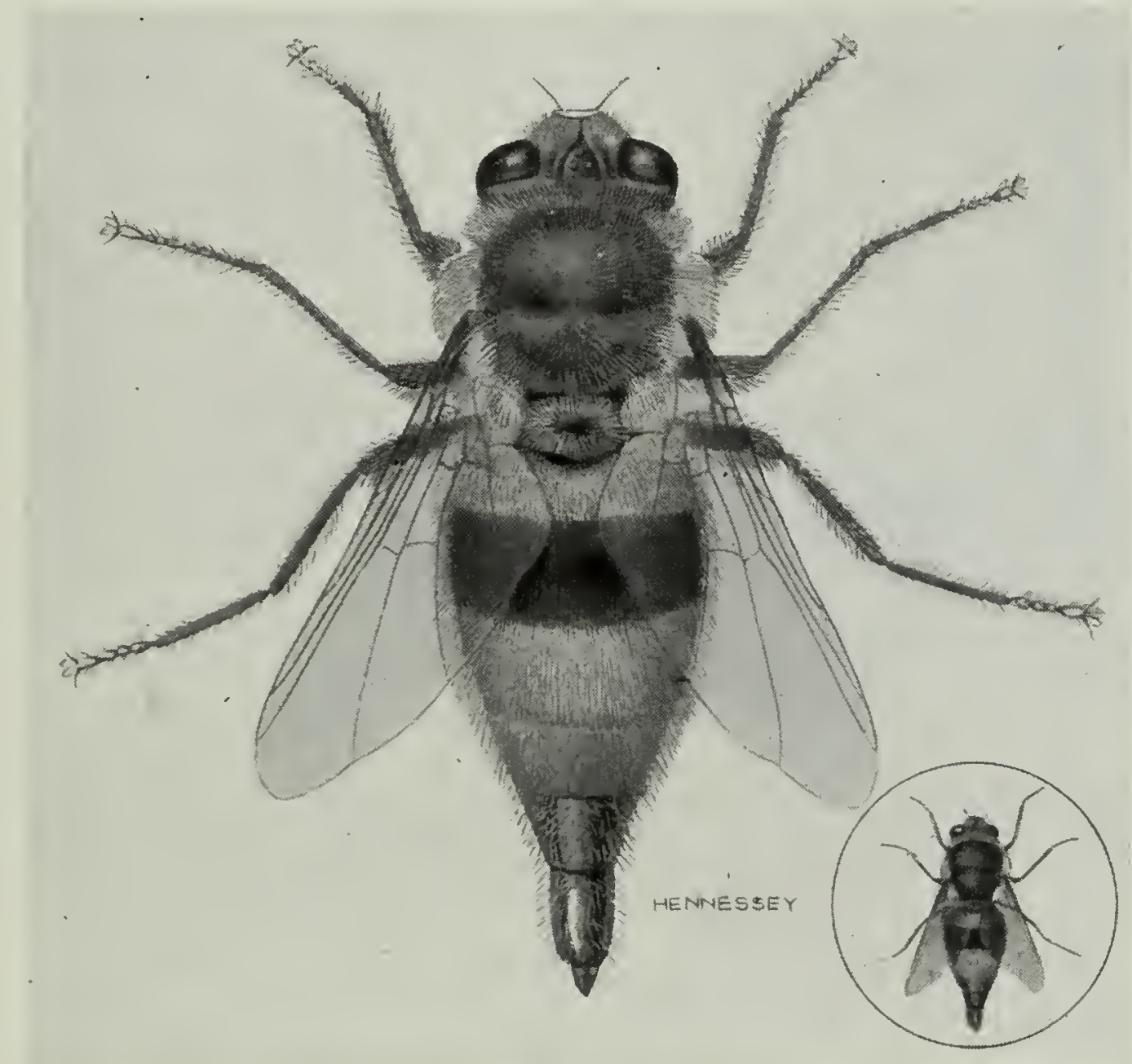

Fig. 34-Femelle adulte de l'œstre de la gorge, Gastrophilus nasalis L., grossie et grosseur naturelle (Original).

les chevaux pendant la saison des ostres. Les chevaux cherchent aussi à se poser la tête sur le dos et sur le cou les uns des autres, afin de se protéger contre les attaques de cet œestre aussi bien que de l'œstre hémorroïdal.

L'œstre de la gorge est un peu plus répandu que l'œstre hémorroïdal; il abonde surtout dans les provinces de l'Ouest mais il est moins commun dans le Canada en général et particulièrement dans l'Est que l'œstre ordinaire; il a cependant été signalé en assez grand nombre dans l'Etat de New-York.

L'adulte fait sa première apparition vers la mi-juillet et il peut être nombreux pendant tout le mois d'août, mais après cette époque, on en voit peu. Les chevaux redoutent moins cette espèce que l'œstre hémorroïdal; cependant, elle leur cause beaucoup d'inquiétude. Un trait nuisible de cet ostre, que ne possèdent pas les autres espèces, c'est l'habitude singulière qu'ont les jeunes larves de s'attacher à l'intérieur de la gorge, où elles se trouvent parfois en si grand nombre qu'elles causent la mort par suffocation.

Cycle évolutif.-En général, les habitudes de cette espèce sont assez semblables à celles de l'œestre hémorroïdal. Chaque femelle pond de quatre à cinq cents œufs jaunâtres, qui sont déposés séparément, un par un, généralement près de la base des longs poils, entre les mâchoires, et attachés par un sillon sur presque toute leur longueur. On a trouvé jusqu'à 68 œufs sur un poil, mais ils passent souvent inaperçus à cause de l'endroit où ils se trouvent Les 
œufs éclosent en un peu moins de deux semaines; la friction et l'humidité ne sont pas nécessaires pour l'éclosion. On sait que les larves pénètrent directement à travers la peau et qu'elles voyagent à travers les tissus de l'animal

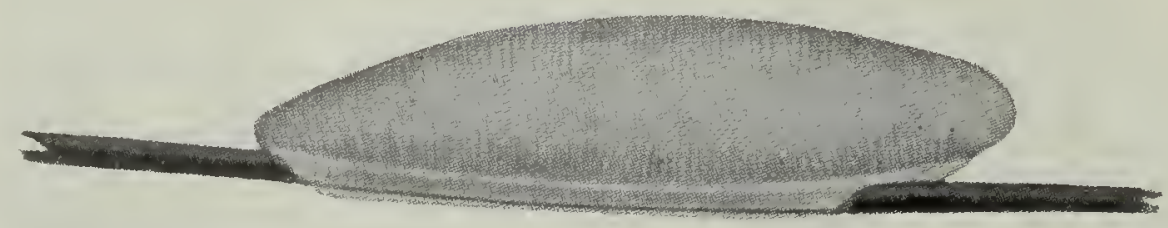

Fig. 35-Cuf de l'œestre de la gorge, très grossi (d'après Hadwen et Cameron).

pour se rendre à la région de la gorge. On voit de nombreuses croûtes sur la peau dans le voisinage des oufs, à l'époque où les larves éclosent. Plus tard les larves sont trouvées dans le duodénum, cette partie du petit intestin qui se trouve immédiatement derrière l'estomac. Les larves sont enfin évacuées avec les déjections au printemps, se transforment en nymphes puis en insectes parfaits environ deux mois plus tard. Les mouches adultes vivent environ deux semaines.

Moyens répressifs.-Le traitement au bisulfure de carbone et les refuges obscurs sont tout aussi bons contre cette espèce que contre l'œstre hémorroïdal; mais un protecteur différent est nécessaire pour empêcher la ponte des œufs. Il consiste en un morceau de toile que l'on suspend à partir de la sous-gorge jusqu'aux anneaux du mor's, afin de couvrir complètement la région entre les mâchoires.

\section{L'CESTRE DU CHEVAL OU CESTRE COMMUN (Gastrophilus intestinalis De Geer)}

Cette espèce est la plus grosse, la plus commune et la plus répandue de toutes les espèces d'ostres. Par sa taille, sa couleur brune, et son aspect il ressemble à la mouche à miel. L'abdomen est long et effilé, mais, lorsque l'insecte

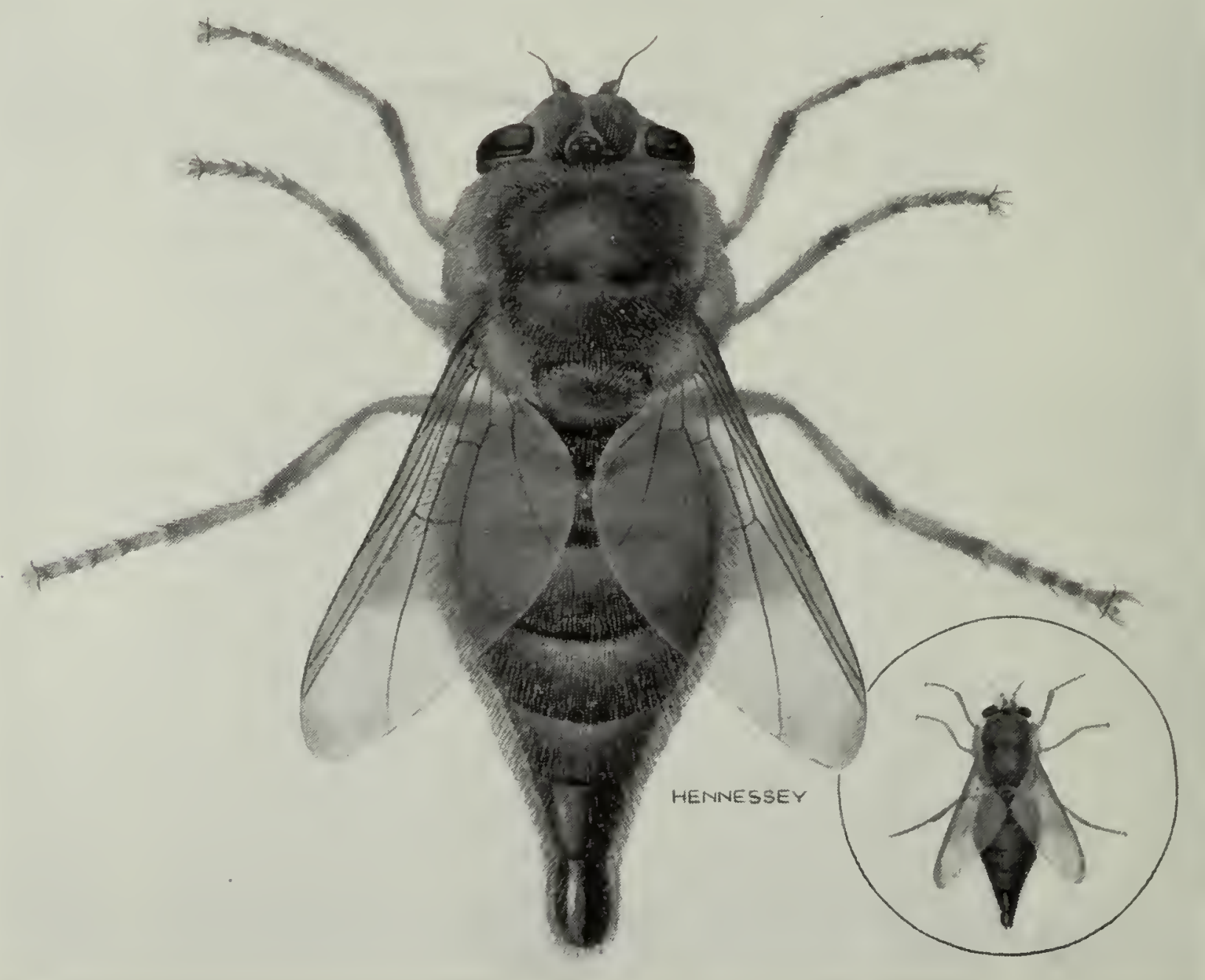

Fig. 36-L'ostre du cheval, Gastrophilus intestinalis DeG., grossi et grosseur naturelle (Original). 
est au repos, l'extrémité distale est tenue serrée sous le corps. Lorsqu'il se prépare à pondre ses oufs, l'insecte prend une posture en forme de $\mathrm{V}$, de même du reste que tous les autres oestres. Le gros oviscapte ou "tube de ponte" est courbé vers le haut, ce qui donne à l'insecte un aspect singulier et caractéristique. Contrairement aux deux autres espèces qui ont des ailes claires, les ailes de cet œestre sont obscurcies par des plaques foncées, couleur de fumée.

Cette espèce est plus tardive que les deux autres, et il est rare qu'elle prenne son vol avant la troisième semaine de juillet. Les ostres deviennent beaucoup plus abondants en août, et se voient encore pendant une bonne partie de septembre. Nous en avons vu en grand nombre dans la troisième semaine de septembre dans les provinces des Prairies. Ils peuvent être actifs même encore plus tard sur la côte du Pacifique, où on en a vu le 5 octobre.

La ponte de cette espèce est moins affectée par les conditions de température que celle de l'œestre hémorroïdal; peut importe le temps, qu'il soit couvert, ou sombre, ou qu'il y ait une légère brise, la ponte se fait quand même. Les chevaux ne s'inquiètent que peu de cet ostre dans les districts où les deux autres espèces se rencontrent également. Cet œstre a des mouvements lents, bien différents du vol brusque et rapide de l'œstre hémorroïdal.

Cycle èvolutif.-Les œufs jaunâtres sont attachés un pal un le long des poils, généralement vers l'extrémité extćrieure. Ils ne sont fixés que sur les deux tier's de la base, l'extrémité encapuchonnée faisant saillie à un angle de 30 degrés. Chaque femelle pond environ 550 œufs. Elle choisit de préférence pour la ponte

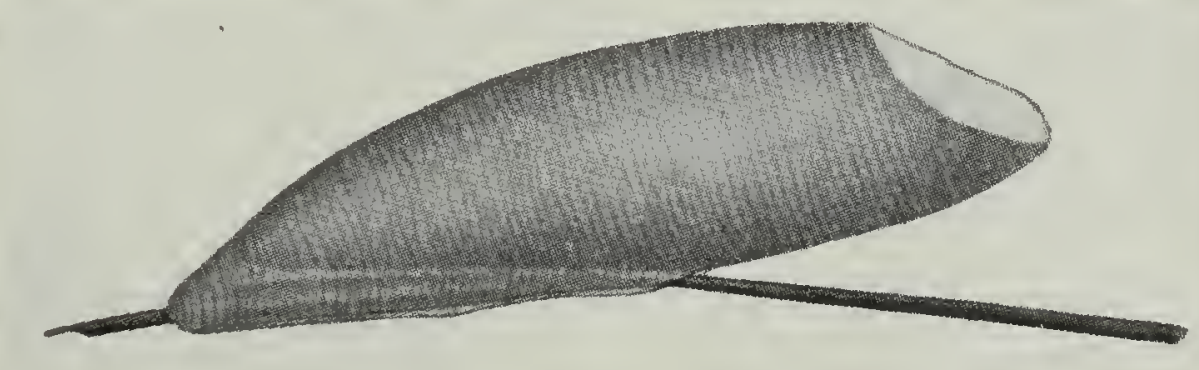

Fig. 37-Cuf de l'oestre du cheval, très grossi (d'après Hadwen et Cameron). les longs poils sur les côtés intérieurs des jambes de devant, mais les côtes de l'animal, les épaules, la crinière peuvent aussi recevoir un grand nombre d'œufs. Cet oestre choisit surtout les parties du corps que l'animal atteint facilement avec sa bouche, car il est rare que les œufs éclosent sans l'humidité et la friction que le cheval cause en se frottant ou en se mordant. Il est évident que l'angle auquel les oufs sont pondus aide la larve fraîchement éclose à s'accrocher aux lèvres ou à la langue de l'animal. Il est rare que les oufs éclosent en moins de dix jours, et la durée moyenne de l'incubation est d'environ deux semaines. Ils peuvent rester en vie sur le cheval pendant trois mois au moins, et c'est là un détail de grande importance dans la lutte contre cet insecte. Lorsque les petites larves éclosent dans les conditions favorables que nous venons de décrire, elles pénètrent dans la bouche
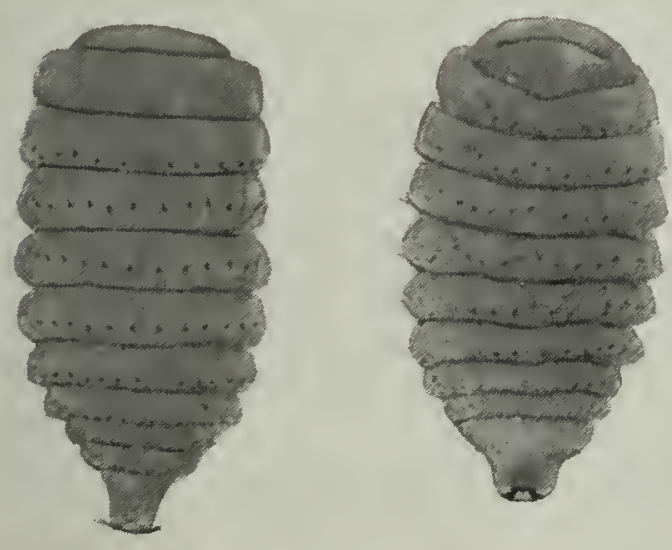

Fig. 38-Larve de l'œestre du cheval, vues dorsale et ventrale, un peu grossie (Original). et s'enfoncent probablement sous la langue, pour pénétrer ensuite jusqu'à l'estomac, où elles demeurent attachées à la tunique de l'estomac pendant environ dix mois. Elles sont alors évacuées dans les déjections, se transforment en nymphes dans le sol et l'insecte parfait sort au bout de cinq semaines environ. La vie de la mouche adulte de cette espèce paraît être plus longue que chez les autres espèces, et peut durer trois semaines.

Moyens répressifs.-Le traitement au bisulfure de carbone a beaucoup d'effet sur les larves de cette espèce, mais il ne faut pas oublier que les œufs restent en vie pendant un long temps 
et le traitement ne doit pas être appliqué trop tôt après que l'insecte adulte a cessé de déployer de l'activité. Si l'on trouve des œufs non éclos, il faut tondre l'animal ou le laver pour tuer les œufs. On s'est beaucoup servi d'huile de charbon pour cela, mais elle a peu de valeur et une solution à 2 pour cent de l'un des bains réguliers de coaltar-créosoté est bien préférable.

Les refuges obscurs en broussailles protègent beaucoup les animaux, mais ils sont moins utiles pour cet œestre que pour les deux autres, car l'œstre commun suit parfois les chevaux dans l'ombre pour pondre ses œufs sur eux. Le séjour à l'écurie pendant le jour fournit une protection absolue.

Comme les oufs sont déposés à bien des endroits différents sur le corps des animaux, il serait évidemment impossible de fournir des protecteurs pour prévenir la ponte, comme on peut le faire pour les deux autres espèces d'ostres. On a imaginé cependant des licous qui empêchent le cheval d'atteindre les oufs avec la bouche et de provoquer ainsi l'éclosion.

La tonte systématique du poil sur les parties infestées d'œufs jaunes peut être très utile pendant l'été. Cette tonte, ou l'application de solutions pour tuer les œufs, devrait se faire toutes les semaines pendant toute la saison de

la ponte. Quand les chevaux peuvent se tenir dans des bourbiers ou de l'eau boueuse, la couche de boue dont leurs jambes sont recouvertes empêche le dépôt des œufs sur les membres de devant. L'emploi de substances repoussantes pour empêcher la ponte n'est pas très satisfaisant. On peut cependant se servir de parties égales de goudron de pin et de saindoux sur les chevaux de selle et de travail. Cet enduit, appliqué sur les parties où les œufs sont généralement pondus, diminue jusqu'à un certain point l'infestation par les œestres.

\section{Les hypodermes du bœuf}

Les hypodermes sont des mouches velues, foncées, assez grosses, traversées de bandes jaunes ou orangées qui leur donnent une ressemblance superficielle à de petits bourdons. Deux espèces (Hypoderma lineatum de Vill et $H$. bovis DeG.) sont devenues très communes dans bien des parties du monde, et spécialement en Europe, dans l'Amérique du Nord et, à un moindre degré, en Asie. Ce sont les insectes les plus nuisibles des bovins partout où ils pullulent. Ils se rencontrent dans toutes les parties du Canada où l'on élève des bestiaux. La mouche et sa larve sont également nuisibles; la mouche terrifie les bestiaux lorsqu'elle pond ses œufs, et la larve ou "varron", exerce un effet néfaste sur la santé, l'état de chair et la production du lait des animaux affectés, et abîme les peaux par les orifices ou trous qu'elle perce pour respirer. Le bœuf est leur hôte normal, mais ils s'attaquent également aux autres animaux et on a vu des larves dans les chevaux, les bisons américains et les chèvres. On a également signalé à maintes reprises la présence de larves chez l'homme.

Le cycle évolutif et les habitudes des deux espèces se ressemblent sous bien des rapports et nous les récapitulons ici sommairement avant de les considérer en détail. Les œufs sont pondus pendant les journées claires, ensoleillées, sur les jambes et les parties inférieures de l'animal et ils sont fixés aux poils. Les petites larves éclosent au bout de trois à sept jours, pénètrent à travers la peau et circulent dans l'organisme de l'hôte, se rassemblant parfois en un certain nombre dans la région de l'œesophage. Elles restent là pendant la fin de l'été et jusqu'à la fin de l'hiver, puis elles entreprennent une deuxième migration et se fixent sous la peau du dos qu'elles perforent afin de faire des orifices de respiration. Après un séjour de deux mois environ dans cet endroit pendant lequel elles se nourrissent de la matière engendrée dans les kystes en forme de tumeur qui sont formés, elles sortent par les trous de respiration, tombent à terre et se nymphosent en objets durs, noirs, semblables à des graines, mesurant près de trois-quarts de pouce de longueur. Beaucoup d'investigateur's prétendent que les lar'ves adultes se réfugient sous des débris pour se protéger ou même s'enfoncent dans la terre meuble, comme font les œestres des rongeurs; 
Bishop a démontré qu'elles peuvent voyager sur une dizaine de pieds afin de trouver de l'ombrage. Cependant des expériences récentes conduites par $R$. C. Gaut indiquent que les larves ne cherchent pas à s'enfouir et qu'elles reviennent à la surface lorsqu'elles sont enfouies. La mouche adulte sort au bout de un ou deux mois. L'accouplement peut avoir lieu le jour même de la sortie et la mouche se met à pondre immédiatement. Elle peut pondre jusqu'à 800 œufs pendant sa vie, mais la moyenne est probablement un peu supérieure à

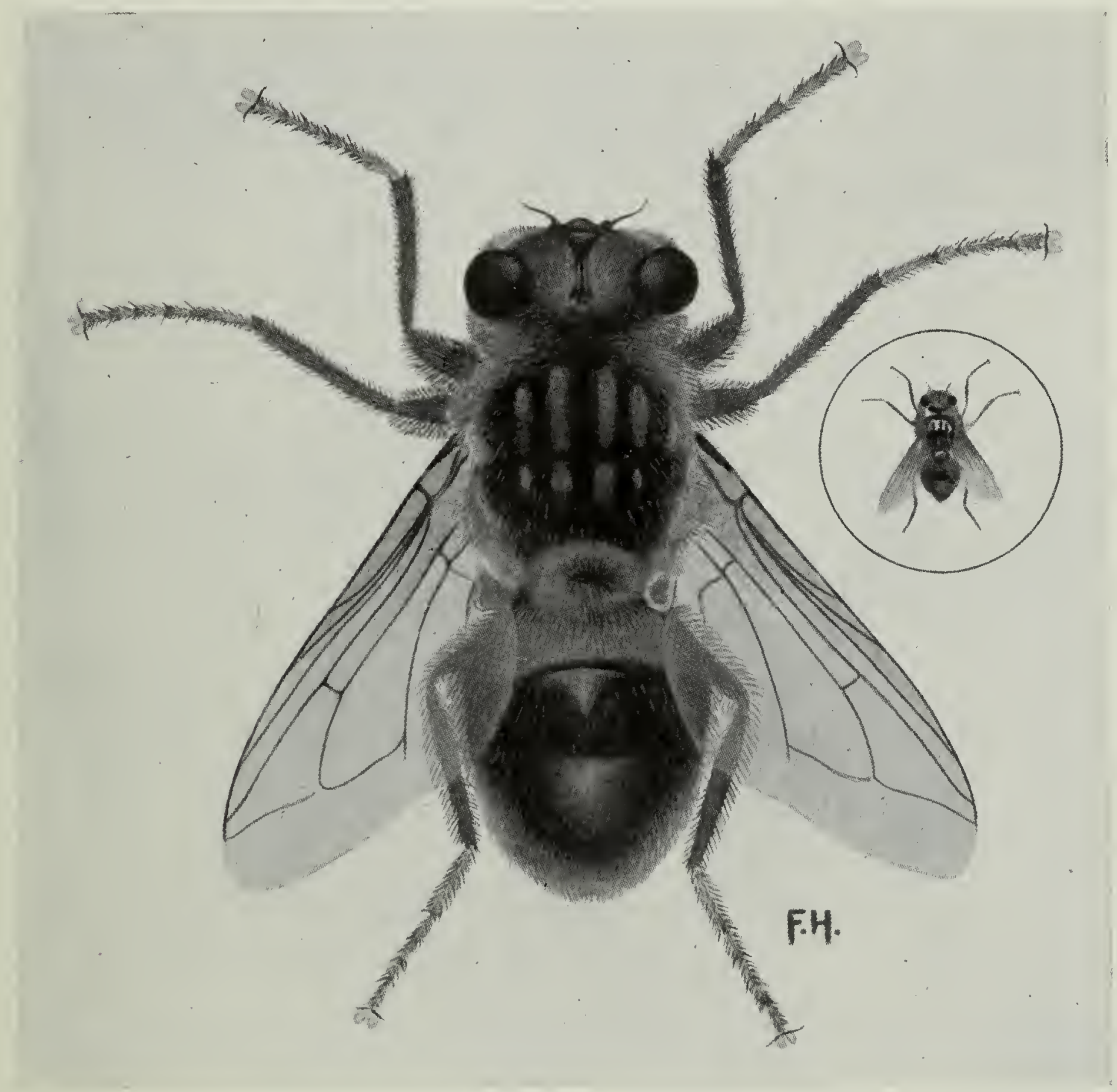

Fig. 39-L'hypoderme rayé ou commun, Hypoderma lineatum de Vill., grossi et grosseur naturelle (illustration de l'auteur).

la moitié de ce montant. La vie des mouches adultes est très courte, environ une semaine dans les conditions naturelles, mais la période d'activité est longue, de un à cinq mois ou plus, à partir du mois de mars. Il se développe des générations successives d'adultes pendant cette période et une espèce paraît être plus tardive à prendre son vol que l'autre. La période totale de développement, d'un œuf à l'autre, exige environ une année, et au moins neuf mois de ce temps sont passés sous forme de larve dans l'animal hôte. Il y a un certain nombre de mues et cinq phases distinctes de larves pendant cette période.

HYPODERME RAYÉ OU TAON DES TANNEURS, Hypoderma lineatum de Villers

L'hypoderme rayé, appelé en angläis "heel fly" ou "mouche du talon", est la plus petite des deux espèces; il mesure environ un demi-pouce de longueur. Une bonne partie du corps est recouverte de poils noirs, mais il y a de larges plaques de poils jaunâtre pâle sur les côtés du thorax et la base de l'abdomen. 
La pointe de l'abdomen porte des poils orangés rougeâtres. Les poils pâles et foncés sur le thorax sont rares sur la partie antérieure et n'obscurcissent pas les quatre lignes ou marques foncées distinctes à cet endroit. Les pattes sont raides et velues.

Les reconnaissances qui ont été faites dans différentes régions du Canada indiquent que cette espèce est très répandue et qu'elle est connue dans presque tous les districts où l'on élève des bestiaux.

L'hypoderme rayé est la plus hâtive des deux espèces. Les mouches adultes prennent généralement leur vol aux premières journées chaudes du printemps, et leur période d'activité, sur la plus grande partie du Canada, commence en mars ou avril pour finir en juin. L'hypoderme rayé pond de préférence ses œufs par les journées claires et ensoleillées, mais il choisit cependant les parties ombragées du corps. Il a "l'habitude de se poser sur la terre, à l'ombre des talons d'une vache, et au moyen de son long oviscapte il fixe ses oufs aux poils, autour de la couronne. Lorsque les vaches sont couchées, l'hypoderme dépose ses œufs furtivement sur ces parties du corps de la bête qui sont près de terre, sur une ligne partant d'un point à six pouces au-dessous des hanches et allant, le long des flancs jusqu'aux coudes et sur les côtés du poitrail"* (voir figure 40). Il procède généralement d'une façon très calme, très prudente et n'inquiète pas l'animal autant que le gros hypoderme, plus brutal et moins furtif. Les œufs sont pondus en séries, depuis quelques-uns jusqu'à une douzaine ou plus, et ils sont fermement cimentés aux poils par une espèce de pince qu'ils portent à la base. Ils sont généralement placés à mi-chemin sur le poil, et se voient malàisément à cause de cela. Une femelle peut pondre de 400 à 800 œufs et certains observateur's ont noté une ponte de plus de 500 œufs en moins d'une heure par une seule mouche.

Les œufs éclosent au bout de quatre à sept jours, et les petites larves, appelées vulgairement "varrons", qui mesurent un trentième de pouce de longueur, se faufilent immédiatement le long du poil jusqu'à la peau qu'elles percent pour disparaître dans le tissu sous-jacent. "Les vaches adultes résistent à la pénétration des larves par une réaction qui a lieu dans la peau. Un gonflement se produit à l'endroit où les larves sont entrées et il en sort une matière aqueuse. Au bout d'un jour ou deux, une crôtte se forme que l'on peut enlever, et sous laquelle on voit une petite fosse conique remplie de pus." ${ }^{*}$ Cette inflamation

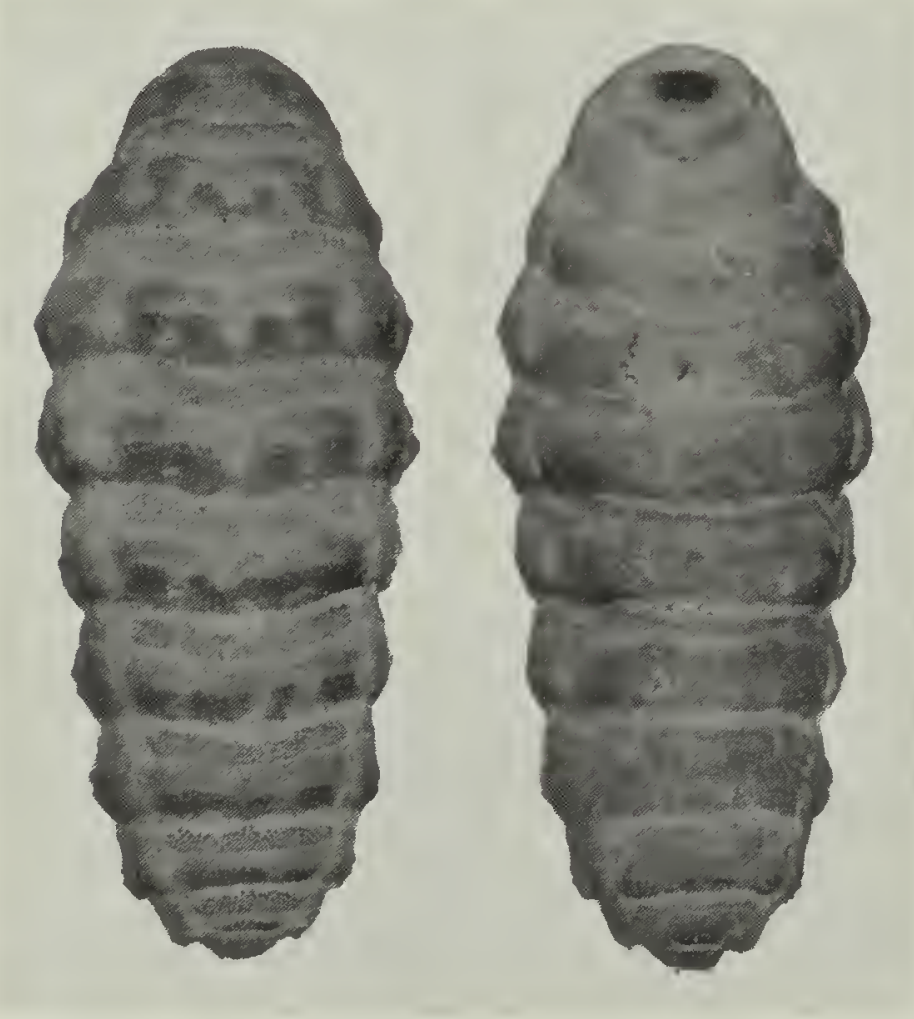

Fig. 40-Larve de Hypoderma lineatum de V., vues dorsale et ventrale, grossie (Original). et ce gonflement ont été appelés "hypodermose". Un bon nombre des larves sont sans doute détruites par cette réaction, et c'est là peut-être l'une des raisons pour lesquelles le nombre de larves qui arrivent à maturité sur les vaches adultes est bien inférieur à celui que l'on trouve sur les animaux plus jeunes, qui n'ont pas encore développé cette réaction défensive. On ne sait pas encore au juste quelle route prennent les larves après avoir pénétré dans le corps; ce que l'on sait, c'est que, dans cette espèce, elles finissent par arriver aux parois de l'œsophage où elles se trouvent en grand nombre. Les premières arrivent à cet endroit en juin et les dernières à le quitter le font en mars; c'est dans le milieu de l'hiver qu'elles sont le plus nombreuses dans cette partie du corps. Généralement les larves restent dans le corps environ deux

* Hadwen. 
mois et demi avant d'apparaître dans l'œesophage. Hadwen dit que "les lar'ves quittent l'œsophage à son extrémité inférieure, près de la panse, et qu'elles remontent jusqu'à l'épine dorsale par le diaphragme ou, clans certains cas, le long du dos des côtes. Elles pénètrent dans le canal de l'épine dorsale et passent le long de ce canal pour se rendre à la région des lombes; elles le quittent alors et montent jusqu'à la peau" à travers laquelle elles percent de petits orifices de respiration, apparemment au moyen des épines qu'elles portent à l'extrémité de la queue. L'époque à laquelle la larve arrive à cet endroit est très importante au point de vue de la lutte contre cet insecte, et c'est pourquoi elle a été l'objet de longues études dans différentes parties du Canada. Dans les parties chaudes du littoral de la Colombie-Britannique, les larves de cette espèce peuvent faire leur apparition dès la mi-décembre, mais il est rare qu'elles soient présentes en nombre tant soit peu important avant la première ou la deuxième semaine de janvier. Cependant dans les parties intérieures et plus

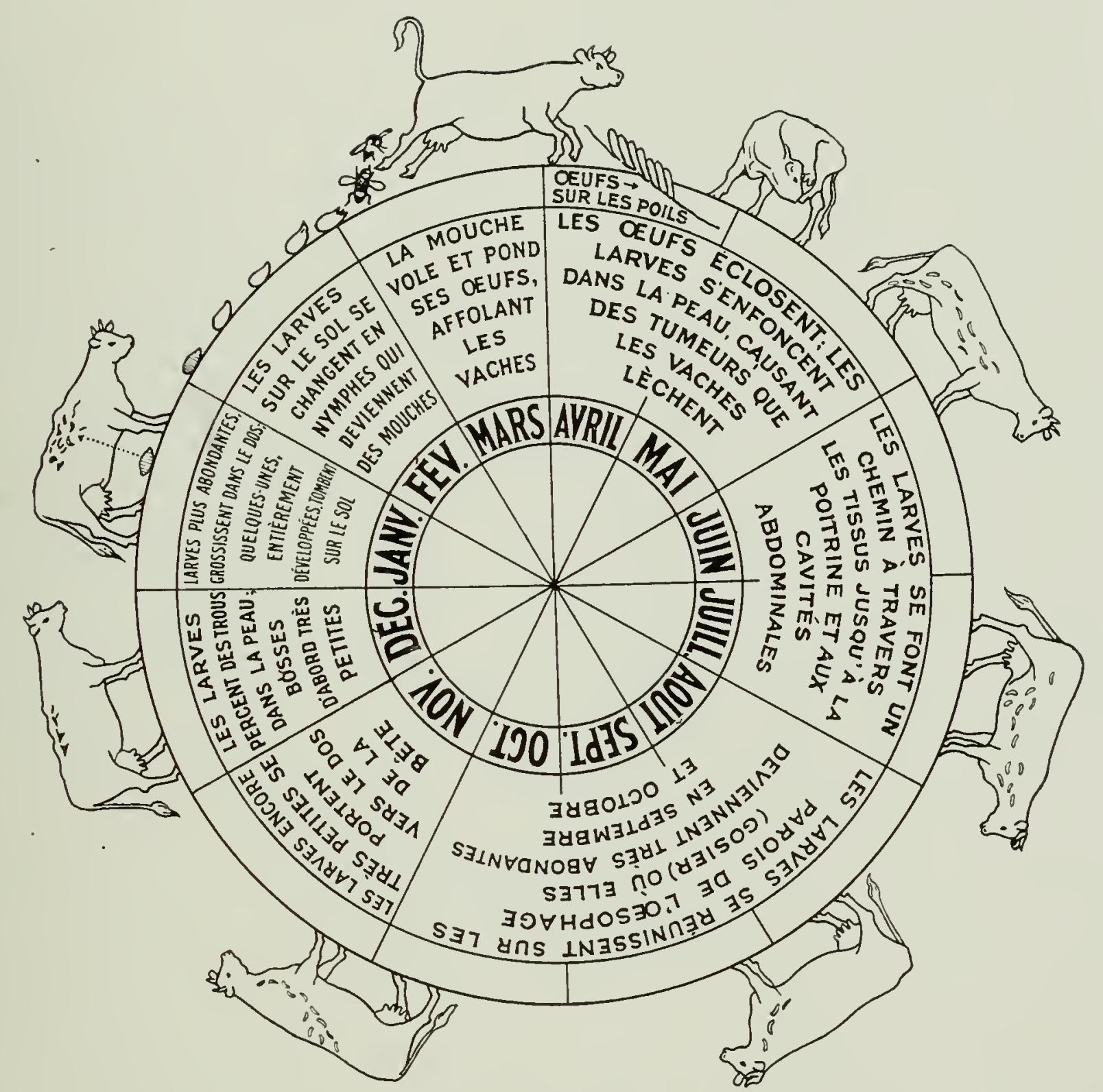

Fig. 41-Cycle évolutif de l'hypoderme rayé, Hypoderma lineatum de Villers (retracé d'après Bishopp, Laake et Wells).

froides de la province elles font rarement leur apparition avant la mi-janvier, mais parfois, en certaines saisons, on les a vues à la fin de décembre. Dans l'Ontario, c'est à la fin de décembre que les lar'ves font leur première apparition et dans les Provinces des Prairies, c'est à la fin de janvier.

La présence de larves d'hypodermes dans le dos des bêtes à cornes peut se prolonger plusieurs mois, car des générations successives de larves émigrent vers cette partie du corps. La durée de l'infestation varie suivant les districts et il en est de même pour la date de la première apparition des larves dans le dos; il y a sans doute aussi des fluctuations saisonnières causées par les conditions variables de température pendant la saison de ponte précédente. En 
Saskatchewan, la durée de l'infestation est d'environ quatre mois, mais elle peut se prolonger jusqu'à six mois ou plus par l'arrivée de quelques larves retardataires. Lorsque la larve arrive au dos, elle est dans sa troisième phase, et elle mue dans les quatre jours qui suivent pour entrer dans la quatrième phase. Elle se nourrit de la matière formée dans le kyste en forme de tumeur où elle se trouve et se développe lentement pour entrer dans la cinquième phase au bout d'un mois ou un peu avant. La période pendant laquelle les larves habitent les tumeurs du dos est en moyenne de deux mois environ; elle peut, d'après Bishopp, ne pas dépasser 35 jours et parfois se prolonger jusqu'à 89 jours. La larve, blanche d'abord, prend une couleur plus foncée vers la maturité. Les. deux organes de respiration (plaques stigmatiques) qui se trouvent directement sous l'orifice dans la peau changent aussi de couleur, d'orange pâle à noir, et ils constituent un indice utile de l'âge de la larve. C'est pendant les deux mois que la larve est sous la peau du dos que l'insecte est le plus vulnérable et que l'on peut le mieux le détruire par les moyens indiqués ci-dessous. Lorsqu'elles arrivent à maturité, les larves passent à travers les orifices de respiration dans. la peau, aidées en cela par les nombreuses épines inclinées vers l'arrière qu'elles portent sur les segments, tombent à terre et se cherchent un endroit ombragé; au bout de quelques jours elles se transforment en nymphes ou pupes dures, noires, semblables à des graines et inertes. La durée de la phase de nymphe est beaucoup plus variable que celle des phases larvaires dans l'hôte, car elle est sujette aux fluctuations de température et aux autres vicissitudes de climat. En ce qui concerne les larves qui ont atteint l'âge adulte au commencement de la saison, elle peut parfois se prolonger jusqu'à deux mois et demi; pendant les temps chauds, elle peut n'être que de trois semaines; la période moyenne de nymphose est donc d'environ six semaines.

La mouche adulte sort en repoussant le capuchon qui recouvre la coque de nymphe, elle se faufile en dehors et peut se mettre à voler au bout d'une demi-heure. Elle a emmagasiné suffisamment de nourriture pendant la phase larvaire pour le développement des oufs et l'adulte n'a besoin d'aucune nourriture pendant sa courte vie. En fait les parties buccales sont dégradées, et l'insecte adulte est incapable de se nourrir. L'accouplement a lieu très tôt. Il peut se produire une heure ou deux après la sortie de la coque. La mouche est maintenant prête à pondre ses cufs et c'est pendant ce procédé que les bestiaux, pris de panique, la queue relevée et les yeux terrifiés, se sauvent devant leurs petits tourmenteurs. On n'a pas trouvé de bonne explication pour cette panique, car les mouches n'infligent aucune douleur, mais le bourdonnement de l'insecte est suffisant par lui-même pour affoler les bestiaux. Cette espèce inspire moins de crainte que son parent plus gros et plus rude-le gros hypoderme- parce que ses habitudes sont plus calmes et qu'elle attaque d'une façon plus prudente.

\section{HYPODERME DU BEUF OU GROS HYPODERME, Hypoderma bovis de Geer}

Cette espèce, comme son nom commun l'indique, est un peu plus grosse que l'hypoderme rayé. La partie antérieure du thorax est plus velue, portant une couche plus épaisse de poils jaunes, et les quatre lignes ou marques caractéristiques sont moins visibles que dan's l'autre espèce. L'extrémité de l'abdomen est orangée au lieu d'être rouge, et les pattes sont plus lisses et moins velues.

Le gros hypoderme est aussi répandu au Canada que le petit, mais l'abondance relative des deux espèces est réglée jusqu'à un certain point par les conditions de température et une espèce peut temporairement dominer sur l'autre en certains districts lorsque les conditions sont favorables à la ponte. Nous ne connaissons pas de district agricole au Canada qui jouisse d'une immunité complète, en ce qui concerne l'un ou l'autre de ces hypodermes. 
Le gros hypoderme se développe plus tard que l'hypoderme rayé et les mouches adultes volent à partir du commencement de juin jusqu'en août; c'est surtout pendant le mois de juillet qu'elles se montrent le plus gênantes. Plus encore que pour le petit hypoderme, la ponte est limitée aux journées claires et ensoleillées. Les œufs sont généralement fixés assez haut sur les pattes. Ils sont invariablement placés séparément, un à un, sur les poils et non pas en rangées comme ceux de l'hypoderme rayé, $H$. lineatum. Comme le nombre d'œufs pondus est tout aussi grand, il en résulte des attaques intermittentes plus fréquentes. Ce fait et la conduite plus brutale de cet insecte expliquent pourquoi il terrorise plus les bestiaux que l'autre hypoderme. Les œufs éclosent au bout de quatre à sept jours, et les larves qui sortent s'enfoncent immédiatement dans la peau. Des gonflements se produisent à l'endroit de pénétration

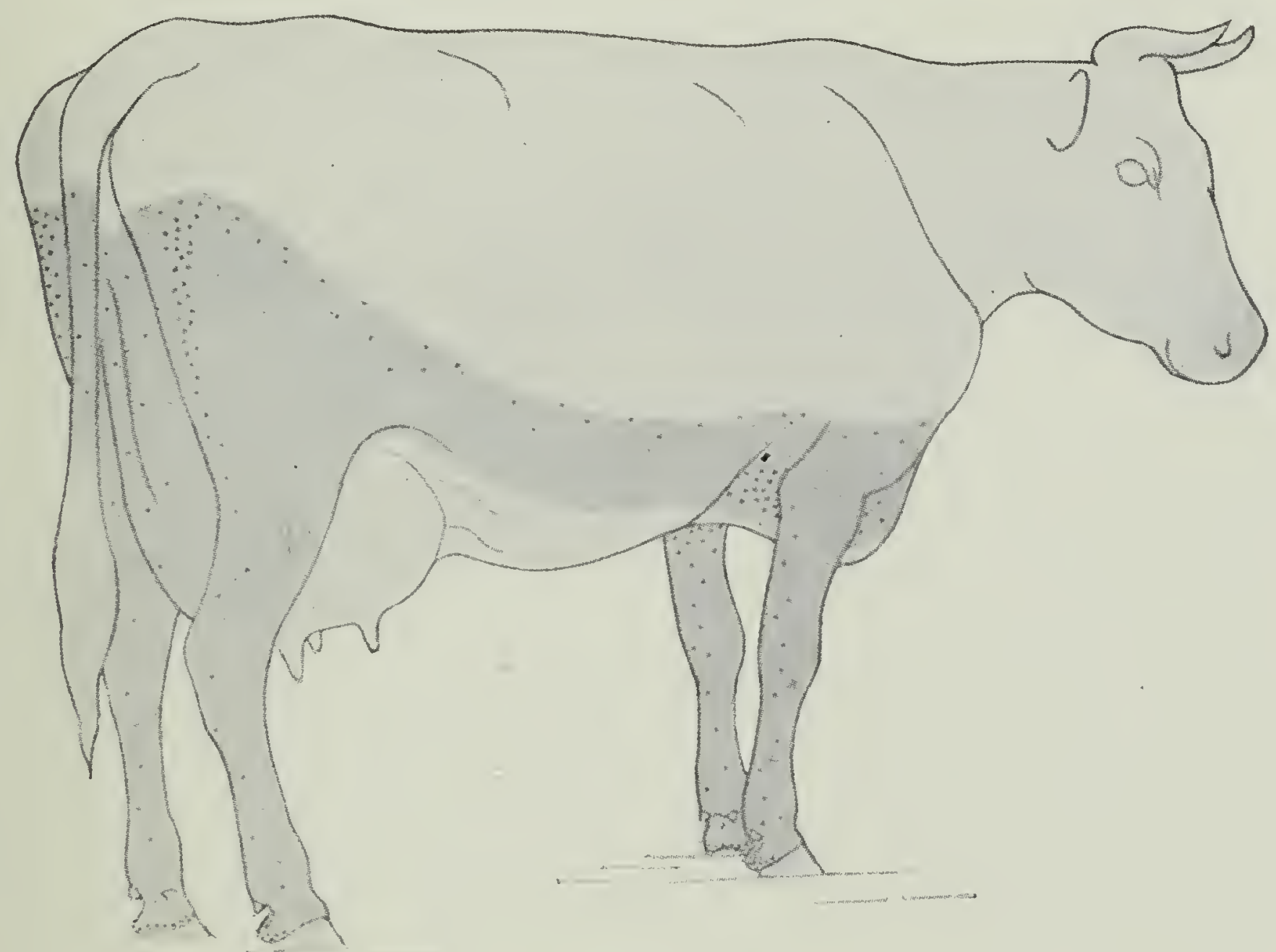

Fig. 42-On voit ici les régions où les œufs d'hypodermes sont déposés. Les marques noires montrent les endroits où l'on a trouvé le plus d'œufs et les parties ombragées toutes les régions où les oufs peuvent être déposés (d'après Hadwen).

mais ils ne sont pas aussi gros que ceux qui sont causés par le petit hypoderme et on ne les voit que sur les animaux plus âgés. On connaît mal les migrations de cette larve dans le corps, mais on sait que dans cette espèce les larves de la deuxième phase ne s'arrêtent pas dans la région de l'œesophage. La migration vers le dos commence une ou deux semaines plus tard que pour l'hypoderme rayé et les premières larves arrivent généralement à cette partie du corps en février et en mars. Elles mettent aussi plus longtemps à faire cette migration et peuvent arriver dans la région du dos en juin seulement. La durée du séjour des larves dans le dos est aussi plus longue que pour l'hypoderme rayé, elle est en moyenne de soixante-douze jours, d'après Bishopp. La position de la larve dans le dos ou les dommages causés sont les mêmes dans les deux espèces. La période de nymphe n'est pas aussi longue que dans l'espèce précédente, ce qui s'explique par la température plus chaude à laquelle la plupart des larves sont sujettes; la durée moyenne de cette phase est d'un mois. La ponte commence en juin, environ une semaine après que les adultes de l'hypoderme rayé ont cessé leur activité, et peut se prolonger jusqu'en août. 
Dommages causés par les hypodermes.-Nous avons vu que les hypodermes sont le fléau le plus grave des bovins partout où ils abondent, mais il est évident que même ceux qui sont bien au courant de l'industrie animale se rendent
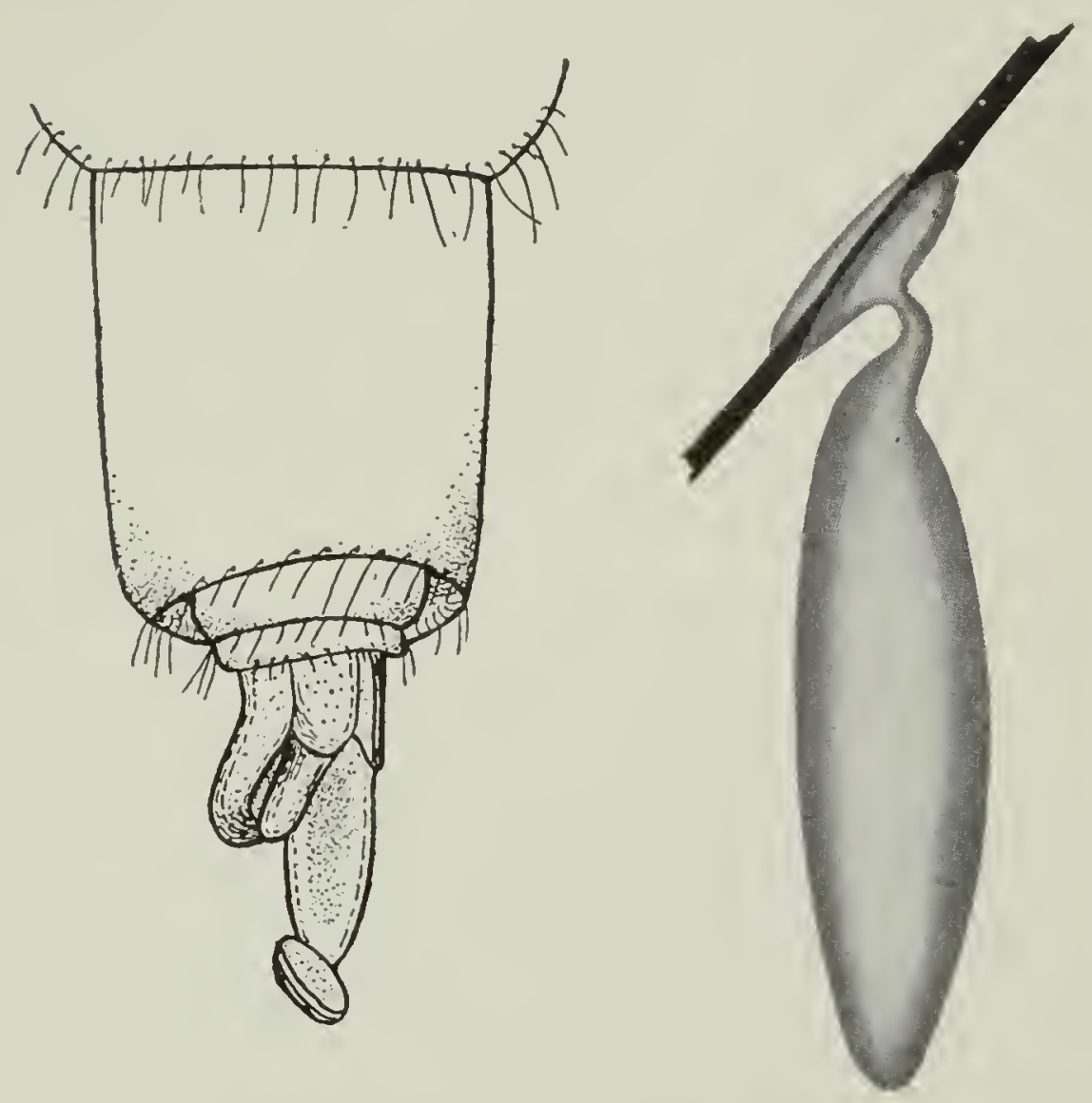

ig. 43-A gauche, tube d'œufs de Hypoderma bovis DeG., montrant la sortie de l'œuf (d'après Carpenter et Hewitt); à droite, œuf de $H$. bovis DeG., très grossi, montrant comment il est fixé au poil (d'après Hadwen).

giste provincial estime que les pertes totales dans l'Ontario se montent à $\$ 5,000,000$ par an. Nous estimons que les pertes provenant de toutes les causes attribuables aux hypodermes au Canada se chiffrent par une somme de $\$ 7,000,000$ à $\$ 14,000,000$ et qu'elles peuvent même dépasser ce dernier chiffre en certaines saisons.

Ces pertes, qui sont causées de plusieurs façons différentes, peuvent se récapituler comme suit:

(a) Dommages causés par l'inquiétude et la terreur occasionnées aux animaux par la mouche adulte quand celle-ci pond ses œufs.

(1) Diminution du rendement du lait ou de la production de viande chez les animaux au pâturage. La diminution dans le rendement du lait provenant de cette cause est placée entre 10 et 25 pour cent, suivant le district et la saison.

(2) Perte de temps causée par la difficulté que l'on éprouve à conduir'e les animaux dans les grands herbages (range). Les animaux deviennent souvent intraitables et il est extrêmement difficile et parfois même impossible de les conduire pendant le jour.

(3) Dommages physiques causés aux animaux qui sont pris de panique devant les attaques des mouches. Les animaux s'enlisent parfois dans les fondrières, se blessent gravement ou même se tuent dans leurs efforts frénétiques pour échapper aux attaques des hypodermes.

(b) Dommages occasionnés par la présence des larves.

(1) Amaigrissement et perte de vigueur chez les animaux infestés. Il existe peu de chiffres exacts pour indiquer les pertes causées par la présence d'un grand nombre de larves dans le dos, mais dans une expérience qui a été notée, les animaux tenus sans larves ont fait une augmentation moyenne de 34 livres de plus que les animaux non traités. 
(2) Diminution dans le rendement du lait. Les laitierss s'accordent généralement à dire que la production du lait diminue pendant l'époque où les vaches laitières sont infestées de larves. Cecí parâ̂t être confirmé par des preuves expérimentales et un cas a été cité où une augmentation de près de 10 livres a été notée dans le rendement d'une vache quelques jours après l'extraction de 80 larves.

(3) Perte de viande causée par le "bœuf léché". La région infectée dans le dos d'un animal très infesté exige beaucoup de nettoyage et il en résulte souvent une perte d'au moins 2 livres de viande dans les morceaux qui coûtent le plus cher.

(4) Peaux endommagées ou "varronnées". C'est là le dommage le plus net et dont on peut faire un estimé assez exact. Au Canada, le Dr W. E. Graham est d'avis que les pertes résultant des dommages causés aux peaux se montent au total à $\$ 700,000$ par an. C'est là évidemment un chiffre très modéré, car le Dr' L. Stevenson estime que les pertes de

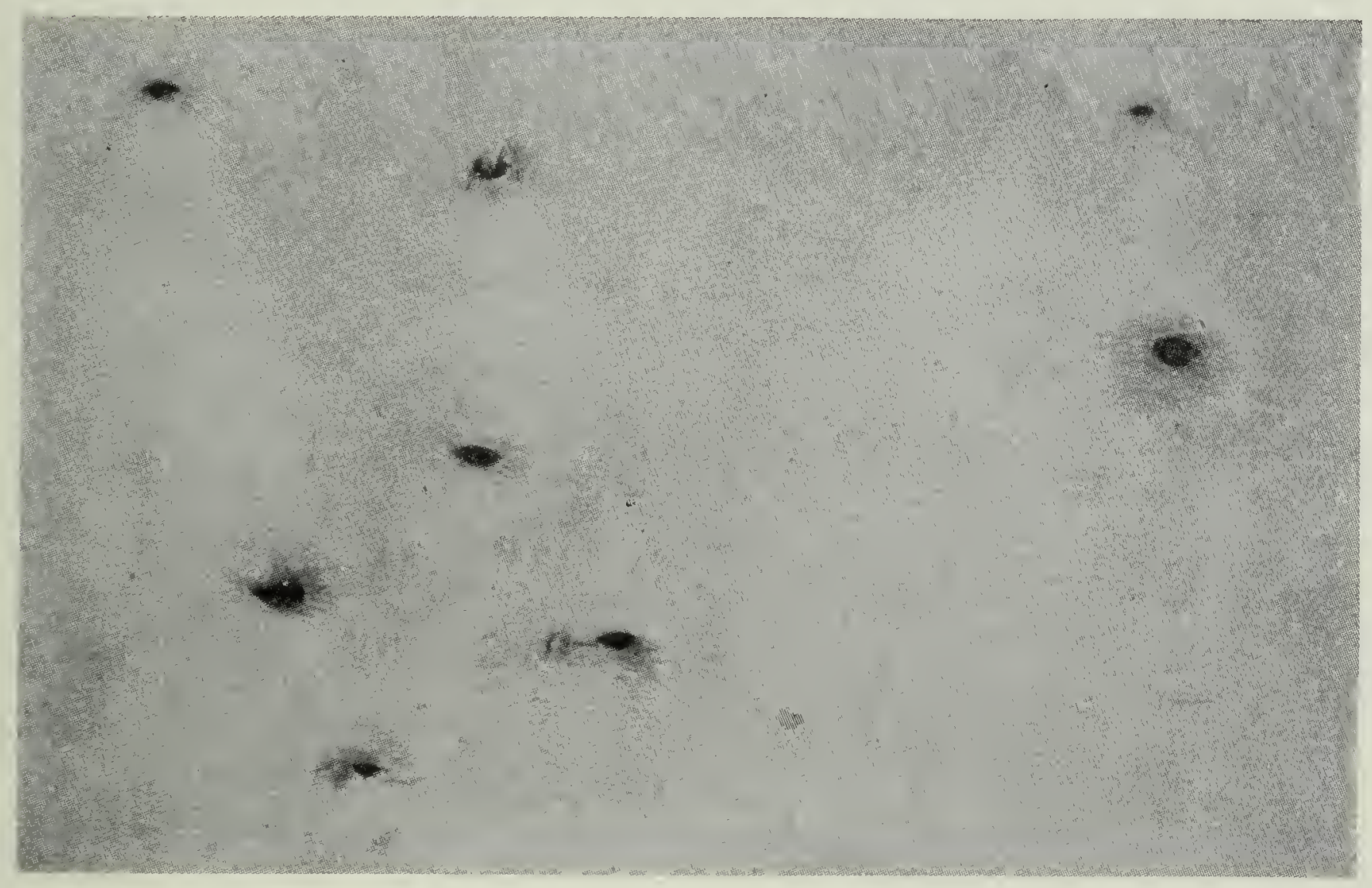

Fig. 44-Morceau de cuir montrant les dégâts causés par les larves de l'hypoderme ou "varrons".

ce chef, dans la seule province de l'Ontario, se montent à un million de dollars. En Grande-Bretagne on estime qu'elles se chiffrent par plus de $\$ 2,000,000$ et aux Etats-Unis par $\$ 5,000,000$. Les peaux sont abîmées de deux façons différentes: par les petits trous que font les larves nouvellement écloses en pénétrant dans la peau de l'animal; et par les perforations plus grosses ou orifices de respiration qu'elles pratiquent dans la peau du dos. Même lorsqu'ils sont cicatrisés ces trous affectent la valeur du cuir. Les premiers n'ont qu'une importance relativement minime, car les flancs et les parties basses affectés sont les parties les moins chères du cuir, mais les trous du dos sont beaucoup plus graves, car lorsqu'ils sont tant soit peu nombreux, la partie la plus utile de la peau n'a aucune valeur pour la plupart des fins commerciales. Quelque 30 pour cent de toutes les peaux reçues pendant l'année au Canada sont abîmées par les larves, et pendant la saison des larves, de janvier à juin, de 50 à 60 pour cent de toutes les peaux enlevées des animaux sont véreuses ou "varronnées" et le prix en est réduit de 1 à 2c. par livre, même lorsqu'il n'y a que quelques trous; ceci signifie souvent une diminution d'un dollar 
par peau. Même les peaux qui ne sont pas enlevées dans la saison des larves peuvent être dépréciées, car Stevenson a constaté que 60 pour cent de toutes les peaux présentent des marques à l'endroit où les trous se sont cicatrisés. Quelques tanneurs déclarent que 95 pour cent de toutes les peaux portent quelques traces de dommages causés par les larves, ce qui enlève de la valeur au cuir pour bien des modes d'utilisation. Beaucoup de grands commerçants de peaux au Canada font une inspection des cuirs et les classent suivant le nombre de trous de larves, mais la coutume générale parmi les petits commerçants est de déduire un certain montant en bloc de toutes les peaux reçues pendant la saison des hypodermes. En Angleterre, les marchands de peaux et de cuirs ont fait adopter une réforme dans le système de vente par laquelle les peaux sans trous d'hypodermes reçoivent une prime d'environ 34 pour cent sur le marché. C'est là un encouragement à l'élarvement et il y aurait avantage à adopter ce même système au Canada.

(5) Dommages causés par les attaques des pies et des mouches à viande. Une autre cause indirecte de dommages, qui n'a de l'importance que de temps à autre, est l'attaque des pies sur le dos des animaux infestés de larves. Il suffit parfois d'une légère plaie sur un animal pour attirer des attaques persistantes de la part de ces oiseaux et les blessures qui en résultent peuvent être assez graves pour occasionner la mort. Les pies sont très nombreuses au pied des montagnes et dans les grands herbages de l'Alberta, et les ranchers nous disent que les animaux infestés de larves sont parfois exposés à de graves attaques de la part de ces oiseaux. De même, les mouches bleues de la viande sont attirées par le pus qui exsude des trous laissés à la sortie des larves du dos de l'animal, et une infestation de larves de ces mouches peut en résulter.

(6) Choc anaphylactique. Les larves d'hypodermes contiennent une substance qui est un poison violent pour les bestiaux et lorsque ces larves sont écrasées, comme par exemple quand un animal passe par-dessous une clôture, ou lorsque l'extraction en est faite négligemment, une réaction singulière se produit dans l'animal hôte et elle peut entraîner la mort. "Les bestiaux écument de la bouche, la peau se ride, spécialement autour des yeux et de l'anus, il y a diarrhée et dyspnée" (Hadwen). L'attaque vient avec une soudaineté remarquable; si elle n'a pas de suite fatale, elle disparaît généralement assez vite. Le Dr Graham-Gillam, secrétaire de l'Association vétérinaire de la Colombie-Britannique, qui a eu beaucoup d'expérience dans le traitement du choc anaphylactique, préconise un simple traitement pour les animaux qui souffrent de cette crise. Il s'agit de donner une potion d'une pinte d'eau de chaux, lentement. L'administration de cette potion peut être répétée au bout de deux heures, mais cela est rarement nécessaire. On peut soulager la partie affectée en baignant les tumeurs sur l'animal au moyen d'une lotion composée d'une cuillerée à soupe de soda à pâte dans une pinte d'eau froide. Il est toujours bon d'appeler un vétérinaire qualifié dès que l'on constate des symptômes d'anaphylaxie, mais nous mentionnons le traitement qui précède pour l'avantage de ceux qui demeurent dans les districts où il n'y a pas de vétérinaires qualifiés.

Moyens répressifs contre l'hypoderme.-Il est possible de supprimer complètement l'hypoderme, du moins sur certaines étendues de territoire; ce n'est pas là une possibilité théorique, la démonstration en a été faite. L'Ile Clare, en Irlande, a réussi à se débarrasser complètement de ce fléau après cinq années de travaux systématiques. La démonstration n'était pas très importante, 
elle ne portait que sur 400 bestiaux et elle a été effectuée dans des conditions à peu près idéales, mais des démonstrations conduites sur une plus grande échelle au Canada, en Angleterre, en Allemagne et au Danemark, ont fait voir que l'on peut très bien réduire dans une grande mesure les dommages causés par les hypodermes. Dans ce dernier pays, une mesure législative d'application obligatoire a été promulguée en 1923. L'année précédente 29.5 pour cent de toutes les peaux étaient varronnées (infestées de varrons, ou larves), et au bout de trois ans de l'application de la loi le nombre de peaux varronnées avait été réduit à $2 \cdot 5$ pour cent et l'on prévoyait que l'application continuelle des moyens répressifs employés supprimerait complètement ces dommages. En Grande-Bretagne, un arrêté du Ministère de l'Agriculture et des Pêcheries, en date du 31 janvier 1936, prescrit que toutes les personnes d'Angleterre, du Pays de Galles et de l'Ecosse, qui ont en leur possession des bovins visiblement infestés ou qui sont chargés d'animaux de ce genre doivent prendre les mesures prescrites pour détruire les larves. L'application organisée de moyens répressifs au Canada a été développée jusqu'à un certain point en ces dernières années, spécialement dans l'Ontario, et dans certaines régions du Québec et de la Colombie-Britannique, et elle a donné de superbes résultats. Un compte rendu de ce travail a été publié par Gibson et Twinn.*

Il existe plusieurs moyens différents de réduire les dommages causés par l'hypoderme. La stabulation des animaux pendant la journée, la construction de refuges obscurs ou d'abris de broussailles déjà décrits (voir p. 9) réduisent beaucoup l'infestation par les larves en protégeant les animaux contre la ponte des mouches. S'il y a des refuges de ce genre, les vaches s'y rendront dès que les hypodermes font leur apparition. A une grande vente de taureaux dans l'Ouest, il a été constaté qu'un lot seulement de ces animaux était sans larves. Questionné à ce sujet le propriétaire a déclaré que ces animaux étaient invariablement tenus en stabulation pendant le jour et qu'ils n'étaient mis dehors pour paître et prendre leurs ébats que pendant la nuit. A l'une des fermes expérimentales de l'Ouest, certains animaux laitiers soumis au contrôle de la production pour l'jnscription au Livre d'Or, qui n'étaient jamais sortis de la vacherie, étaient les seuls membres du troupeau qui fussent complètement sans larves. La présence de flaques d'eau peu profondes permet également aux animaux de se protéger, car les mouches ne les attaquent pas tant qu'ils sont dans l'eau.

Beaucoup de propriétaires de bestiaux se fient implicitement à l'application de substances repoussantes pour protéger leurs animaux contre l'hypoderme, mais les recherches expérimentales qui ont été faites sur ce point n'ont pas réussi à démontrer la valeur pratique d'aucune des substances repoussantes reconnues sous ce rapport, et l'extrait suivant d'un feuillet publié par le Ministère anglais de l'Agriculture et des Pêcheries indique l'impression générale qui existe parmi les chercheurs scientifiques sur l'efficacité de ce traitement: "Il n'y a aucune preuve que les lavages ou les enduits généralement recommandés pour l'emploi en été sont utiles pour empêcher les hypodermes de pondre leurs œufs sur les bestiaux". On se rend mieux compte de la futilité de cette méthode quand on considère le long temps pendant lequel les hypodermes adultes déploient de l'activité. Les mouches adultes volent pendant au moins 16 semaines du printemps et de l'été, et les meilleures des substances repoussantes devraient être appliquées au moins deux fois par semaine. Ceci nécessiterait 32 applications, tandis que l'on peut détruire complètement les larves au moyen de quatre ou cinq pansements peu coûteux dont l'application n'exige guère plus de peine que celle des substances repoussantes. Dans tous les cas, les hypodermes, et spécialement les gros hypodermes, ont un vol si rapide et frappent avec une telle brusquerie que l'on ne peut guère compter sur des solutions pour les repousser. Le bourdonnement seul de l'insecte cause une grande inquiétude aux bestiaux et ce n'est pas les substances repoussantes qui peuvent

\footnotetext{
* Sci. Agric. Vol. XVII, déc. 1936.
} 
empêcher les mouches de bourdonner autour des bestiaux. Ceux qui prétendent avoir obtenu de bons résultats de l'emploi de ces solutions oublient souvent que les animaux adultes acquièrent une immunité partielle contre les larves. Généralement, ce sont les vaches laitières que l'on traite au pulvérisateur et on les compare aux jeunes animaux qui sont en liberté dehors et qui, par conséquent, portent beaucoup plus de larves, ce qui fait croire que la pulvérisation est utile. En réalité, on ne peut faire de comparaison exacte entre ces deux catégories de bestiaux. Les animaux plus jeunes n'ont pas encore acquis de résistance et ils ne sont pas non plus aussi bien protégés que les vaches qui sont logées à l'étable pendant une partie de la journée.

Comme les varrons (larves d'hypodermes) se développent à peu près exclusivement chez les bêtes à cornes, et qu'ils se trouvent dans un endroit accessible du dos, pendant quelque temps d'une période saisonnière bien définie, il est évident que c'est là le point le plus faible du cycle compliqué de la vie de cet insecte. En fait, c'est pendant ce temps même qu'il est le plus facile à

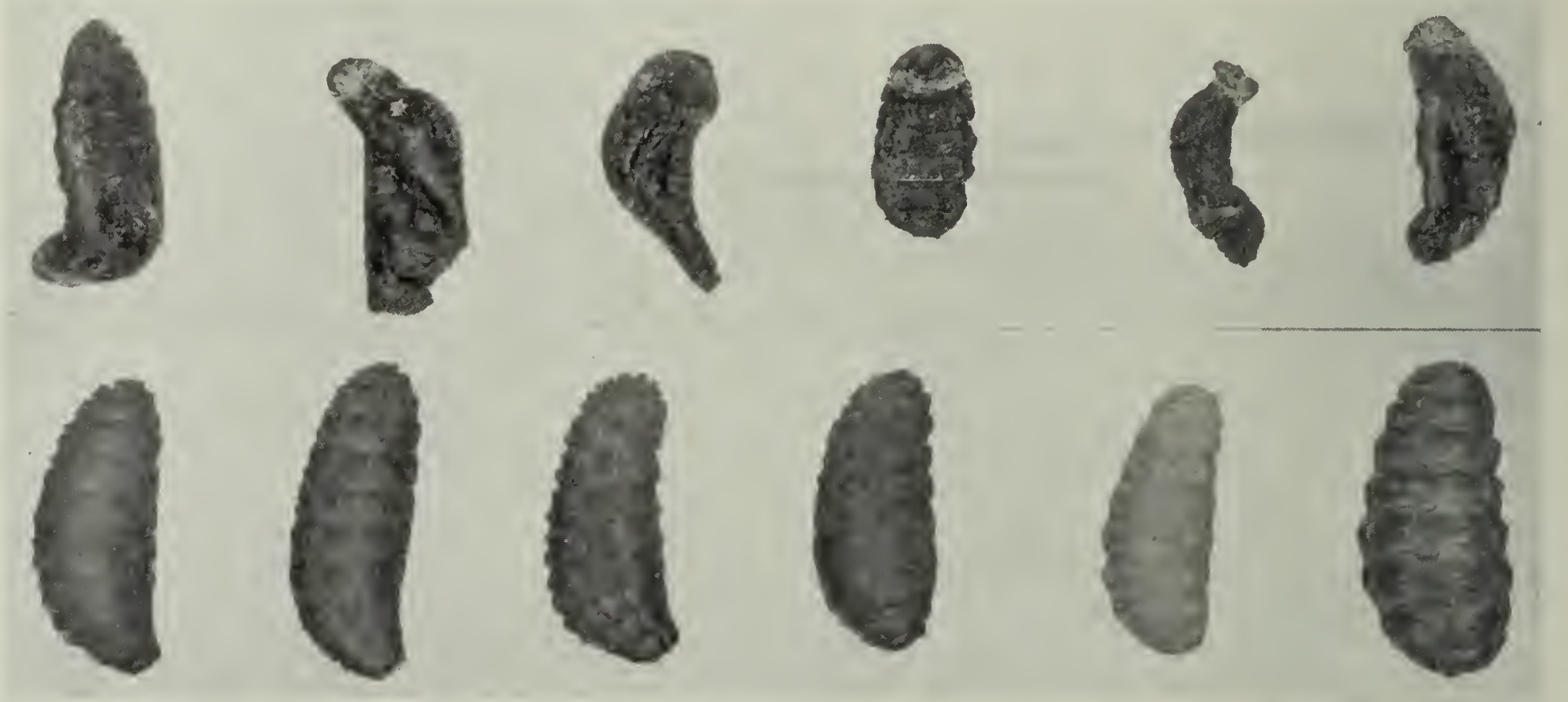

Fig. 45-Varrons ou larves de l'hypoderme: en bas, larves normales bien nourries provenant de vaches non traitées; en haut, larves mortes, noircies et ratatinées provenant de vaches traitées avec un lavage de savon de derris (illustration de l'auteur).

combattre. L"élarvement" à la main, systématiquement entrepris, a donné des résultats remarquables. Il n'est pas aussi facile à pratiquer sur certaines races de bétail que sur d'autres cependant; chez les races à peau souple comme les races de Jersey et de Guernsey, on peut aisément faire sortir les larves en comprimant la base des tumeurs avec les doigts, mais c'est là une entreprise excessivement ardue chez les animaux à peau plus raide, comme les Holsteins, et il serait certainement difficile de la faire adopter dans les conditions ordinaires de lí ferme au Canada. L'emploi d'un couteau tranchant pour élargir l'ouverture n'est pas à conseiller car il présente des inconvénients, mais il y a des pincess spéciales, très utiles pour cela. Cet "élarvement" doit se faire lor's de la première apparition des larves, qui a lieu en janvier dans la plupart des districts, et on le répétera cinq ou six fois à intervalles de trente jours au plus. Si une larve est rompue ou écrasée au cours de l'extraction, il faut immédiatement laver la tumeur avec un désinfectant dilué pour éviter un choc anaphylactique. C'est une grosse erreur que de croire que l'on ne peut enlever les larves que lorsqu'elles sont entièrement développées ou "mûres".

Pour surmonter les difficultés que présente l'élarvement à la main, on a entrepris, dans bien des parties du monde, des recherches pour trouver des matériaux qui puissent détruire les larves sur le dos de l'animal sans faire de tort à celui-ci, et ce moyen a été très l'ecommandé en ces dernières années; on a 
découvert un certain nombre de lavages, d'onguents et de poudres qui accomplissent ce résultat. Le Bureau d'entomologie des Etats-Unis a entrepris des essais détaillés de deux ou trois cents substances sous ce rapport, et les matériaux utiles ne manquent pas. Leur multiplicité, cependant, peut prêter à la confusion, et toute substance employée devrait être jugée par le critère suivant: il faut qu'elle tue complètement, c'est-à-dire qu'elle détruise au moins 80 pour cent des larves présentes; qu'elle soit inoffensive pour l'animal qui porte les larves; qu'elle soit inodore, afin de ne pas contaminer le lait chez les vaches laitières; qu'elle soit sous une forme qui en r'ende l'application économique et facile, et qu'elle soit bon marché; enfin, que l'on puisse se la procurer facilement, prête à être employée ou du moins que sa préparation n'exige pas un procédé compliqué. En outre, il est important que la substance mélangée se conserve bien.

Il y a heureusement plusieurs substances qui possèdent toutes ces qualités, et la meilleure de toutes est un insecticide appelé "derris". Le derris, sous forme de lavage, s'est montré utile dans des expériences qui ont été conduites sur une grande échelle dans plusieur's pays, et notamment au Canada.

La préparation et l'application du lavage de derris sont assez simples; les quantités à employer sont les suivantes: une livre de poudre standardisée de derris, un quart de livre de savon mou, un gallon d'eau. On fait bouillir le savon mou dans une pinte d'eau, et lorsque cette solution est un peu refroidie, on en ver'se un peu sur la poudre de derris dans une chaudière, et on fait une pâte. L'eau froide et le reste de la solution savonneuse sont alors ajoutés lentement, en remuant, en quantité suffisante pour faire un gallon, et le mélange est prêt à servir. On trouve dans le commerce des poudres standardisées de derris contre les hypodermes, prêtes à être employées. Il faut brasser fréquemment la solution de derris avant de l'appliquer, pour bien la mélanger. Cette solution se conserve bien lorsqu'elle est placée dans un contenant hermétiquement bouché, mais il vaut mieux n'en préparer qu'une quantité suffisante pour application immédiate. Lorsqu'il y a forte infestation, le lavage doit être appliqué en quantité abondante sur le dos des animaux au moyen d'un linge doux ou d'une brosse amollie, en ayant bien soin de recouvrir complètement toute la région affectée par les larves. Dans bien des cas, cependant, il est plus économique de verser un peu de la solution de derris sur chaque tumeur, et de l'y faire pénétrer en frottant avec les doigts. Les animaux qui ne sont pas attachés à l'étable pourront être immobilisés au moyen d'un appareil de décornage.

La date de la première application de la solution de derris varie dans les différentes parties du Canada; elle se fait au commencement du printemps lorsque les enflures causées par les larves sur le dos des animaux sont visibles. Dans l'intérieur de la Colombie-Britannique, ce traitement s'applique à la mi-février; dans les Provinces des Prairies et dans l'Est du Canada, vers la troisième semaine de mar's. La deuxième et la troisième applications se font à intervalles de 28 jours, et la quatrième après un nouvel intervalle d'environ 35 jours. Une cinquième application 35 jour's après la quatrième est nécessaire dans les régions plus douces comme l'intérieur de la Colombie-Britannique où la première application se fait au milieu de février. Les intervalles entre la troisième et la quatrième, et entre la quatrième et la cinquième applications sont plus longs qu'entre les applications précédentes, à cause de la longue période du développement larvaire de Hypoderma bovis.

En ce qui concerne le traitement des troupeaux de boucherie contre l'hypoderme rayé en hiver et au printemps beaucoup de ranchers n'aiment pas mettre les animaux dans une passerelle de peur de faire avorter les vaches. Notre expérience nous a appris que ces craintes sont mal fondées. La glace est un danger plus sérieux, mais on peut empêcher les animaux de glisser en répandant du sable dans les cours. Le traitement d'avril peut être combiné avec le décornage si l'on a l'habitude de décorner. 
En ce qui concerne le traitement des bœufs d'engrais contre $H$. Bovis sur les grands herbages, il y a une difficulté dans le fait que la plupart des animaux sont sur l'herbe à l'époque où le traitement doit être appliqué, c'est-à-dire en mai ou juin, et que leur rassemblement exigerait de gros frais. L'expérience indique, cependant, que lorsque les bœufs d'embouche sont bien traités et qu'ils sont transportés sur les herbages plus élevés à mesure que les herbages inférieurs se dessèchent, ils laissent derrière eux, sur les prairies plus basses, toutes les larves qui peuvent tomber, et évitent ainsi d'être infestés par les mouches qui naissent de ces larves.

La suppression de l'hypoderme offre encore certaines difficultés en ce qui concerne les animaux tenus sur les grands herbages, mais les moyens répressifs que nous venons de recommander, pour les districts où l'on pratique la culture mixte et l'industrie laitière, réduiraient beaucoup ou même supprimeraient complètement ce fléau s'ils étaient entrepris en commun, ainsi que nous l'avons déja amplement démontré.

\section{L'HYPODERME DU CARIBOU (Oedemagena tarandi L.)}

L'hypoderme qui affecte le caribou est de couleur jaune-orange et ressemble à une mouche à miel. L'adulte fait sa première apparition tar'd en juin et vole jusqu'en septembre. La période de la ponte dure environ trois mois. Cette mouche est très répandue dans toute la région habitée par son hôte; elle est aussi commune dans le nord de l'Europe que dans les régions septentrionales du continent américain. Il est évident qu'elle s'étend jusqu'aux limites sud de l'habitat de son hôte, car des peaux de caribous de montagne recueillies à moins de 100 milles au nord de Kamloops, Colombie-Britannique, exhibaient les dommages typiques causés par l'hypoderme.

Le cycle évolutif ressemble à celui de l'hypoderme du bœuf. Les œufs sont pondus sur les poils du dessous, principalement sur les parties qui touchent

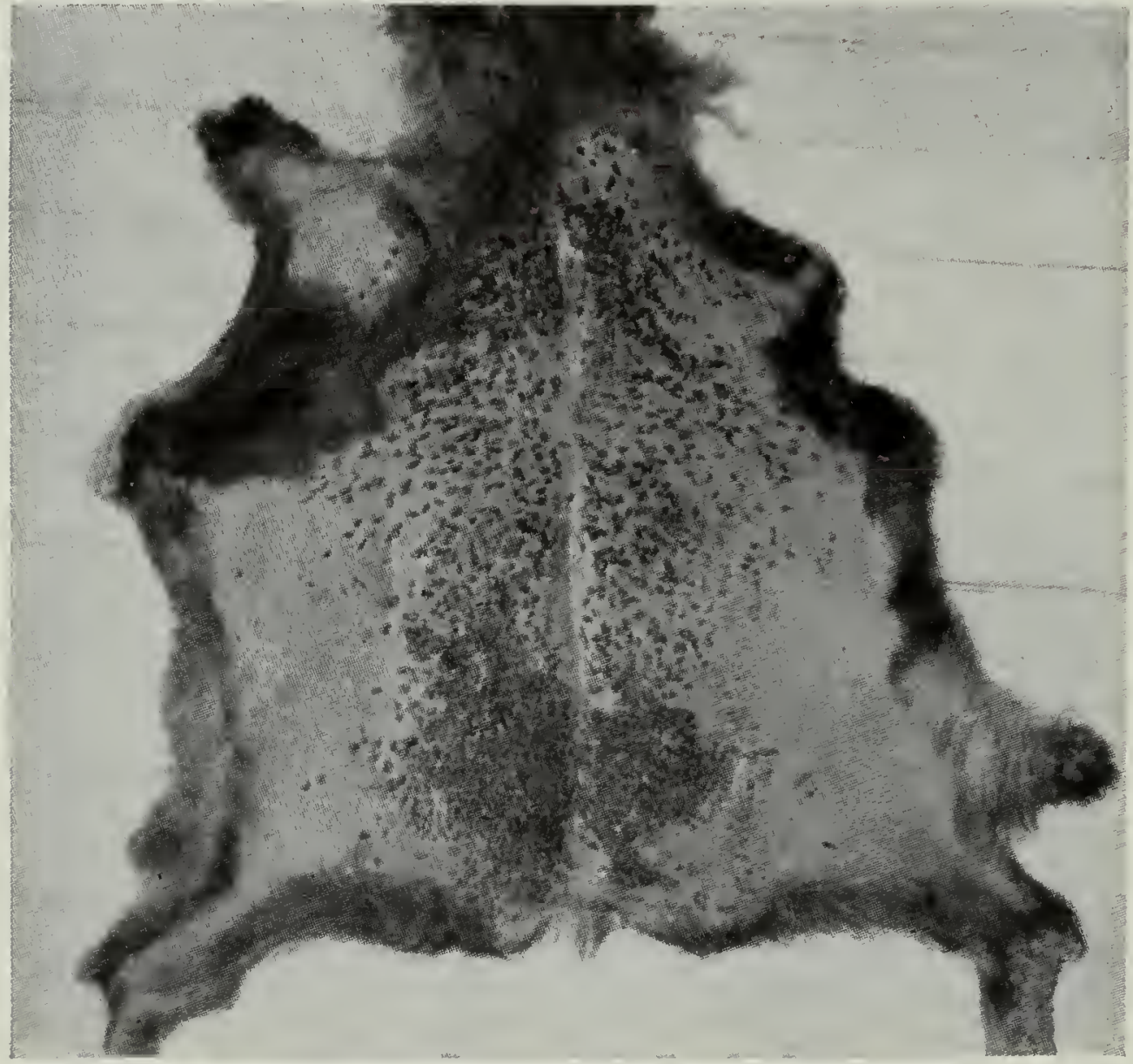

Fig. 46-Peau de caribou portant près d'un millier de larves de l'hypoderme du caribou, Oedemagena tarandi L. (d'après Hadwen et Palmer).

Les dommages causés par l'hypoderme du caibou sont très semblables à ceux de l'hypoderme du bœuf. Les animaux s'agitent et s'affolent lorsque bout, les œufs sont pondus principalement dans la région du grasset, par derrière, et sur le coude, par devant. De six à dix œufs sont placés. en une rangée sur un seul poil, et chaque femelle peut pondre 500 œufs ou plus. Les larves, qui éclosent au bout d'une semaine environ, pénètrent à travers la peau et se rendent directement dans le dos de l'animal, où elles se percent des orifices pour r'espirer. Les premières larves percent le dos en septembre, et elles continuent à se développer jusqu'en mai, puis elles tombent à terre et se nymphosent. Elles continuent à tomber pendant tout le mois de juin. La nymphose se complète en deux jours et la période de nymphe dure environ un mois. couché. Sur les animaux de- 
les mouches pondent leurs oufs. Une grosse infestation peut affecter la santé de la bête et, naturellement, le cuir est déprécié par les trous. On a trouvé jusqu'à 1,000 larves dans le dos d'un animal (voir figure 46). La pénétration des larves nouvellement écloses peut être suivie d'une infection bactérienne, qui provoque parfois la formation de gros abcès suppurants et même gangréneux. De graves dommages peuvent aussi résulter de l'infestation par les larves d'une mouche à viande (Protophormia terrae novae Desv.) à l'époque où les larves de l'hypoderme entièrement développées sont prêtes à sortir de leur hôte. Les trous sont grands à cette époque et le pus attire les mouches pour la ponte des oufs. Il arrive souvent que des animaux meurent des suites de cette infestation.

Comme les régions arctiques et boréales présentent des conditions qui favorisent l'élevage en grand du renne domestique, et comme le gouvernement fédéral a pris des mesures actives pour aider cette industrie, notamment par l'achat, en 1929, de 3,000 caribous en Alaska, la suppression de ce fléau et des autres fléaux qui affectent le caribou, prend une importance et un intérêt considérables. Un moyen pratique, conseillé par Hadwen, serait de changer tous les caribous de place au commencement de juillet, en les conduisant à quinze milles au moins de l'endroit où ils se trouvaient; la majorité des larves sont tombées à ce moment et peu d'hypodermes adultes ont encore pris leur vol. La construction de refuges obscurs est utile également. Il est relativement facile d'élarver c'est-à-dire de faire sortir les larves par la compression, car les trous sont gros, les larves relativement dures, et la peau du caribou est mince, souple et flexible. L'élarvement est spécialement nécessaire si l'on redoute que les tumeurs soient infestées par les vers des mouches de la viande et il devrait être entrepris en avril et mai, car les trous ont ainsi le temps de se cicatriser avant que les mouches de la viande fassent leur apparition.

\section{Estres qui attaquent les rongeurs}

Les larves de très grosses mouches appartenant à la famille de l'hypoderme se rencontrent souvent en grand nombre chez les animaux rongeurs sauvages et affectent aussi parfois les chiens et les chats. On ne sait pas jusqu'à quel point elles peuvent s'opposer à la multiplication des rongeurs, mais il est certain qu'elles doivent avoir une certaine utilité sous ce rapport, car on a trouvé jusqu'à dix-sept grosses larves dans un seul rat. On sait qu'il en existe au moins sept espèces au Canada, dont deux des plus communes sont les Cuterebra tenebrosa Coq., et Bogeria grisea Coq. La première de ces deux espèces est une très grosse mouche luisante, de couleur bleu foncé, et la deuxième une mouche plus petite, grise et noire. Elles s'attaquent à un grand nombre d'hôtes, depuis la souris jusqu'au chien. On s'est plaint sur l'Ile Vancouver que les mêmes larves affectent les volailles, et le Dr E. A. Bruce dit les avoir trouvées sur les gélinottes. De jeunes visons ont beaucoup souffert de ces larves sur deux fermes d'animaux à fourrure du centre de la Colombie-Britannique, et les propriétaires déclarent que les animaux seraient morts s'ils n'avaient pas été élarvés. Malheureusement il n'a pas été recueilli de spécimens ni fait d'identification précise dans aucun de ces cas. Les éleveurs qui voient ces larves se demandent souvent si elles ne sont pas les mêmes que celles des hypodermes du bœuf.

Les adultes sont très gros; certaines espèces mesurent près d'un pouce; ce sont les membres les plus volumineux de cet ordre d'insectes au Canada. Les uns sont de couleur très foncée, à corps bleu-noir luisant, d'autres portent des bandes jaunâtres sur la tête, le thorax et l'extrémité de l'abdomen. Les larves entièrement développées sont noires et portent de nombreuses petites épines sur les anneaux. Elles peuvent atteindre un pouce de longueur et ressemblent de façon marquée aux larves de l'hypoderme rayé. 
Les adultes se rencontrent vers la fin du printemps et pendant les mois de l'été, mais il est rare qu'on les voie alors parce qu'ils se cachent et préfèrent les endroits obscurs comme les dépendances et les terriers des rongeurs. Leurs métamorphoses sont peu connues, pas plus d'ailleurs que les moyens par lesquels les larves pénètrent dans leur hôte, mais on sait qu'elles vivent sous la peau dans différents endroits et que, comme les varrons des bovins, elles se percent un orifice pour respirer. On sait qu'elles ont émasculé des écureuils. Lorsqu'elles sont entièrement développées, ou que leur hôte meurt, les larves sortent, s'enfouissent et se nymphosent en deux ou trois jours. Dans la majorité des cas que nous avons observés, elles atteignent tout leur développement vers la fin de l'été et en automne. La nymphose est longue, et on signale un cas où elle a duré dix mois.

On sait que les oufs de $C$. tenebrosa restent en vie pendant au moins deux mois ou plus, et qu'ils éclosent de façon intermittente. Les larves nouvellement écloses peuvent vivre une semaine sans hôte. Ces observations portent à croire que les oufs sont pondus dans des endroits fréquentés par les rongeurs. Dans tous les cas qui sont venus à l'observation des préposés au laboratoire de Kamloops, C.-B., il a été constaté que les larves n'ont pas de kyste ou de tumeur bien définis, mais qu'elles sont enfouies dans les muscles de l'hôte. Il est donc préférable, à cause de cela, d'enlever les larves au moyen de pinces ou d'autres outils plutôt que de les tuer dans la chair, comme on le fait pour les varrons des bovins, qui sont fortement.enkystés.

L'CESTRE DU MOUTON, Oestrus oris I.

Cet œstre est une mouche grisâtre, de grosseur moyenne, mesurant environ un demi-pouce. Le thorax est jaune, mais il est recouvert de petits nodules foncés et de quatre bandes indistinctes. L'abdomen est velouté, à reflets blancs et noirs, et porte un certain nombre de taches noires, irrégulièrement

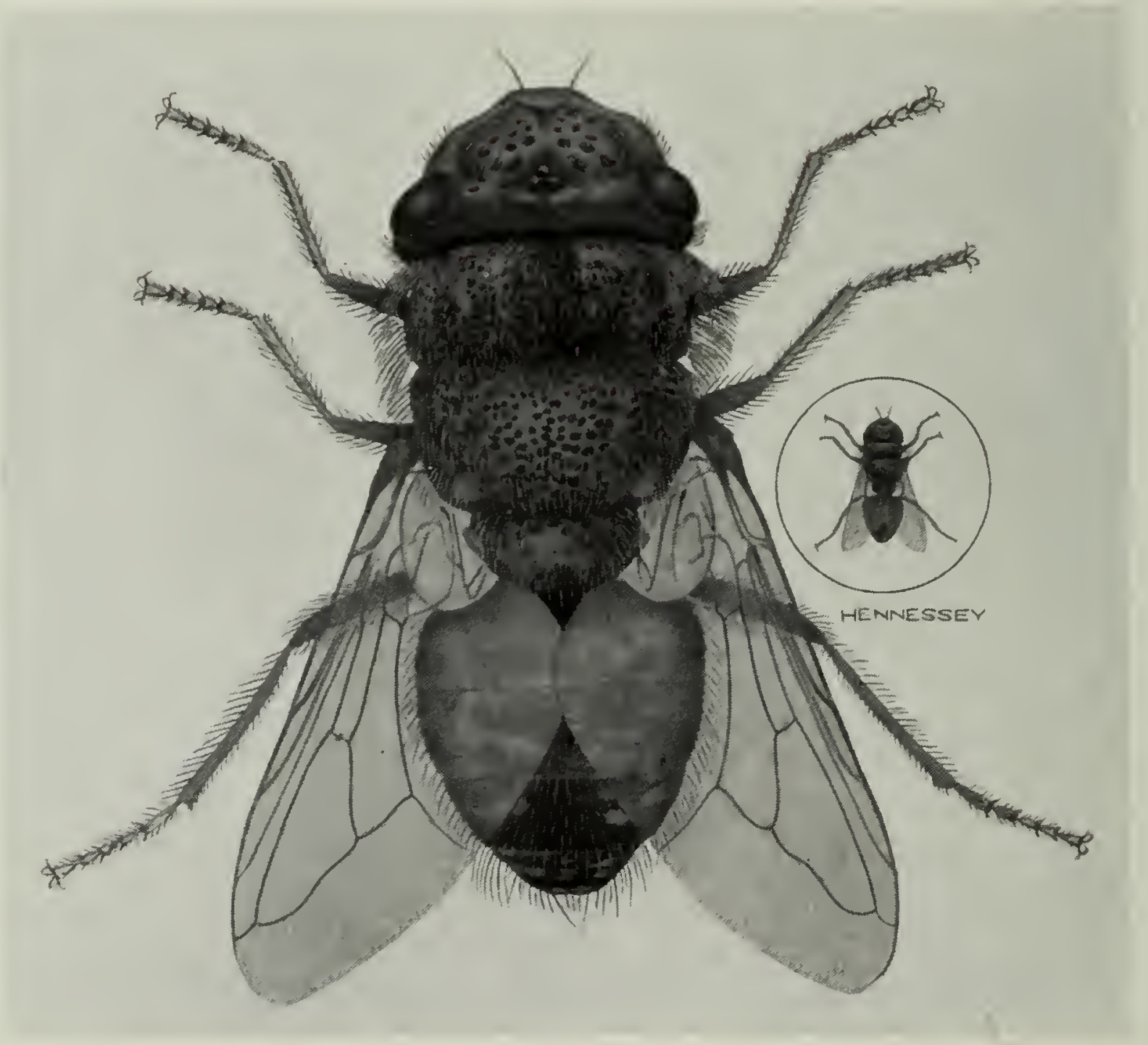

Fig. 47-L'œestre du mouton, Oestrus ovis L., grossi et grosseur naturelle (Original). 
réparties. L'insecte a une apparence légèrement velue. Lorsqu'il attaque les moutons pour déposer ses larves, il est très actif et a un vol rapide, mais à tout autre moment son allure est lente.

Cet insecte est très répandu; il a été signalé dans presque tous les districts où l'on élève des moutons, dans le monde entier. On le rencontre dans toutes les parties du Canada, et, partout où il abonde, il constitue l'un des grands fléaux du mouton.

La mouche fait son apparition ver's la fin de mai, et sa période d'activité peut se prolonger jusqu'en août ou même plus tard, mais c'est en juin et juillet qu'elle est le plus gênante. Elle attaque les moutons surtout pendant la chaleur de la journée, et reste au repos le matin et le soir. Les oufs éclosent dans le corps de la mouche femelle adulte, et les petites larves blanches, qui mesurent seulement un vingtième de

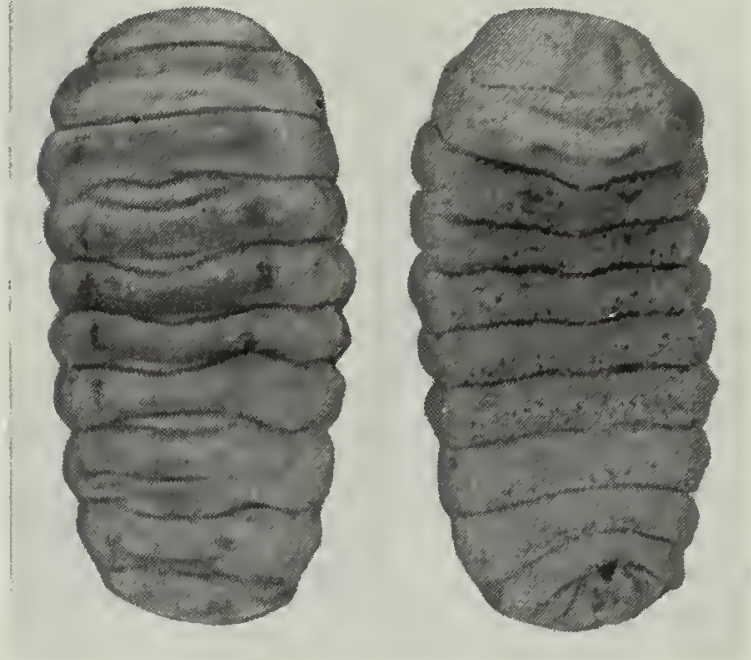

Fig. 48-Larve adulte de l'oestre du mouton, vues dorsale et ventrale (Original). pouce, sont déposées sur les naseaux des moutons. On a vu une mouche déposer en une heure jusqu'à soixante larves dans les naseaux d'un mouton. Les chèvres sont aussi attaquées plus ou moins, et l'on a signalé des attaques sur l'homme: la larve était déposée dans l'œil. Les larves, que l'on désigne souvent par le nom de larves des narines du mouton, sont pourvues, à l'extrémité antérieure, d'une paire de crochets noirs, en forme de griffes et elles portent sur chaque anneau de nombreuses épines dirigées vers l'arrière. Elles s'aident de ces épines pour grimper dans les cavités nasales, où elles causent une grave inflammation. Elles parviennent finalement dans les sinus nasaux, au-dessus des yeux, où elles complètent leur développement en dix mois environ à partir de la ponte. Elles se nourrissent du mucus des cavités nasales, et l'on dit même qu'elles attaquent parfois les tissus. Leur couleur change de blanche à jaunâtre, pour devenir finalement très foncée. Lorsqu'elles ont toute leur taille, les larves, qui mesurent alor's quatre cinquièmes de pouce, reviennent aux cavités nasales, d'où elles sont rejetées à terre par l'éternûment. Elles sont très actives et cherchent à se protéger dans la terre ou sous des débris. Au bout de deux ou trois jour's, elles se contractent et se durcissent en un objet noir ressemblant à une graine. La période de nymphe varie de trois semaines à deux mois, mais la moyenne est d'environ six semaines. Les mouches s'accouplent peu de temps après leur sortie et se mettent rapidement à déposer des larves. Les parties buccales sont dégradées ou imparfaites et les adultes ne prennent aucune nourriture pendant leur vie, qui est courte. Les mouches ont parfois un vol excessivement rapide, mais leurs mouvements sont restreints et elles ne s'écartent pas beaucoup du lieu de leur naissance.

Les moutons souffrent autant de l'inquiétude que leur causent les mouches adultes que de l'effet des larves parasitaires sur leur santé. Le bourdonnement bruyant des cestres qui s'approchent d'eux pour déposer leur's larves les terrorise. Ils se serrent les uns contre les autres, la tête contre terre, à l'intérieur du groupe; ou bien, pris de panique, ils courent çà et là, la tête en bas, et appliquent subitement leur museau contre la terre. Lor'squ'une mouche touche le museau, les moutons secouent violemment la tête et montrent leur inquiétude en frappant le sol de leurs pattes de devant. La démangeaison provoquée par les larves sur les membranes délicates des naseaux les porte à se frotter cette partie avec leurs pieds de devant, ou sur les autres sujets du troupeau ou sur le sol. Cet état d'inquiétude est surtout manifeste pendant la grande chaleur du jour, alors que les mouches sont actives.

Le nombre de larves trouvées sur un animal varie beaucoup, mais de cinq à dix larves arrivent généralement à maturité dans les cavités nasales. On en 
a trouvé plus de soixante dans les sinus frontaux et les cavités nasales. Avec les gros crochets de leur bouche et les épines dont leurs corps sont garnis, les larves causent une grande irritation en remontant dans ces passages. Il y a d'abord un jetage clair, puis, après l'infection bactérienne, le fluide s'épaissit, devient jaunâtre, et bientôt un état catarrhal que les éleveurs appellent "nez coulant" se développe. Les moutons ont de la peine à respirer et l'épaississement de la membrane nasale vient encore compliquer la situation. Lorsque les sinus sont envahis, ils sont le siège d'une irritation et d'une inflammation graves dont les symptômes caractéristiques sont une toux fréquente et une respiration pénible. Les yeux s'enflamment; l'animal marche les pattes hautes et vacille, la tête en l'air. Il ne faudrait pas confondre les symptômes de ce vertige qui est le vertige d'œstres ou "faux tournis" avec ceux du vrai tournis causé par la larve d'un ténia du chien (Multiceps multiceps Leske) dans le cer-

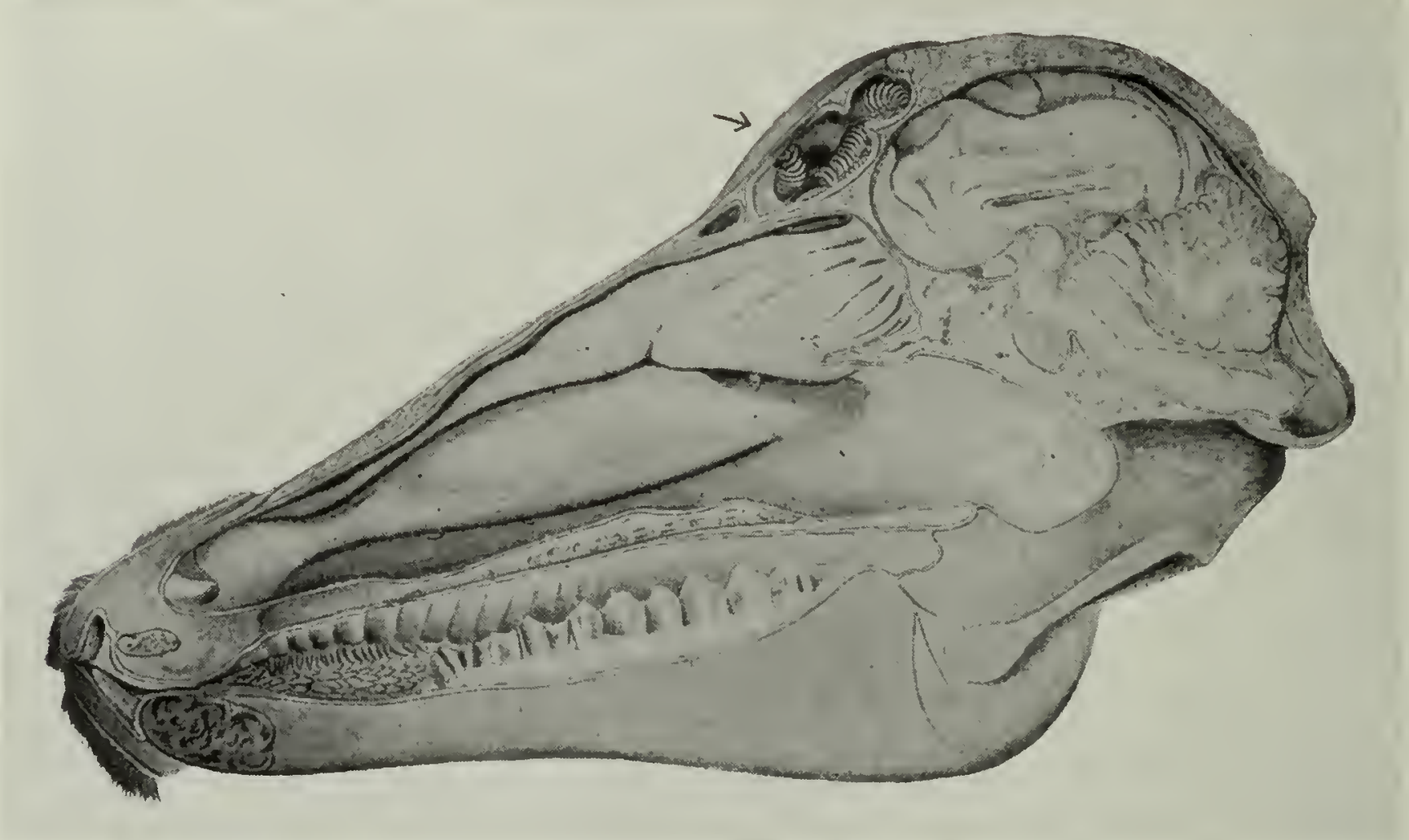

Fig. 49-Coupe de la tête d'un mouton révélant la présence de larves de l'œestre du mouton (adapté d'après Curtice).

veau. La larve de l'œstre ne provoque pas ce tournoiement caractéristique d'un animal qui souffre du "tournis". Il existe une idée généralement répandue que les larves des œestres du mouton pénètrent à travers les os dans la cervelle, mais cette idée est erronée.

Moyens répressifs et remèdes.-Les remèdes n'ont guère d'utilité contre cette mouche après que les cavités nasales sont infestées de larves et il est nécessaire d'avoir recours aux moyens préventifs. "Une rotation rapide des pâturages est toujours un bon système pour les moutons et surtout sur les grands herbages; il est souvent possible de les conduire à de longues distances de l'endroit où les larves les ont quittés. Comme les larves mettent plusieurs semaines à se transformer en mouche, le troupeau peut être trop éloigné alors pour qu'elles le retrouvent" (Hadwen), car la rapidité de la vie et les habitudes généralement lentes des œestres les empêchent de se porter au loin. Dans les régions montagneuses de la Colombie-Britannique et de l'Alberta, la transhumance des moutons, c'est-à-dire leur migration aux pâturages alpestres vers la fin de mai ou au commencement de juin, aide beaucoup à réduire les souffrances causées par cet insecte, car les moutons ne reviennent aux pâturages d'hiver qu'en automne, lor'sque la période d'activité de la mouche adulte a pris fin. On a constaté que les moutons ayant accès à des bosquets d'arbres épais sont moins affectés que ceux qui vivent dans les champs dénudés où il n'existe pas de protection de ce genre; c'est donc une excellente protection pour un 
petit troupeau de la ferme que de lui fournir des refuges obscurs, dont l'ouverture de la porte est recouverte d'un rideau pour exclure la lumière. Les moutons se réfugient sous ces abris aux premières attaques des cestres et ils en évitent une bonne partie grâce à cette protection.

Un vieux remède, qui se recommande par beaucoup d'avantages, consiste à enduire le nez du mouton de goudron de pin pour empêcher les larves de s'y déposer. La première application doit être faite parfaitement à la main, dès la première apparition des mouches adultes, généralement à la fin de mai; dans les petits troupeaux, les applications hebdomadaires sont généralement très pratiques. Chez les grands troupeaux, on peut obtenir que les moutons se goudronnent eux-mêmes; on leur fournit pour cela des auges spéciales, consistant en billots de cèdre percés d'une série de trous que l'on remplit de sel et l'on enduit le bord des trous de goudron de pin assez souvent pour que la surface reste collante.

Il est utile de retourner à la charrue quelques bandes de terre dans un champ pour que les moutons puissent se protéger en se mettant le nez dans la terre molle.

L'application de remèdes après que l'animal est infesté n'a que relativement peu de valeur, surtout après que les larves ont atteint les sinus. Une plume trempée dans de la benzine ou de la térébenthine, poussée aussi haut que possible dans les naseaux et à laquelle on donne une torsion rapide avant de la retirer peut atteindre quelques-unes des larves qui se trouvent dans cet endroit; les sécrétions muqueuses et la toux causée par les substances introduites peuvent déloger les larves et donner un peu de soulagement, mais toutes ces mesures ne sont au mieux qu'un pauvre succédané pour les moyens préventifs.

La larve des narines chez les chèvres.-La larve des narines des moutons affecte les chèvres jusqu'à un certain point et, dans certaines parties de l'Asie, ces animaux sont les hôtes principaux d'une autre espèce étroitement apparentée, mais distincte. Nous n'avons pas de renseignements sur la fréquence de ces larves parmi les chèvres au Canada, mais comme la population caprine est assez dense dans certains districts de l'Ile de Vancouver, les propriétaires de ces animaux feront bien d'examiner leurs troupeaux de près pour découvrir les symptômes des attaques de ces mouches et de prendre les moyens préventifs indiqués ci-dessus dès que ces symptômes apparaissent.

\section{L'CESTRE DU CARIBOU, Cephenomyia trompe L.}

Cet insecte, de couleur foncée, semblable à une abeille, est l'un des grands fléaux de cès animaux domestiques utiles des terres stériles du Nord. Elle est très répandue dans toute la région habitée par le caribou, en Europe et en Amérique. La mouche adulte est au vol de juin à septembre. Chaque femelle peut produire environ 500 larves. Les larves sont déposées dans les narines, elles remontent dans les passages du nez et s'attachent devant l'entrée de la gorge. Le développement est lent jusqu'en mars, puis il s'accélère beaucoup; les larves atteignent leur plein développement en mai. Elles tombent à terre et se nymphosent en six heures environ. La période de nymphe dure de deux semaines à un mois.

Ces mouches sont nuisibles par la crainte qu'elles engendrent parmi les animaux lorsqu'elles déposent leurs larves, par l'irritation provoquée dans les cavités nasales par les mouvements des jeunes larves (quoique l'on prétende que cette irritation soit beaucoup moins marquée que dans le cas de la larve des narines du mouton); enfin par les souffrances et l'incommodité que ressent l'hôte lorsque les larves sont adultes ou qu'elles atteignent toute leur grosseur. Les animaux lèvent la tête et toussent continuellement pour essayer de déloger les larves. La mort par suffocation résulte parfois d'une forte infestation, et l'on a rencontré jusqu'à 130 larves dans les cavités nasales et la gorge d'un seul animal. 
L'installation de refuges obscurs paraît être un bon moyen préventif, mais, comme dit Hadwen, dans les latitudes arctiques les insectes sont au travail pendant la plus grande partie des vingt-quatre heures et lorsqu'il fait chaud, les animaux pourraient n'avoir que peu d'occasion de se nourrir. On aide à léduire les attaques en changeant souvent les troupeaux de place.

\section{Larves du nez et de la gorge du chevreuil et du wapiti}

Plusieurs espèces de mouches foncées, semblables à des abeilles, attaquent le chevreuil et le wapiti à peu près de la même façon que la larve du caribou attaque cet animal. Les passages nasaux et les cavités de la gorge deviennent parfois infestés d'un grand nombre de larves; on en a trouvé jusqu'à 64 chez un seul animal. Les métamorphoses paraissent être très semblables à celles des ostres du mouton et du caribou. Il n'a pas encore été fait d'identification des espèces trouvées au Canada, mais le Cephenomyia pratti Hunter est tout probablement l'espèce la plus commune. Ces mouches ont une très grande distribution et elles constituent parfois un fléau sérieux pour le gros gibier qu'elles affectent, mais comme les larves sont grosses et qu'elles se voient surtout au printemps, et moins pendant la saison de chasse en automne, il n'existe que peu de renseignements sur la quantité de dégâts qu'elles causent. Au printemps de 1930, il a été reçu de points très éloignés l'un de l'autre en Colom-

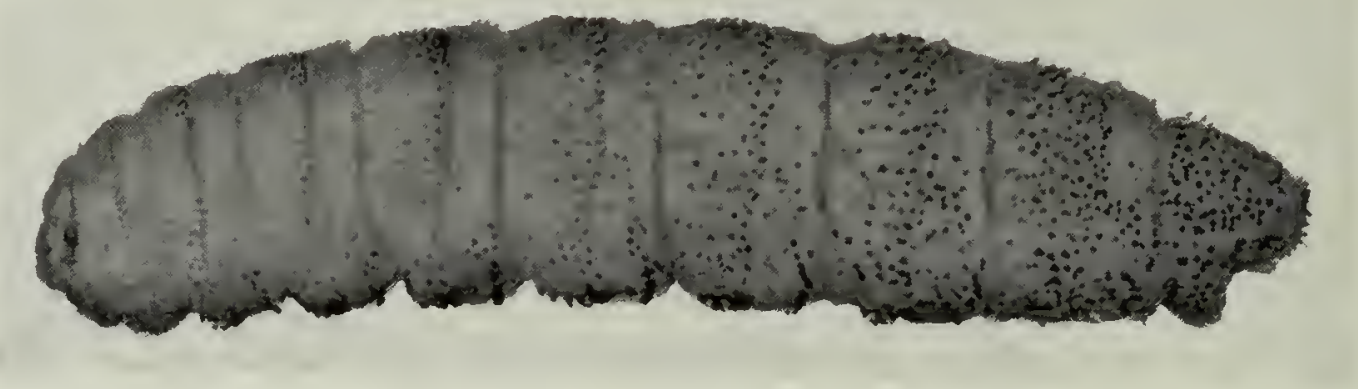

Fig. 50--Larve de la gorge du chevreuil, esp. Cephenomyia, très grossie (Original).

bie-Britannique des rapports que des chevreuils et des wapitis avaient été trouvés dans un état affaibli et mourant à la suite de l'attaque de ces parasites. M. Bryan Williams, Commissaire de la chasse en Colombie-Britannique à cette époque, a déclaré que les gardes-chasse et d'autres personnes avaient signalé une certaine mortalité causée chez les chevreuils par la larve de la gorge, dans l'intérieur et sur le littoral de la province. Ce fléau a été blâmé également pour la destruction de la majorité de quelque 150 chevreuils semi-apprivoisés sur l'une des petites îles au large de la côte de la Colombie-Britannique. La mort d'un grand nombre de chevreuils par suite de cette cause a été signalée au Colorado et ailleur's aux Etats-Unis.

Il est possible, comme le disait le Dr S. Hadwen, que d'autres conditions, par exemple, le manque de nourriture, aient été la première cause de la mort dans les cas signalés, et que la présence des larves ne soit que secondaire, mais les gardes-chasse et les autres per'sonnes qui ont fait ces rapports paraissent être convaincus que les larves de la gorge étaient entièrement responsables. Le Dr' E. A. Bruce dit que ces parasites "tuent peut-être plus d'animaux qu'on ne le suppose généralement". Il serait peut-être intéressant de faire une enquête sérieuse pour connaître le rôle exact de ce fléau dans la destruction des chevreuils.

\section{Mouches bleues de la viande}

Un certain nombre de mouches communes, qui normalement se propagent. dans les charognes, "frappent" parfois les animaux vivants lorsqu'elles se trou- 
vent dans des conditions favorables, et il en résulte une invasion de larves appelée "myiase", qui peut causer des dégâts assez graves pour entraîner la mort.

Beaucoup des mouches à viande bleues ou vertes que l'on rencontre partout au Canada ont été incriminées dans d'autres parties du monde, mais il n'y a en général que très peu d'espèces qui causent des désordres de ce genre au Canada. Quoi qu'il en soit, la majorité de nos espèces communes, qui sont au nombre d'une douzaine ou plus, doivent être considérées comme suspectes,

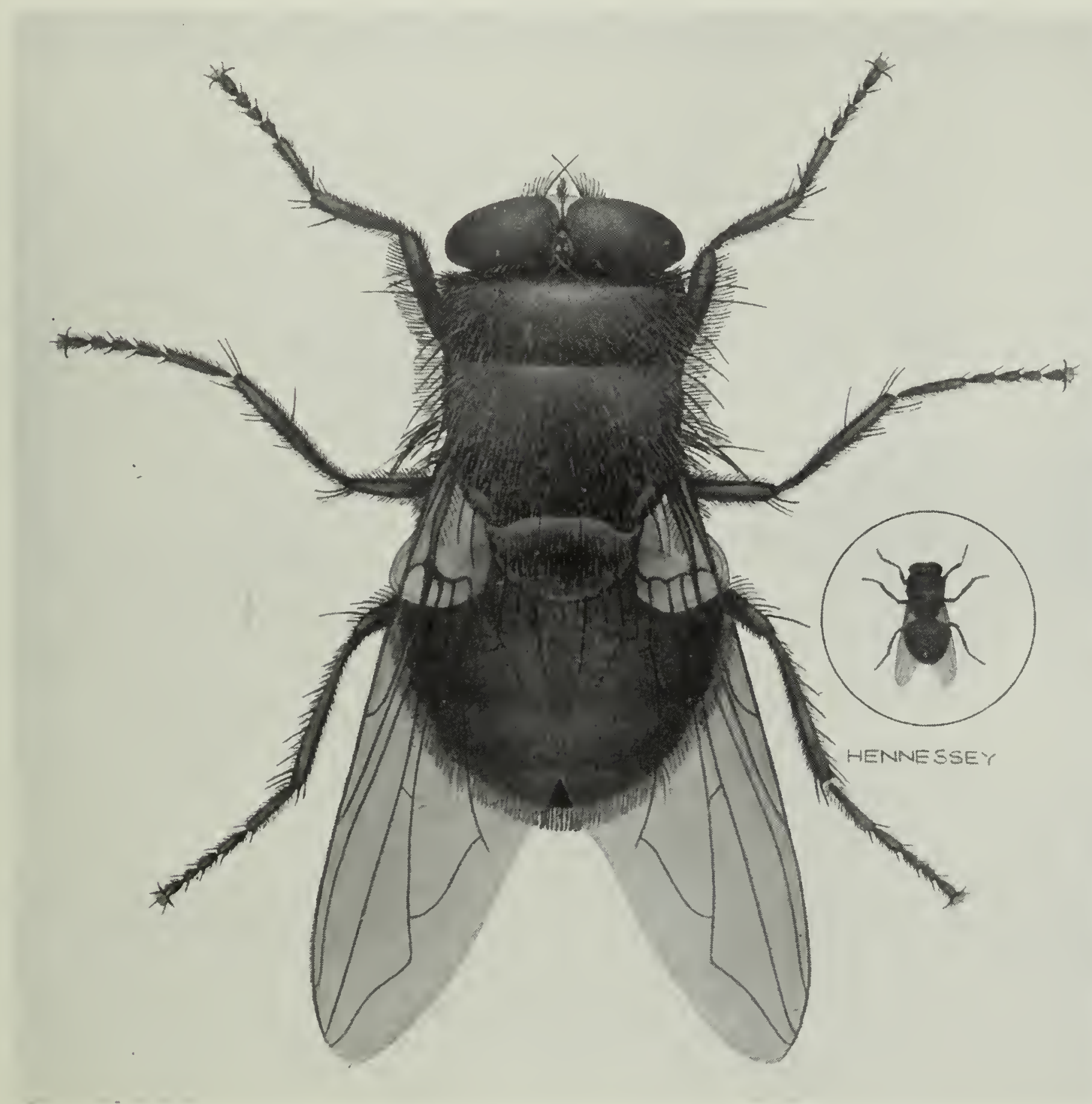

Fig. 51-La mouche noire de la viande, Phormia regina Mgn., grossie et grosseur naturelle (Original).

car ces mouches, qui se nourrissent de déchets, peuvent changer leur's habitudes et devenir des parasites; on a vu des mouches bleues jusque là inoffensives devenir l'insecte le plus nuisible de tous ceux qui affectent l'industrie ovine en Australie.

L'identification des larves et des mouches provenant d'un certain nombre de cas de myiase chez les bovins et les moutons de l'Ouest du Canada indique que la mouche noire de la viande, Phormia regina Meig., une espèce d'un bleu métallique sombre, est presque toujours la coupable dans beaucoup de districts. Dans l'Est, une espèce plus grosse, plus noire et plus velue, Calliphora vomitaria L., est nuisible, et dans les régions sub-arctiques une petite espèce bleu foncé, Protophormia terrae novae Desv., ressemblant à la mouche noire de la viande, serait, au dire de Hadwen, un fléau des troupeaux de caribous 
domestiques. La lucilie anglaise de la laine des moutons, une mouche d'un vert métallique, Lucilia sericata Meig., et une autre qui lui ressemble beaucoup, L. casar L., sont d'autres mouches bien connues qui peuvent causer des incommodités. On rencontre aussi parfois dans les plaies, des larves des mouches. à chair rayées de gris, esp. Sarcophaga, et le Dr E. M. Walker a signalé un certain nombre de cas de myiase chez l'homme causés par Wohlfahrtia vigil Walker, dans l'Ontario. La mouche à viande du Sud, Cochliomyia macellaria Fabr., se rencontre au Canada; heureusement, elle n'a causé jusqu'ici que peu de dommages dans ce pays, mais dans certaines parties du Sud-Ouest du Texas c'est un fléau si formidable de l'industrie animale, que les ranchers ne peuvent élever des veaux et sont obligés d'importer pour la paissance des antenais et des animaux plus vieux.

Le cycle de la vie de toutes ces mouches est très semblable; celui de la. mouche noire de la viande servira d'exemple. La femelle peut pondre jusqu'à 500 œufs d'un blanc jaunâtre, qui sont déposés par grappes de vingt ou plus. dans la laine salie ou dans les plaies. Les vieilles plaies suppurantes attirent spécialement les mouches, mais nous avons vu des œufs sur des blessures propres, qui venaient d'être faites. Les orifices exsudant du pus formés par les. larves des hypodermes chez les bovins et les caribous sont parfois infestés par ces mouches et constituent le point principal d'attaque dans ces derniers animaux. Les attaques de la larve suivent surtout les attaques des tiques, et dans une invasion récemment étudiée en Colombie-Britannique, plus de soixantecinq bœufs avaient été frappés dans un troupeau fortement infesté de tiques. La tique de la paralysic est une cause qui contribue directement, car les bœufs en se démenant et en tombant avaient délogé les croûtes résultant du décornage, ils avaient écrasé les tiques gorgées et s'étaient meurtris à tel point qu'ils étaient devenus jnfestés de milliers de larves. Par un temps très chaud, les œufs peuvent éclore en moins d'une journée, mais lorsqu'il fait plus froid, l'éclosion peut être retardée de quelques jours. Les larves blanches, allongées et segmentées, sont tronquées à l'extrémité postérieure mais forment une pointe effilée à l'extrémité de la tête, qui est pourvue d'une paire de petits crochets adaptés pour déchirer les tissus. Elles exsudent de la bouche un liquide visqueux qui liquéfie la chair et leur permet de se procurer de la nourriture pour leur développement très rapide. La croissance peut être complétée en moins d'une semaine lorsqu'il fait chaud, mais elle peut aussi durer le double de ce temps et le cycle entier couvre de trois semaines à plus d'un mois. Il y a probablement six générations ou plus par saison dans les conditions canadiennes. Lorsqu'elles arrivent à maturité, les larves tombent à terre, se contractent et se transforment en nymphes brunes, ovoïdes, et en forme de baril. La période de nymphe dure généralement plus longtemps que la période de larve, elle peut se prolonger

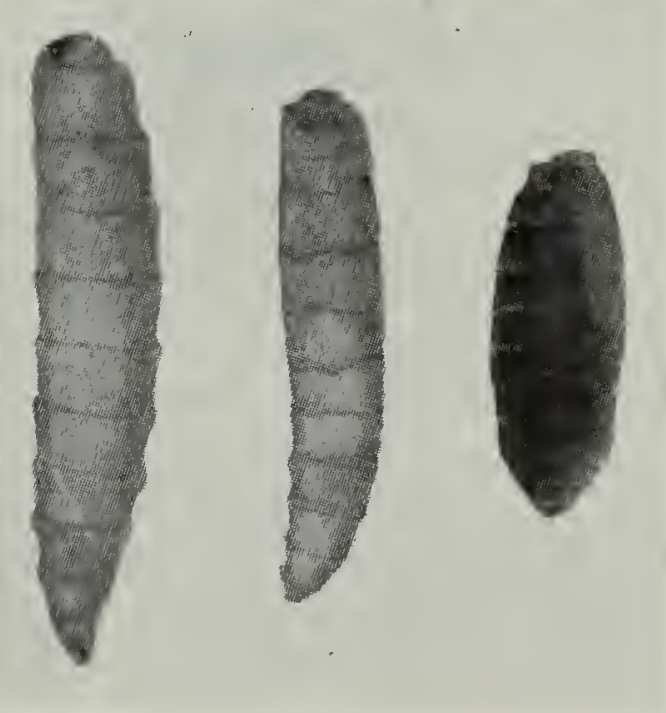

Fig. 52-Larves et nymphes de la mouche noire de la viande, Phormia regina Mgn., grossies (Original). d'une à trois semaines. Dans la dernière génération en automne, la période de nymphe est beaucoup plus longue, et c'est principalement dans cet état que l'insecte passe l'hiver, mais on l'a vu cependant hiverner sous forme d'adulte. Les mouches adultes peuvent vivre un mois ou plus; elles commencent à pondre une semaine environ après leur sortie. Des expériences entreprises en Australie et ailleurs indiquent que les mouches bleues peuvent se porter avec aise sur une distance de plus de dix milles. Contrairement à la mouche à viande du Sud, la mouche noire peut résister à une température assez froide et elle prend son vol aux premiers jours de température douce au printemps. De nombreux cas de moutons et de bovins frappés par cette mou- 
che ont été notés en Colombie-Britannique dès la première semaine d'avril, mais c'est à partir de la fin d'avril et jusqu'en juin que ces attaques se développent spécialement. Elles se ralentissent beaucoup pendant les journées chaudes et sèches de l'été, mais elles peuvent revenir vers l'automne.

Dommages, pertes et symptômes.-Il existe deux formes de dommages causés par les larves. Les larves peuvent infester les blessures ou, chez les moutons, elles habitent la laine souillée. Si un traitement n'est pas promptement appliqué, la chair saine, par-dessous la toison, peut être envahie. Toutes les opérations comme le décornage, la castration, le marquage, l'ablation de la queue, etc., peuvent être suivies d'une attaque des larves si elles ne sont pas entreprises à une époque où les mouches sont rares et inactives. L'agnelage et le

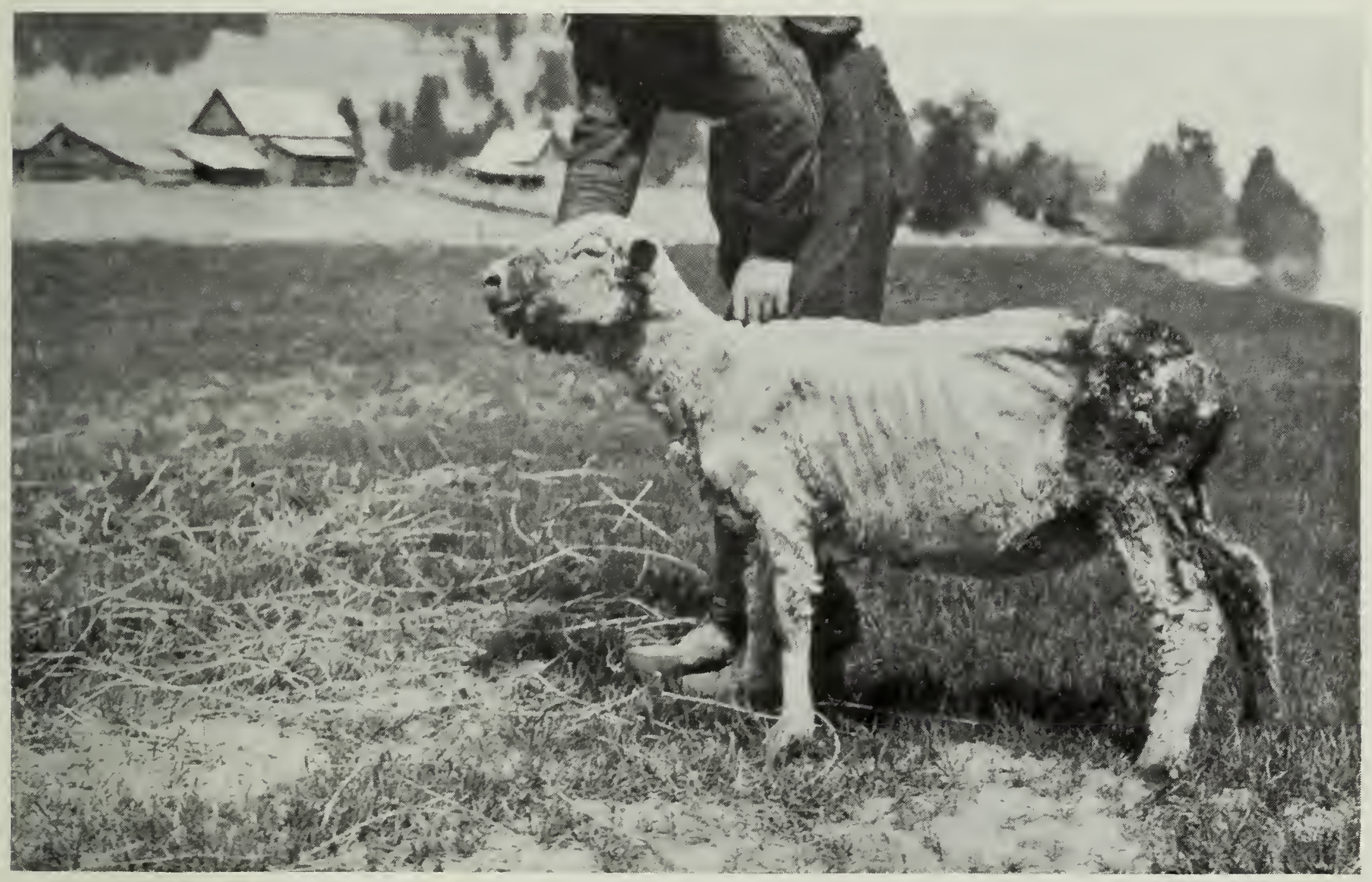

Fig. 53-Mouton affecté du myiase dans les quartiers de derrière, causée par les larves de la mouche noire de la viande, Phormia regina Mgn. (Original).

vêlage sont des périodes spécialement dangereuses et lorsque les moutons sont mis pour la première fois sur un pâturage succulent au printemps, ils peuvent développer la diarrhée et devenir victimes des attaques des mouches. Les vers parasitaires internes ont aussi quelque importance sous ce rapport, car une grosse invasion de ces vers provoque souvent une diarrhée aiguë, même si les moutons sont sur un pâturage peu garni ou s'ils sont nourris de fourrages secs. L'effet des attaques des tiques et la présence de tumeurs d'hypodermes exsudant du pus sont aussi des facteurs importants. Les blessures causées par la tonte ou par les fils de fer barbelés, les dommages qui résultent des coups de cornes d'autres animaux ou des attaques des pies peuvent attirer une invasion de larves, résultant en des dommages permanents ou même la mort. Les conditions de température exercent un effet marqué sur la quantité de mouches, les journées douces et humides, marquées par des averses, favorisent spécialement la ponte. L'humidité sur les moutons attire les mouches bleues, et il est rare que des troubles se développent pendant un temps très sec, sauf lorsque les animaux ont la diarrhée. 
Dans les pays chauds, comme l'Australie et l'Afrique, les mouches bleues de la viande sont les pires fléaux qui affectent l'industrie ovine; elles prélèvent un tribut qui se monte à des millions de dollars par an. Les pertes causées à l'industrie animale aux Etats-Unis sont estimées à $\$ 5,000,000$ par an. Heureusement, les pertes d'argent sont loin d'être aussi considérables au Canada, mais elles sont très sérieuses dans certaines saisons lorsque les conditions de température sont spécialement favorables.

Les animaux frappés, surtout les moutons, manifestent des symptômes assez marqués; ils sont irrités, inquiets, ils frappent du pied et se mordent les endroits attaqués. Les moutons agitent constamment la queue. Plus tard ils deviennent engourdis, perdent l'appétit et ont une tendance à se séparer du troupeau et à se cacher dans des endroits reculés.

Moyens préventifs.-Les moyens préventifs sont les suivants:

(1) Réduction des mouches à viande, susceptibles de causer la myiase, en détruisant les charognes et prenant les mouches adultes au piège ou en les empoisonnant.

(2) Modification des pratiques de ferme pour réduire les risques d'attaque.

(1) Toutes les mouches qui peuvent causer la myiase chez les bestiaux au Canada se multiplient principalement dans les charognes, et la destruction de toutes les charognes par le feu est une mesure de première importance. Il faut creusel une tranchée étroite et y faire un bon feu de bois. On met les carcasses des animaux sur des barres de fer par-dessus la tranchée, ce qui permet de les détruire facilement. On estime que la carcasse d'une vache peut donner naissance à 1,000,000 de mouches, et 42,000 mouches sont sorties d'un seul mouton. Comme un animal mort peut donner naissance à une quantité suffisante de mouches pour un rayon d'au moins dix milles, on voit toute l'importance que présente la destruction des charognes. L'enfouissement n'est pas très satisfaisant, car les mouches peuvent remonter plusieur's pieds à travers le sol lor'squ'elles sont prêtes à se nymphoser. Si l'on a r'ecours à ce moyen, il faut employer beaucoup de chaux vive, enfouir les carcasses profondément et bien piétiner la terre. Si aucun de ces moyens n'est pratique, il ne faut pas laisser la carcasse dans un endroit humide ou ombragé, mais la tirer dans un endroit sec ou ouvert où elle se dessécher'a sous l'action du soleil et des vents, et la multiplication des mouches sera ainsi réduite au minimum. Si l'on a soin de verser des quantités abondantes d'huile de coaltar-créosoté sur la carcasse, aucune mouche ne s'y déposera.

On a employé différents genres de pièges à mouches pour réduire le nombre des mouches à viande sur les fermes d'élevage et ils ont donné de bons résultats. Le piège de Bishopp, mentionné dans le chapitre sur les mouches communes (voir page 17) est très utile, mais le piège africain qui se compose de deux bidons de gazoline ou d'huile de charbon est préférable aux autres types. L'un de ces pièges a pris plus d'un quart de million de mouches en trois mois. La construction en est assez simple, comme on le voit dans le cliché ci-joint. La matière visqueuse des intestins, provenant des abattoirs, ou le foie, fait un bon appât; on peut aussi se servir de rongeurs comme les siffleux (marmotte d'Amérique), mais il faut les fendre en deux. L'un des meilleurs appâts est la poudre d'œufs desséchée (comme celle dont se servent les boulangers) à raison de trois onces et une cuillerée à thé de soda à pâte mélangés dans une pinte d'eau pour chaque bidon d'appât.

L'empoisonnement est très utile, mais il faut le faire de façon à ce qu'il ne constitue aucun danger pour les chiens ou les autres animaux. Un baril d'huile de 40 gallons coupé en deux moitiés dans le sens' de la longueur fait deux auges. On recouvie le dessus de chaque auge de fort grillage solidement fixé. On remplit ensuite les auges en partie d'une solution d'arsénite de soude à raison de deux onces par quatre gallons d'eau et l'on sucre avec deux livres 
de sucre bon marché. On place par-dessus le grillage des charognes comme des cadavres de moutons, etc., et les mouches sont attirées pour pondre leurs œufs. Elles se nourrissent presque toujour's du liquide sucré et sont empoisonnées. Les larves qui se développent dans les carcasses tombent dans le liquide qui est par-dessous et périssent.

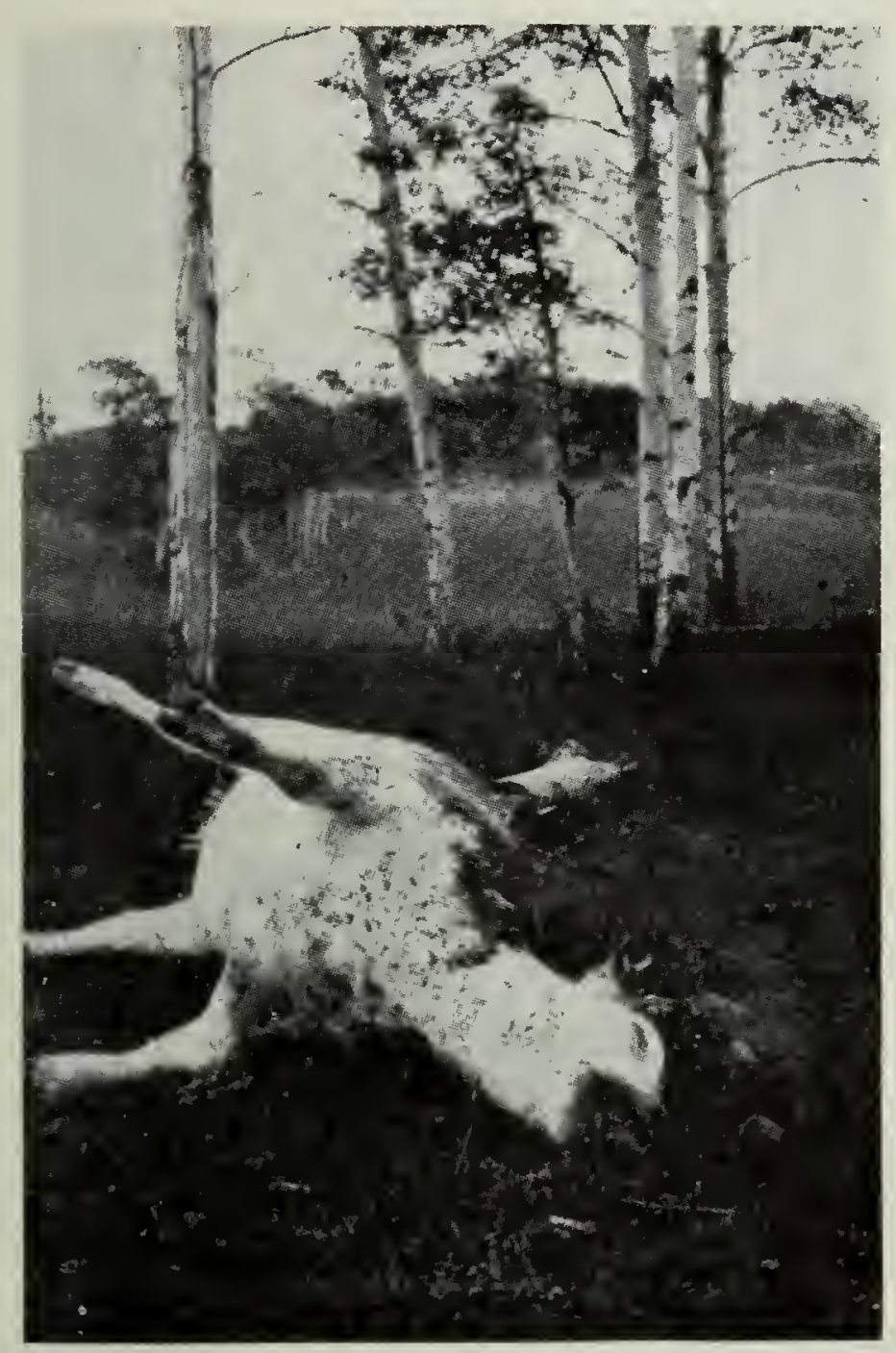

Fig. 54-Les mouches de la viande se propagent dans les carcasses d'animaux et les autres charognes. Il peut se développer jusqu'à un million de mouches dans la carcasse d'une vache (Original).

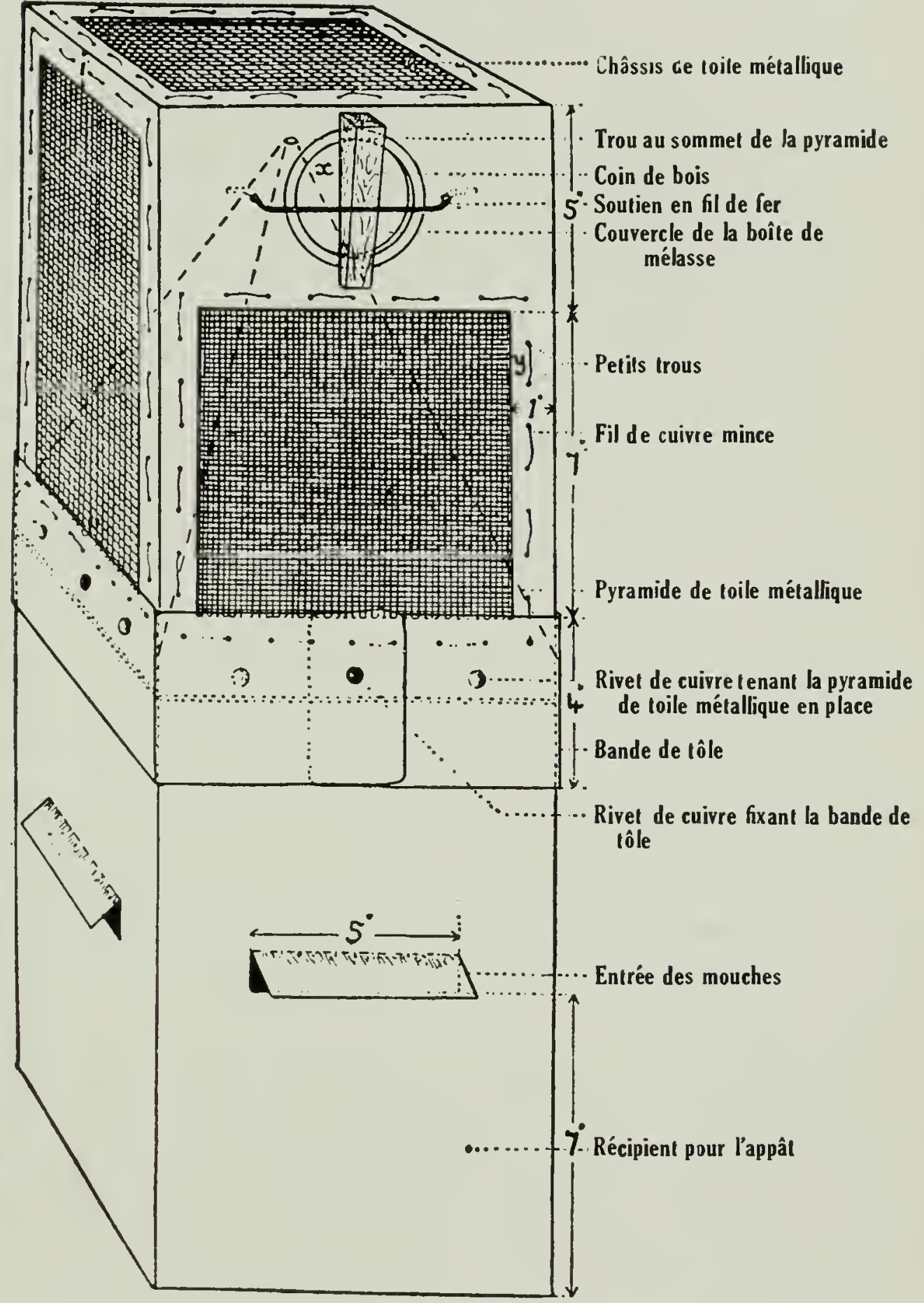

Fig. 55-Piège à mouches africain amélioré (d'après Smit).

(2) On peut, en modifiant certaines pratiques de la ferme, réduire les risques d'infestation par les larves. On devrait toujours, par exemple, châtrer, décorner ou marquer les animaux aux premiers jours du printemps, ou vers la fin de l'automne. Il faut tondre les moutons aussitôt que possible et enduire toutes les blessures de la pesu avec des substances repoussantes comme l'huile de goudron de pin. On aura soin de tenir les animaux aussi propres que possible et de tondre l'entre-cuisses de bonne heure; cette opération doit se faire avec un soin tout spécial sur les brebis, avant ou immédiatement après l'agnelage. On tondra la toison et les crottins jusqu'à un point bien au-dessus de la queue, de chaque côté de la culotte et le long du dos des pattes jusqu'aux jarrets. Il faut éviter les transitions trop brusques dans la nourriture des animaux, comme par exemple le changement d'une nourriture verte succulente aux fourrages secs d'hiver, de crainte qu'ils ne contractent la diarrhée, qui les rend plus sujets aux attaques des mouches. Il faut éviter aussi de brutaliser les animaux, car les petites blessures et les coupures peuvent s'aggraver lorsqu'elles sont infestées par les mouches. Les mesures tendant à réduire les tiques et les larves d'œstres sont utiles également pour amoindrir les dangers que présentent les mouches à viande. La santé du mouton est un facteur important dans la résistance aux attaques des mouches à viande, et la destruction des vers intestinaux est très nécessaire. 
habitudes différentes et vit dans des gonflements en forme de tumeur sur les oiseaux, à peu près comme font les larves des hypodermes sur les bovins. On a extrait des larves de ces tumeurs dans le dos des hirondelles dans l'Est du Canada. D'après le professeur G. J. Spencer, l'espèce qui affecte les hirondelles est P. Avium, Shann. \& Dobr., et les larves extraites des poussins appartiennent à une espèce non identifiée du même genre.

\section{Dommages subis par les volailles qui se nourrissent de larves et d'insectes}

Une maladie des volailles appelée "paralysie du cou" se développe parfois chez les oiseaux qui mangent de grandes quantités de larves de mouches. Il a été démontré que cette maladie est causée lorsque les larves en question se sont nourries de chair putréfiée, contenant des germes et des bactéries de botulisme ou d'empoisonnement par les ptomaïnes. La paralysie des muscles du cou est un symptôme caractéristique; l'oiseau est incapable de lever la tête de terre. Les mouches à viande de couleur vert d'émeraude brillant ou bleuvert, Lucilia coesar L. et L. sericata Meigen, sont parmi les espèces qui ont été étudiées au cours des recherches, mais il est tout probable que les larves de beaucoup d'autres mouches à viande peuvent aussi avoir une part de responsabilité dans cette maladie. Celle-ci se produit parfois lorsque les volailles se nourrissent directement de charognes ou de conserves gâtées. Comme moyen préventif, on recommande de supprimer avec soin toute charogne. Gallagher dit qu'un purgatif sous forme de une demi-cuillerée à thé de sels d'Epsom, ou trois à quatre cuillerées à thé d'huile de ricin (huile de castor) pour chaque oiseau adulte, constitue le meilleur traitement, mais il faut l'administrer promptement car la maladie a un cours rapide.

Le hanneton ordinaire du rosier, Macrodactylus subspinosus Fab., contient une substance qui est très toxique pour les jeunes poussins, les canetons, les: oisons et les dindonneaux, et l'on prétend que des oiseaux sont morts après. avoir mangé seulement quelques-uns de ces insectes. Lorsque les insectes. sont nombreux et que les oiseaux en mangent de grandes quantités, les pertes. peuvent être très considérables. Sur certaines fermes avicoles des Etats-Unis de l'Est, on signale la mort de centaines, et, dans un ou deux cas, de milliers de poulets. De grosses pertes ont été signalées dans l'Est du Canada, et Ross et Hall signalent la perte de plus de 100 poulets par cette cause dans un endroit de l'Ontario. Pendant la saison du hanneton du rosier, il est bon de mettre les jeunes oiseaux dans des cours où il ne se trouve pas de vignes à raisin, de rosiers, de marguerites, de pivoines ou d'autres végétaux qui attirent spécialement ces coléoptères. Lampton dit qu'il a réussi à réduire les pertes sur de grandes fermes avicoles en fauchant les parcours juste avant la saison des hannetons. Dans l'Ontario les hannetons adultes du rosier commencent à sortir dans la première semaine de juin et ils pullulent généralement vers le milieu du mois. Au bout de trois semaines environ de pullulation, leur nombre commence à décroître graduellement et tous ont généralement disparu à la mijuillet. On ne sait pas si son proche parent, le hanneton de l'Ouest Macrodactylus uniformis Horn, est toxique pour les volailles.

D'autres charançons qui ont été trouvés dans les gésiers de poulets empoisonnés aux Etats-Unis, sont des espèces de coléoptères à ailes parcheminées, très communs, de l'espèce Cantharis. Un certain nombre d'espèces sont communes au Canada, mais jusqu'ici aucune plainte d'empoisonnements causés par ces insectes ne nous est encore parvenue.

\section{LES HIPPOBOSQUES OU MOUCHES-ARAIGNÉES (Hippobossidés)}

Ce sont des mouches aplaties, dégradées, ressemblant un peu à une tique. Certaines d'entre elles, notamment les espèces tropicales qui affectent les bovins. et d'autres espèces parasitaires des oiseaux du Canada, conservent leur ailes. Quelques-unes, comme le lipoptène du chevreuil, laissent tomber leurs ailes 
après qu'elles ont trouvé un hôte, mais l'espèce la mieux connue, le mélophage du mouton, est dépourvue d'ailes et est aussi parasitaire que le pou.

LE MÉlOPHAGE OU BARBIN DU MOUTON, Melophagus ovinus L.

Cet insecte, aussi appelé pou du mouton et parfois tique du mouton, est en réalité une mouche sans ailes, dégradée, et c'est un vrai insecte qui n'est même pas apparenté aux tiques. L’emploi général du terme "barbin du mouton"

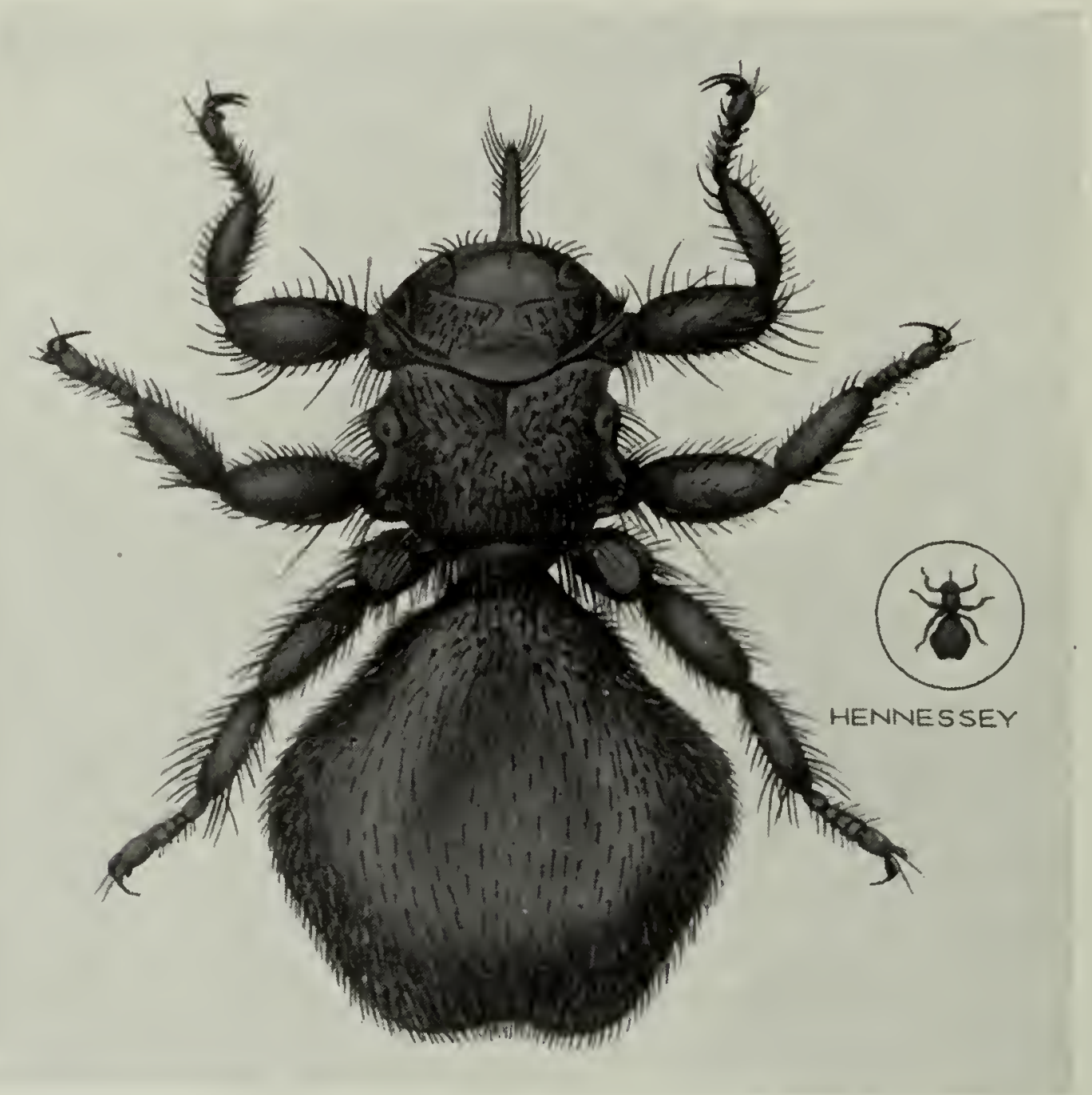

Fig. 56-Le barbin ou mélophage du mouton, Melophagus ovinus L., grossi et grosseur naturelle ((Original).

ferait disparaître une bonne partie de la confusion actuelle lorsqu'on parle de ce parasite. Le barbin est très répandu dans presque tous les pays du monde où l'on élève des moutons et c'est aussi un fléau commun dans toutes les parties du Canada où l'industrie ovine est pratiquée.

L'insecte adulte est d'une couleur grise à brun rougeâtre, il a environ un quart de pouce de longueur. Le corps est recouvert de courtes épines. La tête petite, enfoncée, est armée d'une trompe ou proboscis assez longue, en forme de suçoir, et généralement portée de côté. Les six pattes sont fortes et se terminent en griffes solides, bien adaptées pour accrocher l'insecte fermement à la laine. Le corps est gros, en forme de sac. L'insecte, qui peut se déplacer rapidement, passe facilement d'un animal à l'autre. Lorsqu'il suce le sang, ce qu'il fait en plongeant son proboscis profondément dans la chair, il peut rester longtemps inerte, mais il peut aussi généralement se gorger de sang en vingt-quatre heures environ.

Cycle évolutif et habitudes.-Il se produit une larve à la fois. Les œufs éclosent dans le corps de la femelle et la larve n'est évacuée que lorsqu'elle est complètement développée. La larve qui vient de naître a une apparence blanchâtre à cause de la membrane blanche, molle, dont elle est enveloppée, mais au bout de quelques heures cette membrane durcit, prend une couleur plus foncée, et devient une pupe luisante, dure, couleur de marron, ressemblant beaucoup par la grosseur et l'apparence à une graine de radis. Lorsque la larve vient de sortir, la membrane qui l'entoure est collante et recouverte d'une sub- 
stance semblable à de la glu qui, en séchant, attache la pupe sur la laine. Les "lentes" ou graines, comme on appelle généralement les pupes, sont généralement attachées à un point qui est à un demi-pouce ou un pouce de la peaü. C'éti là un détail important en ce qui concerne la tonte. Contrairement à la vrasc tique prolifique, qui pond des milliers d'œufs, le barbin ne produit que dix à quinze larves pendant sa vie, qui dure de quatre à six mois. Malgré cela, la progéniture d'une paire de barbins peut se chiffrer par 700 individus en une année. La période d'incubation, avant que le barbin sorte de la pupe, varie de dixneuf à vingt-quatre jour's, mais elle peut aussi se prolonger longuement si cette phase se passe loin de l'hôte, sur la laine tondue ou sur la terre. Les barbins nouvellement éclos se faufilent à travers la laine jusqu'à la peau où ils plongent leur bec et commencent à se nourrir. L'accouplement se produit au bout de quatre ou cinq jours. Les premières larves sortent environ huit à dix jours après l'accouplement ou deux semaines après la sortie du barbin femelle de l'œuf. Les larves sont déposées pendant toute la vie de de la femelle, à intervalles de sept à neuf jours. Les moutons, et parfois les chèvres,

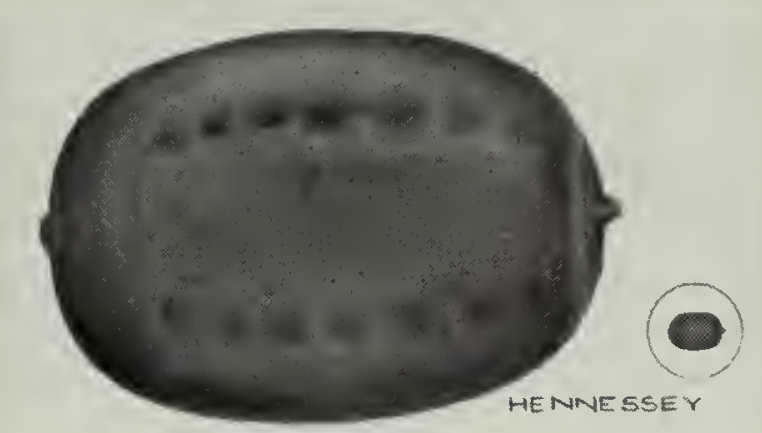

Fig. 57-Pupe du mélophage du mouton, grossie et grosseur naturelle (Original). sont les seuls animaux sur lesquels le barbin se nourrit, et les adultes qui tombent à terre ou qui sont enlevés avec la laine meurent au bout d'une semaine. Si la tonte est faite pendant une journée chaude, un grand nombre de barbins sont enlevés, car l'insecte préfère les parties extérieures de la toison lorsqu'il ne se nourrit pas. Lorsqu'il fait plus froid, on les trouve groupés dans la profondeur de la toison, contre la peau. Les pupes restent viables lorsqu'elles sont enlevées de l'hôte dans la laine et il s'en enlève une bonne proportion, à cause de l'endroit où elles se trouvent dans la toison. Elles se détachent souvent lorsque l'animal se frotte ou se gratte. Dans ce cas, la sortie des jeunes barbins est longuement retardée. Elle peut ne pas se produire avant six semaines, et e'est là un détail important en ce qui concerne la réinfestation. Les pupes séparées de l'hôte succombent à la gelée.

Dommages et importance économique.-La présence d'un petit nombre de barbins n'incommode pas beaucoup le mouton, mais leur accumulation graduelle, malgré le petit nombre de larves que produit chaque femelle, peut résulter en quelques mois en une très forte infestation et les moutons infestés d'un grand nombre de parasites souffrent beaucoup, ils maigrissent, perdent leur vigueur et ne profitent pas. Une évaluation modérée fournie par des éleveurs pratiques au Bureau de l'industrie animale des Etats-Unis évalue les pertes annuelles à 20 cents par tête pour les moutons adultes et à 25 cents pour les agneaux. Après que les brebis sont tondues, les barbins se concentrent sur les agneaux, dont la croissance est souvent retardée. C'est pendant l'hiver, quand les animaux sont serrés ensemble dans les enclos ou dans les bergeries et que leur vitalité est affaiblie par le froid et souvent par de mauvaises conditions d'alimentation, que les attaques des barbins sont les plus graves. Il n'y a pas que la perte de sang qui résulte de l'alimentation de ces parasites, mais la laine est souvent aussi endommagée et sa valeur est dépréciée. Les animaux infestés se grattent, se mordent la toison et celle-ci devient déchiquetée. La laine est aussi souillée et salie par les fientes de ces insectes. La présence de coques vides de pupes est une objection, car il faut les enlever de la toison. Il n'a pas été constaté que le barbin transmette des maladies du mouton.

Moyens répressifs.-Heureusement le barbin est assez facile à combattre, et si tous les propriétaires de moutons d'un district voulaient unir leurs efforts, ils pourraient supprimer complètement ce fléau. Un bain d'automne avec l'une des préparations commerciales régulières vendues pour cela est très utile. Les bains sont principalement de trois espèces: chaux-soufre-arsenic insoluble, 
nicotine et produits de coaltar-créosoté. Comme les pupes dures et luisantss sont protégées par une couverture ressemblant à de la glu, elles sont très résistantes aux solutions connues, sauf peut-être pendant les quelques premiers jours qui suivent la ponte. Deux bains sont donc essentiels, le premier pour tuer tous les adultes sur les animaux et le deuxième pour tuer tous les jeunes barbins qui sortent plus tard des pupes présentes à l'époque du premier traitement. Il est très important que l'intervalle qui s'écoule avant le deuxième bain soit de la longueur nécessaire. L'étude du cycle évolutif de l'insecte indique qu'un intervalle de vingt-quatre heures est le plus satisfaisant pour accomplir ce résultat. Il faut avoir soin de ne pas laisser les moutons qui ont été baignés venir en contact avec des animaux non traités, et tous les parquets et les champs où les moutons ont été gardés avant le traitement devraient être considérés comme contaminés pendant au moins six semaines, après quoi tous les jeunes barbins éclos des pupes sur la terre, ou sur les touffes de laine ou sur les clôtures sont morts. Pour la même raison, il faut serrer la laine au moins à cinquante pieds de la bergerie. Lorsque le bain d'automne a été négligé et que l'on constate une forte invasion de barbins à l'époque de la tonte, il est bon de traiter les animaux en donnant une attention spéciale aux agneaux, sur lesquels les barbins se concentrent généralement à cette époque. On peut se servir de l'un ou de l'autre des bains commerciaux ou encore d'un lavage composé d'une solution de crésol à 2 ou 3 pour cent dans de l'eau. Pour la plupart des bains réguliers, il faut laisser le temps à toutes les blessures que l'on a pu faire en tondant de se cicatriser avant de baigner, sinon l'empoisonnement du sang pourrait en résulter. En hiver, lorsqu'il est impossible de donner des bains, on peut traiter les troupeaux très infestés au moyen de poudre de pyrèthre, que l'on insuffle dans les profondeurs de la toison. Il est impossible d'extirper complètement les insectes par ce moyen et plusieurs saupoudrages peuvent être nécessaires. C'est là un procédé lent et pénible et il ne peut guère être entrepris que sur un petit nombre d'animaux précieux; il vaut mieux compter sur les bains doubles d'automne chaque fois qu'il est possible. Le bain ne coûte que 2 ou 3 cents par tête et il devrait être entrepris comme pratique générale par tous les éleveurs de moutons pour réduire la propagation de ce fléau et les dommages qu'il cause.

\section{LE LIPOPTÈNE OU MOUCHE-ARAIGNÉE DU CHEVREUIL, Lipoptena depressa Say}

Cet insecte singulier est très apparenté à l'espèce précédente et il lui ressemble beaucoup. Les éleveurs qui le voient sur le chevreuil le prennent parfois pour le barbin, mais il est plus petit

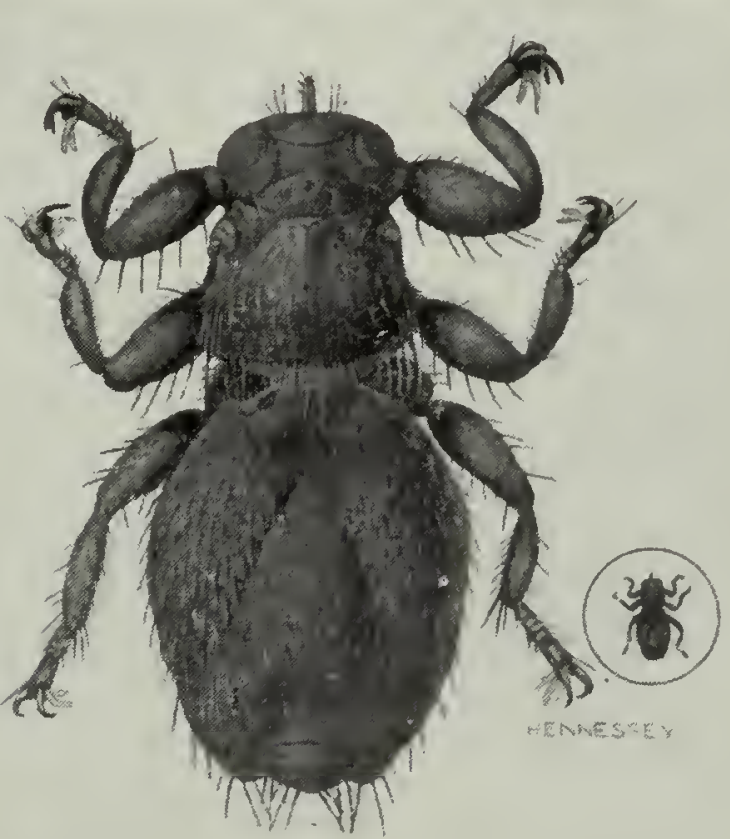

Fig. 58-La mouche-pou ou mouche-araignée du chevreuil, Lipoptena depressa Say, grossie et grosseur naturelle (Orig.). que celui-ci et sa couleur est moins grise. Les premières mouches qui sortent des pupes ont des ailes bien développées qui

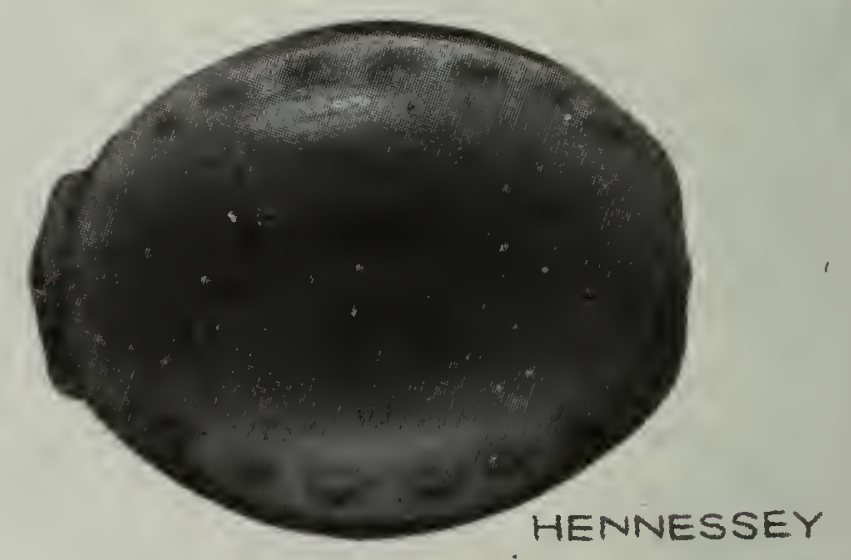

Fig. 59-Pupe de la mouche-araignée du chevreuil (Original). 
leur permettent de se transporter sur de nouveaux hôtes, mais elles laissent tomber ces ailes dès qu'elles s'attachent à une vie parasitaire. Ces insectes sucent le sang et produisent des larves uniques complètement développées, prêtes à se nymphoser tout comme font celles des barbins du mouton. Leur importance économique est peu connue, mais on a trouvé un grand nombre de chevreuils infestés en Colombie-Britannique.

\section{MOUCHES-POUX DES OISEAUX, Lynchia et Ornithoica}

Les pigeons domestiques et divers oiseaux sauvages, et spécialement les oiseaux de proie, sont parfois attaqués par de grosses mouches-poux plates, ailées, qui cependant ne paraissent pas avoir d'importance économique au Canada mais qui sont intéressantes parce qu'elles sont étroitement apparentées au mélophage du mouton sans cependant avoir dégénéré autant que cette espèce.

\section{PUCES}

Les puces sont de petits insectes bruns, à corps dur, dépourvus d'ailes, un inconvénient compensé en partie par la possession de pattes très développées et puissantes, spécialement adaptées pour le saut. Elles diffèrent de la plupart des parasites par le fait qu'elles sont très actives et très agiles, pouvant sauter à une hauteur de sept pouces, et horizontalement à près de deux fois cette distance, ce qui correspond à un saut d'environ 300 pieds pour un homme de six pieds. Leur corps comprimé, aplati sur les côtés, et les nombreuses épines, fortes, recourbées dont il est revêtu, leur permettent de se faufiler rapidement dans les poils de leur hôte. Les parties buccales sont spécialement adaptées pour percer la peau et sucer le sang, la seule nourriture que prennent les puces adultes des deux sexes. Elles peuvent vivre très longtemps sans nourriture, mais il semble qu'elles ne peuvent s'accoupler pour produire des oufs qu'après avoir pris un repas de sang.

Les puces sont très répandues dans le monde, et l'on en connaît plusieur's centaines d'espèces. Quelques-unes seulement ont de l'importance au Canada, mais il s'en trouve un grand nombre d'espèces sur les animaux sauvages. Les espèces les plus communes qui s'attaquent à l'homme et aux animaux domestiques sont la puce du chat et la puce du chien. Ctenocephalus felis Curt. et $C$. canis

Bouche. La puce de l'homme

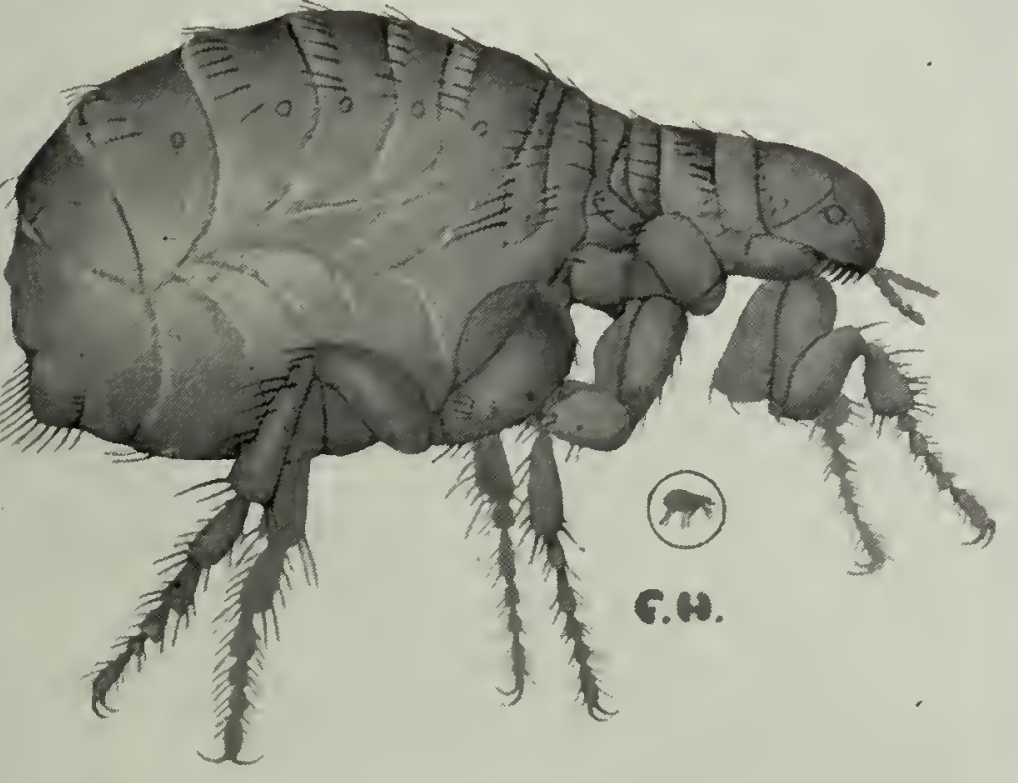

Fig. 60-La puce du chien, Ctenocephalus canis Curtis, grossie et grosseur naturelle (d'après Gibson etTwinn). Pulex irritans L., est aussi gênante en quelques endroits. Ces espèces infestent les chats, les chiens, les renards domestiques et les porcs aussi bien que l'homme. La puce européenne ordinaire des volailles Ceratophyllus gallinae Schrank, se rencontre dans l'Est du Canada, et plusieurs autres puces des volailles ont été signalées dans différentes parties du Canada. La puce de l'homme se rencontre parfois aussi en Colombie-Britannique. A l'exception du cochon, aucun des gros animaux domestiques n'est tant soit peu affecté par les puces. Ces parasites sont souvent des hôtes très gênants sur les fermes où l'on élève des animaux à fourrure: les renards, les lapins et d'autres animaux à fourrure sont spécialement sujets à une forte invasion de puces dans les conditions domestiques. Indépendamment des puces de l'homme, du chien et du chat, les 
lapins sont aussi affectés par la vraie puce du lapin Spilopsyllus cuniculi Dale. Comme le cycle de la vie est très semblable chez toutes les espèces de puces, et que les moyens répressifs généraux s'appliquent à la plupart des espèces, il suffira d'en présenter un exposé général.

Cycle évolutif.-Les œufs des puces sont de tout petits objets blancs, de forme ovoïde, à peine visibles à l'œil nu. Ils sont généralement déposés non fixés en place dans la fourrure de l'hôte, mais ils en tombent bientôt, et l'on peut en trouver en grand nombre dans les endroits où couchent les animaux. Ils sont spécialement abondants dans la litière et les nids. On peut se faire une idée du grand nombre d'œufs qui peut être produit, même sur un seul animal, quand on sait que l'on a recueilli sur le giron d'une femme qui avait caressé un petit chat, une petite cuillerée à thé d'œufs de puces. Chaque puce femelle peut pondre environ 450 oufs sur une période de plusieurs mois. Ces œufs éclosent et il en sort des larves blanches minuscules, allongées, de forme cylindrique, et pourvues d'un certain nombre de poils sur chaque anneau. Elles vivent dans les fentes poussiéreuses des planchers, dans les tapis ou dans la litière des animaux, et se nourrissent des particules de poussière et d'autres débris. Les larves de certaines espèces paraissent avoir besoin des particules incomplètement digérées de sang évacuées par les puces adultes. Lorsqu'elles ont atteint toute leur taille, elles forment un cocon, dans lequel la larve se change en nymphe ou pupe. Dans beaucoup d'espèces, la puce adulte, complètement formée dans le cocon, peut rester très longtemps inerte, surtout lorsqu'il fait froid. Elles sortent de leur's cocons en grand nombre lorsqu'elles sont dérangées par quelque commotion dans le voisinage. Elles se cherchent alors un hôte. s'accouplent et commencent bientôt à pondre. Le cycle entier de la vie, depuis l'œuf jusqu'à l'adulte, peut être complété dans un temps qui ne dépasse pas de 17 à 21 jours, mais qui se prolonge souvent beaucoup plus. On a vu des puces adultes vivre sans nourriture pendant quatre mois, et lorsque les conditions sont favorables et qu'elles peuvent se procurer de la nourriture, elles peuvent vivre pendant un an et demi et plus. Leur's habitudes parasitaires varient quelque peu; il y a certaines espèces, comme la puce de l'homme, qui restent en dehors de leur hôte sauf pendant de courts intervalles, tandis que d'autres, comme la puce du lapin, quittent rarement l'animal qu'elles habitent. Les lieux où la poussière s'accumule comme les fentes des planchers sont spécialement favorables au développement des puces, mais ces insectes se développent aussi parfois en grand nombre en plein air, spécialement dans les enclos sablonneux des porcs et les porcheries, où les conditions d'humidité sont assez uniformes et où il y a beaucoup d'humus et de matière végétale pour fournir de la nourriture. Les puces naissent aussi parfois en grand nombre sous les bâtiments où les chiens, les chats, les porcs et d'autres animaux se réfugient.

Dommages et importance économique.-Les animaux très infestés souffrent beaucoup des piqûres des puces, et ces parasites ont une importance économique considérable dans l'industrie du renard argenté et la production des animaux à fourrure en général. Les animaux constamment incommodés par les puces se grattent continuellement; ils ne profitent pas et ne donnent pas une fourrure d'une belle texture. Non seulement les puces causent de l'irritation par leurs morsures, mais certaines d'entre elles transmettent la peste bubonique tant redoutée, une maladie causant une très forte mortalité et qui affecte certains rongeurs ainsi que l'homme. Elles sont aussi les hôtes intermédiaires des ténias ou vers solitaires, comme le ténia du chien Dipylidium caninum L., qui est très répandu chez les chiens et parfois aussi chez les enfants. Les puces s'infestent dans leur phase larvaire en avalant les œufs des ténias 
présents dans les déchets et la poussière dont elles se nourrissent. L'infection de l'hôte final, que ce soit le chien, le chat ou l'enfant, se produit lorsqu'une puce adulte est avalée; c'est là une circonstance fréquente chez les chiens qui font une chasse assidue à ces petits persécuteurs.

Remèdes et moyens répressifs.-Pour combattre une invasion de puces il est très nécessaire d'abord de traiter les foyers de reproduction où se trouvent les premières phases des puces, et en même temps de traiter les animaux infestés. Pour ces derniers, un très bon lavage est celui qui se compose d'une faible solution de cresol ou de créoline. Il faut laver la tête en premier lieu, car c'est là que les puces se rassemblent quand l'animal est submergé. On tient l'animal plusieurs minutes dans le bain et l'on frotte bien sa fourrure pour bien l'imprégner de la solution. Pour les chiens, une solution à 3 pour cent, ou environ quatre cuillerées à soupe de cresol par gallon d'eau, est la meilleure, mais pour les chats, la solution doit être plus faible et ne pas dépasser 2 pour cent. Quant aux renards, on peut les traiter sans danger avec une solution à 1 pour cent. En ce qui concerne les chats et les renards, il est bon d'enlever la solution immédiatement par un lavage. Ce lavage ne doit pas se faire par un temps froid. La plupart des auteurs ne recommandent pas de baigner les renards; ils préfèrent l'emploi de poudres à cause de la nervosité de ces animaux. Lorsque l'application de ce traitement ne peut se faire chez les renards et les chats, on peut injecter de l'esprit de camphre dans la fourrure au moyen d'un pulvérisateur et bien le faire pénétrer en frottant; cependant, il est peut-être préférable de se servir de pyrèthre ou de poudre de derris. Pendant le traitement, il faut tenir l'animal sur une grande feuille de papier et après un intervalle de 10 à 15 minutes, enlever la poudre à la brosse; puis l'on ramasse le papier avec les puces engourdies qui sont tombées dessus et on brûle le tout. Le traitement recommandé pour les poux des porcs donne aussi à ces animaux quelque soulagement contre les attaques des puces.

Les chenils et tous les logis des chiens, des chats, des renards, des lapins et des autres animaux à fourrure devraient être nettoyés fréquemment; on ne laissera jamais des déchets ou des saletés s'y accumuler. On donnera une attention toute spéciale à la litière; il est bon de faire coucher les chiens et les chats sur des paillassons que l'on peut secouer souvent en plein air. La poudre de pyrèthre ou de derris, saupoudrée sur les planchers et dans la litière des animaux est utile. On peut prévenir les puces en pulvérisant les planchers et les boiseries avec de l'huile à brûler', de l'huile de charbon, de préférence un mélange de pyrèthre et d'huile de charbon, de l'huile de créosote ou un bon bain commercial de coaltar-créosote. Il faut nettoyer les enclos ou porcheries infestés et les pulvériser avec de l'huile de créosote, de même que les poulaillers et les parcours à volaille. Le sel détruit très bien les puces dans leurs premières phases, et un bon moyen de les combattre est d'imprégner de saumure les planchers de bois ou de terre des poulaillers, des porcheries, etc. Il ne faut pas oublier que le sel est un poison pour les volailles, et on aura soin de mettre les sacs de sel dans les endroits où ces oiseaux ne peuvent pénétrer.

\section{LES PUNAISES COMMUNES, COMME FLÉAU DES VOLAILLES}

La punaise commune, Cimex lectularius L., est généralement considérée comme un fléau de l'homme, mais cette espèce, de même que plusieurs espèces alliées, cause souvent aussi des incommodités aux volailles. Ces parasites sont de forme ovale, aplatie, et sans ailes, de couleur brun-rougeâtre, et mesu- 
rent environ un quart de pouce de longueur. La longue trompe suceuse est généralement repliée sous l'insecte.

La punaise ne recherche son hôte que le soir, lorsqu'elle a besoin de se repaître de sang; en d'autres temps, elle se cache dans les crevasses et les fentes. Elle y dépose des œufs blancs, petits, allongés, et chaque femelle pond jusqu'à 200 œufs environ. Les jeunes punaises sortant de ces œufs ressemblent aux adultes, mais elles sont de couleur plus pâle. Tous deux, adultes et nymphes, ne se nourrissent que de sang, mais ils peuvent vivre plusieurs mois sans un seul repas. Le cycle, de l'œuf à l'adulte peut être complété en six semaines, mais il est souvent plus long.

Un des moyeris les plus simples et les plus satisfaisants de débarrasser les poulailler's de leur's punaises est de pulvériser toutes les fentes dans les boiseries, les juchoirs, etc., avec de l'huile de créosote ou de l'huile de charbon. On fera une deuxième application au bout d'une dizaine de jours si toutes les punaises ne sont pas détruites par la première pulvérisation.

\section{POUX DES ANIMAUX DOMESTIQUES ET DES VOLAILLES}

Presque toutes les espèces d'animaux sauvages et domestiques ont une ou plusieurs espèces de poux qui leur sont particuliers, et quelques formes de ces poux se portent même d'une espèce à l'autre. Par exemple, certains animaux étroitement apparentés, comme les chevaux, les ânes et les mulets, peuvent donner asile aux mêmes espèces des poux, suceur's et broyeurs. Les principaux poux des mammifères sont les poux suceurs, mais il y a aussi des poux broyeurs, en petit nombre, qui infestent ce genre d'hôtes. On connaît environ une douzaine d'espèces de Mallophages-c'est le nom technique des poux broyeurs-qui se rencontrent sur les animaux domestiques de l'Amérique du Nord. Les poux qui attaquent les volailles et les oiseaux sauvages ne sont pas du type suceur, mais du type broyeur, et ceux-ci se multiplient parfois au point de devenir un fléau très sérieux. Les différents membres de ce groupe de parasites s'en tiennent presque invariablement à des espèces particulières d'oiseaux sauvages ou à différentes catégories de volailles, mais une espèce d'oiseau peut être infestée par plusieur's espèces de poux. On a trouvé par exemple au moins une douzaine de poux broyeur's d'espèces différentes sur la poule commune.

Les deux types, broyeurs et suceurs, sont des parasites permanents, différant en cela des puces; ils passent toute leur vie à partir de l'œuf et des premières phases, sur le corps de leur hôte. Ils vivent rarement plus de quelques jours lorsqu'ils sont enlevés de leur hôte. Les jeunes poux ressemblent beaucoup aux adultes par l'apparence et les habitudes.

\section{POUX SUCEURS}

Les poux suceurs (Anoplura) sont des insectes à corps mou, un peu aplatis, d'une couleur qui varie de blanc à gris bleu foncé. Beaucoup d'entre eux ressemblent à un crabe d'une façon caractéristique. Le corps relativement gros, ovoïde, porte quelques poils et les trois paires de pattes se terminent en griffes d'apparence formidable. Il est très utile pour l'éleveur de pouvoir distinguer entre les poux suceurs et les poux broyeurs, car les métamorphoses et les habitudes des deux espèces ne sont pas les mêmes et elles exigent des traitements différents. La tête d'un pou suceur est habituellement quelque peu pointue, plus longue que large, tandis que la tête d'un pou broyeur est très large, bien ar'rondie sur le devant et munie de parties buccales adaptées pour broyer ou mordre. Les poux suceurs ont, comme leur nom l'indique, des parties buccales adaptées pour percer la peau et tirer le sang, qui constitue leur seule nourriture. Ces parasites peu actifs sont répandus dans le monde entier. 
LE POU DU PORC, $H$ cematopinus suis L.

Le pou du porc est peut-être le membre le mieux connu de ce groupe d'insectes. C'est la plus grosse espèce de toutes celles qui affectent les animaux domestiques, il peut atteindre une longueur d'un quart de pouce. Le corps est large et oval, les pattes fortes se terminent en griffes grosses, foncées, bien adaptées pour que l'insecte puisse s'attacher aux poils ou se faufiler sur l'hôte. Ces parasites sont d'une couleur gris sale et portent des marques brun foncé sur la tête, le thorax et sur les bords du corps. Ils se rassemblent principalement dans les replis de la peau, au cou et aux abajoues, à la base et à l'intérieur de l'oreille (ce dernier endroit est spécialement préféré par les jeunes poux), le long du ventre et sur les côtés intérieurs des pattes. Le dos et les parties supérieures des côtés sont beaucoup moins infestés. Ies détails qui précèdent ont une grande importance et l'on doit en tenir compte lorsque l'on veut appliquer des moyens répressifs. Les œufs sont principalement situés en une large bande le long des parties inférieures du corps et à la base des oreilles. Cette espèce ne s'en prend qu'au cochon et c'est la seule espèce de pou qui attaque ces animaux.

L'espace nous manque pour donner une description détaillée du cycle évolutif de chaque espèce de pou, mais comme il existe une ressemblance assez grande sous ce rap-

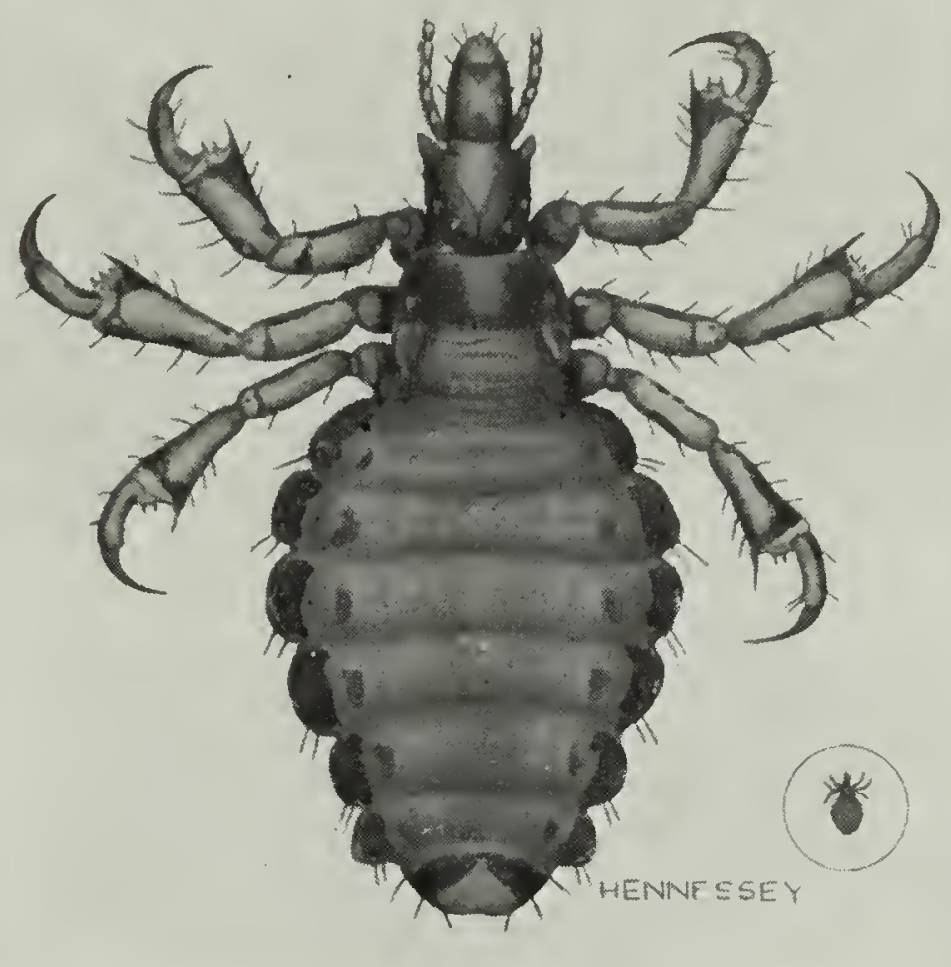

Fig. 61-Le pou du porc, Hamatopinus suis L., grossi et grosseur naturelle (Original).

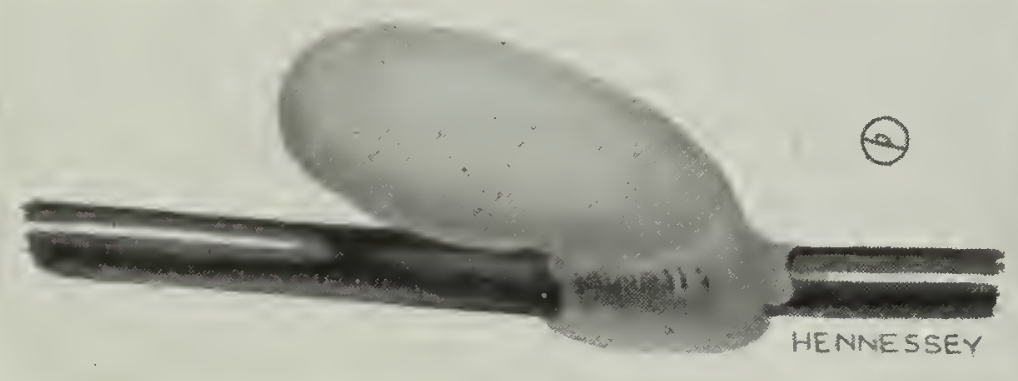

Fig. 62-Giuf du pou du porc, grossi et grosseur naturelle (Original).

port entre les différentes espèces, nous donnons, après l'étude des différentes espèces économiques, quelques notes sur leur vie générale. Les moyens de destruction sont indiqués après le chapitre qui traite des poux broyeurs, car dans bien des cas les mêmes méthodes s'appliquent aux deux groupes.

\section{POUX SUCEURS DU BEEUF}

Les bovins sont attaqués par trois espèces de poux suceurs; l'un des plus communs et des plus gênants est le pou à large thorax ou grand pou du bœuf (en anglais short-nosed cattle louse (pou à nez court), Hcmatopinus eurysternus Nitzsch; c'est un pou assez gros, mesurant un peu plus d'un huitième de pouce de long. La couleur est gris bleuâtre. Il est un peu plus large que les deux autres espèces. La tête plus large, moins pointue, le rend assez facile à distinguer des autres espèces que l'on rencontre plus généralement, c'est-à-dire les poux à nez long. Les animaux sont infestés principalement sur les épaules, la partie supérieure du cou, le front, la gorge, l'écusson et la queue, spécialement vers la base. Les oufs blancs sont attachés aux poils dans les endroits principalement infestés par les adultes.

Le pou à long nez du bétail, Linognathus vituli L., est une espèce plus petite que la précédente, il est plus mince et a généralement une couleur beau- 
coup plus foncée. Le trait le plus caractéristique est la tête allongée. Lorsqu'il se nourrit, ce pou paraît se tenir sur la tête, le corps droit. On dit que ces parasites se rencontrent le plus généralement sur les veaux et les jeunes bestiaux, mais on en a aussi trouvé un grand nombre sur des animaux adultes dans différentes parties du Canada. Les endroits du corps qu'ils préfèrent sont le garrot et les parties mentionnées au paragraphe traitant de l'espèce précédente. Les oufs diffèrent de ceux du grand pou du bœuf par leur couleur qui est presque noire.

Une autre espèce de pou suceur, le pou capillé, Soloneptes capillatus Enderlein, est en abondance suffisante aux Etats-Unis pour être un fléau sérieux des bovins et c'est évidemment aussi une cause d'incommodité dans différentes parties du Canada. Il ressemble beaucoup par l'apparence au grand pou du bœuf, mais il est plus petit et n'est pas aussi large. On dit que cette espèce a une tendance à s'attacher par groupes épais sur la tête et le cou de l'animal qui lui sert d'hôte. Les œufs sont jaunâtre pâle.

\section{POU SUCEUR DU CHEVAL OU POU DE L'ÂNE, Hamatopinus asini L.}

Parmi les trois poux qui attaquent les chevaux, les ânes et les mulets, l'espèce qui suce est la plus gênante. Elle est très répandue dans toutes les parties du monde, c'est parfois un fléau sérieux des chevaux mal soignés au Canada; elle est peut-être plus abondante dans les grands herbages de l'Ouest qu'ailleur's. C'est un pou un peu plus petit que le pou du porc, mais qui ressemble à cette espèce par la forme générale, le corps est large, la tête allongée et la couleur brun jaunâtre. Le cou, les flancs, et le dessous de la mâchoire sont les endroits où les poux se rencontrent généralement en plus grand nombre, mais toutes les parties du corps peuvent être envahies lorsque l'animal est très infesté.

\section{POU SUCEUR DU MOUTON}

Il y a deux espèces de poux suceurs du mouton, mais elles paraissent être assez rares dans la plupart des parties du Canada. Le pou du pied du mouton, Linognathus pedalis Osborn, est unique entre les poux par le fait qu'il manifeste une préférence marquée pour les pattes. Dans les invasions modérées, il ne se rencontre qu'autour des pieds et sur les parties les plus basses des pattes, au-dessous de la vraie laine. Il préfère spécialement la région des onglons et les œufs sont déposés principalement dans cet endroit. Lorsqu'il est présent en grand nombre cependant, il peut aussi envahir d'autres parties du corps, mieux recouvertes de laine. On l'a trouvé pour la première fois aux EtatsUnis sur des moutons importés du Canada. Cette espèce est de forme semblable à celle du grand pou du bœuf, mais elle n'est pas tout à fait aussi large et sa couleur est plus pâle.

L'autre espèce de pou suceur du mouton, Homatopinus ovillus Neum., peut infester toutes les parties du corps, mais les poux sont portés à se rassembler en plus grosses colonies. Des masses d'œufs agglutinent la laine ensemble. Ce n'est pas un pou très répandu et nous ne savons pas s'il se rencontre dans beaucoup d'endroits au Canada.

\section{LE POU SUCEUR DE LA CHÈVRE, Linognathus stenopsis Burm.}

Il y a une espèce de pou suceur qui attaque les chèvres; c'est le pou ordinaire de la chèvie. On dit que ces parasites sont parfois assez considérables pour causer des dommages. Ils sont très répandus. 
LE POU SUCEUR DU CHIEN, Linognathus piliferus Burm.

Le pou suceur du chien, Linognathus piliferus Burm., est un petit pou, de couleur jaune pâle à rosâtre, qui abonde parfois sur les animaux mal soignés dans toutes les parties du Canada. On sait qu'il affecte aussi les renards, mais jusqu'ici nous ne sachons pas que ce pou ait causé des pertes dans les renardières canadiennes.

\section{LE POU SUCEUR DU LAPIN, $H$ remodopsis ventricosus Denny}

C'est un pou de forme ovale, large, à pattes plus courtes que l'ordinaire. Il est très répandu et il infeste différentes espèces de lapins et de lièvres sauvages; c'est aussi parfois un fléau important dans les clapiers commerciaux. On sait qu'il peut répandre la tularémie parmi les lapins sauvages.

\section{LE POU SUR LES FERMES À FOURRURE}

Il est rare que le pou suceur cause des dégâts dans les élevages de renards, mais comme beaucoup des autres animaux que l'on élève actuellement dans des conditions domestiques donnent asile aux poux, les propriétaires de renardières feront bien d'examiner leurs animaux attentivement pour s'apercevoir de la présence de ces parasites et appliquer les remèdes dès que la présence des poux est constatée. On ne peut pas s'attendre en effet à ce que les animaux gravement infestés donnent de bonnes peaux.

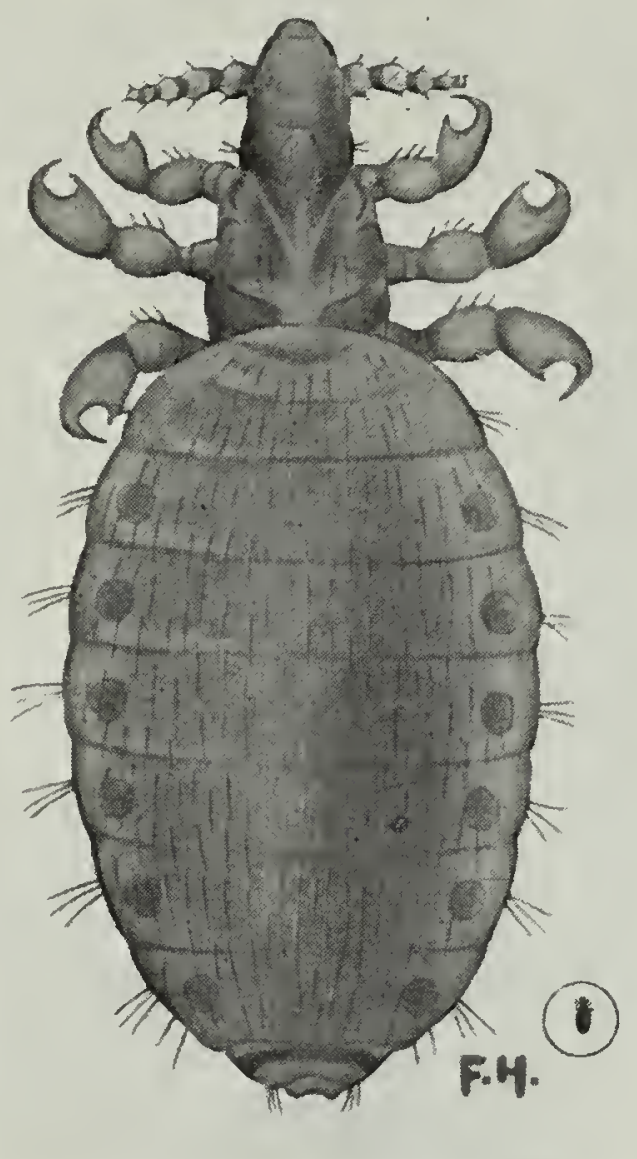

Fig. 63-Pou suceur du chien, Linognathus piliferus Burm., grossi et grosseur naturelle (Original).

\section{CYCLE ÉVOLUTIF ET HABITUdES DES POUX SUCEURS}

Ces parasites passent toute leur vie et toutes leur's métamorphoses sur l'animal qui leur sert d'hôte. Les cufs, blancs ou jaunâtres dans la plupart des espèces, sont des objets épais en for'me de baril, revêtus d'une capsule à l'extrémité supérieure. Ils sont solidement fixés aux poils, près de la peau, au moyen d'une substance semblable à de la glu. Le nombre des œufs varie suivant les espèces, par exemple, le grand pou du bœuf pond de 35 à 50 œufs et le pou du por'c jusqu'à 90 œufs. Les jeunes poux, qui ressemblent aux adultes par l'apparence, sortent en soulevant la capsule qui recouvre l'extrémité des œufs. L'incubation dure de 10 à 15 jour's, mais elle peut durer trois semaines ou plus si les ceufs ou "lentes" sont tombés de l'animal hôte sur la terre. Les poux nouvellement éclos se faufilent jusqu'à la peau qu'ils percent, et ils se nourrissent du sang de l'animal. Ils ne se gorgent pas d'un gros repas, comme font les tiques, mais ils se nourrissent à intervalles fréquents et chaque fois que le pou insère son bec ou proboscis à travers la peau, il provoque une irritation nouvelle. Plusieurs mues ont lieu avant que la phase adulte soit atteinte. Dans la plupart des espèces l'accouplement ne se produit que huit jours ou plus après que les insectes ont toute leur taille, et seulement après qu'ils se sont procurés un repas de sang; la ponte a lieu très peu de temps après et commence généralement une quinzaine de jours après que les insectes sont arrivés à l'état adulte. La femelle pond quelques œufs tous les jours de sa vie, qui se prolonge en moyenne de quatre à cinq semaines dans beaucoup d'espèces. Les générations se succèdent et l'on estime qu'il y a de 9 à 12 générations par an chez le pou des porcs. On voit par ce qui précède qu'une multiplication énorme peut se produire en peu de temps et que, en ce qui concerne le pou du porc, dans des 
conditions favorables, la présence d'un très petit nombre de poux peut être suivie d'une invasion extrêmement forte en quelques mois. Les poux ne quittent pas souvent volontairement leurs hôtes; ils succombent assez rapidement s'ils sont jetés à terre par un grattage ou un frottage. Ils se propagent assez rapidement d'un animal à un autre de la même espèce, par contact, lorsque les vaches, les chevaux, les porcs, les moutons, etc., sont entassés dans des loges. Quelques animaux très infestés, admis dans un troupeau propre, causent bientôt une infestation générale. Dans le cas de ces parasites, l'état des animaux eux-mêmes a plus d'importance que l'état des étables, de la litière, etc. Les animaux en mauvais état sont plus infestés que les animaux sains.

\section{DOMMAGES CAUSÉS ET IMPORTANCE ÉCONOMIQUE DES POUX SUCEURS}

La présence de quelques poux ne cause pas beaucoup d'incommodité aux animaux, mais lorsque l'invasion est forte, l'irritation est grande et dans ces conditions les poux constituent un fléau sérieux. On considère par exemple que le pou du porc est, après le choléra des porcs, le pire ennemi des cochons. On a vu des moutons mourir après une invasion de poux des pattes et toutes les catégories de bestiaux cessent de profiter et s'affaiblissent, à tel point qu'elles sont beaucoup moins en état de résister aux maladies et aux mauvaises conditions d'alimentation. Il est douteux que les poux des vaches et des chevaux causent la mort directement, mais ils y contribuent certainement et de façon importante dans certaines conditions. Le pou suceur, qui perce la peau et suce le sang à intervalles fréquents, est en général un fléau plus sérieux que le pou broyeur, et cependant en ce qui concerne le mouton, on considère que le pou broyeur est le pire des deux. L'irritation provoquée par le pou en suçant le sang et en se faufilant sur la peau est parfois si intense que les animaux très infestés se mordent, se grattent et s'enlèvent, en ce faisant, beaucoup de de poils et même de grosses plaques de peau. Il se forme parfois de grosses croûtes, si étendues qu'on les prend pour de la gale, et souvent aussi des plaies saignantes; certaines espèces de poux, et spécialement les poux du porc, ont l'habitude singulière de se rassembler et de se nourrir en grand nombre autour de ces endroits, ce qui aggrave beaucoup l'état de l'animal. Les poux attaquent surtout les animaux malsains, débilités, et le manque de nourriture est souvent l'une des causes qui favorisent une forte infestation.

Sur les chevaux, les vaches et les moutons, ainsi que sur les animaux sauvages, les poux sont surtout gênants vers la fin de l'hiver. Ils ne manifestent pas beaucoup d'activité en été, mais, parce qu'on ne les voit pas à cette époque, il ne faudrait pas en conclure que les animaux en sont débarrassés. Il reste assez de parasites pour se multiplier en grand nombre lorsque les conditions favorisent leur développement. Leur multiplication remarquable en hiver s'explique par plusieurs raisons, la pousse plus épaisse de poil sur l'animal les protège; de même la nourriture sèche et souvent insuffisante pendant l'hiver fait que la peau et la robe de l'animal sont sèches, moins huileuses que lorsque les animaux ont des fourrages succulents en abondance, et les poux se développent beaucoup mieux lorsque le poil est sec. En outre pendant l'été les animaux sont généralement moins serrés qu'à l'étable, dans les loges ou stalles ou pendant l'hiver', et l'entassement tend toujour's à répandre les poux.

\section{POUX BROYEURS}

Les poux broyeur's sont très petits, sans ailes, quelque peu aplatis, à corps mou dans les premières phases, mais à couverture ou à tégument plus dur que le pou suceur pendant les phases adultes. La tête est grosse relativement au corps et elle est largement arrondie sur le devant. La couleur varie de blanc à brun rougeâtre dans les différentes espèces. Les poux broyeurs, comme l'indique leur nom, ne sucent pas le sang, mais ils ont des parties buccales adaptées pour mordre ou se nourrir des particules de plumes, de poils, de squames 
et d'autres débris sur la peau de leur hôte. Ils sont assez actifs, se meuvent beaucoup plus que les poux suceurs et ces mouvements constants causent beaucoup d'irritation et d'incommodité aux hôtes. Plusieurs espèces ont de l'importance sur les animaux domestiques et tous les grands mammifères domestiques, à l'exception des chevaux et des chèvres, ont une espèce qui leur est caractéristique. Les chevaux sont affectés par deux espèces et les chèvres par trois ou plus. Les porcs ne sont pas sujets à ce fléau. Un bon nombre d'espèces se rencontrent sur les volailles, mais chaque espèce est généralement plus ou moins restreinte à un hôte particulier.

POU BROYEUR DU BEEF, Bovicola bovis L*

Les éleveurs de bestiaux désignent souvent ce pou par le nom de "petit pou rouge" pour le distinguer du pou suceur bleu, plus gros. C'est un pou assez court, à corps compact, mesurant environ un treizième de pouce de longueur. La tête est rouge; le corps blanc jaunâtre est traversé d'un certain nombre de bandes foncées très visibles. Ces poux sont parfois répandus sur tout le corps, mais généralement ils se concentrent en groupes nombreux autour de la base de la queue et sur le garrot et le cou. L'irritation intense résultant de leur présence peut porter les animaux infestés à s'enlever' par frottement le poil des parties affectées et il se produit souvent de grosses lésions qui ressemblent à la gale ou aux croûtes de la teigne tondante.

\section{LE POU BROYEUR DU CHEVAL, esp. Trichodectes}

Il y a deux espèces de poux broyeur's, Trichodectes pilosus Giebel et T. equi L.,† qui affectent les chevaux, les ânes et les mulets. Ils se ressemblent l'un l'autre et sont aussi très semblables au pou broyeur du bœuf. Les parties antérieures sont de couleur rougeâtre ou brun marron, mais le corps est jaunâtre, à l'exception

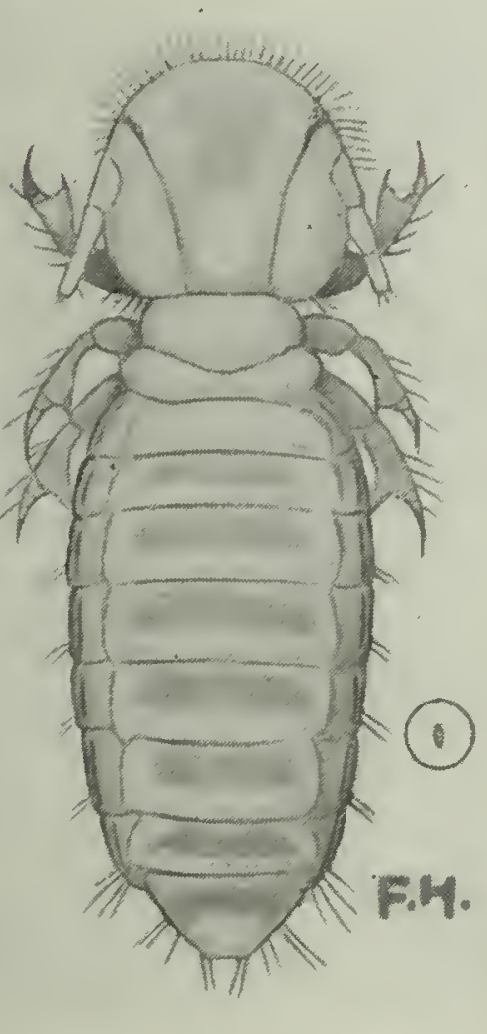

Fig. 65-Pou broyeur du cheval, Trichodectes equi L., grossi at grosseur naturelle (Original).

de quelques bandes transversales cendrées. Ils sont un peu plus gros que le pou du bœuf et mesurent environ

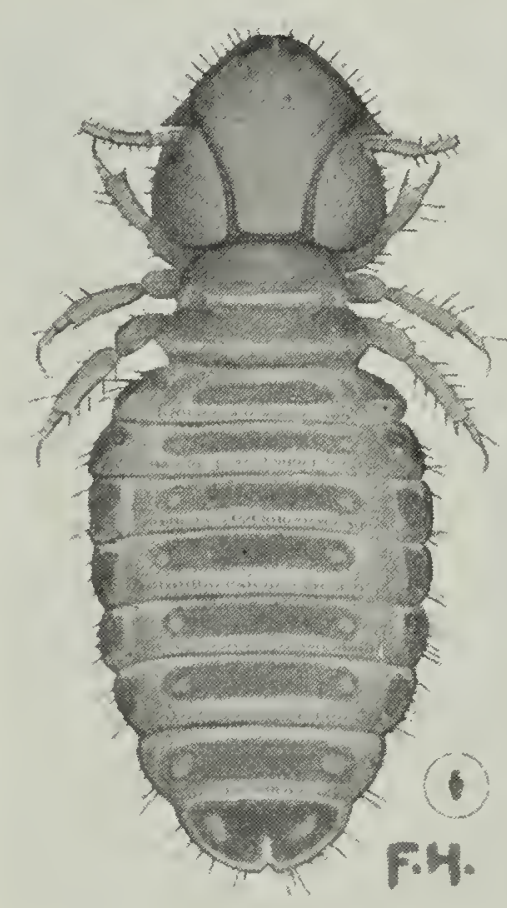

Fig. 64-Pou broyeur du bouf, Bovicola bovis, grossi et grosseur naturelle (Original). un dixième de pouce de longueur. Les parties généralement les plus infestées chez le cheval sont la région de l'encolure, surtout le long de la crinière, et la base de la queue, mais lorsqu'ils sont très nombreux, ces poux peuvent se rencontrel sur toutes les parties du corps.

Le pou commun des volailles, Menopon gallinae L., attaque parfois les chevaux quand l'écurie se trouve près des parcs à volailles.

POU BROYEUR DU MOUTON, T'richodectes ovis L.

Les éleveurs de moutons appellent souvent ce petit insecte le "pou à tête rouge" du mouton. Le corps est brunâtre pâle tandis que la grosse tête arrondie a une couleur rouge très apparente. C'est un très petit pou qui ne mesure qu'un vingtième de pouce de longueur. Il est cependant souvent plus nuisible que le pou suceur malgré sa dimension minuscule et, en cela, il diffère de la plupart des autres poux qui mordent

\footnotetext{
* Trichodectes scalaris Nitzsch. $\quad \dagger T$. parumpilosus Piaget.
} 
les animaux. Outre la démangeaison intense provoquée par la multitude de ces parasites qui rampent sur un animal, il y a aussi les dommages causés par le fait qu'ils mordent à travers les fibres de la laine. Les animaux infestés se frottent constamment contre les poteaux de clôture, etc., ils se grattent et se mordent eux-mêmes, arrachant ainsi les mèches de laine qui ont été coupées par les poux et prennent ainsi une apparence minable. Lorsqu'on voit ces mèches de laine qui se détachent de la partie extérieure de la toison, il faut toujours examiner les animaux de près pour voir s'ils ont des poux; on trouvera généralement ces derniers sur la peau ou très près de la peau. Le pou du mouton ne paraît pas être très répandu, quoiqu'il ait été signalé dans différentes parties du Canada et qu'il soit peut-être généralement distribué dans toutes les provinces. C'est un fléau sérieux en Australie et en Nouvelle-Zélande et dans les autres pays qui élèvent des moutons.

\section{POU BROYEUR DE LA CHÈVRE}

La chèvre donne parfois asile à un très grand nombre de plusieurs espèces de poux broyeurs. L'un des plus répandus et des plus communs de ces poux est le pou commun de la chèvre, Trichodectes caprae Gurlt. Cette espèce est très semblable à celles que nous venons de décrire. Il est spécialement nuisible sur les chèvres Angoras parce que le mohair si précieux peut être gravement endommagé.

\section{POUX BROYEURS DES CHIENS ET DES CHATS}

Le pou commun du chien, Trichodectes canis De Geer, est une petite espèce très large, mesurant environ un seizième de pouce; sa couleur est jaune clair. De même que chez la plupart des autres poux broyeurs, le corps porte une série de bandes cendrées. Ce pou est répandu dans le monde entier; il se rencontre rarement au Canada sur les chiens bien entretenus, mais il peut se multiplier en grand nombre sur les animaux mal soignés, et c'est un fléau sérieux dans ces conditions et une source continuelle de gêne et d'incommodité. On dit qu'il affecte spécialement les jeunes chiens. On sait que ce pou transmet le ténia aux chiens.

Il est rare que les chats soient incommodés par les poux, mais il y a une espèce, le pou du chat, Trichodectes subrostratus Nitzsch, qui se rencontre parfois sur eux. Il est à peu près de la même grosseur que les dernières espèces mentionnées, mais il diffère de la plupart des poux broyeurs par sa tête qui est un peu pointue.

\section{POUX BROYEURS DES VOLAILLES}

Ce groupe de poux est l'un des pires ennemis de toutes les catégories de volailles domestiques. Il est trop souvent la cause du mauvais état dans lequel se trouvent les poules et les autres volailles de la ferme. Les propriétaires de grands établissements avicoles n'ignorent pas en général que le succès ou l'échec de leur entreprise peut dépendre du succès qu'ils obtiennent dans la lutte contre ces parasites, mais il y a beaucoup de petites basses-cours sur les fermes ou dans les villes qui ne reçoivent pas l'attention qu'elles devraient recevoir sous ce rapport et qui deviennent extrêmement infestées. Dans ces conditions les poules paraissent être engourdies, indifférentes, et la ponte diminue.

On connaît environ une douzaine d'espèces de poux broyeur's qui attaquent les poules, mais il n'y en a que trois ou quatre qui sont des fléaux sérieux au Canada, car beaucoup des autres se tiennent principalement sur les plumes où elles ne causent que peu d'irritation.

L'une des espèces la plus répandue et peut-être la plus nuisible est le pou du corps des volailles, Menopon stramineum Nitzsch, qui mesure environ un dixième de pouce et qui est de couleur jaunâtre. En raison de sa grosseur et du fait qu'il vit sur la peau ou très près de la peau, ce pou cause une grande irritation lorsqu'il pullule. 
Une autre espèce, très répandue également dans toutes les parties du Canada, est le pou commun des volailles, Menopon gallinae L. Il n'a qu'environ la moitié de la longueur de la première espèce, mais il est presque aussi large. Sa couleur est paille clair. Ce pou rampe activement sur toutes les parties du corps, mais il se rencontre, de même que l'espèce précédente, surtout dans le voisinage de l'anus et sous les ailes.

Le pou de tête des volailles, Lipeurus heterographus Nitzsch, serait, au dire d'un grand nombre d'éleveurs de volailles, spécialement nuisible à cause de sa préférence pour la tête. On prétend que les jeunes poulets succombent rapidement lorsqu'ils sont très infestés. Ce fait est encore à confirmer cependant.

Le pou variable de la poule, Lipeurus variabilis Nitszch, est une espèce facile à reconnaître, qui mesure un seizième de pouce. C'est un pou pâle, long, maigre, à marques noires. Les plumes des ailes et de la queue sont principalement infestées.

D'autres espèces de moindre importance, comme le petit pou des poulets, Goniocotes hologaster Nitzsch, et plusieurs formes étroitement apparentées, peuvent être reconnues par leur largeur remarquable. Quelques-uns sont relativement gros, mais le premier nommé ne mesure qu'un vingtième de pouce de longueur. On

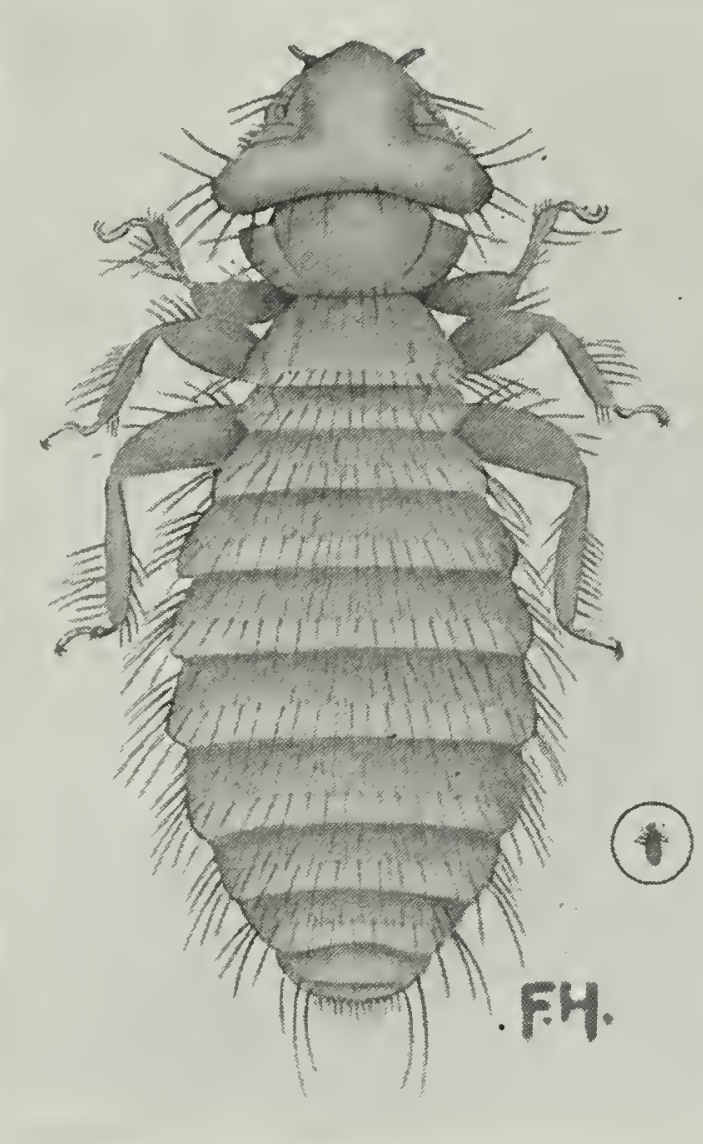

Fig. 66-Pou du corps des volailles, Menopon stramineum Nitzsch, gi\%ssi et grosseur naturelle (Original). l'appelle aussi souvent le pou duveteux.

Toutes les autres catégories de volailles, comme les canards, les oies, les dindons, les pigeons, etc., sont aussi attaquées par différentes espèces de poux broyeurs, mais la poule compte un plus grand nombre de ces fléaux que les autres volailles.

\section{VIE ET HABITUDES DES POUX BROYEURS}

Le pou broyeur a une existence entièrement parasitaire et ne quitte l'animal ou l'oiseau qui lui sert d'hôte que pour se porter sur un autre de la même espèce. Les œufs, qui sont blancs et de forme ovale ressemblent à ceux du pou suceur; ils sont attachés aux poils ou aux plumes de l'hôte. Ceux du pou commun des poulets se voient souvent en groupes nombreux autour de la base des plumes dans le voisinage de l'anus. Dans cette espèce et dans quelques autres, les œufs sont des objets très frappants, en raison de la rosette luisante d'épines qu'ils portent à l'extrémité supérieure. Ils éclosent au bout de cinq à dix jours, la période d'incubation varie suivant la température plus ou moins froide, la protection que reçoivent les hôtes et ainsi de suite. Lorsque les œufs sont enlevés de l'hôte par frottement, cette période peut durer jusqu'à trois semaines. Les poux nouvellement éclos ressemblent aux adultes, mais ils sont moins gros. De même que les adultes, ils se nourrissent de particules de poils, de plumes, d'écailles de la peau, etc., et après avoir passé par un certain nombre de mues, arrivent à maturité au bout de onze jours à deux semaines. Les poux broyeurs sont plus rustiques que les suceurs et ils peuvent vivre jusqu'à dix jours, même lorsqu'ils sont séparés de leur hôte, mais ils succombent généralement au bout d'une semaine.

\section{DESTRUCTION DES POUX BROYEURS ET SUCEURS SUR LES ANIMAUX}

Le meilleur moyen de détruire les deux espèces de poux sur les vaches, les chevaux, les moutons et les chèvres, est de baigner ces animaux à l'automne. 
pour chaque animal. La poudre de derris employée en solution de dix parties, au plus, d'un véhicule inerte, comme la fécule de maïs, est assez utile contre les deux types de poux, sur toutes les catégories de bestiaux. Si l'on emploie des poudres contenant de la naphtaline ou du pyrèthre sur les chevaux et les vaches, il est bon de recouvrir l'animal d'une couverture retenue par une courroie immédiatement après que la poudre a été appliquée, pour retenir les vapeurs.

Comme les poux se propagent rapidement par contact, surtout lorsque les animaux sont entassés, il faut prendre les plus grandes précautions pour empêcher que les troupeaux qui ont été traités et débarrassés de leurs poux, ne se contaminent au contact des animaux infestés. Un ou deux animaux pouilleux introduits dans un troupeau causent bientôt une infestation générale. Il a été constaté que les oufs ou "lentes" des poux qui sont tombés de leur hôte peuvent éclore au bout de trois semaines; on ne peut donc considérer comme propres les locaux qui ont été occupés par des animaux infestés avant qu'une période de près d'un mois se soit écoulée. Tous les poils enlevés par la tonte

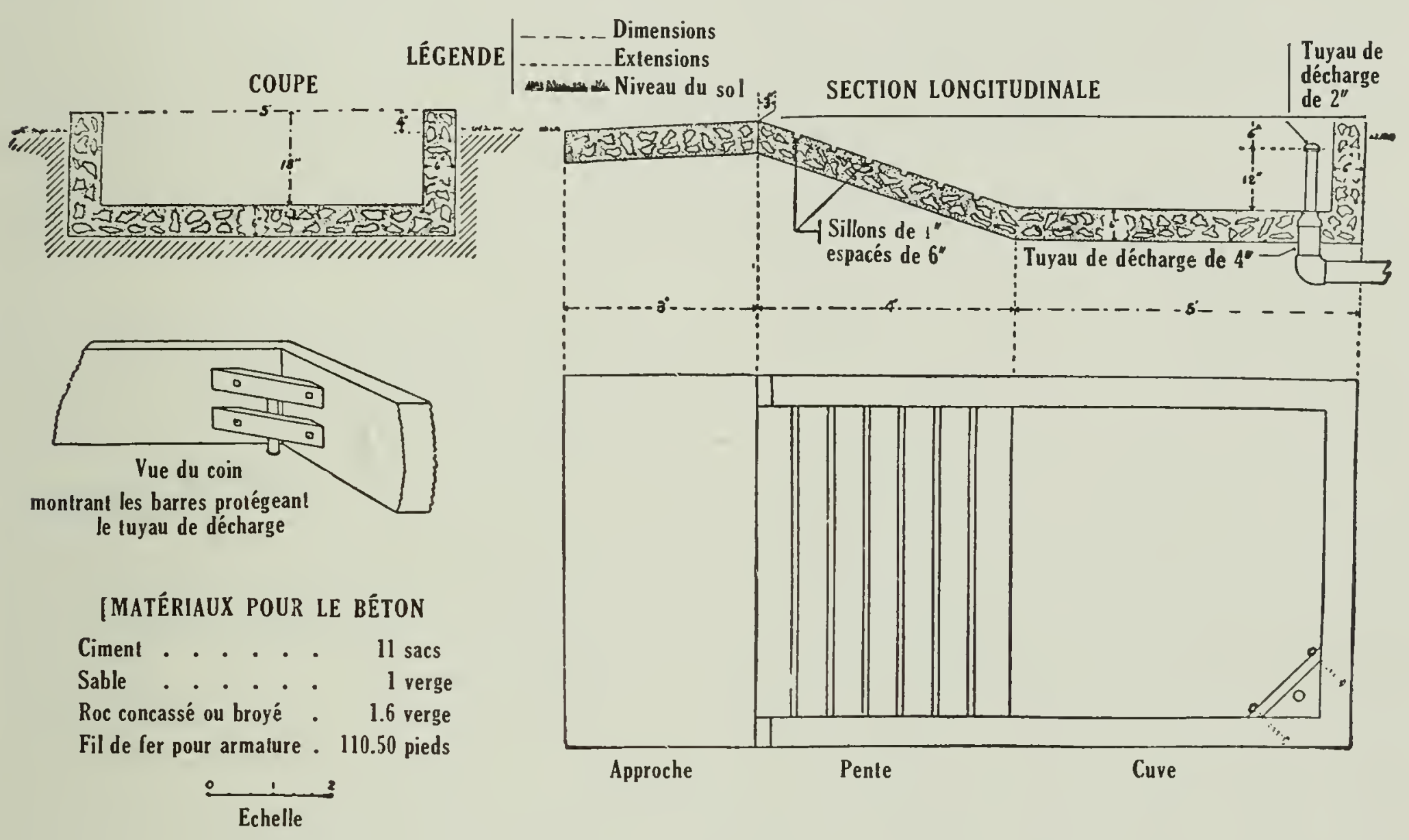

Fig. 67-Plan d'une cuve à porcs-construction de béton (d'après Imes).

des animaux pouilleux doivent être brûlés. Il faut aussi enlever la litière et le fumier des lieux infestés, et employer une quantité abondante de solution de coaltar-créosoté pour tuer tous les poux qui peuvent se trouver sur les planchers et dans les boiseries des stalles.

Quelques-uns des traitements généraux mentionnés ci-dessus sont utiles également pour détruire les poux des porcs, mais, en ce qui concerne ces derniers, le traitement le plus économique et qui a le plus d'effet est le pétrole (huile de charbon) brut. Pour un petit nombre d'animaux, on peut faire une application parfaite au moyen d'une brosse ou vadrouille (mop) à long manche, en donnant une attention spéciale aux replis de la peau dans le cou et les abajoues, aux côtés intérieurs des pattes et à toutes les autres parties des animaux sur lesquelles les poux sont les plus abondants. Un bain médicamenté, dont nous donnons le détail plus loin, est plus satisfaisant; il est même nécessaire lorsque le nombre des animaux à traiter est considérable. La cuve, qui devrait être en béton, est placée dans un endroit ombragé; la profondeur doit être suffisante pour que les animaux puissent bien s'y recouvrir quand ils s'y vautrent. En général, trois ou quatre pouces de liquide suffisent, et le bain n'a pas besoin d'avoir plus de cinq pieds carrés. Il vaut mieux laisser les porcs bien s'habituer à ce bain d'abord avec de l'eau seule, puis on ajoute de l'huile brute de 
pétrole à l'eau à raison de une à deux chopines pour chaque animal, suivant leur taille. Si l'huile est ajoutée vers le soir et que les animaux peuvent trouver beaucoup d'ombrage, il n'y a pas à craindre la formation d'ampoules sur la peau. Après que l'huile a été en place un jour ou deux, il faut égoutter le bain et le remplir d'eau propre. Une deuxième application d'huile est nécessaire au bout de deux semaines, et d'autres traitements peuvent aussi être nécessaires dans l'intervalle jusqu'à ce que les poux soient entièrement détruits.

Il s'emploie beaucoup dans certains districts de préparations à base d'huile, commerciales ou faites à la maison, pour détruire les poux des porcs, mais les meilleures de ces préparations n'ont pas beaucoup d'effet et elles ne détruisent que peu de poux, car les huiles n'atteignent pas les parties du corps où les parasites pullulent spécialement.

Quel que soit le traitement employé, on fera bien de ne pas remettre les animaux dans les parcs ou locaux qu'ils occupaient tant que l'on n'aura pas nettoyé parfaitement ces locaux. Il faut aussi enlever tout le fumier et toute la litière et les traiter avec une quantité abondante d'un bon insecticide comme une solution de coaltar-créosoté, pour tuer tous les poux qui peuvent être tombés de l'animal. Si c'est possible, il vaut mieux donner au parquet ou à la cour un repos de trois semaines; tous les poux seront morts au bout de ce temps.

On peut détruire les poux du chat ou du chien au moyen de lavages au crésol ou à la créoline dont il est question dans le chapitre sur les puces. La poudre de derris est également utile.

Destruction des poux qui affectent les volailles.-Le fluorure de sodium saupoudré dans les plumes des poules ou des autres volailles infestées de poux, donne des résultats satisfaisants, car seuls les poux broyeurs affectent les oiseaux, et le fluorure de sodium est fatal pour ces parasites. Bishopp et Woods disent qu'une application parfaite de fluorure sur tous les oiseaux d'une même bassecour détruit complètement tous les poux qui s'y trouvent. La poudre reste dans le plumage pendant quelque temps et les jeunes poux sont tués dès qu'ils éclosent et qu'ils se mettent à se nourrir. La méthode suivante est simple et économique:-On tient l'oiseau au-dessus d'une tôle ou casserole peu profonde, et l'on applique une petite pincée de la poudre à chacun des endroits suivants: la tête, le cou, le long du dos, la poitrine, au-dessous de l'anus, sur la queue, sur chaque cuisse, et une pincée sur le dessous de chaque aile étendue. Ce moyen est utile sans doute, mais il est assez laborieux; le moyen qui consiste à plonger les oiseaux dans une solution contenant une once de fluorure de sodium par gallon d'eau tiède est plus rapide, mais il ne peut être employé que par un temps chaud. Beaucoup d'aviculteurs n'aiment pas à mouiller leurs poules, mais si celles-ci ont le temps de sécher avant la nuit et que ce lavage soit effectué lorsqu'il fait chaud, il n'a pas de mauvais effets.

La méthode qui paraît être la meilleure au point de vue de la simplicité, de l'économie et de l'utilité, est celle qui consiste à enduire les perchoirs ou juchoirs dont se servent les oiseaux d'une couche très mince de sulfate de nicotine (à 40 pour cent). Les vapeurs qui se dégagent de cet insecticide lorsque les oiseaux sont sur les juchoirs, tuent les poux auxquels ils donnent asile, protègent également contre les mites et les autres parasites, ce que le fluorure ne fait pas. Des essais séparés conduits à Ottawa par C. R. Twinn, et en Colombie-Britannique par l'auteur, indiquent que la mortalité des poux est très élevée et qu'ils peuvent être complètement supprimés par ce moyen. Il faut suivre à la lettre les instructions fournies par les fabricants de cet insecticide.

Nous désirons mettre nos lecteur's en garde contre un autre genre d'ingrédients brevetés, recommandé pour la destruction des poux et des mites; ce sont certaines poudres ou tablettes que l'on met dans l'eau à boire. On prétend que ces poudres et ces tablettes, mises dans l'eau que les oiseaux boivent, les débarrassent complètement de leurs poux, mais des essais ont démontré qu'il n'en est rien. 
Quand on établit de nouvelles basses-cours, il est facile d'éviter tous les ennuis que causent les poux; de simples précautions suffisent. Si l'on a soin de ne prendre que des poussins d'incubateurs, ils n'introduiront pas de poux, et si l'on a soin également de traiter contre les poux avant de les mêler au reste du troupeau, tous les cochets et les autres oiseaux que l'on achète plus tard, on évitera complètement la présence de ces parasites tant que les oiseaux ne viendront pas en contact avec d'autres troupeaux.

\section{MITES DES ANIMAUX DOMESTIQUES ET DES VOLAILLES ACARES OU MITES À GALE}

Ces parasites blancs, minuscules, vulgairement appelés "mites", sont si petits qu'ils ne sont guère visibles sans l'aide du microscope. La plupart d'entre eux mesurent de un quarantième à un soixantième de pouce; ils sont sphériques, ovoïdes, et ont huit pattes courtes, tronquées. Les acares ou mites des follicules des poils ont une apparence très différente des autres; ils sont allongés, en forme de ver, et encore plus petits que les autres. On connaît à peu près deux douzaines d'espèces ou de variétés d'espèces d'acares ou mites affectant les animaux domestiques, et quelques-unes de ces espèces sont les pires fléaux du bétail. La gale du mouton, du cheval, du bœuf et du renard domestique cause de si lourdes pertes que la Loi des épizooties impose de fortes amendes. à ceux qui négligent de signaler les cas de cette maladie. Heureusement, les quarantaines et les règlements rigoureux appliqués avec énergie par le Service fédéral sanitaire des animaux, ont fait beaucoup pour supprimer le danger que présentent ces fléaux au Canada, et il n'a pas été signalé de cas de gale du mouton depuis plusieurs années; quant à celle du cheval et du bœuf, elle a été réduite à un très bas point, si bien que son extirpation n'est plus qu'une affaire de temps. Si la gale est soupçonnée, le plus sage est d'aviser immédiatement un vétérinaire du gouvernement, celui qui est le plus près de chez soi, car il est généralement nécessaire de faire un examen microscopique de grattures de la peau sous les croûtes des gales pour établir un diagnostic précis. Il y a en effet plusieurs affections de la peau, et notamment l'irritation causée par les poux de la vache et du cheval, qui ressemblent beaucoup à la gale.

Beaucoup des acares de la gale se ressemblent à tel point qu'il est difficile même pour les experts de les différencier les uns des autres, mais leurs habitudes varient beaucoup cependant, de même que les effets et les dégâts produits sur l'hôte. Par exemple les femelles de la vraie mite à gale, esp. Sarcoptes, s'enfoncent dans la peau en creusant de petits sillons où elles déposent leurs œufs, tandis que les mites des espèces Psoroptes et Chorioptes, vivent à la surface de la peau où l'irritation et les secrétions causées par leurs parties buccales suceuses provoquent la formation de grosses croûtes. La gale psoroptique ou gale humide peut se répandre par tout le corps, mais la forme chorioptique ou gale symbiotique ne dépasse pas généralement la base de la queue, les pieds et les pattes des animaux et montre peu de tendance à se répandre. La mite à follicules, espèce Demodex, vit profondément enfoncée dans la peau dans les follicules des poils, et certaines autres mites, notamment la mite de la gale rouge des chiens très gênante, causent une irritation intense et une infection bactérienne qui peut provoquer la chute des poils, le durcissement de la peau et l'empoisonnement général de l'organisme. Il y a une autre sorte de mites qui infeste les oreilles des chats, des chiens et des renards et qui peut causer la surdité et même la mort. Beaucoup des mites à gale qui infestent les animaux domestiques ne présentent entre elles que des différences anatomiques si légères qu'on les considère simplement comme des variétés de deux ou trois espèces, mais si elles peuvent infester temporairement d'autres hôtes que l'hôte préféré, ces infestations ne persistent pas généralement, et disparaissent assez vite.

Presque tous les types de gale des bestiaux "sont pires lorsqu'il fait froid parce que les animaux sont affaiblis par le manque de nourriture et les rigueurs 
de l'hiver. Dès que l'herbe repousse au printemps, une amélioration immédiate se manifeste dans l'état des animaux, la peau redevient normale et la maladie disparaît, mais la guérison n'est qu'apparente" (Hadwen) et la gale revient dès que les conditions favorisent son développement. Il y a presque toujours quelques mites qui survivent et celles-ci, placées dans des conditions favorables, se multiplient avec rapidité. Ce sont là des facteurs qui ont une importance considérable au point de vue du traitement et de l'extirpation de la gale. L'irritation intense qui résulte de la gale n'est pas causée par le mouvement des parasites, mais surtout par les substances toxiques qu'ils sécrètent.

Etant donné la gravité plus ou moins grande de l'affection causée par les différentes mites, rous passons sommairement en revue ici les différents types qui se rencontrent dans les animaux domestiques, en donnant les symptômes les plus apparents et les caractéristiques par lesquels on peut assez aisément différencier les maladies, au moins dans les premières phases. On peut vérifier ces considérations en examinant les grattures prises sur les bords des croutes.
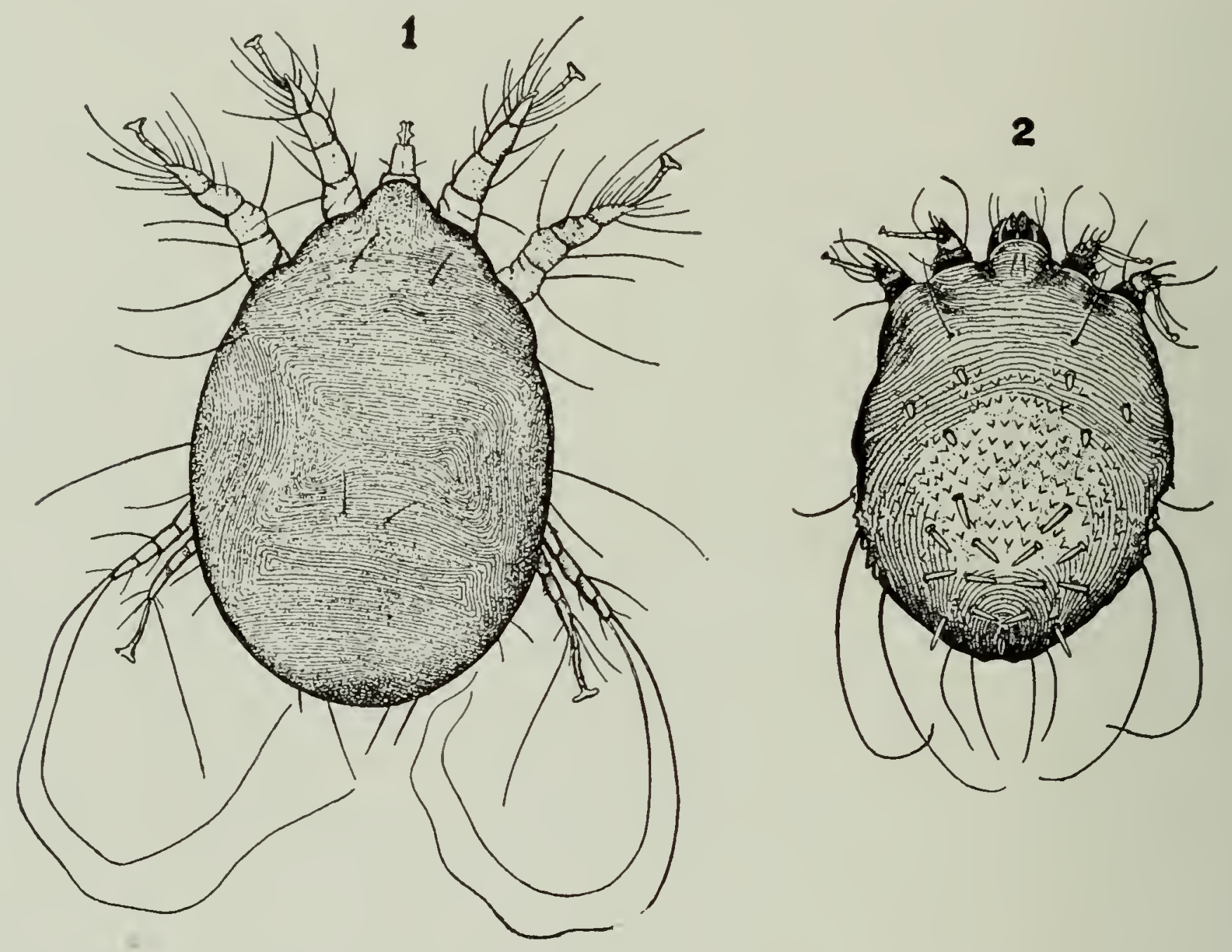

Fig. 68-1, acare ou mite de la gale humide ou psoroptique; 2, acare ou mite de la gale sèche ou sarcoptique (d'après Hilton).

\section{GALE DU BGEF}

Il y a quatre espèces de gale qui affectent les bêtes bovines et la plus répandue est la gale commune ou gale humide, causée par Psoroptes communis bovis Hering, une espèce qui ne s'enfonce pas dans la peau, mais qui vit à la surface de la peau. L'attaque peut commencer sur une partie du corps recouverte d'une couche épaisse de poils, mais elle se manifeste généralement en premier lieu sur le garrot, le cou et la racine de la queue; les mites partent de ces endroits pour se répandre sur tout le reste du corps. Dans les premières phases de la gale, les symptômes marqués ne sont pas très visibles. La première infestation, quand les mites sont peu nombreuses, ne produit que peu de croûtes. Cependant même les animaux légèrement infestés ont une tendance à gratter et à frotter les parties infestées, et l'état échevelé des poils donne une indication de la maladie. Si l'on constate la présence de petites papules exsudant 
du sérum au centre d'une région humide, rouge, on devrait y prendre des grattures au moyen d'un couteau à lame émoussée et un examen de ces grattures à la loupe ou sous un microscope puissant révélera probablement la présence des mites (acares) blanches minuscules. On les voit d'autant mieux si l'on a soin de les réchauffer légèrement et de les mettre contre un fond noir. Le nombre de mites augmente énormément en quelques semaines; de grandes régions du corps perdent leur poil et se recouvrent d'un sérum exsudant des endroits où les mites se sont nourries. Ce sérum sèche, formant de grosses croûtes ou gales jaunâtres. La démangeaison est intense; l'animal se gratte et se frotte constamment pour essayer de se soulager. La peau se durcit, se plisse et si les progrès de la maladie ne sont pas enrayés, une émaciation très marquée se produit et l'animal peut mourir.

La gale sèche du bœuf, causée par Sarcoptes scabiei bovis Robin, est beaucoup moins répandue que la gale humide ou psoroptique, mais on dit qu'elle est plus gênante et plus difficile à guérir que cette dernière parce que les mites

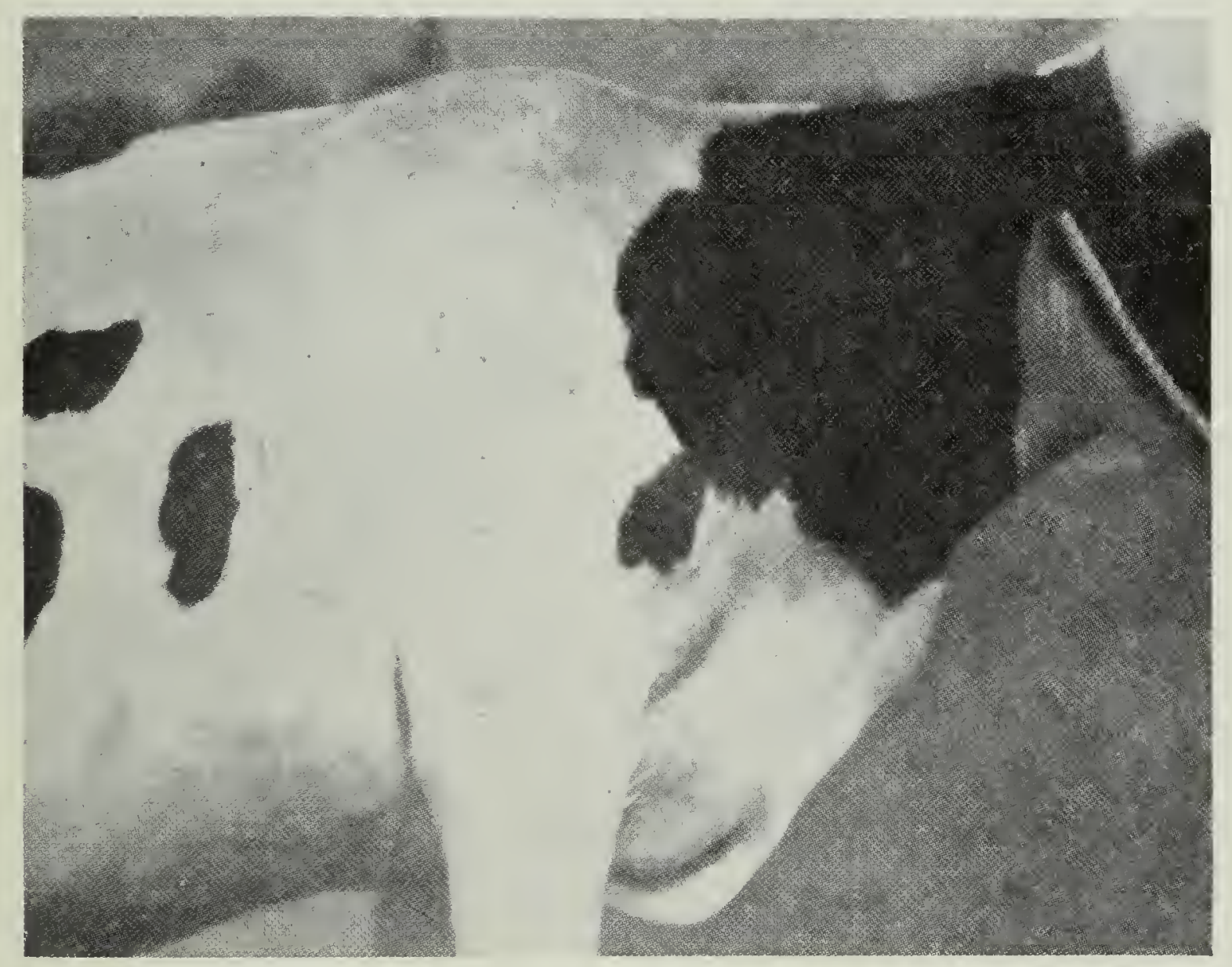

Fig. 69-Gale folliculaire de la vache; à noter les taches' sur les épaules (d'après Hadwen).

s'enfouissent dans la peau et passent une bonne partie de leur temps à l'abri dans des galeries minuscules où elles pondent leurs œufs. Isa gale sèche diffère de la gale humide par le fait qu'elle se rencontre généralement sur les parties du corps où les poils sont courts, par exemple dans l'entre-cuisses, sur le poitrail et dans les replis autour de la base de la queue, mais une fois qu'elle s'est établie, elle peut envahir toutes les parties du corps. De petites papules ou des cônes de peau font leur apparition et se recouvrent de petites granules jaunâtres de sérum séché. Plus tard la peau prend une apparence sèche, croûteuse. Le grattage et le frottage constants peuvent provoquer la formation de grosses croûtes et il n'est pas facile alors de distinguer entre la gale humide et la gale sèche sans faire un examen des mites.

La gale de la queue, causée par le Chorioptes bovis Gerlach, est assez rare chez les bêtes bovines. Les mites vivent sur la surface de la peau et ont des caractères en commun avec la mite de la gale commune, mais la maladie reste généralement localisée sur la queue ou sur les pattes. 
La gale foliculaire est la forme la plus rare et se rencontre assez rarement. Les très petites mites en forme de ver, Demodex follicularum bovis Stiles, pénètrent dans les follicules des poils et s'enfoncent profondément dans la peau.

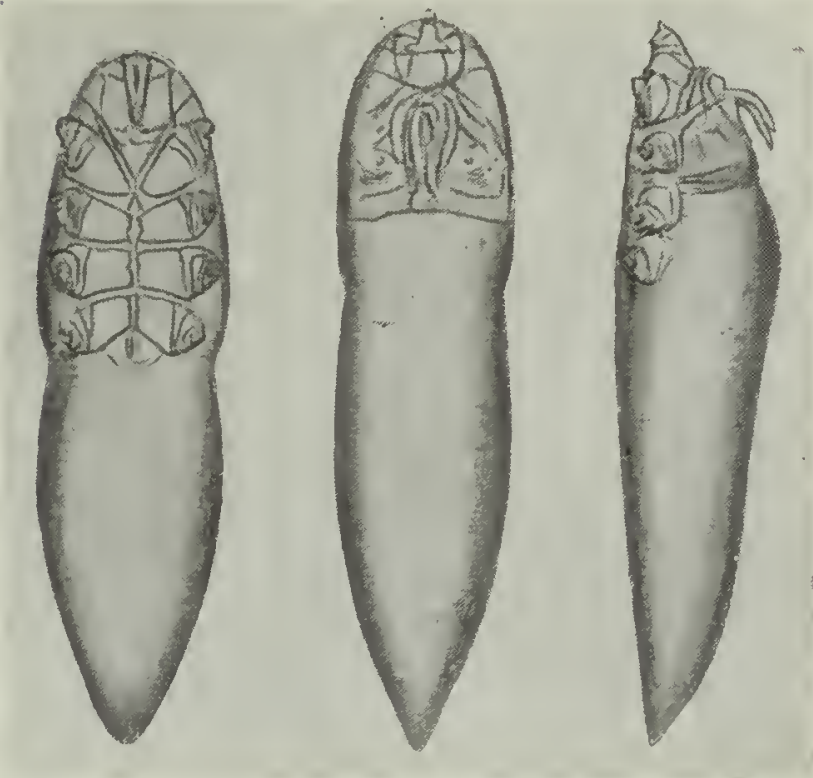

Fig. 70-Mite de la gale folliculaire. Demodex bovis Stiles, très grossie (d'après Hirst). Il se forme de petites tumeurs rondes, dont la grosseur varie depuis celle d'un grain de millet à celle d'un pois; ces tumeurs sont remplies de matière caséeuse. Elles apparaissent généralement en premier lieu sur l'épaule et sur le cou. Les larves d'hypodermes peuvent aussi former de petites papules semblables, mais pas dans les endroits que nous venons de mentionner. Ce type de gale peut abîmer tellement la peau qu'elle en réduit beaucoup la valeur pour le tannage. On considère que la maladie est à peu près incurable. Cependant on peut en retarder beaucoup les progrès au moyen de bains réguliers. Heureusement le développement est lent et le danger de propagation d'un animal à l'autre est beaucoup moindre que dans les autres types de gale. On fera bien cependant de se débarrasser des animaux gravement infestés. Ce type de gale n'est pas sur la liste des maladies que la Loi des Epizooties fait une obligation de déclarer.

\section{LA GALE DU CHEVAL}

Il n'y a pas eu depuis quelque temps d'épidémies sérieuses de gale du cheval au Canada, et du reste la maladie n'a jamais été très répandue dans les districts agricoles les plus éclairés, où les chevaux reçoivent de bons soins et sont tenus en bon état. Les animaux à demi-sauvages, errant en liberté sur les herbages et qui parfois s'affaiblissent beaucoup à cause du manque de nourriture, sont beaucoup plus exposés à souffrir de la gale que les animaux bien soignés et bien nourris.

On rencontre trois types de la maladie chez les chevaux, les ânes et les mulets, mais le type sarcoptique ou gale sèche, causé par Sarcoptes scabiei equi Gerlach, est le plus nuisible et le plus gênant de tous. L'encolure, les épaules et la tête sont généralement les parties attaquées en premier lieu. La maladie ne se propage que lentement dans les premières phases, mais plus tard elle se répand assez rapidement en plaques irrégulières et finit par affecter toute la surface du corps. De petites vésicules se forment et le sérum qui en sort forme de petites croûtes sèches. Le frottement continuel augmente ces croûtes, si bien qu'elles s'agrandissent et finissent par couvrir de grandes régions du corps; elles sont teintées de sang; la peau devient sèche, squameuse, parcheminée, et les parties affectées se dénudent plus ou moins. Il n'est pas rare de voir l'animal mourir, quand on n'a rien fait pour enrayer les progrès de la maladie.

La gale psoroptique ou gale humide, aussi appelée "roux vieux" provoquée par le Psoroptes communis equi Hering, est moins nuisible que la première et c'est cependant aussi une maladie très grave. Toutes les parties les plus velues du corps peuvent servir de point de départ à l'infection, mais la gale fait généralement sa première apparition à la bsse de la crinière, sur la tête, sous la touffe de devant, ou à la base de la queue. L'aspect frotté, ou rompu du poil à ces endroits est généralement le premier signe apparent de trouble. On voit une éruption de petits boutons qui contiennent du liquide, et les croûtes qui se développent restent humides et diffèrent sous ce rapport des croûtes sèches formées dans la gale sarcoptique. Non traitée, la maladie se propage sur toutes les parties du corps, la peau s'épaissit, se ride et les poils se détachent par plaques. 
La gale du pied ou de la queue, qui est causée par Chorioptes bovis equ (Hering)* ne se rencontre que sur la queue et les jambes. On dit que les gros chevaux, comme les Clydesdales, chez lesquels la partie inférieure des jambes de derrière est recouverte d'une couche abondante de poils, sont plus sujets à être infestés que les races plus légères. Cette maladie est assez rare au Canada. Les animaux infestés frappent du pied et se frottent les jambes l'une contre l'autre. Les mites de cette gale ont à peu près les mêmes habitudes que celles de la mite psoroptique et les lésions produites sont aussi très semblables, mais la maladie reste localisée et se traite assez aisément.

\section{GALE DU MOUTON}

La gale humide du mouton ou "rogne" est la plus grave de toutes les maladies causées par les mites de la gale et, en l'absence d'un bon traitement, la mortalité est très élevée. Aucun cas de cette gale n'a été signalé au Canada

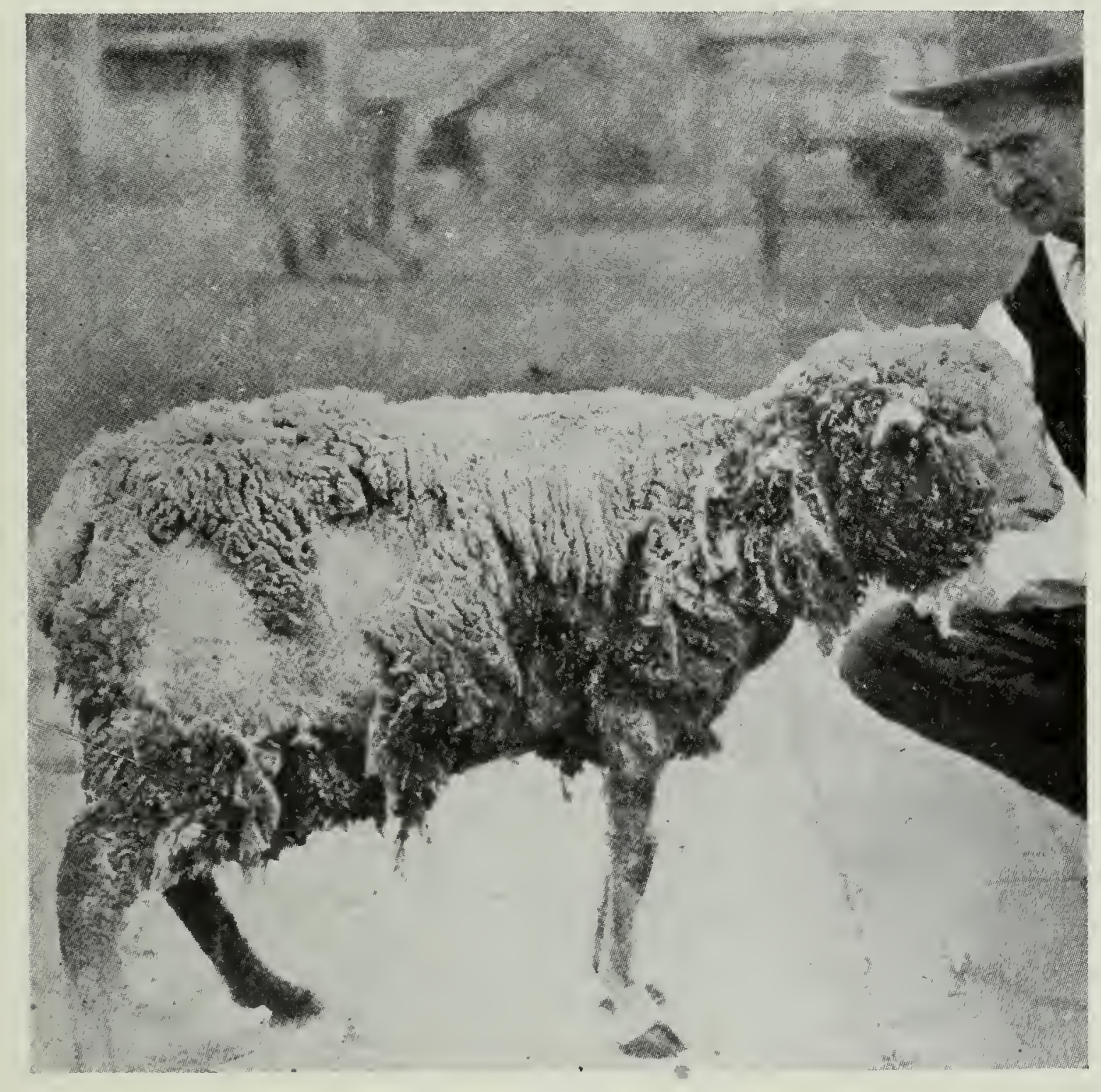

Fig. 71-Mouton affecté de la mite à gale, Psoroptes communis ovis Hering (d'après Imes).

depuis quelques années, les foyers qui existaient autrefois ayant été complètement supprimés. On prétend que les mouflons sauvages des Montagnes Rocheuses s'infestent parfois en se nourrissant sur les mêmes herbages que les moutons domestiques galeux. La maladie est causée par la mite de la gale du mouton, Psoroptes communis ovis Hering, une mite qui vit sur la surface de la peau. Les premiers symptômes passent généralement inaperçus à cause de l'épaisseur de la toison; ils consistent en une région rougie et enflammée, exsudant du sang et du sérum. Les parties supérieures et médianes du corps sur le garrot et le dos sont généralement les premières attaquées. Il y a démangeaison de la partie affectée, le mouton se frotte et se gratte continuellement,

\footnotetext{
* Chorioptes equi Gerlach.
} 
et ces indications de même que les ouvertures dans la toison devraient toujours être considérées comme suspectes. Le sérum exsudé sèche, formant de petites croûtes qui s'élargissent plus tard et couvrent de grandes régions. Le mouton se mord et se frotte constamment pour soulager l'irritation, la laine tombe, laissant de grandes parties du corps à nu, la peau s'épaissit et présente de nombreuses plaies galeuses.

Les deux autres types de gales du mouton, la gale de la tête ou gale sarcoptique, et la gale du pied, ne se rencontrent pas très souvent et ils ont beaucoup moins d'importance que la gale humide. Le premier est causé par une mite fouilleuse, Sarcoptes scabiei ovis Megnin, qui attaque la tête généralement dans les parties non revêtues de laine, et provoque la formation de nodules durs, qui plus tard se recouvrent de croûtes. Les éleveurs l'appellent "noir museau". La gale du pied, causée par Chorioptes communis Verh. var ovis, une mite de surface, n'affecte que les parties inférieures des pattes, au-dessous de la laine. Elle cause une grande irritation, mais elle ne se propage que peu dans le troupeau et son traitement est assez facile.

\section{GALE DE LA CHÈVRE}

On rencontre quatre types différents de gale chez la chèvre, mais cette maladie n'a causé jusqu'ici que peu de pertes dans les districts où l'on élève des chèvres au Canada. La forme la plus commune est la gale sèche ou sarcoptique causée par Sarcoptes scabiei caprae Fürstenburg. Elle commence généralement à la tête et aux oreilles, mais la maladie n'est pas limitée à ces endroits, comme dans le cas du type semblable de gale chez les moutons; elle se propage sur le corps et les membres. Il se forme des croûtes sèches et la peau s'épaissit, se plisse et se dénude. L'irritation est intense, les animaux s'affaiblissent et peuvent mourir. Le type de gale humide ou psoroptique, Psoroptes communis caprae, qui est limitée à l'intérieur de l'oreille, est assez rare et ne paraît causer parfois que peu de dégâts. Elle peut cependant provoquer la surdité. W. Dwight Pierce, dans une étude sur les problèmes des chèvres laitières en Californie, déclare que 50 pour cent des animaux examinés au cours de son enquête étaient infestés et que chez beaucoup d'entre eux les oreilles étaient recouvertes de mites. ${ }^{*}$ On dit que la gale chorioptique, Chorioptes caprae Gerv. et Benedin, commence sur le côté du cou et du garrot et qu'elle peut se propager sur tout le corps. Elle est assez peu commune. Dans quelques pays d'Europe où il s'élève des chèvr'es, on dit que la gale folliculaire, Demodex caprae Railliet, est assez répandue et nous la mentionnons à cause de la difficulté que l'on éprouve à en découvrir les premières phases et de la possibilité qu'elle soit introduite sur les animaux importés. Des tumeurs arrondies de la grosseur d'un pois, contenant de la matière grise, se produisent sous la peau et déprécient beaucoup le cuir pour le tannage. La maladie est presque incurable.

\section{GALE DU PORC}

La gale sarcoptique causée par la mite, Sarcoptes scabiei suis Gerlach, est le seul type assez répandu et qui ait de l'importance chez les porcs. Il y a aussi la gale folliculaire. Demodex phylloides Csokor, qui affecte parfois ces animaux. La gale commune commence généralement sur la tête dans le voisinage des yeux, du nez ou des oreilles et elle se propage de là sur le cou et l'épaule; elle peut à la longue recouvrir tout le corps. Les parasites tracent des sillons dans la peau; les premiers symptômes sont de tout petits boutons recouverts de granules de sérum séché. Le poil est hérissé et, dans les dernières phases, de grandes étendues de la peau sont dénudées. Les parties affectées ont d'abord une apparence sèche, écailleuse, gris bleu, puis en raison du grattage et du frottement constants par l'animal, ces lésions se rompent et les croûtes restent

\footnotetext{
* Etat de la Californie, Min. de l'Agric. Pub. spéc. 22, p. 10, 1922.
} 
humides. Dans les cas avancés, la peau est généralement très ridée et durcie. La maladie est très grave et les animaux très infestés se portent très mal.

\section{GALE DU CHIEN, DU RENARD ET DU CHAT}

Les chiens et les renards sont sujets à être infestés par plusieurs mites à gale, qui causent des effets très semblables sur leurs hôtes. La gale sèche ou sarcoptique, causée chez le chien par Sarcoptes scabiei canis Gerlach, et chez le renard par Sarcoptes scabiei vulpis Railliet, commence généralement sur la tête, mais elle peut se répandre sur tout le corps au cours d'un mois. Les mites s'enfoncent dans la peau et de petits points rouges se produisent. Il en sort du sérum et des gales se forment. La démangeaison intense qui en résulte porte l'animal infecté à se frotter et à se gratter continuellement. La peau se dénude et se recouvre de grosses plaies galeuses. Si la maladie n'est pas enrayée, elle entraîne généralement la mort au bout de trois mois. Cette gale qui se rencontre assez souvent chez les chiens est très rare dans les renarderies canadiennes et c'est fort heureux parce qu'elle enlève toute valeur à la fourrure de ces précieux animaux.

La gale de l'oreille chez les chiens, les renards et les chats est causée par Otodectes cynotis Hering, une mite un peu plus grosse que la plupart des autres espèces et qui vit à la surface de la peau, à l'intérieur des oreilles. Les tout petits trous qu'elle fait en se nourrissant causent beaucoup d'irritation, mais les infestations modérées ne paraissent pas être remarquées. Lorsque l'invasion est forte, il en résulte une irritation marquée, l'animal se frotte et se gratte les oreilles, et lorsque la partie médiane de l'oreille est envahie, des symptômes très marqués de trouble peuvent se développer; la tête est portée d'un côté et l'animal tourne sur lui-même. L'infection bactérienne peut être suivie de la surdité ou même de convulsions et de la mort. On dit que cette maiadie est très répandue dans les renardières canadiennes; heureusement, elle se combat aisément au moyen de simples remèdes.

La gale folliculaire causée par Demodex canis Leydig, et que l'on appelle ordinairement "gale rouge", est une maladie très grave du chien, mais sa présence sur les renards n'a pas été constatée. Les mites allongées, vermiformes, vivent dans les couches profondes de la peau. Les premiers symptômes sont généralement des taches rouges sans poils, autour des yeux, des coudes ou des hanches. Ces régions dépilées s'étendent généralement, et la peau prend plus tard une apparence morte et grisâtre. Il y a moins d'irritation qu'avec la gale sarcoptique, mais l'animal peut se gratter de temps à autre. Il r'ésulte presque toujours une inflammation bactérienne et des vésicules pustuleuses. La peau s'épaissit et l'animal s'affaiblit graduellement et meurt. Le cours de la maladie n'est pas rapide et peut durer une année et plus. La plupart des vétérinaires refusent de traiter les cas de ce genre; et l'incertitude de la guérison est telle qu'il vaut mieux détruire les animaux affectés.

Les chats sont parfois affectés par une gale de tête causée par une mite que l'on appelle Notoedres minor Fürst. var cati Hering. L'attaque commence souvent dans le cou et s'étend jusqu'aux oreilles, au front et dans le voisinage des yeux; il est rare que le corps soit affecté. Des croûtes grises caractéristiques et un plissement de la peau sont visibles dans les dernières phases.

\section{GALE DU LAPIN}

Le lapin est affecté par quatre gales différentes, dont deux qui sont causées par les mites de surface, Psoroptes cuniculi Delafond et Chorioptes cuniculi Zürn; ces dernières se produisent dans l'oreille, et deux autres sur la face et le corps. Celles-ci sont causées par des mites fouilleuses. Sarcoptes scabiei cuniculi Gerlach, et Notoedres minor cuniculi Railliet. La gale de l'oreille est généralement limitée à la surface intérieure de l'oreille; il se forme des 
croûtes brunâtres à cet endroit. Les animaux affectés se secouent les oreilles et se les grattent avec les pattes de derrière. Dans les cas avancés, lorsque la partie médiane et intérieure de l'oreille est envahie, la tête peut pencher d'un côté. Parfois les jeunes animaux sont pris de convulsions et meurent.

Les deux autres variétés de gale sont très

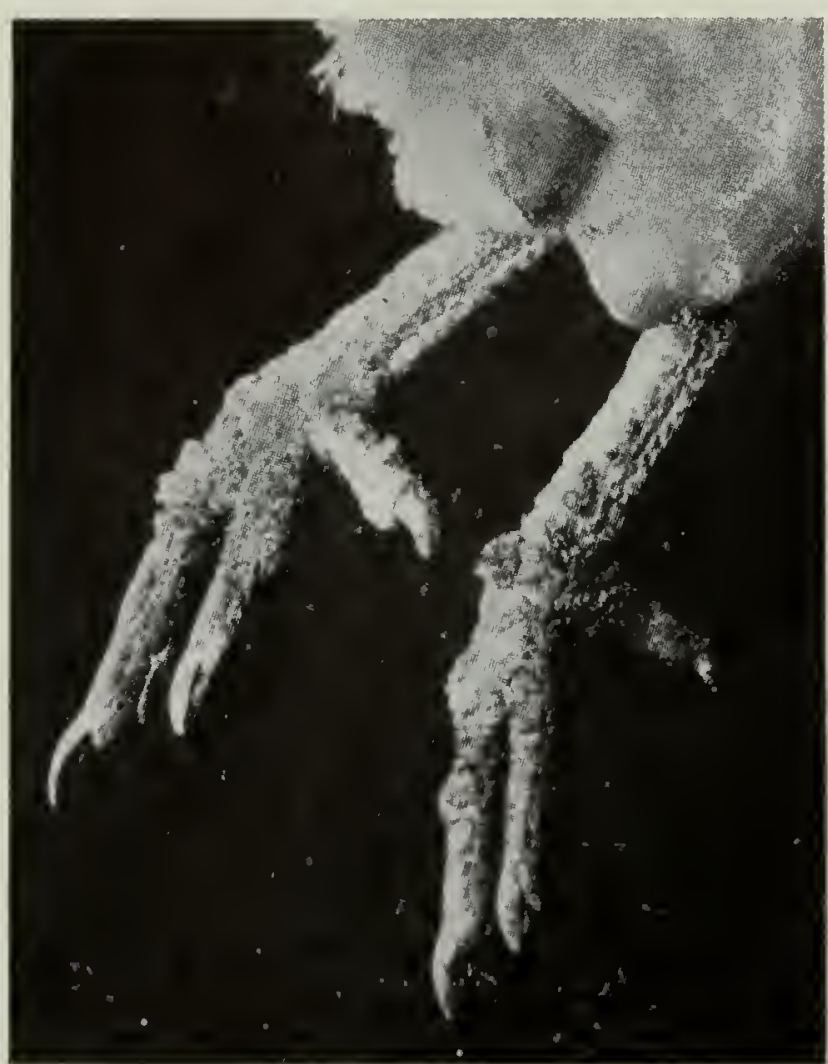

Fig. 72-Gale des pattes des volailles causée par la mite, Cnemidocoptes mutans Robin (d'après Storrs). semblables et, dans les deux cas, les mites s'enfouissent dans la peau. La région du nez est généralement la première à être affectée, mais le menton, le front, les oreilles et les pattes sont envahis, et la maladie peut se propager plus tard à toutes les autres parties du corps. Des croûtes caractéristiques apparaissent sur les parties infestées et le frottement et le grattage continuels peuvent être suivis de la formation de plaies ouvertes.

\section{GALES DES VOLAILLES}

Gale des pattes.-Un état pathologique assez commun chez les poules et d'autres oiseaux domestiques et sauvages, comme le dindon et la gelinotte, est appelé "gale des pattes", en raison les boursouflures écailleuses et des incrustations singulières qui se forment sur les pattes. Cette maladie est le résultat des attaques d'une mite fouilleuse, presque ronde, aplatie, Cnemidocoptes mutans Robin, très semblable aux différentes mites Sarcoptes déjà mentionnées. Les oiseaux boitent et leur santé devient sérieusement affectée, si bien que la mort peut s'ensuivre si la maladie n'est pas maîtrisée. On dit que la crête et le cou sont parfois affectés aussi bien que les pattes.

Mites déplumeuses.-Ces petites mites ovales, Cnemidocoptes gallinae Railliet, attaquent le peau de l'oiseau près de la base des plumes. L'irritation qui en résulte est si intense que les oiseaux s'arrachent les plumes, laissant la peau dénudée par plaques. Le voisinage de la queue est généralement la première partie attaquée, mais plus tard d'autres parties deviennent infestées. On sait que cette mite se rencontre aussi au Canada, mais jusqu'ici très peu de dommages ont été signalés qui soient attribuables à ce parasite.

\section{CYCLE ÉVOLUTIF ET HABITUDES DES MITES ACARES DE LA GALE}

Pour décrire la vie de ces parasites, il suffira de donner un exemple typique de l'une des espèces fouilleuses et de l'une de celles qui vivent à la surface, car la plupart des espèces comprises dans ces deux groupes sont assez étroitement apparentées et ont un cycle évolutif à peu près semblable. Les mites folliculaires du poil ont des habitudes et un cycle un peu différents, mais elles sont beaucoup moins importantes que les autres; aussi, nous n'en ferons pas une discussion détaillée, faute de place. Pour presque toutes les mites de la gale, le cycle de la vie, de l'œuf à l'adulte, est complété dans un temps très court lorsque les conditions sont favorables. Les générations se succèdent à intervalles assez rapides, et l'on estime que la progéniture d'un couple de mites peut produire un total de 1,500,000 individus en trois mois. Cette puissance prolifique extraordinaire indique la nécessité d'appliquer les moyens répressifs avec le plus grand soin possible.

Une forme typique de la mite fouilleuse est la mite du porc Sarcoptes scabiei suis Gerlach. Les femelles fécondées s'enfouissent dans les couches superficielles de la peau, creusant des galeries ou sillons tortueux. Elles préfèrent 
les parties les moins velues du corps. Ces mites produisent des sécrétions toxiques d'une nature extrêmement irritante, et ce sérum s'écoule de l'ouverture de la galerie. Des œufs de forme ovale, qui paraissent être plutôt gros pour la dimension de la mite, sont pondus séparément ou par groupes, à courts intervalles, dans les galeries pendant une période d'environ deux semaines.

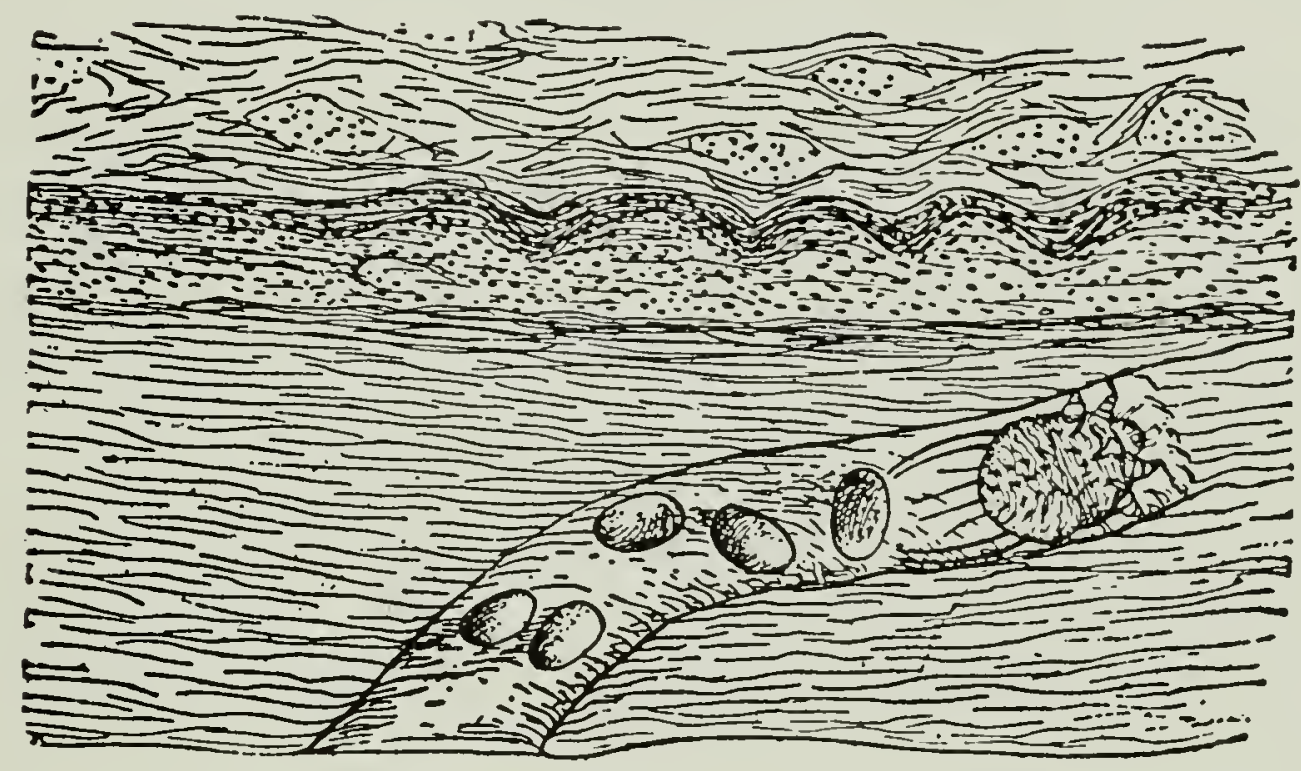

Fig. 73-Croquis des sillons creusés dans la peau par une mite sarcoptique (d'après Hirst).

La mite meurt à l'extrémité des galeries après avoir déposé de dix à vingt œufs. Ces œufs éclosent au bout de trois à dix jours et il en sort des mites larvaires à six pattes, qui subissent plusieurs mues avant d'arriver à maturité. Elles sortent ensuite de leurs galeries, errent à la surface de la peau, s'accouplent, et les femelles percent de nouvelles galeries dans lesquelles elles se mettent à pondre des oufs au bout de dix jours environ. Les mites mâles ont une vie relativement plus courte. Il se produit ainsi de nouvelles générations à intervalles d'environ deux semaines.

Les mites fouilleuses ne se propagent pas aussi rapidement d'un animal à l'autre, que les mites de la surface, mais elles sont assez contagieuses lorsque les animaux sont entassés. Les premières lésions se voient au bout de deux à quatre semaines de la date d'infection. Les phases actives des mites ne vivent généralement pas longtemps lorsqu'elles sont séparées de leur hôte, mais les œufs peuvent n'éclore qu'au bout d'une semaine ou plus.

Types de surface.--Mite de la gale humide ou "rogne" du mouton, Psoroptes communis ovis Hering. Les mites de ce groupe (Psoroptes, Chorioptes) ne pénètrent jamais dans la peau; elles vivent à la surface ou sous les croûtes de gale formées. Elles préfèrent les parties du corps qui sont bien protégées par les poils. Pour se nourrir, elles percent la peau avec leurs parties buccales courtes, et elles injectent dans le trou une substance toxique, très irritante. Le sérum qui suppure de ce trou forme une croûte, petite d'abord, mais qui s'étend graduellement à cause de la préférence que les mites manifestent pour la peau saine. En outre, les différentes mites émigrent de nouveau et créent d'autres foyers d'infection sur différentes parties du corps. Les œufs sont pondus quelques-uns à la fois, par petits groupes, sur la peau ou à la base des follicules de la laine, et chaque femelle pond ainsi de quinze à vingt-quatre œufs au cours de sa vie. L'éclosion se produit au bout de quatre jours environ, et les nouvelles mites n'ont que trois paires de pattes. Elles arrivent à maturité au bout d'environ une semaine, après plusieurs métamorphoses. L'accouplement a lieu, et la ponte commence après trois ou quatre jours. L'intervalle d'une génération à l'autre est d'environ deux semaines. Les mites ne peuvent se multiplier loin de leur hôte, mais elles ont plus de vitalité que l'espèce sarcoptique dans ces conditions et peuvent survivre deux ou trois semaines. Dans 
les conditions de laboratoire, elles sont parfois restées en vie pendant deux mois loin de leur hôte. Ce détail est important, car il indique une possibilité de réinfection sur les pâturages et les parquets qui avaient été contaminés par des animaux affectés.

\section{TRAITEMENT DE LA GALE CHEZ LES ANIMAUX DOMESTIQUES ET LES VOLAILLES}

On voit par le mode de vie et les habitudes des groupes principaux des mites à gale, que certaines espèces sont beaucoup plus difficiles à combattre que d'autres. Cependant, les mêmes principes généraux répressifs s'appliquent à tous les groupes, et il est essentiel, pour léussir, que toutes les mites soient détruites, jusqu'à la dernière. Le seul moyen pratique de supprimer la plupart des mites de la gale est de baigner l'animal en le plongeant complètement dans une solution médicamentée appropriée. Il est rare qu'un seul traitement suffise, et pour certains types de gales, une succession de bains à certains intervalles est nécessaire. Comme les mites de la gale se plaisent surtout sur les animaux peu vigoureux, il est toujours bon de bien nourrir les animaux, pour que le traitement appliqué ait plus d'efficacité.

Le traitement de la gale chez les chevaux, les vaches, les moutons et les chèvres.Bien employés, tous les traitements r'éguliel's de chaux soufrée ou de nicotine ou de coaltar-créosoté sont utiles contre les mites de la gale. Lorsque le nombre des animaux à traiter est considéräble, le bain de chaux soufrée est peutêtre le meilleur marché de tous. On peut faire le mélange soi-même à la maison; les quantités à employer sont les suivantes:

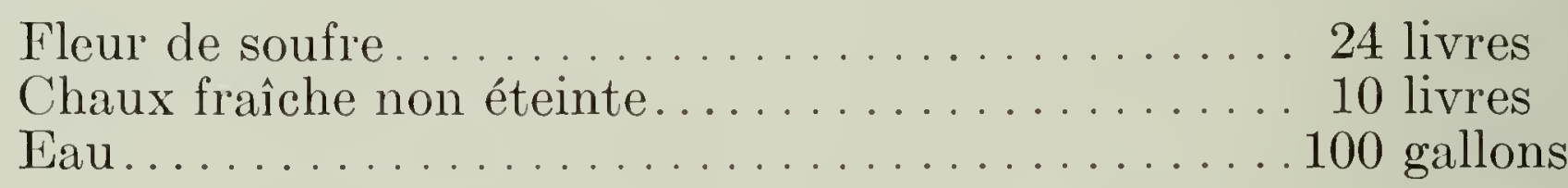

On fait éteindre la chaux et on en fait une pâte, puis on ajoute le soufre que l'on mélange parfaitement en ayant soin de rompre toutes les mottes. Cette pâte est ajoutée à trente gallons d'eau bouillante et bouillie pendant deux heures; il faut la remuer fréquemment pendant ce temps. On laisse le mélange reposer toute la nuit et on enlève la partie liquide au siphon, sans troubler le sédiment qui est au fond. On ajoute au liquide une quantité suffisante d'eau pour faire 100 gallons et la solution est prête à être employée dans le bain. Il est nécessaire qu'elle soit chaude et la température doit être maintenue entre $105^{\circ} \mathrm{F}$. et $110^{\circ} \mathrm{F}$. pendant le bain. On prendra les précautions nécessaires pour éviter que le sédiment ne se mélange à la solution.

Dans l'emploi des bains commerciaux de chaux soufrée ou des autres bains commerciaux que nous venons de mentionner, on suivra fidèlement les instructions des fabricants. Quelle que soit la solution dont on se sert, il est nécessaire tout d'abord de dégager toutes les croûtes ou gales en frottant avec une brosse raide, tandis que les animaux sont dans la solution, pour que le liquide puisse bien pénétrer dans toutes les crevasses qui logent des mites. On tient les animaux dans le bain pendant deux minutes et on les y plonge à deux reprises différentes.

Deux bains suffisent généralement pour détruire les mites des gales humides et symbiotiques, mais il en faut quatre ou plus pour les mites de la gale sèche, qui sont plus résistantes. Les intervalles entre les bains doivent être de dix à quatorze jours pour les deux premiers types de gale et de six à dix jours pour le derniel.

Il est bon de tondre le poil des chevaux et des vaches avant d'appliquer le traitement; le bain a aussi plus d'effet sur les moutons lorsque ceux-ci sont tondus. Quand bien même on ne noterait que quelques cas de gale dans un troupeau, il est nécessaire de traiter tous les animaux, car tous ceux qui sont 
venus en contact avec les sujets infestés peuvent donner asile à quelques mites et pourraient développer la gale s'ils n'étaient pas traités, quand bien même ils ne présenteraient à ce moment aucun symptôme d'infection.

Le traitement à la main peut être employé quand les animaux à traiter sont peu nombreux et qu'ils sont dociles. On tond le poil, on lave la peau avec du savon et on la frotte soigneusement avec le mélange que voici:

Fleur de soufre.

2 livres

Huile de goudron de pin................8 onces

Huile de graine de lin crue............. 1 gallon

On fait chauffer ce mélange, sans le faire bouillir, et on l'applique chaud. On le laisse une dizaine de jours, puis on l'enlève par un lavage et on répète l'application. Ce traitement est utile également pour tuer les poux.

Le traitement de la gale du pied est facile. Il suffit de faire passer les animaux infectés dans des auges profondes, remplies d'une solution curative, ou encore de traiter les animaux avec l'onguent qui précède; cet onguent est utile également pour le "noir museau" ou la gale sèche du mouton. Il est très utile pour les chèvres, qui sont des animaux réfractaires et difficiles à traiter.

Dans toutes tentative d'extirpation de la gale, un détail très important est le nettoyage des locaux qui ont logé les animaux infestés. Nous avons vu que les animaux peuvent se réinfester dans ces locaux aussi bien que sur les champs qui ont porté des animaux galeux. On considérera donc ces champs comme dangereux pendant au moins un mois ou deux et l'on se gardera bien d'y mettre des animaux. Toute la litière sera enlevée des étables et des autres bâtiments, et brûlée au moment du premier bain. On enlèvera également le fumier que l'on mettra dans un endroit hors de la portée des animaux. Après ce nettoyage général, il est bon de laver les planchers et les boiseries avec un fort désinfectant ou une solution appropriée. Un très bon moyen est de mélanger un bon désinfectant-insecticide avec un lait de chaux et de l'appliquer en pulvérisation sur les boiseries. L'acide carbolique dilué à 5 pour cent ou le créosol dilué à 2 pour cent sont utiles sous ce rapport. Il existe aussi beaucoup de bons produits commerciaux que l'on emploiera dans la dilution recommandée par les fabricants.

Traitement de la gale du porc.-Le traitement recommandé contre le pou du porc est utile également contre la gale de cet animal; on peut aussi se servir des bains et des autres méthodes mentionnés pour les chevaux et les bovins. Le lavage d'huile brute est économique et efficace, et un bain est généralement suffisant pour la gale. Quand on se sert d'une solution de chaux soufrée, quatre bains sont nécessaires à intervalles d'une semaine environ. La température doit être maintenue entre $95^{\circ} \mathrm{F}$. et $100^{\circ} \mathrm{F}$. et l'on tient les animaux trois minutes dans le bain. La chaux soufrée est, dit-on, sans effet sur le pou du porc. Il faut nettoyer les locaux et les désinfecter de la manière indiquée dans le premier chapitre et éviter de se servir pendant au moins six semaines des parquets qui ont été occupés par des porcs galeux.

Traitement de la gale chez les chiens, les renards, les chats et les lapins.Dans toute tentative d'extirpation de la gale chez ces animaux, une précaution toujours importante est de donner une attention spéciale au régime alimentaire et de tenir les animaux en aussi bon état physique que possible. Les moyens employés pour combattre la gale du corps et de la tête consistent à tondre le poil et à laver avec de la chaux et du savon vert, après avoir enlevé les croûtes et les gales avec une brosse. Le lendemain on applique un onguent médicamenteux sur le quart de la surface du corps de l'animal, on traite un autre quart le jour suivant et ainsi de suite jusqu'à ce que toute la surface de la peau ait été couverte. On attend ensuite trois ou quatre jour's, après quoi on lave l'animal à nouveau avec du savon et de l'eau, et l'on répète ce traite- 
ment jusqu'à ce que la peau soit complètement guérie et que toute démangeaison ait disparu. L'un des onguents les plus simples et les plus efficaces est le suivant:

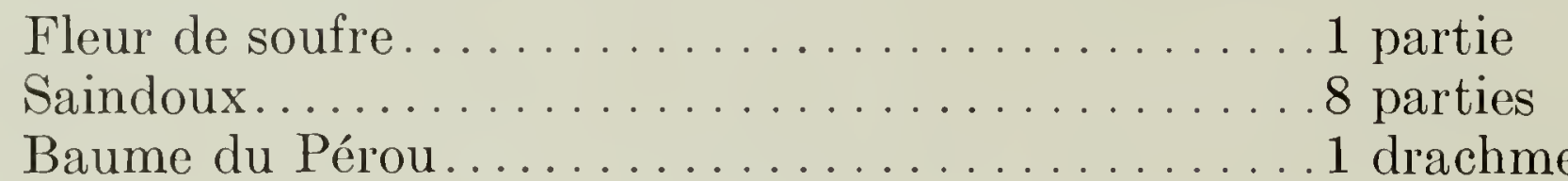

Ce traitement est bon pour les renards, mais comme la propagation de cette grave maladie est toujours à craindre, il vaut mieux, quand le nombre d'animaux affectés est peu considérable, les détruire et brûler les carcasses, en faisant suivre par un nettoyage et une désinfection parfaite des bâtiments. On laissera sans les utiliser pendant quatre mois au moins les enclos qui ont été occupés par des animaux infestés. Si l'on décide d'essayer de conserver des renards d'un grand prix, on s'adressera à un vétérinaire compétent, qui indiquera les mesures à prendre.

Si la gale folliculaire du chien est tant soit peu avancée, il vaut mieux ne pas essayer de traiter l'animal mais de le détruire. Si le chien est d'un grand prix et que l'on désire le sauver, on fera mieux de s'adresser à un vétérinaire.

La gale auriculaire (de l'oreille) se guérit facilement sur ces animaux, à condition de suivre soigneusement le traitement que voici. On prend 1 pour cent de crésol, 1 pour cent d'acide carbolique ou de créosote que l'on ajoute à la glycérine. Pour les renards on recommande des parties égales de teinture d'iode et de glycérine. Pour les mites des oreilles sur les chèvres, un onguent de fleur de soufre dans de l'huile douce est économique et efficace. Dans tous les cas, il faut toucher l'intérieur de l'oreille avec un tampon de coton, tenu au moyen de pinces, et que l'on mouille au préalable avec la solution prescrite. Avoir soin de ne pas irriter le tambour de l'oreille. On enlève ensuite soigneusement avec un tampon la matière et les détritus qui restent dans l'oreille, et on fait une deuxième application de la solution. On répétera ce traitement au bout de sept jours pour détruire toutes les mites qui peuvent être sorties des œufs qui étaient là à l'époque du premier traitement. Les enclos, les loges, etc., occupés par des animaux affectés seront parfaitement nettoyés, lavés avec une solution de coaltal'-créosoté ou un autre insecticide approprié, pour prévenir toute réinfestation

Volailles.-Le traitement de la gale des pattes chez les poules ou les autres volailles est simple; il consiste à tremper les pattes dans l'huile de charbon brute ou un mélange de parties égales d'huile de charbon et d'huile de lin crue. L'huile de charbon seule n'est pas aussi efficace. Il faut avoir soin de ne pas imprégner d'huile les parties charnues ou les plumes. Certains aviculteurs sont d'avis que ce traitement est un peu trop rigoureux; ils préfèrent la méthode plus laborieuse qui consiste à tremper les pattes dans de l'eau savonneuse chaude pour amollir les écailles ou les incrustations et à appliquer ensuite un onguent composé d'une partie de soufre et neuf parties de saindoux. Certaines autorités prétendent que le meilleur remède est de l'essence de carvis mélangée avec du saindoux, dans une proportion d'une partie d'essence pour quatre parties de saindoux. Pour prévenir la contamination, on isolera les oiseaux malades des sujets sains et on pulvérisera les juchoirs dans le poulailler avec de l'huile brute ou l'un des désinfectants commerciaux de coaltar émulsifié.

Le bain est utile également contre la mite déplumeuse; on ajoute un gallon d'eau, deux onces de fleur de soufre et une demi-once de savon à linge. S'il y a des poux, il faut ajouter au mélange qui précède, $\frac{3}{4}$ d'once (une cuillerée à soupe comble) de fluorure de sodium. Ce traitement est utile également pour la mite du Nord qui est mentionnée plus loin. Le bain se donne de la même façon et il exige les mêmes précautions que pour le traitement contre le pou broyeur des volailles, alors que les volailles sont plongées dans une solution de fluorure. 


\title{
LE DERMANYSSE DES POULAILlERS OU POU DES VOlAILlES, Dermanyssus
}

\author{
Gallinae L.
}

Le dermanysse des poulaillers, vulgairement appelé "pou des volailles", ou "mite des volailles", est incontestablement le pire fléau des volailles au Canada, et il est tellement répandu que presque tous ceux qui gardent des poules le connaissent. Lorsqu'il pullule, ses fientes donnent aux planches du poulailler un aspect de "sel et poivre". Le pou des volailles, qui se cache dans les fentes pendant le jour est un petit objet rouge ou grisâtre, de la grosseur d'une tête d'épingle lorsqu'il est repu. Il a quatre paires de pattes modérément longues. A jeun, sa couleur est grisâtre, mais lorsqu'il est gorgé de sang, il devient rouge foncé. Les œufs minuscules, elliptiques, sont blancs et luisants. Cette espèce n'est pas un parasite permanent comme la mite de la gale; pendant une bonne partie du temps, elle vit loin de son hôte et ne visite les oiseaux que pour se repaître de sang au moyen de ses parties buccales, pointues et suceuses. Elle est essentiellement nocturne et se cache pendant le jour dans les fentes et les fissures où ses œufs sont pondus. Au cour's d'un intervalle qui varie de six à quarante-huit heures après s'être repue de sang, la femelle pond de trois à sept œufs et elle continue à pondre de temps à autre après s'être nourrie, jusqu'à ce qu'elle ait pondu deux ou trois douzaines d'œufs. Ces oufs éclosent au bout de deux jours et donnent naissance à des poux de couleur pâle qui se nourrissent de sang entre chaque mue. Le développement est rapide, le cycle de la vie peut ne pas durer plus d'une semaine lorsque le temps est chaud. Ces parasites, qui se multiplient surtout dans les journées très chaudes de l'été se montrent spécialement gênants dans les parties les plus sèches du pays. Lorsqu'ils sont nombreux, ils peuvent grandement incommoder les volailles et il en résulte souvent une diminution anormale de la ponte. Les volailles constamment tourmentées et sucées par ces parasites deviennent engourdies, inertes; la couleur pâle de la crête indique la perte desang. Il n'est.

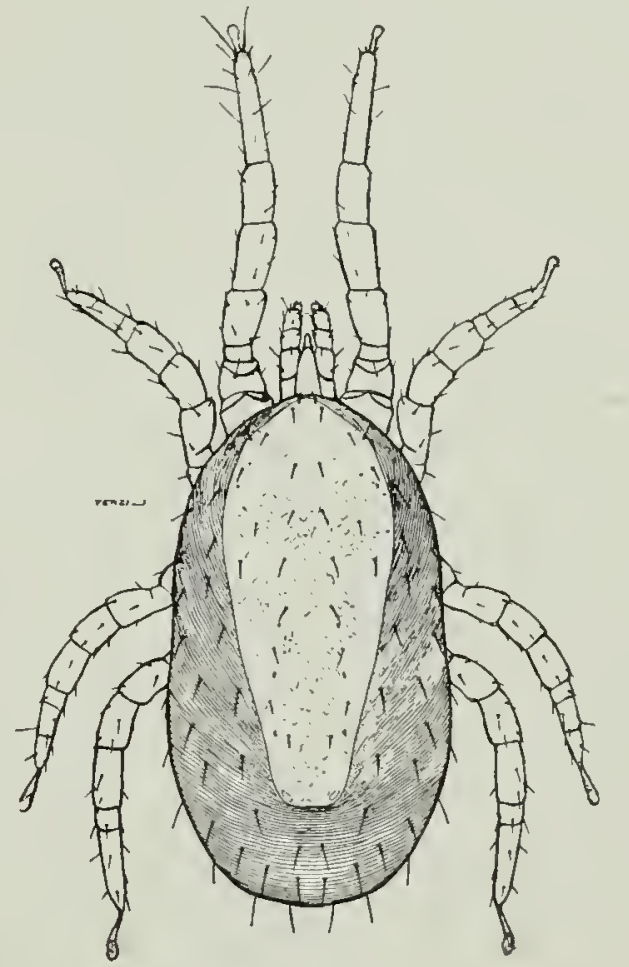

Fig. 74-Le dermanysse des poulaillers ou pou des volailles, Dermanyssus gallinae L.. (d'après Hirst). pas rare de voir des poules couveuses mourir à la suite d'attaques particulièrement fortes. Un détail important au sujet du traitement est la longévité remarquable de ces poux, même quand ils n'ont pas d'occasion de se procurer de la nour'riture; on connaît des poulaillers vides qui sont restés infestés de poux pendant quatre mois.

On prétend que le sulfate de nicotine (au titre de 40 pour cent), recommandé pour les poux ordinaires des volailles, est utile également contre le dermanysse, mais comme ces poux dermanysses sont des parasites des locaux plutôt que des volailles, il faut aussi les détruire dans les endroits où ils se cachent, dans les fentes des poulaillers, et le meilleur moyen de le faire est de pulvériser parfaitement les locaux avec des substances huileuses. Une brosse à blanchissage peut être employée dans les petits poulailler's. Il se vend beaucoup de mélanges commerciaux pour cela, mais l'une des substances les meilleur marché est une tasse de créosote mélangée avec un gallon d'huile usagée. On prétend cependant que les matériaux les plus efticaces sont certains préservatifs du bois qui contiennent de l'huile d'anthracène. L'action de ces mélanges dure plusieurs mois et réduit les risques de réinfestation. Avant de commencer à pulvériser, il est bon d'enlever toutes les planches non clouées, le fumier et les débris, et de sortir également tous les juchoirs pour les gratter. Ces juchoirs de même que les nids ne devraient jamais être fixés solidement avec des clous; il faut qu'ils soient mobiles pour pouvoir s'enlever. On réduira autant que possible les fentes et les fissures dans ces bâtiments, car c'est dans ces fentes 
que les poux se réfugient. C'est un avantage que d'avoir un bon éclairage dans le poulailler. Certains aviculteurs suspendent leurs juchoirs au moyen de fils de fer attachés au toît, et ce dispositif protège beaucoup les volailles contre les poux. Lorsque les poulaillers sont débarrassés de leurs poux, on aura soin d'éviter d'y faire entrer les caisses dans lesquelles on a reçu des oiseaux achetés, car elles pourraient réinfester les locaux.

\section{AUTRES ESPẼCES DE MITES DES VOLAILLES}

On rencontre parfois sur les volailles au Canada plusieurs autres espèces de mites suceuses du sang comme la mite du Nord, Liponyssus sylviarum C. \& F., et aussi une autre espèce appelée Liponyssus canadensis Banks, mais jusqu'ici ces mites ne paraissent avoir que peu d'importance. La première est assez généralement répandue, elle offre un intérêt particulier par le fait que ses habitudes diffèrent de celles du dermanysse. C'est un parasite permanent qui passe toute sa vie sur le corps de l'hôte, les oufs sont déposés dans les plumes et c'est là qu'ils éclosent. Elle ressemble beaucoup au dermanysse, mais elle est beaucoup plus petite. Le traitement consiste à plonger les volailles dans un bain de soufre et d'eau savonneuse, comme pour la mite déplumeuse.

La mite à sac d'air, Cytoleichus nudus Vizioli, est très commune au Canada et on la trouve dans les voies respiratoires, les poumons, etc. On ne connaît pas de traitement contre cette mite, la seule chose à faire est de tuer et de brûler les oiseaux affectés.

La mite du tissu connectif, Laminosioptes cysticola Vizioli, est une forme singulière qui habite les tissus et ses cadavres forment des granules blanches, calcaires dans les tissus connectifs sous la peau des oiseaux. Il ne semble pas que ces mites fassent le moindre tort à leur hôte, mais elles offrent de l'intérêt par le fait que les granules sont parfois confondues avec les symptômes de la tuberculose.

\section{TIQUES OU LOUVETS}

On connaît dix-huit espèces de tiques (aussi appelées louvets) au Canada et il est tout probable que d'autres seront découvertes. Peu d'entre elles heureusement, offrent de l'importance au point de vue économique, et cinq seulement méritent d'être considérées comme fléaux des animaux. Il y en a une sixième, cependant, dont il est fait mention ici parce que c'est la plus abondante et la plus répandue de toutes les espèces de tiques et qu'elle propage des maladies.

Les tiques adultes sont des créatures à huit pattes, mesurant à jeun un peu moins d'un quart de pouce. Elles sont aplaties et ont une ressemblance superficielle avec la punaise commune. Les sexes sont dissemblables en ce sens que les mâles ont tout le dos recouvert d'une plaque dure, tandis que cette plaque est beaucoup plus petite dans la femelle et couvre moins de la moitié de l'extrémité antérieure. La tique femelle repue a une apparence très différente, elle se gonfle beaucoup, prenant la forme d'un œuf, et ressemble à une fève gris bleuâtre d'un demi-pouce ou plus de long. Les deux sexes s'attachent à la peau au moyen d'une espèce de dard barbu, l'hypostome, par lequel ils aspirent le sang de leur hôte. Les tiques n'ont pas d'autre nourriture que le sang des mammifères, des oiseaux et des reptiles, qui leur est nécessaire pour compléter leur développement, mais beaucoup d'entre elles sont extraordinairement rustiques et peuvent vivre deux ans ou plus sans nourriture. La vie compliquée des différentes espèces présente des différences remarquables. Cependant, toutes les espèces ont quatre métamorphoses: l'œuf, la larve à six pattes, la nymphe et l'adulte; les deux dernières phases se ressemblent et possèdent huit pattes. Pour beaucoup de tiques, trois hôtes séparés sont nécessaires pour compléter leur développement, la tique tombe après chaque repas de sang pour se transformer en la phase suivante; ces espèces sont appelées 
tiques à trois hôtes. Dans une au moins de nos espèces les plus communes la tique ne tombe pas pour muer, mais elle reste sur l'hôte original à partir de la larve jusqu'à la phase adulte; c'est ce que l'on appelle la tique à un hôte. Toutes les tiques abandonnent l'animal qui leur sert d'hôte pour pondre leurs œufs. Beaucoup d'espèces ont une préférence marquée pour une espèce d'animal; les unes n'attaquent que certains gros animaux dans toutes leurs phases, tandis que d'autres, qui se bornent à attaquer les petits animaux pendant qu'elles sont dans la phase de l'œuf et de la nymphe, préfèrent, lorsqu'elles sont adultes, attaquer les animaux domestiques ou sauvages de plus grosse taille. Quelques espèces ont des préférences et elles se rencontrent sur toutes sor'tes d'hôtes différents. Les tiques sont extrêmement nombreuses dans les régions tropicales, où elles constituent un très grand fléau. Cependant, même dans les pays tempérés comme le Canada, elles offrent encore une importance économique considérable. Les animaux très infestés de tiques s'affaiblissent, s'émacient et peuvent mourir. On a constaté une diminution d'une pinte de. lait par jour dans la production du lait chez les vaches laitières infestées de tiques. On sait également que plusieurs espèces transmettent des maladies. sérieuses de l'homme et des animaux domestiques.

LA TIQUE A PARALYSIE (Dermacentor andersoni Stiles)*

Cette espèce est aussi désignée par le nom de "tique à fièvre" ou "tique. à fièvre (Spotted fever) des Montagnes Rocheuses". Très souvent, on l'appelle.

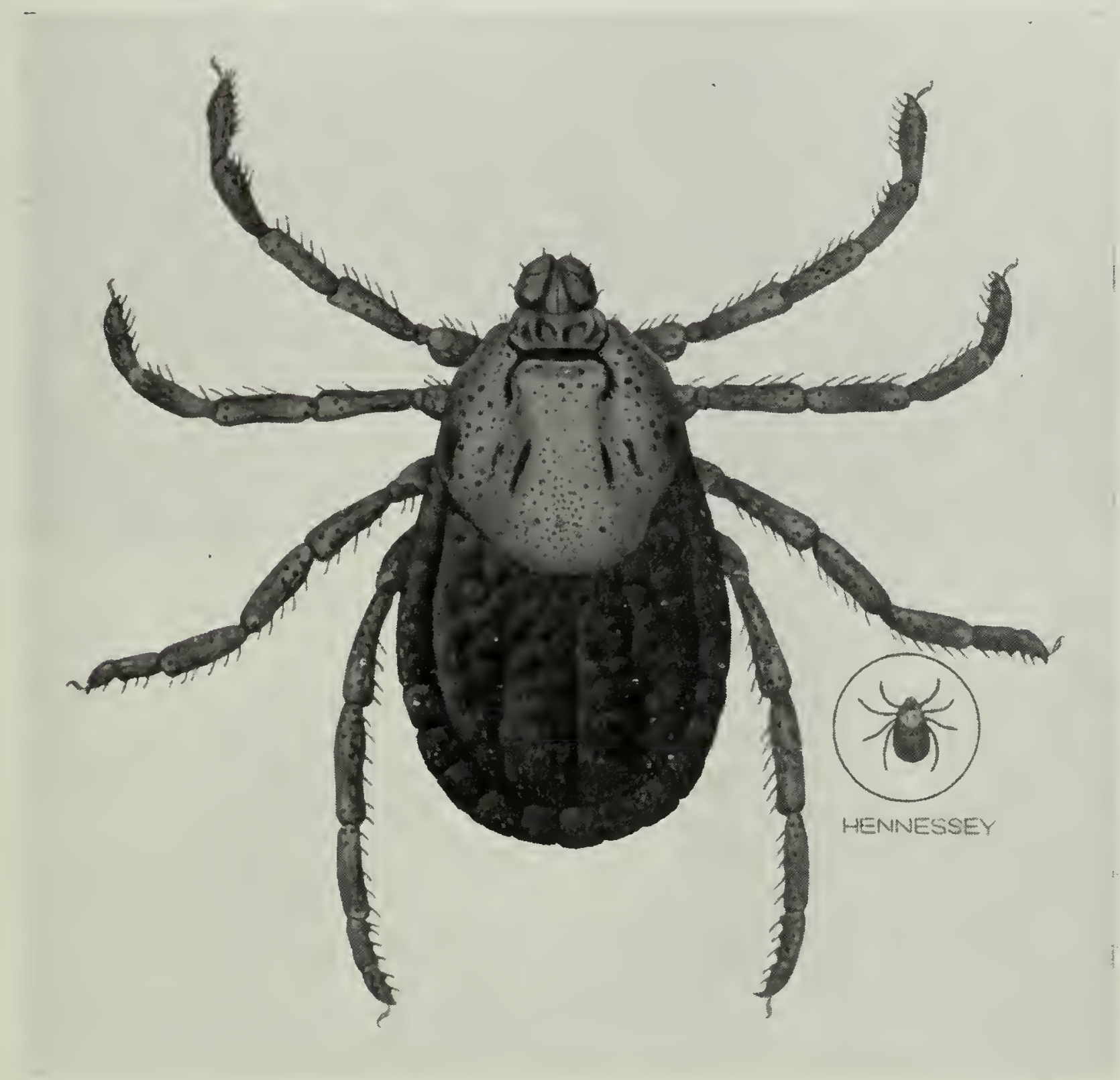

Fig. 75-La tique à paralysie, Dermacentor andersoni Stiles, femelle, grossie et grosseur naturelle (Original).

aussi "tique des bois", mais ce nom induit en erreur, car il s'applique aussi à des tiques entièrement différentes, habitant d'autres districts, et il donnerait.

\footnotetext{
${ }^{*}$ D. Venustus Banks (synonyme).
} 
à croire que cette tique n'habite que les ter'es boisées, tandis qu'en réalité, elle se rencontre rarement dans les forêts et pullule souvent dans les étendues recouvertes d'armoise, de saules ou de broussailles. Sauf une exception encore douteuse, c'est la seule tique qui soit incriminée dans les cas de paralysie chez l'homme ou les animaux domestiques sur ce continent, et c'est aussi cette espèce qui attaque le plus souvent l'homme dans l'ouest de l'amérique du Nord. Le corps, la tête et les pattes des tiques femelles sont d'une couleur rouge brun foncé, et le bouclier est blanc, traversé de petites bandes courbes, de couleur rouge, de chaque côté du centre. Les mâles sont d'un blanc grisâtre et portent aussi un certain nombre de marques irrégulières gris-bleu foncé.

Cycle évolutif et habitudes.-L'hiver se passe sous forme de nymphe ou sous forme d'adulte sans nourriture; les deux sexes hivernent sans nourriture. Les

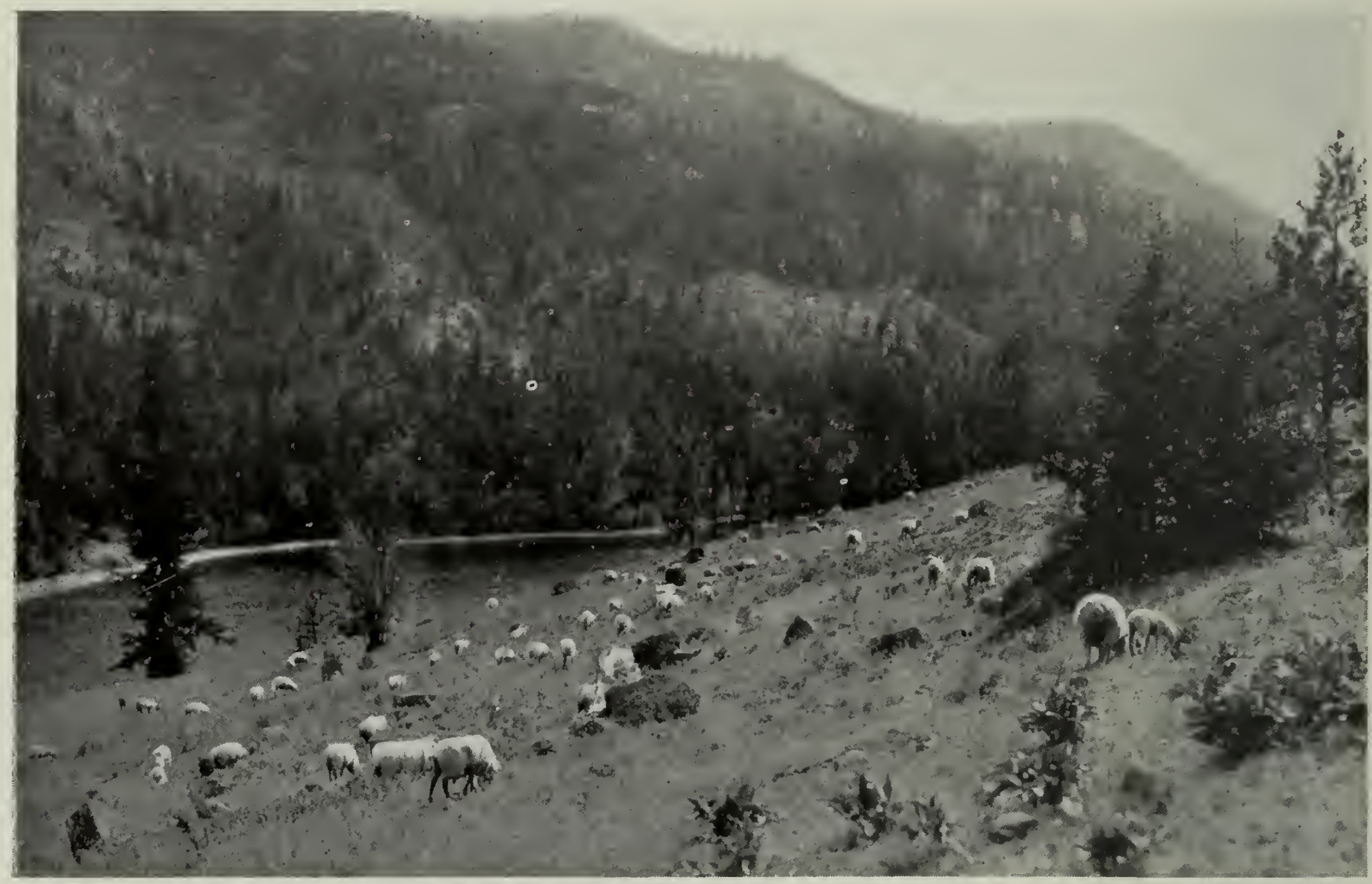

Fig. 76-Moutons au printemps sur pâturage de flanc de colline où les tiques pullulent (Original).

tiques adultes se réveillent aux premières journées chaudes du printemps (généralement vers la fin de mars); elles sortent des endroits où elles s'étaient cachées pendant la période d'inertie et grimpent jusqu'à la pointe de rameaux morts ou d'autres végétaux, où elles attendent le passage d'un animal. Elles peuvent attendre ainsi jusqu'en juin si elles ne réussissent pas à se trouver un hôte plus tôt, mais l'arrivée des chaleurs de l'été porte les adultes à se chercher un abri, d'où elles ne sortent pas avant le printemps suivant. On en a vu quelquesunes répéter ce procédé quatre années de suite. Lorsqu'elle attend sur un végétal, la tique adulte manifeste beaucoup d'agitation au moindre dérangement; elle se tient les pattes étendues, prête à saisir tout gros animal qui pourrait passer à proximité. Lorsqu'elle a trouvé un hôte, elle grimpe généralement sur le dos de l'animal, s'attache principalement d'un côté de l'échine ou sur le dos de la tête. On les rencontre aussi parfois sur le fanon et le poitrail des vaches, et très souvent sur le ventre et entre les jambes de derrière des chevaux. L'accouplement a lieu sur l'hôte, sur lequel les tiques femelles restent fixées de une à deux semaines avant de se gorger complètement. C'est pendant la dernière partie de l'engorgement, quand la tique se nourrit très rapide- 
ment, que la paralysie peut être provoquée chez l'animal. Les femelles repues: tombent à terre et se réfugient pour se protéger sous les pierres ou les débris, où chacune d'elles pond environ 6,500 œufs. Comme la femelle repue est engourdie et ne sort pas de son refuge, tous les oufs sont pondus en une masse au même endroit. La ponte commence au bout de deux semaines, parfois un mois après que la femelle est tombée de l'animal, et se prolonge sur une période de plusieurs semaines, car il ne se pond que deux ou trois cents oufs par jour. La femelle se ratatine de plus en plus à mesure qu'elle pond et elle meurt après avoir déposé tous ses œufs. Les œufs sont bruns et ovoüdes, couverts d'une substance gommeuse qui les tient ensemble et les empêche de se dessécher. L'éclosion commence au bout de quatre ou six semaines et peut se prolonger sur une période de quinze jours ou plus. Les larves font généralement leur appa-

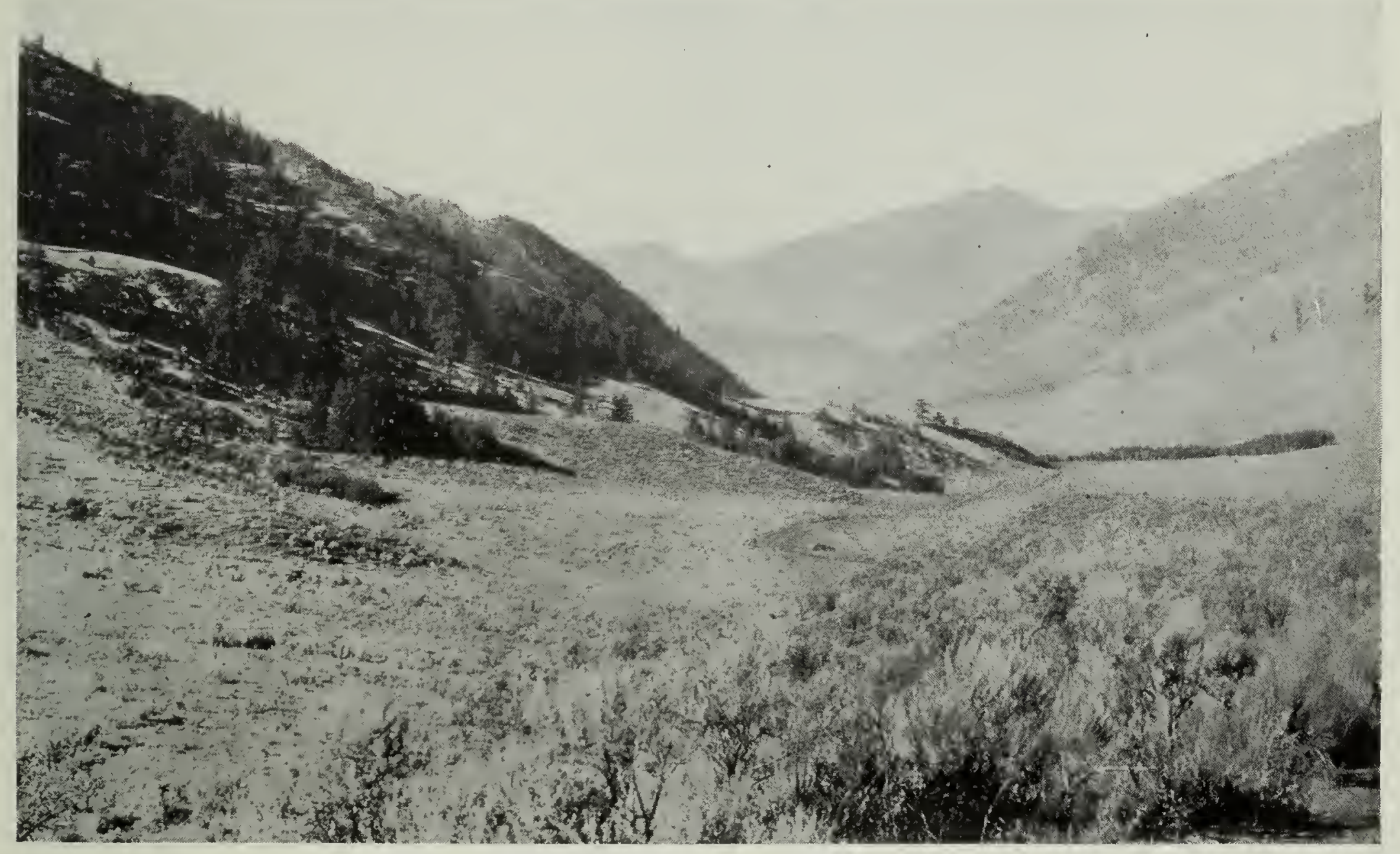

Fig. 77-Type de pays infesté par la tique à paralysie, Sud de la Colombie-Britannique (Original).

rition en juin, peu après la fin de la saison des tiques adultes; elles sont spécialement nombreuses sur les rongeurs en juillet. Les larves, qui n'ont que trois paires de pattes, grimpent sur l'herbe et les autres végétaux et s'attachent au premier rongeur ou autre petit animal qui passe près d'elles. Elles ne sont pas aussi rustiques que les adultes ou que les nymphes et, dans des conditions naturelles, vivent rarement plus de deux mois et demi sans nourriture. Lorsqu'elles réussissent à se trouver un hôte, elles mettent environ six jours pour se repaître. Elles tombent ensuite et, après une période de repos qui peut durer une à quatre semaines, se transforment en nymphes à huit pattes. Les chaleurs qui arrivent portent généralement les nymphes à se chercher un endroit ombragé, où elles restent jusqu'au printemps suivant. Les tiques nymphosées sont rustiques et peuvent vivre pendant près d'un an. En sortant de l'hivernement, aux premières journées chaudes du printemps, les tiques nymphes attendent aussi sur les végétaux le passage d'un petit animal, comme un siffleux ou un écureuil, et, après s'être gorgées de sang pendant environ une semaine, elles tombent et restent inertes sur la terre pendant une période allant de six à dix semaines. Elles se métamorphosent alors en insectes adultes. Cette phase est généralement atteinte pendant l'été ou au commencement de l'au- 
tomne. Les chaleurs sèches à cette époque portent les tiques des deux sexes à se réfugier dans des endroits protégés où elles restent cachées jusqu'au printemps suivant. Tout l'été, elles restent plates, à jeun, et ne font aucune tentative pour se nourrir; même, si on les place sur un animal, elles le quittent aussitôt.

On voit par ce qui précède que deux années sont nécessaires pour compléter le cycle normal de la vie, et que parfois ce cycle peut se prolonger pour embrasser trois ou même quatre ans. Il y a beaucoup d'empiétement, car les nymphes d'une génération et les adultes d'une autre sortent de leurs quartiers d'hiver à peu près vers la même époque au printemps, les premières pour se nourrir sur les rongeurs et autres petits animaux, et les autres pour se gorger sur les animaux domestiques plus gros et les mammifères sauvages. Lorsque

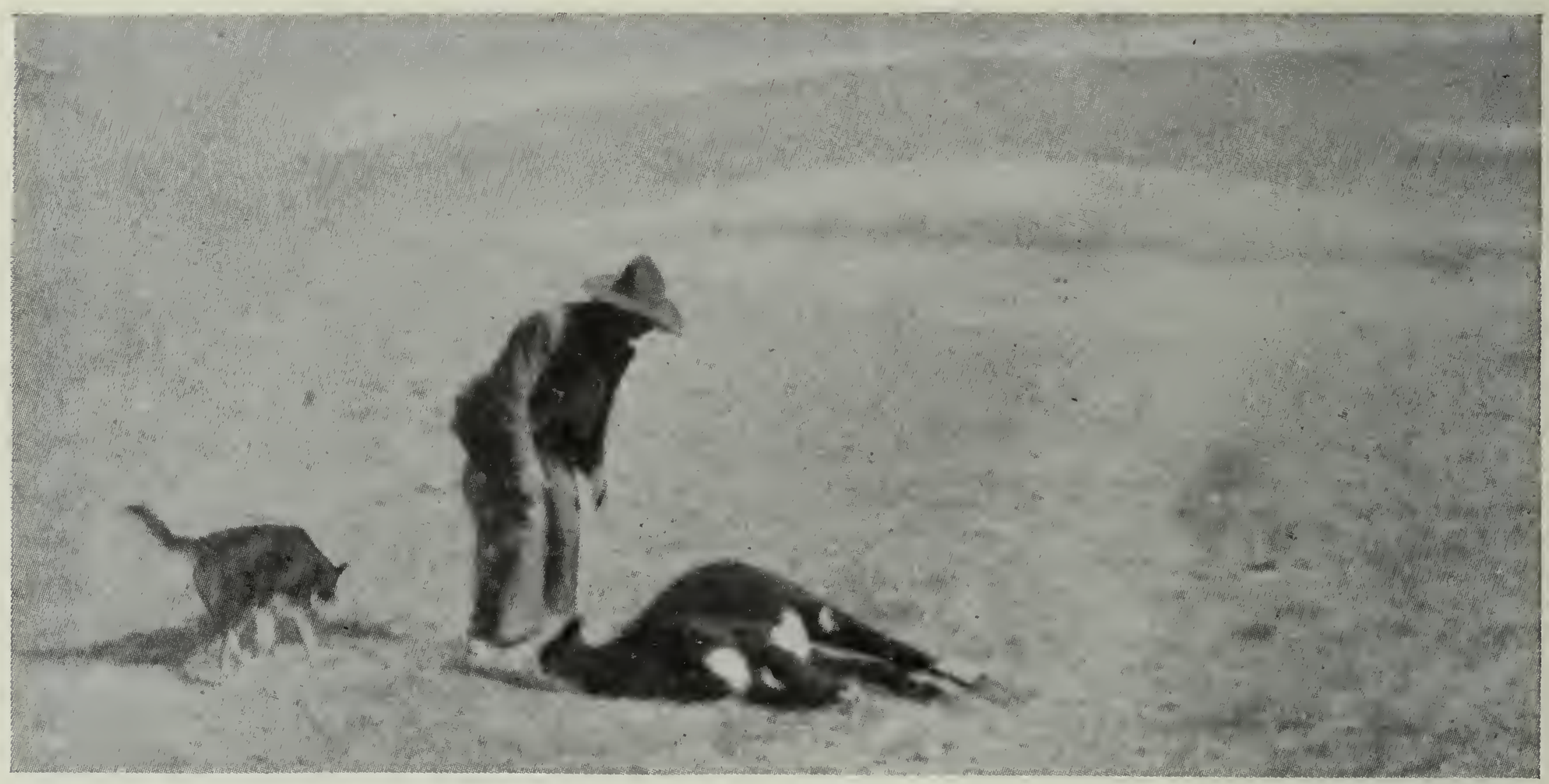

Fig. 78-Eouf paralysé sur l'herbage par la tique à paralysie (Original).

la saison des tiques adultes et nymphes est terminée et que l'été est commencé, on trouve les larves des tiques en abondance sur les petits rongeurs sauvages.

Importance économique.-La tique à paralysie est celle qui cause le plus de dommages au Canada; elle constitue un danger à cause de la possibilité de transmission de la maladie. Dans l'Ouest des Etats-Unis, le long des Montagnes Rocheuses, elle est le véhicule ou le porteur d'une maladie redoutable appelée la "fièvre (Spotted fever) des Montagnes Rocheuses"; elle transmet aussi la tularémie, une maladie très répandue, sorte de peste des rongeurs, qui est parfois contractée par l'homme et certains animaux domestiques. On a signalé des cas de fièvre des Montagnes Rocheuses dans l'Ouest du Canada dernièrement et il y a eu un cas fatal à Manyberries, Alberta, en 1935, et un fatal et un autre non fatal en 1936. En Colombie-Britannique, on a signalé un cas suspect à Pender Harbour, et deux cas possibles à Hedley en 1936 . En 1930, il a été démontré pour la première fois avec certitude que la tularémie existe au Canada, et des cas ont été notés sur l'homme en Alberta et en Ontario; on a aussi trouvé des rongeurs affectés en Colombie-Britannique. Cette maladie peut affecter les vaches et les moutons, et la perte de 5,000 moutons en une année, dans une seule localité de l'Idaho, a été attribuée à ces tiques par le Dr R. R. Parker.

L'état pathologique que l'on appelle "paralysie à tiques", qui se développe parfois lorsque cette espèce se nourrit rapidement, est le dommage le plus 
sérieux que l'on attribue à cette espèce dans ce pays. Les rapports incomplets des médecins indiquent que, en ce qui concerne la Colombie-Britannique, près de 150 cas ont été notés sur l'homme dans cette province; il s'en rencontre dans presque tous les districts habités par ces tiques. Les cas ont été spécialement nombreux chez les moutons, et il en est résulté une nombreuse mortalité. Les bovins y sont généralement moins sujets, et, cependant, la paralysie à tiques a été signalée de temps à autre sur ces animaux; au printemps de 1930,
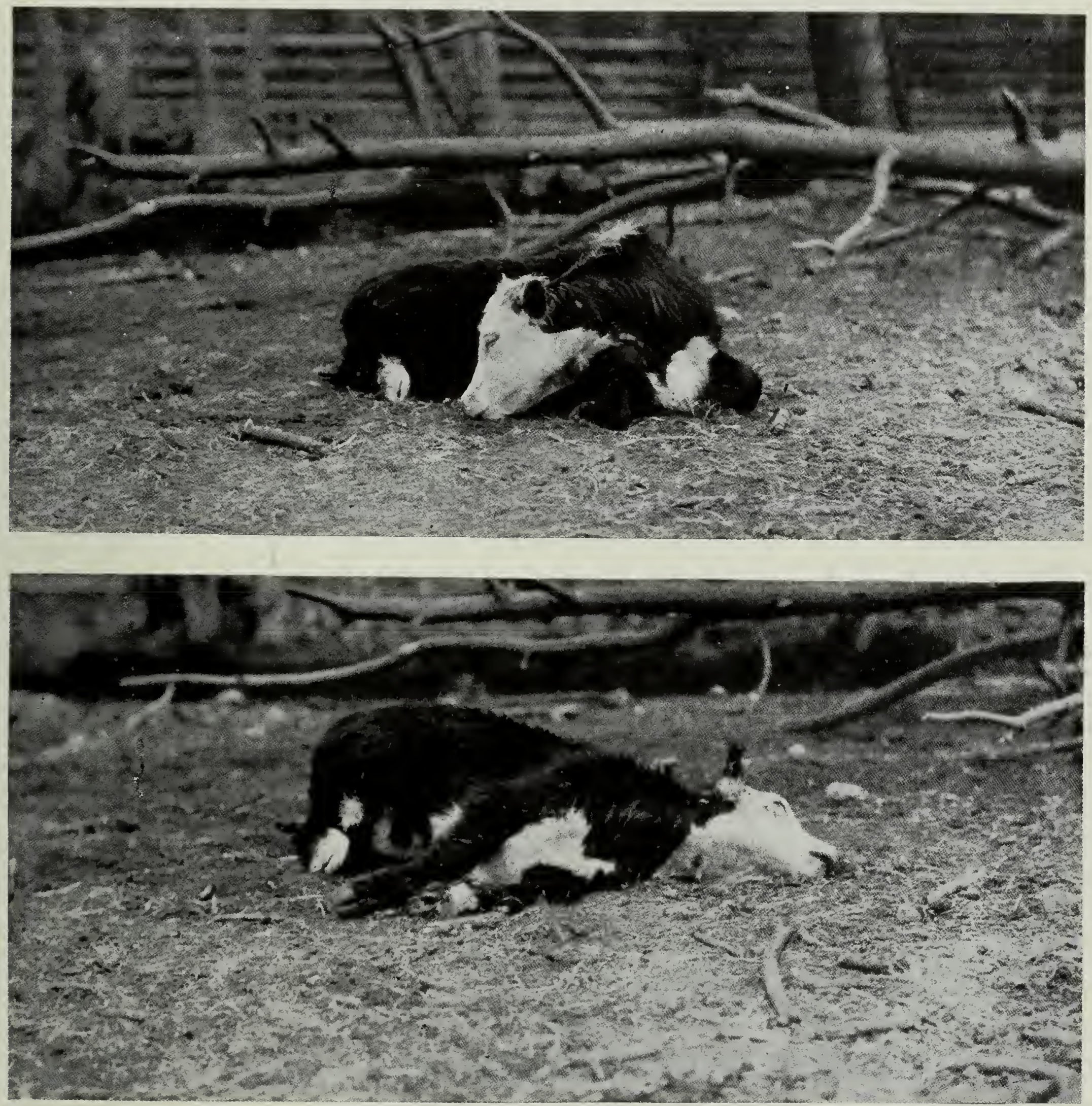

Fig. 79-Attitude caractéristique des boufs paralysés par la tique à paralysie (Original).

une explosion grave chez les bœufs a été l'objet de recherches dans un des herbages à zone sèche de la Colombie-Britannique:-plus de 100 cas de paralysie, dont 60 suivis de mort, ont été notés dans un troupeau. En ce qui concerne les chevaux, un cas seulement a été signalé: Dans les districts à moutons, où cette maladie est répandue, les bergers sont obligés d'examiner leurs animaux fréquemment, afin d'enlever les tiques sur les moutons qui présentent des symptômes de faiblesse ou de vertige. Ceci occasionne une grande perte de temps à une époque où l'on est déjà bien occupé. Tout en propageant les maladies que nous venons de mentionner, les tiques, lorsqu'elles sont nombreuses, rédui- 
sent la vitalité des animaux par l'irritation qu'elles occasionnent et la quantité de sang qu'elles en tirent. Les animaux domestiques, le chevreuil, le cerf (wapiti) et la chèvre des Montagnes Rocheuses sont souvent gravement affectés au printemps. La présence de tiques sur les animaux peut aussi attirer les mouches à viande, bleues ou vertes. Les peaux trouées par les tiques font un cuir de qualité inférieure. L’inflammation appelée "poll evil" et le "mal du garrot" que l'on voit souvent sur les chevaux non dressés des Prairies, au printemps, sont probablement dus à une attaque des tiques, du moins en partie. Enfin, la piqûre des tiques peut provoquer la formation de dangereux ulcères chez l'homme ou les animaux.

Distribution.-Heureusement, cette tique a une distribution restreinte au Canada. Elle abonde dans les régions sèches de la Colombie-Britannique et du sud-ouest de l'Alberta jusqu'à Medicine Hat. Son habitat s'étend à partir de la frontière des Etats-Unis jusqu'à 100 milles au nord de Kamloops; c'est dans le district de Kootenay qu'elle paraît être le plus répandue, mais il semble qu'elle soit absente de la zone humide du littoral, sauf lorsqu'elle est introduite par un hôte importé. Elle ne se rencontre pas du tout dans l'Est du Canada, pourtant on l'a signalée une fois au Manitoba.

Moyens répressifs et remèdes.-Les tiques, et spécialement les espèces à trois hôtes, sont difficiles à combattre, mais les moyens suivants se sont montrés utiles. 'Trois bains à intervalles de dix jours, le premier à l'époque où les tiques font leur première apparition au printemps, ont beaucoup d'effet. La meilleure solution est celle qui se compose de vingt-quatre livres de cristaux de sal soda, huit livres d'arsenic blanc et un gallon de goudron de pin par 500 gallons d'eau. Il est facile de préparer ces solutions à la maison, mais il existe des produits brevetés sûrs, et nous recommandons leur emploi. Il faut suivre fidèlement les instructions des fabricants, car ces ingrédients sont des poisons dangereux. Ceux qui n'ont pas de baignoires pourront appliquer le liquide au moyen de pulvérisateurs. Sur les vaches laitières, les tiques peuvent être arrachées à la main. Lorsque les animaux deviennent paralysés, toutes les tiques qui paraissent être gorgées de sang devraient être immédiatement enlevées; on les cherchera tout spécialement derrière la tête, dans la région de l'épine dorsale et le long du cou, car c'est surtout dans ces régions qu'elles sont fixées. Un enduit composé d'environ trois parties d'huile de coton brute ou d'huile de lin crue, mélangée avec une partie d'huile de goudron de pin et appliqué à partir du derrière de la tête le long du cou et par'-dessus le sommet des épaules jusqu'à mi-chemin le long du dos tue généralement la majorité des tiques qui sont attachées aux bovins. Chez les chevaux, les tiques s'attachent souvent sous la mâchoire et entre les pattes de devant et de derrière. Il est généralement bon de tondre la crinière avant d'appliquer cet enduit, car on trouve parfois un grand nombre de tiques cachées sous les longs poils. Cet enduit non seulement tue les tiques en place, mais il agit aussi comme repoussant et empêche pendant quelque temps les tiques de se poser. Il prévient également les attaques des mouches à viande, qui se produisent souvent aux endroits mordus par les tiques. Partout où il est possible de le faire, les vaches et les autres bestiaux devraient être tenus dans des pâturages clôturés sans tiques pendant la période où les tiques déploient de l'activité au printemps. Certains auteurs ont prétendu que les moutons sont utiles pour détruire les tiques, quoiqu'ils soient eux-mêmes sujets à leurs attaques. C'est parce que la lajne longue ramasse un grand nombre de tiques, dont quelques-unes périssent au contact de l'huile abondante que renferme la toison. Il n'est pas rare de voir un grand nombre de ces tiques mortes à l'époque de la tonte; cependant, le Dr R. A. Cooley doute beaucoup que les moutons soient utiles pour détruire les tiques et il prétend que les moutons font vivre un nombre suffisant de tiques pour maintenir ou même accroître la population de ces dernières dans les étendues où paissent les animaux. Il considère que les moutons font vivre plus de 
ıiques que les chevaux et les bovins. Un fait remarquable c'est que la tique à paralysie pullule dans les endroits où les moutons se couchent, et le Dr Cooley prétend que la fièvr'e des Montagnes Rocheuses dans l'Idaho est surtout répandue parmi les bergers.

Un autre moyen de détruire la tique à paralysie est de réduire le nombre des rongeurs, qui sont essentiels au développement des premières phases des tiques. La destruction systématique des géomys et d'autres petits animaux a beaucoup aidé à réduire lo nombre des tiques dans certaines parties du Montana, où elle a été conduite pendant plusieurs années. C'est un procédé assez coûteux cependant, mais c'est une bonne pratique agricole en raison des gros dégâts causés par les r'ongeurs, sans compter l'effet qu'ils exercent sur l'abondance des tiques. Peaucoup de rongeurs servent d'hôtes, mais les siffleux (marmottes d'Amérique), et les écureuils de Colombie et autres écureuils terrestres (géomys) paraissent être les hôtes principaux des tiques au Canada et c'est contre eux que les efforts devraient être dirigés. L'empoisonnement est un moyen très utile pour les détruire. Le poison suivant est recommandé: on fait dissoudre une cuillerée à thé de saccharine dans une chopine d'eau et après y avoir ajouté une demi-livre de fécule on fait chauffer en remuant jusqu'à ce que le mélange soit épais puis l'on ajoute une chopine de mélasse à bétail. On incorpore ensuite en remuant une once d'alcaloïde de strychnine en poudre très fine et l'on ver'se le mélange sur huit pintes d'avoine concassée de façon à ce que le grain soit parfaitement recouvert, puis l'on mélange rapidement avec les mains. On peut étaler le mélange de grain empoisonné sur une toile ou sur des bandes de mousseline pour faciliter le séchage; il faut avoir soin de faire ce séchage dans un endroit qui soit hors de la portée des enfants ou des animaux. On l'étiquette ensuite soigneusement et on le serre avec précaution pour éviter tout risque d'empoisonnement. On prend environ une cuillerée à thé du grain empoisonné quand il est sec pour l'éparpiller en une couche mince sur une étendue d'environ dix pouces carrés autour de l'entrée de chaque terrier de géomys. Pour les siffleux l'addition d'un peu de cretons rend l'appât encore plus séduisant. Il ne faut jamais oublier que la strychnine est très dangereuse et que sa manutention doit être faite avec le plus grand soin. Il faut porter des gants en caoutchouc pour mélanger l'appât et se laver ensuite parfaitement les mains. Une autre formule recommandée par le Ministère de l'Agriculture de la Colombie-Britannique et qui a eu beaucoup de succès dans les expériences conduites par nos agents est la suivante:

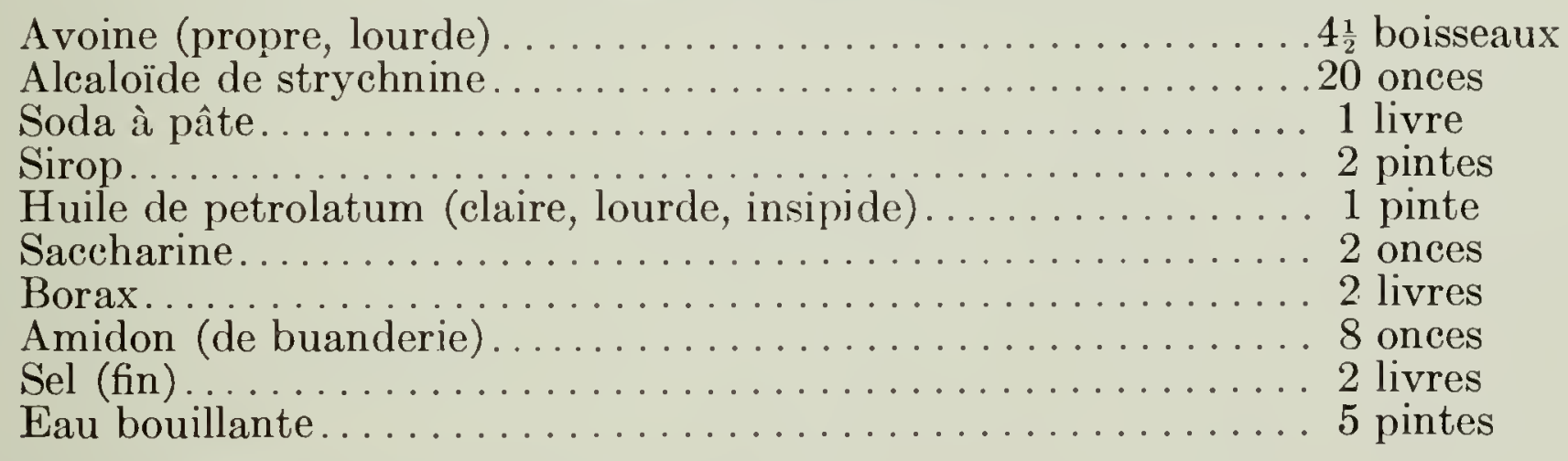

1. Mettre l'avoine sur un plancher lisse.

2. Mélanger le sirop et le petrolatum dans une grande poêle.

3. Mélanger la strychnine et le soda en les écrasant finement.

4. Mélanger la saccharine et le borax dans l'eau bouillante.

5. Faire dissoudre l'amidon dans une chopine d'eau froide et incorporer en remuant lentement dans l'eau bouillante. Faire bouillir et remuer jusqu'à ce qu'une pâte claire, assez épaisse se forme, ayant bien soin de ne pas laisser roussir la pâte.

6. Ajouter la pâte d'amidon au mélange de poison et mélanger parfaitement jusqu'à ce qu'une masse lisse, crémeuse se forme.

7. Verser le mélange sur l'avoine et mélanger rapidement avec une pelle large, ayant bien soin d'empêcher la pâte de couler sur le plancher avant qu'elle soit bien mélangée avec le grain. Bien mélanger jusqu'à ce qu'il ne reste plus de grains secs.

\&. Tamisez le sel sur l'appât humide et mélanger à nouveau. 
On prendra les mêmes précautions dans la préparation et dans l'emploi de cet appât empoisonné que pour la formule précédente.

Le cyanide de calcium est utile également pour détruire les rongeurs; c'est un ingrédient moins dangereux pour l'emploi dans les pâturages à moutons et à por'cs, d'où il pourrait être incommode d'enlever ces animaux pendant les opérations de l'épandage du poison. C'est aussi un poison très violent et il faut s'en tenir fidèlement aux instructions du fabricant.

En ces dernières années on a donné beaucoup d'attention à l'emploi de parasites naturels comme aide dans la destruction des tiques. Il existe plusieurs insectes extrêmement petits ressemblant à des abeilles, qui s'attaquent aux tiques et les détruisent; on en a fait l'élevage dans un laboratoire spécial au Montana et on les a implantés en très grands nombres. Il faut espérer qu'ils se montreront utiles dans la lutte contre la tique à paralysie.

\section{LA TIQUE DU CERF WAPITI OU TIQUE D'HIVER, Dermacentor albipictus Packard}

La tique du wapiti, la tique de l'orignal et la tique du cheval sont les noms communs de cette espèce, car elle se rencontre en grande abondance sur ces hôtes. Elle n'est nullement restreinte à l'orignal ou au wapiti, mais elle attaque un grand nombre de gros animaux domestiques et sauvages.

La tique femelle adulte non repue est généralement un peu plus grosse que la femelle de la tique à paralysie, elle a aussi des mouvements beaucoup plus lents. Le corps, les pattes et la tête sont d'un brun rouge plus pâle, et le bouclier blanc porte une longue ligne rouge centrale, en plus des deux lignes latérales. Lorsqu'elle est complètement gorgée de sang, la femelle prend l'aspect d'une fève et ressemble aux espèces précédentes. Le bouclier qui recouvre tout le dos du mâle est blanchâtre et les nombreuses marques irrégulières sont couleur de saumon.

Cycle évolutif.-Le cycle évolutif de

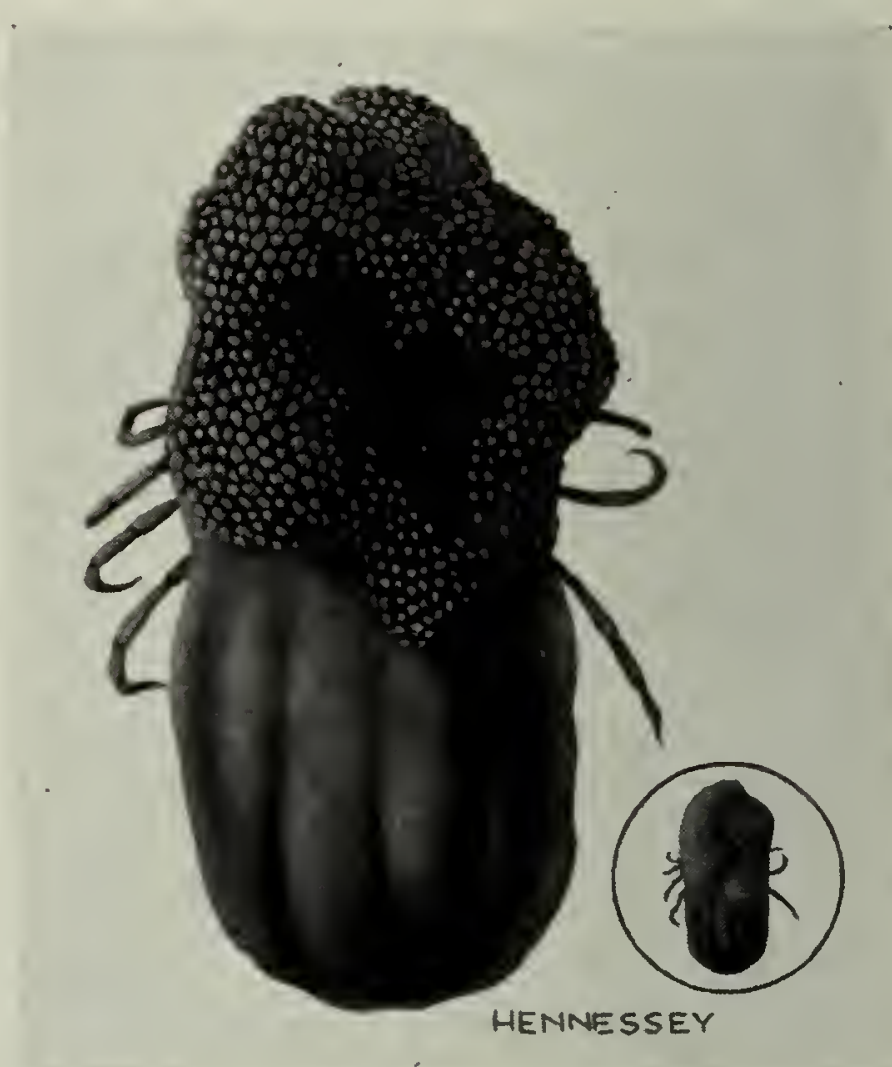

Fig. 80-La tique du cerf wapiti ou tique d'hiver, Dernacemtor albipictus Pack., femelle ratatinée a vec masse d'œufs; grossie et grosseur naturelle (Original). cette espèce diffère beaucoup de celui de la tique à paralysie. Les larves (ou tiquets), qui sont restées inertes et serrées étroitement les unes contre les autres à partir du moment de l'éclosion, se raniment lorsque les premiers froids de l'hiver se font sentir, et elles se tiennent en éveil sur les végétaux, dans l'attente d'un hôte de passage. On les a vues dans cette situation pour la première fois en Colombie-Britannique vers la mi-octobre, mais dans le nord de la Saskatchewan il est probable qu'elles commencent à chercher des hôtes dès la fin de septembre. Elles sont actives pendant toute la dernière partie de l'automne, l'hiver et au commencement du printemps. Cette tique diffère de la tique à paralysie par le fait qu'un seul hôte lui suffit, et qu'elle mue sur le premier animal qui lui sert d'hôte, après chaque repas de sang. La larve mue une dizaine de jours après s'être fixée, et la nymphe au bout de deux semaines. En général, les femelles adultes sont complètement repues et tombent de l'hôte six semaines environ après que les larves se sont fixées. Chez les femelles qui sont tombées au printemps, la ponte peut commencer en moins de deux semaines, tandis que chez celles qui sont tombées de l'hôte pendant l'hiver, la ponte peut être retardée de quatre mois et plus. La ponte se fait principalement pendant les mois du printemps, 
en mars, en avril et en mai. Les oeufs sont pondus en une grosse masse pendant une période de plusieurs semaines; il s'en pond environ 200 par jour jusqu'à ce qu'un total de 4,000 ou plus ait été déposé. L'incubation a lieu au bout de six semaines environ, et la plupart des oufs d'une couvée éclosent en même temps. Les larves se serrent les unes contre les autres pour se protéger contre la dessication pendant les grandes chaleurs de l'été, et elles restent inertes jusqu'aux premiers froids de l'automne. Elles ont une vitalité remarquable et on sait qu'elles peuvent vivre plus d'une année sans nourriture.

Importance économique.-La tique du wapiti ou tique d'hiver est souvent en nombre suffisant pour causer de grandes pertes. Une forte infestation de ces tiques sur les chevaux, les bovins, l'orignal, le wapiti et le chevreuil peut causer la mort par épuisement de la vitalité des animaux infestés. C'est, sous ce rapport, l'espèce la plus importante de toutes les tiques que l'on rencontre

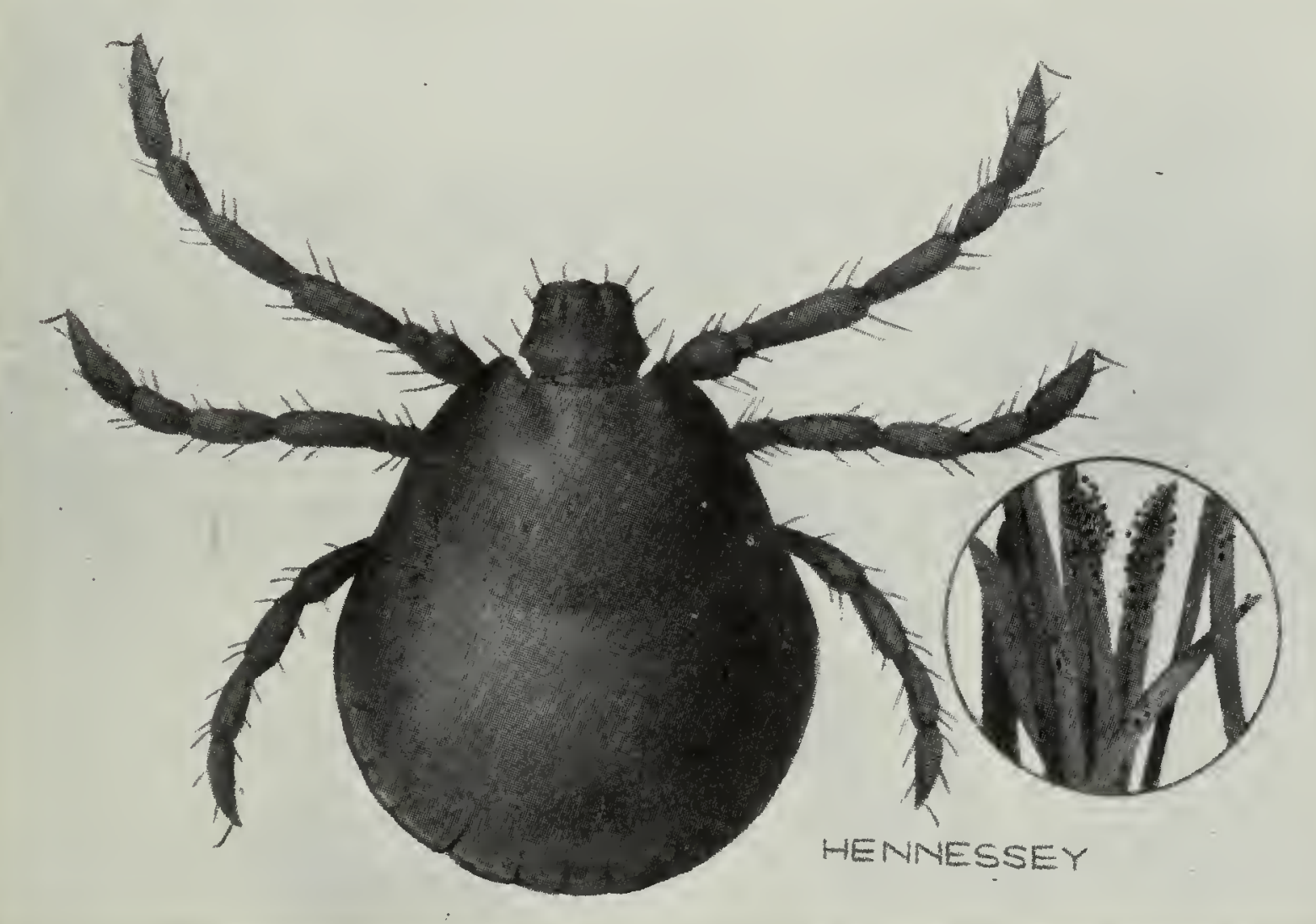

Fig. 81-La tique du cerf wapiti ou tique d'hiver; larve de la tique sur l'herbe attendant, le passage des hôtes, grossie et grosseur naturelle (Original).

au Canada, car elle attaque les animaux pendant l'époque où les conditions d'alimentation laissent le plus à désirer, et c'est un fléau spécialement à redouter pendant les hivers très froids, quand la résistance des animaux est diminuée par le manque de nourriture. On a signalé de temps à autre la mort de chevaux, de chevreuils et d'autres gros animaux sauvages en Colombie-Britannique, dans le nord de l'Alberta et de la Saskatchewan. Un grand nombre d'orignaux sont morts en certaines saisons en Saskatchewan, et au cours d'une invasion de tiques dans la partie nord de cette province, un cultivateur a perdu 107 chevaux et vaches sur un total de 150 bêtes. On a constaté également qu'un grand nombre d'orignaux meurent au Nouveau-Brunswick et en NouvelleEcosse au cours de certains hivers. Le chef forestier de cette dernière province estime qu'en l'hiver de 1930, la tique du wapiti a causé une perte d'au moins 20 pour cent dans la population des orignaux. Les gardes-chasse disent avoir trouvé des animaux infestés morts ou mourants, tandis que d'autres étaient maigres et affaiblis. Sur beaucoup d'entre eux le garrot était à nu et des taches de sang se voyaient sur les parties où ils s'étaient couchés. Le naturaliste Thompson Seton déclare que la tique constitue l'un des quatre fléaux les plus redoutables de l'orignal au Manitoba. La tique d'hiver a un parcours beaucoup plus grand que la tique de la paralysie, et elle se rencontre sur tous les points 
du Canada, du Pacifique à l'Atlantique. Dans les provinces des Prairies, elle ne se rencontre guère que dans les parties boisées du Nord; c'est essentiellement une tique des grands herbages non cultivés et des étendues en broussailles.

Moyens répressifs.-Autant que possible, les bovins et les chevaux devraient être tenus dans des pâtur ges clôturés, sans tiques, de septembre à mai; ils peuvent ainsi échapper aux attaques. Si l'infestation s'est produite avant qu'ils aient été sortis des herbages, on pourra les baigner si cette opération peut se faire avant que le temps se soit trop refroidi. Des applications d'huile sont utiles pour faire tomber les tiques attachées, ainsi que nous l'avons dit plus haut, mais il ne faut pas en mettre trop. Le labour est un moyen des plus utiles pour détruire les tiques dans un champ infesté. On devrait labourer en mai, après que les tiques sont tombées; les femelies repues et les oufs sont enfouis par le labour et ne réapparaîtront pas.

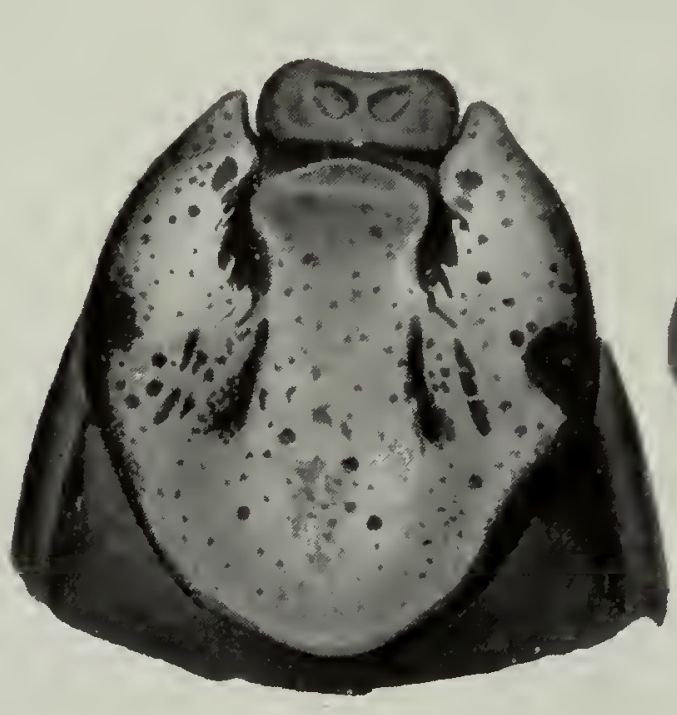

1

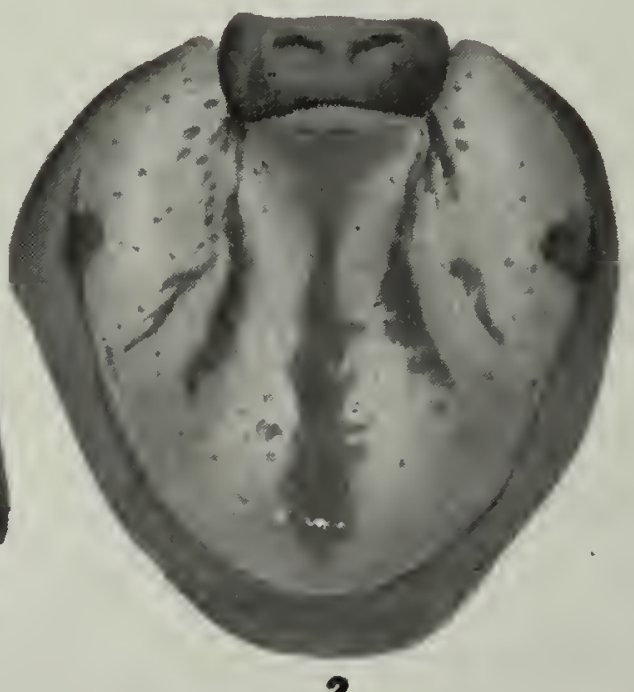

2

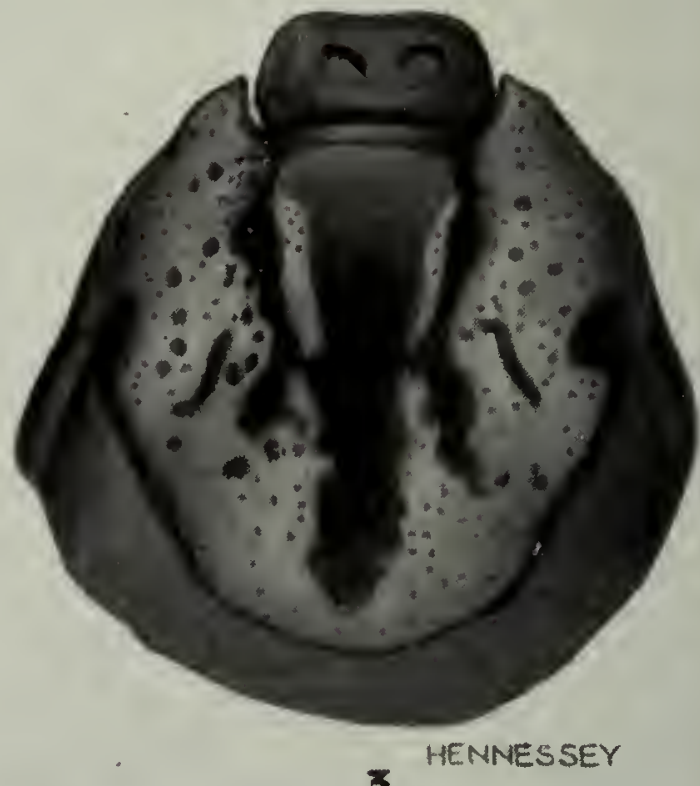

子

Fig. 82-Une comparaison du bouclier et des marques typiques de: 1, la tique à paralysie; 2, la tique de l'élan ou d'hiver; 3 , la tique du chien américain; toutes très grossies (Original).

\section{LA TIQUE AMÉRICAINE DU CHIEN (Dermacentor variabilis Say)}

C'est une tique de l'Est, qui abonde particulièrement au Manitoba, en certaines parties de la Saskatchewan et dans quelques districts de l'Ontario. Elle ressemble beaucoup à la tique de l'Ouest par l'apparence, les habitudes et le cycle évolutif, mais elle s'en distingue par une plus grande plaque rouge sur le bouclier blanc de la femelle; il y a une large plaque centrale de cette couleur. Les adultes sont spécialement nombreux et gênants juste après la disparition de la neige au printemps, mais ce n'est guère que pendant les mois du printemps qu'on peut les voir. Cette espèce exige trois hôtes, et le cycle complet de sa vie peut couvrir deux ans ou plus. Les chiens et les bovins paraissent être les hôtes préférés des adultes, mais ils attaquent aussi d'autres animaux, ainsi que l'homme. Il a été démontré par l'expérience que la tularémie et la fièvre des Montagnes Rocheuses peuvent être transmises par cette tique; elle doit donc être considérée comme une espèce dangereuse. On a signalé des cas de ces deux maladies aux Etats-Unis, où cette tique est la plus répandue de toutes et où la tique de la paralysie est encore inconnue. A part cela, ce n'est pas une espèce ayant une importance économique sérieuse, quoiqu'elle puisse causer des ennuis lorsqu'elle pullule. Ses attaques peuvent causer des plaies suppurantes et irritantes qui persistent pendant des mois. On recommande de recouvrir les tiques en place d'une substance huileuse, de les enlever avec soin et de désinfecter le trou qui reste. 


\section{L'IXODE RICIN OU TIQUE DU CHIEN (Ixodes ricinus L.)}

Cette espèce est grisâtre et porte un bouclier d'une couleur brun rouge. La femelle gorgée de sang ressemble à une graine de ricin, d'où son nom. Au Canada, elle se rercontre surtout en Colombie-Britannique, où elle attaque les chevreuils, les moutons, les bovins, l'homme et quelques autres animaux sauvages. Elle a une distribution cosmopolite; on la trouve partout, en Europe, en Asie, en Afrique, aussi bien qu'en Amérique. Cette espèce ne paraît pas avoir une grande importance économique au Canada à l'heure actuelle, elle est intéressante par le fait qu'elle transmet dans d'autres pays plusieurs maladies des animaux domestiques. En Grande-Bretagne, c'est l'agent principal de transmission de l'hématurie des bovins, et peut-être du "looping ill", une maladie qui cause la paralysie chez les moutons. On prétend également qu'elle transmet d'autres maladies mal comprises, mais aucun cas de ce genre n'a encore été constaté au Canada. C'est encore une espèce à trois hôtes. I es larves se gorgent en moins d'une semaine, et tombent à terre pour muer environ trois semaines plus tard. Après s'être attachée à un nouvel hôte, la nymphe se gorge pendant à peu près le même temps, tombe, et se change en un insecte adulte après un intervalle un peu plus long. Les femelles adultes se nourrissent pendant une ou deux semaines, puis commencent à pondre leur's œufs environ deux semaines après leur chute de l'hôte. L'éclosion commence généralement au bout de six semaines, mais peut retarder bien

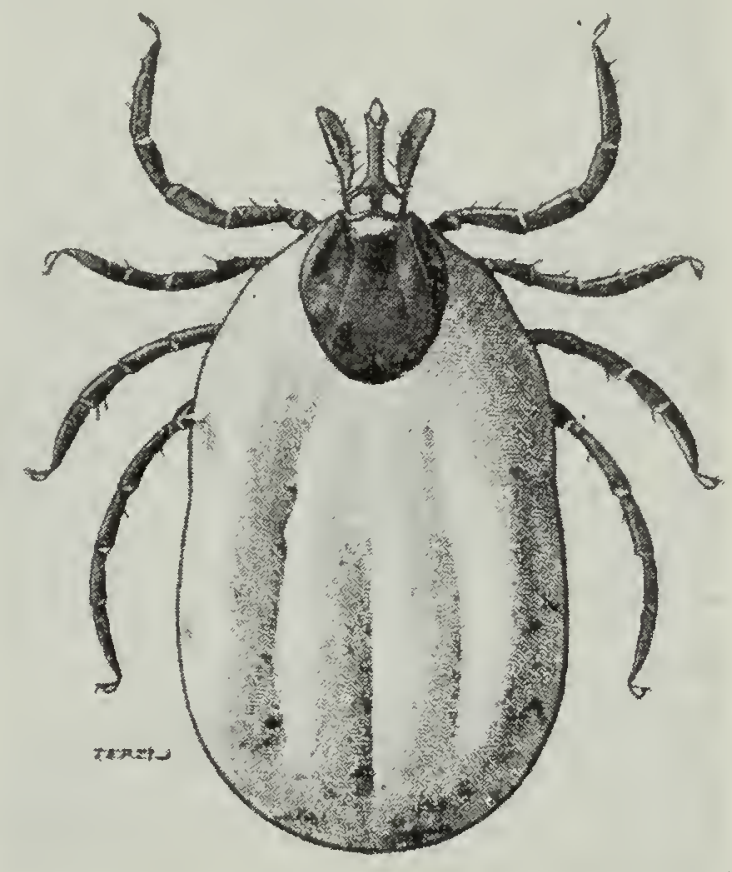

Fig. 83-L'ixode ricin, Ixodes ricinus L., femelle gorgée (d'après Hirst). davantage. Toutes les phases ont ure remarquable vitalité; des larves et des nymphes sont restées vivantes pendant un an et demi, et les adultes pendant deux ans et plus, sans nourriture. L'arrachage brusque d'une tique attachée peut laisser une vilaine plaie, et il est sage d'appliquer une substance huileuse avant d'essayer de l'extraire. Si ce moyen ou l'application d'une broche rougie au feu, à l'extrémité de la tique, pour lui faire lâcher prise, ne réussit pas, on peut tirer doucement sur l'insecte en coupant un petit morceau de peau avec les parties buccales au moyens de ciseaux bien tranchants.

\section{LA TIQUE DES OISEAUX ( $/ 1$ amaphysalis cinnabarina Koch)}

La tique des oiseaux a une couleur brune assez uniforme. De même que les autres tiques du groupe Homaphysalis, ses parties buccales ressemblent un peu à une tête de flèche à cause de ses palpes (antennes) qui s'étendent latéralement à la base. C'est une tique à trois hôtes qui attaque un grand nombre d'animaux domestiques et sauva-es, d'oiseaux et de volailles. Les hôtes varient depuis les bovins jusqu'à la caille. On l'appelle "tique des oiseaux" parce qu'elle se rencontre souvent sur ces derniers. Au Canada, on la trouve principalement au Manitoba, mais elle est connue également en Alberta et en ColombieBritannique, et probablement aussi dans les provinces de l'Est. Seymour Hadwen nous a dit l'avoir trouvée sur des dindons à Elfros, Saskatchewan. Le cycle de sa vie est semblable à celui de l'ixode ricin, mais on trouve généralement les adultes sur les bovins tard en automne. Jusqu'ici, on ne s'en est pas plaint, mais il est probable qu'elle causera des dommages à l'avenir si elle continue à se multiplier. Les recherches qui ont été faites en GrandeBretagne indiquent que cette espèce (ou une espèce proche parente) peut transmettre l'hématurie des bovins. Le seul cas connu de paralysie de la tique au 
Canada causé par une espèce autre que Dermacentor andersoni Stiles, a été attribué à un spécimen de la tique de l'oiseau trouvé attaché au patient. Il est possible, naturellement, qu'il y avait eu une tique de la paralysie également attachée, et que celle-ci n'ait pas été vue. Ce cas a eu une terminaison fatale. On sait que la tique des oiseaux cause des pertes sérieuses parmi les dindons, qui, par leurs habitudes, sont spécialement sujets à être infestés. La mort des dindons en Alberta a définitivement été rattachée à $H$. cinnabarina, et les plaintes que l'on reçoit de temps à autre des différentes parties du Canada sont sans doute dues à l'infestation par la même espèce. Cette tique est répandue parmi les gelinottes bleues et les faisans des herbages desséchés de la ColombieBritannique, et on la soupçonne de causer la mort de la gelinotte dans certaines parties de cette province. Lorsque les bovins sont très infestés, il est bon de leur appliquer une petite quantité d'un onguent huileux. Il faut éviter un excès d'huile, toujour's dangereux; même dans les pires infestations, quatre onces par animal suffisent. Pour les éleveurs de dindons, il faut avoir recours. à l'arrachage à la main, car les tiques se rencontrent généralement seulement sur le cou et la tête de ces volatiles.

\section{LA TIQUE DU LAPIN, I cmaphysalis leporis-palustris Packard}

Cette petite tique de couleur brun foncé attaque principalement les lapins; elle est plus répandue que toute autre espèce au Canada. Les parties buccales et les palpes présentent un aspect caractéristique, en forme de flèche. Trois hôtes sont nécessaires pour son développement, mais toutes les formes de l'insecte-larve, nymphe et adulte-peuvent se rencontrer en même temps sur un même animal. Cette tique attaque également certains oiseaux comme la. gelinotte et les alouettes des prés, mais avec moins de sévérité. Les lapins sont souvent infestés de plusieurs centaines de tiques qui causent une grande faiblesse et un état d'émaciation. L'intérêt principal que présente cette tique c'est qu'clle est un agent indirect dans la transmission de la tularémie et de la. fièvre des Montagnes Rocheuses. Les lapins constituent le réservoir le plus important de tularémie et leur tique est l'agent principál de la transmission de cette maladie d'un animal à l'autre.

\section{AUTRES ESPÈCES CANADIENNES DE TIQUES}

Les animaux sauvages donnent asile à plusieurs autres espèces de tiques: qui offrent peu d'importance économique sauf dans la mesure où elles peuvent attaquer les animaux à fourrure. Deux tiques nuisibles qui attaquent les. bestiaux dans le Sud, la tique étoilée, Amblyomma americana L., et la tique de l'oreille, Ornithodoros megnini Duges, se sont introduites au Canada; il est probable qu'elles sont venues avec des animaux importés, heureusement elles ne paraissent pas s'être encore établies. La dernière espèce n'a pas été trouvée sur des bêtes bovines, mais sur des lièvres dans le Sud de l'Alberta. Une espèce de Dermacentor, dont l'identité est encore inconnue, a été l'objet d'un certain nombre de plaintes dans l'Ile de Vancouver.

\section{PROGRAMME MENSUEL POUR LA LUTTE CONTRE LES INSEC- TES ET LES ARTHROPODES QUI NUISENT AUX BESTIAUX}

Pour plus de commodité, nous donnons ici la liste des principaux insectes qui affectent les bestiaux chaque mois de l'année, en indiquant les moyens à prendre pour les combattre. Ce précis est nécessairement d'ordre très général à cause des différentes conditions que l'on rencontre dans les différentes parties du pays.

Janvier.-Examiner les vaches et les bœufs pour voir s'ils portent des larves de l'hypoderme commun (taon des tanneurs) qui sont visibles vers le milieu de ce mois; faire sortir ces larves en comprimant les tumeurs et s'entendre avec 
les voisins pour une campagne coopérative de lutte (voir page 51). Examiner aussi les chevaux, les bovins et les moutons pour les poux, qui se multiplient beaucoup et pullulent généralement à partir du milieu jusqu'à la fin de l'hiver; Si ces poux sont tous du type broyeur, saupoudrer avec du fluorure de sodium; si les deux espèces sont présentes, poux broyeurs et suceurs, se servir d'huile de lin crue sur les chevaux et les bovins (voir page 82 ); pour les poux du pied sur les moutons, laver les pattes avec une solution (voir page 82). S'il y a de la gale, elle se verra maintenant et, dans ce cas, aviser un inspecteur vétérinaire (voir page 85). Dans les gros troupeaux c'est à ce moment que l'on doit tondre la culotte des brebis pleines, qui pourraient être difficiles à manier en avril (voir page 65).

Février.-Vers le milieu de ce mois (en Colombie-Britannique) appliquer le premier lavage de derris pour la lutte coopérative contre l'hypoderme ou faire sortir les larves en comprimant les tumeurs. Examiner les chevaux et les vaches pour la tique d'hiver. Ces tiques sont grosses et bien visibles à ce moment; si elles sont nombreuses, appliquer de l'huile de lin brute avec un peu d'huile de goudron de pin (voir page 104). S'il y a beaucoup de mélophages (barbin ou pou du mouton) et si le troupeau n'est pas très nombreux et que les moutons ont de la valeur, saupoudrer avec de la poudre de pyrèthre (voir page 70).

Mars.-Vers le 11ème jour du mois (en Colombie-Britannique) appliquer le deuxième lavage de derris pour la lutte coopérative contre l'hypoderme ou faire sortir les larves en comprimant les tumeurs. Dans les Provinces des Prairies et l'Est du Canada appliquer le premier lavage vers la troisième semaine du mois. Si les tiques d'hiver sont abondantes sur les chevaux et les bovins et qu'elles en sortent pour pondre leurs œufs, traiter avec de l'huile de lin brute. A partir de la fin de mars jusqu'en mai, tenir les moutons et les autres bestiaux dans la zone sèche de la Colombie-Britannique sur les pâturages des vallées basses, qui ne sont pas infestés de la tique à paralysie; éviter les flancs de collines broussailleux (voir page 104). En décornant, appliquer de l'huile de lin brute et de l'huile de goudron de pin à partir de la base du crâne, le long du dos des animaux, de façon à tuer la tique à paralysie ou à prévenir ses attaques (voir page 104). Brûler toutes les vieilles meules de paille et labourer plus tard l'emplacement de ces meules pour empêcher la multiplication des mouches piquantes des étables (voir page 18). Epandre en une mince couche le fumier qui s'est accumulé pendant l'hiver sur les champs, et nettoyer tous les endroits qui peuvent donner naissance à des mouches communes (voir page 11).

Avril.-Vers le 11 avril (en Colombie-Britannique), appliquer le troisième lavage de derris pour tuer tous les hypodermes; si l'adulte de l'hypoderme commun commence à inquiéter les bêtes bovines, fournir des refuges assombris. Dans les autres provinces, appliquer le deuxième lavage de derris vers la miavril. Dans les régions de la zone sèche où la tique à paralysie est abondante, enlever toutes les tiques gorgées dès que les moutons ou les bovins paraissent inquiétés; s'il est possible de le faire, baigner les bêtes bovines trois fois à intervalles de dix jours dans les districts les plus infestés (voir page 104) ou appliquer de l'huile de lin brute et de l'huile de goudron de pin sur le dos des animaux; entreprendre une campagne systématique d'empoisonnement à la strychnine, de destruction au fusil ou au piège, pour réduire les siffleux (marmottes), les géomys (gophers) et les autres rongeurs qui sont les hôtes des premières phases de la tique à paralysie (voir page 105). Nettoyer les moutons au commencement du mois en tondant soigneusement les cuisses et la culotte. Si les brebis pleines n'ont pas encore été nettoyées, il ne faut plus retarder, mais il faut tenir ces brebis avec un licou et ne pas les mettre sur le dos. Si l'on emploie des parquets de maternité on peut entreprendre ce nettoyage commodément immédiatement après l'agnelage. Eviter tout changement subit à une nourriture succulente qui provoque la diarrhée, car les mouches à viande commencent à attaquer les animaux vers la fin du mois (voir page 65). Vers 
la fin d'avril, détruire les moustiques en répandant de l'huile sur les flaques d'eau formées par la fonte des neiges (voir page 22). Traiter les poules couveuses avec du fluorure de sodium appliqué en pincée, pour détruire tous les poux avant l'éclosion des poussins (voir page 84).

Mai.-Vers le milieu de mai, appliquer le quatrième lavage de derris en Colombie-Britannique et le troisième dans les autres provinces pour la destruction de l'hypoderme; l'hypoderme adulte est actif à ce moment et des refuges sont nécessaires pour les bovins. Si le temps est pluvieux, c'est à ce moment que les mouches à viande sont les pires; il faudra donc brûler toutes les carcasses et les charognes et faire usage de pièges à poison pour les mouches; traiter toutes les marques, les coupures et les blessures laissées par la tonte sur les moutons avec de l'huile de goudron de pin pour repousser les mouches (voir page 65). Baigner les agneaux après que les brebis ont été tondues pour empêcher les barbins (mélophages) du mouton de se concentrer sur elles (voir page 70). L'œstre du mouton commence à inquiéter ces animaux vers la fin du mois; il faut donc goudronner les naseaux du mouton ou fournir des billots de sel goudronné (voir page 59). Retourner à la charrue les champs infestés de tiques d'hiver afin de détruire les œufs et les nymphes de tiques et le champ sera propre l'automne suivant (voir page 108). Dans l'Ouest, tuer au fusil ou prendre au piège les siffleux, les géomys et les autres r'ongeurs afin de réduire les hôtes de la tique à paralysie. Charrier le fumier et l'épandre en couche mince sur le champ pour empêcher la multiplication des mouches communes ou se servir de claies à fumier et du piège à larves (voir page 12). Recouvrir d'huile toutes les flaques d'eau de neige et de pluie où les moustiques se propagent.

Juin.-Vers le 17 juin, appliquer le cinquième lavage de derris (le quatrième dans les districts plus froids) pour la destruction coopérative de l'hypoderme; le gros hypoderme prend son vol à la fin de ce mois et il déploie de l'activité jusqu'en août; fournir des refuges pour les bestiaux comme protection contre les hypodermes et les taons. La saison des mouches qui piquent commence aux premiers jours de juin; les taons des chevaux, les moustiques et les simulies ou mouches noires tourmentent à ce moment. En Saskatchewan, se protéger contre les essaims de mouches noires qui peuvent faire périr les bovins. Faire des feux de boucane partout où ces mouches apparaissent (voir page 31). Les mouches des cornes seront abondantes, épandre les bouses de vaches dans les pâturages deux fois par semaine pour les dessécher et empêcher les mouches de s'y développer. Ne jamais laisser le fumier s'accumuler dans les cour's de l'étable parce que les mouches s'y multiplient. Surveiller pour découvrir la première apparition des cestres du nez et munir les chevaux de protecteurs (voir page 37). Dans les districts infestés de la tique à paralysie, le commencement de juin est un bon moment pour entreprendre une deuxième campagne contre les siffleux et les autres rongeurs qui servent d'hôtes aux tiques; on devrait s'entendre avec ses voisins pour organiser une campagne systématique d'empoisonnement. Surveiller les crues des rivières, les flaques d'eau qui deviennent des foyers de multiplication pour les moustiques. Les mites ou poux des volailles commencent à tourmenter les volailles lorsque les chaleurs arrivent; nettoyer les poulaillers et pulvériser parfaitement avec de l'huile brute (voir page 97). Appliquer une solution de sulfate de nicotine à 40 pour cent aux juchoirs dans les poulaillers pour détruire les poux et les mites des volailles (voir page 84). Dans l'Est du Canada, le hanneton du rosier fait sa première apparition au commencement de juin et dure jusqu'en juillet; protéger les poussins contre l'empoisonnement en les tenant sur des champs dépourvus des végétaux qui attirent ces hannetons; sur les grandes fermes avicoles faucher les parcours à poulets vers le 1er juin.

Juillet.-Ce mois est le pire de tous pour les mouches qui piquent: taons des chevaux, mouches noires ou simulies, moustiques et mouches des cornes; 
tous se multiplient; les œestres du nez et de la. gorge sont à leur pire sur les chevaux et le gros hypoderme commence à affoler les bestiaux. Il ne faut pas négliger d'adopter des moyens de protection contre ces fléaux si on ne l'a pas encore fait jusque là. On fournira des refuges obscur's faits avec des broussailles ou l'on tiendra les animaux à l'écurie ou à l'étable pendant le jour si cela est possible; on se tiendra prêt à faire des feux de boucane au premier signe d'apparition d'essaims de mouches noires en Saskatchewan et ailleur's. Si les taons des chevaux sont très abondants, se servir de filets à mouches sur les chevaux. Fournir des protecteur's approuvés pour empêcher la ponte des oufs sur les chevaux par les œestres du nez et de la gorge. Les mouches communes deviennent souvent nombreuses à ce moment; épandre le fumier pour les empêcher de se multiplier et placer des pièges à mouches dans les laiteries et les étables (voir page 17). Une deuxième pulvérisation contre les poux ou mites des volailles peut être nécessaire; examiner le poulailler pour voir si la dernière pulvérisation a eu de l'effet.

Août.-Sur les pacages alpestres à moutons, les mouches qui sucent le sang, comme les taons des chevaux et les mouches qui piquent, sont à leur pire au commencement d'août. Les chevaux de somme peuvent avoir besoin d'être protégés, surtout contre les mouches qui piquent; un mélange de substances repoussantes peut être utile; des feux de boucane sont souvent nécessaires. Dans certains endroits les mouches noires (simulies) sont très gênantes maintenant; pour protéger les chevaux contre l'espèce qui infeste les oreilles, recouvrir les oreilles de sacs en toile (voir page 32). La dernière partie d'août est un bon moment pour baigner les troupeaux de la ferme afin de détruire les mélophages ou barbins du mouton. Un deuxième bain est nécessaire après un intervalle de vingt-quatre jours. Traiter' les chiens et les chats et les endroits dans lesquels ils se tiennent, pour détruire les puces (voir page 73). Les mouches communes sont souvent extrêmement nombreuses; continuer à traiter le fumier, se servir de pièges à mouches munis de bons appâts dans les laiteries et autour des étables, et de pulvérisation de pyrèthre et d'huile de charbon pour détruire les mouches qui volent dans ces endroits (voir page 17). Surveiller les moutons pour voir s'ils sont attaqués par les mouches à viande.

Septembre.-C'est le dernier mois de l'année où l'on peut baigner les animaux sans danger dans les régions les plus froides, comme les Provinces des Prairies. On protégera les chevaux et les bovins contre les poux, la gale et les autres parasites extérieurs avant l'hiver en les baignant systématiquement; deux bains sont nécessaires à intervalle d'environ deux semaines (voir pages 81-94). On baignera aussi les moutons des ranches pour détruire le barbin et les autres parasites externes dès que ces moutons sont descendus des pâturages aspestres, car deux bains sont nécessaires et il faut laisser s'écouler un intervalle de vingt-quatre jours entre les deux; généralement, il y a suffisamment de journées chaudes pour faire ces opérations (voir page 70); il est dangereux de baigner lorsqu'il fait froid. Il faut débarrasser les cochons des poux et des autres parasites externes en se servant d'un bain médicamenté si cette précaution n'a pas été prise; donner le traitement avant que les temps froids arrivent (voir page 82). Lorsque la tique d'hiver abonde, ramener les chevaux et les bovins des pacages broussailleux et accidentés avant l'arrivée des froids, lorsque les jeunes tiques deviennent actives et commencent à infester les animaux; les chevaux et les bovins selont hivernés dans les pâturages sans tiques jusqu'au mois de mai (voir page 108). Une autre application de sulfate de nicotine à 40 pour cent sur les juchoirs dans les poulailler's est à recommander pour protéger les volailles contre les poux et les autres parasites externes.

Octobre.-Partout où cela peut se faire, on fera lutter les brebis avant la fin d'octobre pour qu'elles agnèlent en mar's, afin d'éviter les attaques des mouches à viande; il est même préférable de les faire lutter plus tôt si cela est possible. Les mouches noires (simulies) peuvent encore être très gênantes 
dans certains districts et l'on devra protéger les chevaux au moyen de sacs d'oreilles contre les espèces qui préfèrent cette partie du corps.

Novembre.-Le moment est arrivé de mettre tous les bâtiments et les refuges en bon état sanitaire pour l'hiver; se servir d'un lait de chaux désinfectant (voir page 94), qui détruit toutes les mites, tous les poux et tous les autres parasites qui peuvent se loger dans les fentes et les boiseries. S'arranger avec un vétérinaire compétent pour traiter les chevaux avec du bisulfure de carbone pour les oestres; en même temps essuyer les jambes et les autres endroits où des œufs ont été pondus avec un lavage de coaltar-créosoté à 2 pour cent pour détruire tous les œufs encore non éclos de l'œstre ordinaire; s'arranger avec les voisins pour faire un traitement systématique de tous les chevaux dans le district. Chez les grands troupeaux dans les parties intérieures de la ColombieBritannique et dans les parties les plus froides du Canada, les bergers sont d'avis que le mois de novembre est le meilleur pour faire lutter leurs brebis pour que les agneaux viennent au monde en avril. Comme les attaques de la mouche à viande sont à r'edouter, les brebis deviaient être luttées aussitôt que possible.

Décembre.-Le traitement des chevaux pour les ostres devrait être terminé vers la mi-décembre, si cela est possible. Surveiller les animaux pour les symptômes de poux ou de gale. 


\section{INDEX}

Aedes.

Acares ou mites des follicules.

Acares ou mites des follicules des poils

Acide borique.

Acide carbolique.

Acide tannique.

A mblyomma amerieana $\mathrm{L}$

Ane, pou de l'.

Animaux "frappés "...

Anopheles, esp.

$8,76,82,85,111,113$

Anoplura.

Appâts contre les mouches.

Appâts empoisonnés contre les mouches..

Arsénite de soude

Formaline.

Arduenna strongylina Rudolphi

Arsenic blanc.

Arsénite de soude

Arthropodes.

Bain de chaux soufrée.

Bain de coaltar-créosoté.

$94,96,114$

Bain médicamenté pour les pores........ 83, 84, 113

Bains................ 8, 66, 69, 70, 82, 94, 104

Bains d'arsenic...................

Bains pour les moutons.............. $66,69,83,94$

Barbins (mélophages) des moutons.......8, 68, 111

Baume du Pérou.

Benzine.

Benzol.

Billots goudronnés remplis de sel

Bisulfure de carbone.

Boeuf, gale du.

$8,08,111$

59,66

8,66

59,112

Bøuf, hypodermes du. . 5, 7, 10,42-52, 111, 112, 113

Bøuf léché.

49

Boeuf, poux broyeurs du...8, $79,81,82,85,111,113$

Bœuf, poux suceurs...........8, 75, 82, 85, 111

Bogeria grisea Coq.

Bois, tique des.

Borax....

Boucanes

Bousiers

Bovicola bovis L

$8,10,24,31,112$

Breeze flies.

Brûlots ou moucherons.

Calliphora romitoria $\mathrm{L}$.

Camphre...

Canards, maladie des.

Cantharis, esp...

Carbonate de soude

Caribou, hypoderme du

Caribou, oestre du

Cephenomina pratti Hunter.

Cephenomyia trompe $\mathrm{L}$

Ceratophyllus gallinae Schrank

Cerf wapiti, larve du nez et de la gorge du

Cerf wapiti, tique du..............106, 112, 113

Charbon...

$\ldots .6,12,25$

Charbon symptomatique.

Chat, gale du.

Chat, gale du...............

Chats, poux broyeurs des...

Chats, puces des.

Chaux.

Cheval, gale du

Cheval, oestres du

Cheval, poux broyeurs du

$\ldots \ldots$

12
91,95

80,84

71,72

$12,69,94,95,114$

$85,88,94,114$

$.5,8,34,40,113$

$8,79,81,84,111$

$112,113,114$

Cheval, poux suceurs du..... 8, 76, 82, 85, 111, 113

Chevaux, fièvre des marais chez les.

Chevaux, taons des.....5, 6, 7, 8, 9, 24, 26, 112, 113

Chèvre, gale de la.................. $90,94,95$

Chèvres, larve des narines chez les......... $\quad 59$

Chèvres, poux broyeurs des............ 80,81

Chèvres, poux suceurs des................... 76, 81

Chevreuil, larve du nez et de la gorge..

60
PAGE

Chevreuil, liptotène ou mouche-araignée du. 67,70 Chevreuil, mouche du................ 6, 24 Chien, gale du.................... 91, 95 Chien, poux broyeurs du............. 80,84

Chien, poux suceurs du.............. 77, 84

Chien, puce du .................. 71, 73

Chien, ténias du............... 58, 72, 80

Chien, tique américaine du............. 108

Chien, tique du................... 9, 108, 109

Chloroforme....................... $\quad 66$

Choc anaphylactique................ 50-52

Choléra des pores....................... $\quad 12$

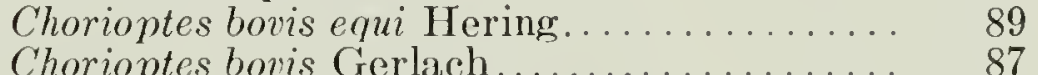

Chorioptes eaprae Gerv. et Benedin......... 90

Chorioptes eommunis Verh. var. ovis......... 90

Chorioptes eunieuli Zürn................ 91

Chorioptes equi Gerlach................ 89

Chorioptes, esp...................... 85

Chorioptique, gale............. 85, 89, 90, 94

Chrysops........................... 24

Chrysops disealis Will...................... 24, 25

Cimex leetularius L.................. $\quad 73$

Citronnelle......................... 23

Cnemidocoptes gallinae Railliet............. 92

Cnemidocoptes mutans Robin.............. 92

Coehliomyia maeellaria Fabr................. $\quad 62$

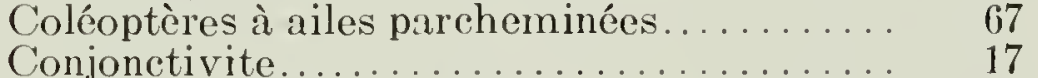

Conjonetivite habronémique............ 16

Créoline ou crésol..............70, 73, 84, 95, 96

Cr'ésol ou créoline.................70, 73, 84, 95, 96

Ctenocephalus eanis Bouche.............. 71

Ctenoeephalus felis Curt................ 71

Culex, esp.......................... 21

Culicidés.......................... 21

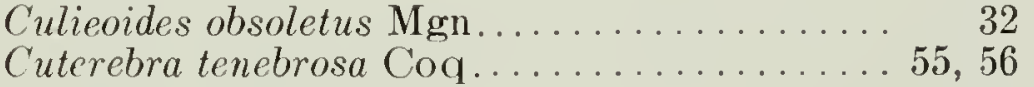

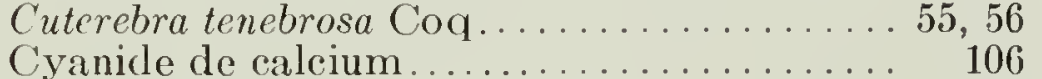

Cytoleiehus mudus Vizioli.................. 98

Demodex eanis Leydig.................. 91

Demodex caprae Railliet.................... $\quad 90$

Demodex follicularum boris Stiles........... $\quad 88$
Demodex phylloides Csokor.......... 90

Dermaeentor albipietus Packard .............. 106, 110

Dermacentor andersoni Stiles...........99, 109, 111

Dermacentor variabilis Say................ 108

Dermaeentor venustus Banks.............. 99

Dermanysse des poulaillers ou pou des vo-

lailles.

$97,98,112$

Dermanyssus gallinae I.............

Derris ................... 8, 53, 73, 83, 84

Dipylidium caninum L................. 7,8

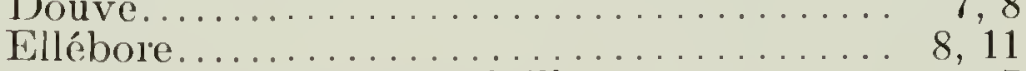

Empoisonnement des volailles.............

Emulsion d'huile de charbon............ 31, 82

Escargots........................ 7,8

Essence de carvis..................... 99

Fièvre des marais chez les chevaux........ 25

Fièvre des Montagnes Rocheuses. . 102, 105, 103, 110

Fièvre des Montagnes Rocheuses, tique à.... 99

Fluorure de sodium...........8, 82, 84, 96, 111

Fluosilicate de soude ................ 8,11

Folliculaire, gale $\ldots \ldots \ldots \ldots \ldots \ldots \ldots \ldots 88,90,91,96$

Formaline....................... 9, 18

Formule pour bains contre la gale......... 94, 95

Formule pour bains contre les poux......... 82

Formule pour bains contre les tiques....... 104, 105

Fumier, soin et traitement...

Fumier, traitement pour supprimer les foyers de multiplication des mouches......... 8

Fumier, transmission des parasites et des

maladies par le....................... 
INDEX-suite

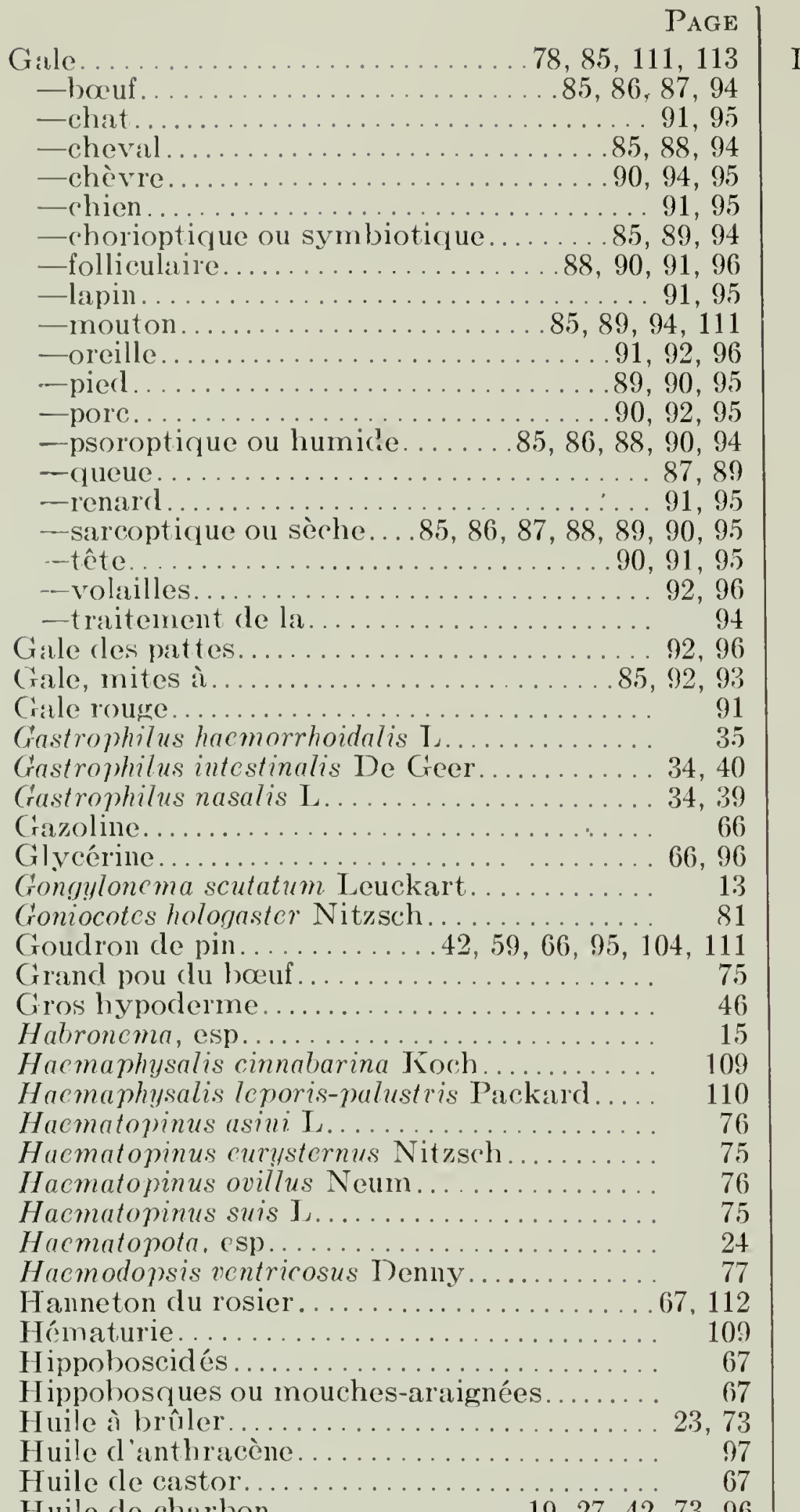

Insecticides-fin

-Benzol.................... 8, 66

-Bisulfure de carbone........8, 37, 40,41, 114

-Borax................... 8, 11

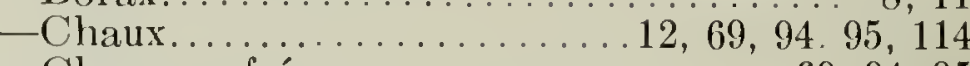

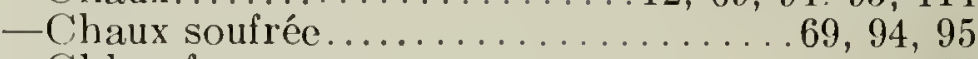

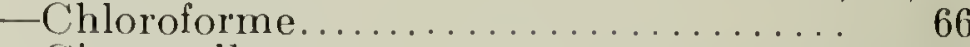

- Citronnelle.................... 23

—Crésol ou créoline......... $70,73,84,95,96$

-Derris...........8,53,73,83,84,111, 112

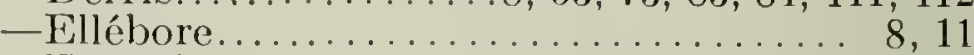

-Emulsion d'huile de charbon .......... . 31, 82

- Essence de carvis............ 96

- Fluorure de sodium.........8, $82,84,96,111$

_Fluosilicate de soude ............... 8, 11

-Formaline.................. 9, 18

- Formule pour bains contre la gâle...... 94

- Formule pour bains contre les poux...... 82

- Formules pour bains contre les tiques... 104

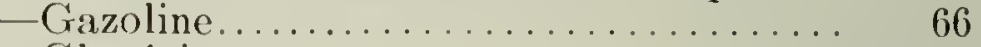

- Glycérine............. . . . . . . 66, 96

- Coudron de pin........42, $59,66,95,104,111$

- Huile à brôler.................. 23, 73

- Huile d'anthracène. . . . . . . . . . . . . . 93

- Huile de charbon.......... 19, 27, $42,73,96$

- Huile de cotoll..................... 104

- Huile de créosote........... 24, 66, 73, 95, 96

- Huile de goudron . . . . . . . . . 7, 19, 31, 66, 111

-Huile de lin brute. $8,31,66,82,95,96,104,111$

- Huile de pin............... 19, 21, 23, 104

- Huile de poisson . . . . . . . . . . . . 19, 23, 31

-Huile miscible.................... 8,31

- Huile usagée. ............ . . . . . . . . 97

- Huiles de pétrole............ 8, 74, 83, 95

-Iode.......................... 96

-Mélanges de soufra..........94, 95, 96, 98

- Naphtaline.................... 83

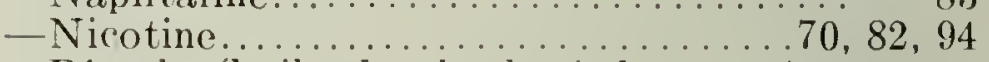

- Pétrole (huile de charbon) brut... .74, 83, 95,

96,113

- Pouliot............................... .

Pulverisation de pylèthre-hulle de char-Pyrèthre............... $8,70,73,83,11$ -Sel

-Sulfate de cuivre ............ 8

- Sulfate de nicotine......... $8,84,97,112,113$

-Térébenthine.......... 59,66

-Tétrachlorure de carbone.......... 8, 66

-Volck..................... 8 , 82

Ixode ricin ou tique du chien . . . . . . . . . . 109

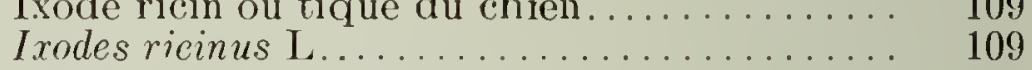

Jiggers (paralysia agitante) ................... $\quad 36$

Laminosioptes cysticola Vizioli.............. 98

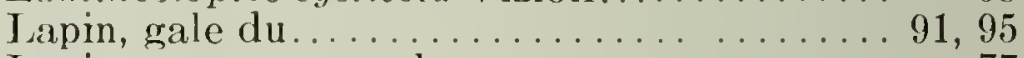

Lapin, poux suceurs $\mathrm{l}$. . . . . . . . . . . . . .

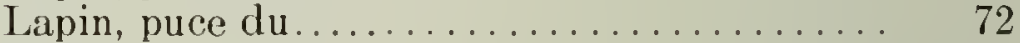

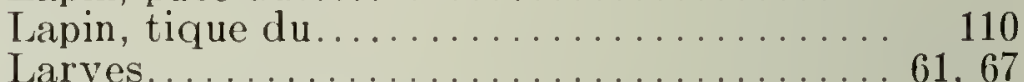

Larves......................... 61, 67

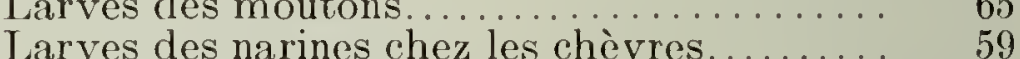

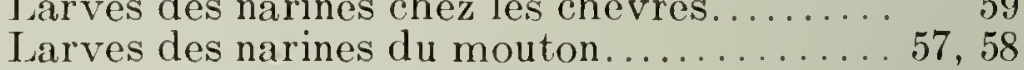

Larves d'hypodermes (varrons) .........8, 36, 88

Larves du nez et de la gorge du chevreuil... $\quad 60$

Larves qui affectent les oiseaux qui couvent. $\quad 66$

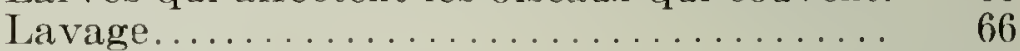

Lavag à la chaux ....................... 94

Lavage au savon derris............ $8,53,111,112$

Lavage contre les larves du mouton........ 66

Leucocytozoon anatis Wickware............. 30

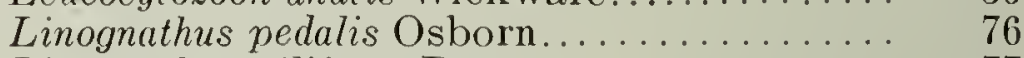

Linognathus piliferus Burm.................. 77

Linognathus stenopsis Burm.............. 76

Linognathus vituli L.................. 75

Lipeurus heterographus Nitzsch.......... 81

Lipeurus variabilis Nitzsch.............. 81

Liponyssus canadensis Banks.............. 98

Liponyssus sulviarum C.\& F............. 98 


\section{INDEX-suite}

Lipoptena depressa Say

Liptotène ou mouche-araignée du chevreuil

Looping ill.

Lucilia caesar I

Lucilia sericata Meig.

Lucilie anglaise de la laine des moutons. .

Lynchia, esp

Lyperosia irritans L...

Lysol.

Macracanthorhynchus hirudinaceus Pallas 1781, Travossos, 1916

Macrodactylus subspinosus Fab.

Macrodactylus uniformis Horn

Maladie des yeux chez les bovins.

Maladie des veux chez les chevaux.

Mal du garrot.

Mallophages...

Maringouins ou moustiques.

Mélanges de soufre.

Mélophage du mouton.

Melophagus ovinus L

Menopon gallinae $\mathrm{L}$. .

Menopon stramineum Nitzsch

Mite à sac d'air.

Mite de la gale rouge

Mite des volailles du Nord

Mite du tissu connectif...

Mites à gale.

Mites à gale du mouton.

Mites déplumeuses...

Mites des follicules ou acares

Mites des volailles.

Mouche à queue rouge.

Mouche-araignée ou liptotène du chevreuil. 67,70

Mouche à viande du Sud. . .

Mouche charbonneuse.

Mouche charbonneuse ou mouche des étables. 6,8

$10,14,18,111,112,113$

Mouche des étables ou mouche charbonneuse 6,8

Mouche du chevreuil

$10,14,18,111,112,113$

Mouche noire de la viande.

6,24

Moucheron buffalo.

61,63

Moucherons ou brûlots.

Mouches à chair (à riande)

21,32

62,67

Mouches bleues de la viande $5,6,7,8,50,55,60$,

Mouches bouledogues

$67,104,111,112,113$

Mouches communes.6, 8, 10, 11, 12, 13, 111, 112, 113

Mouches des cornes.

$5,8,10,19,112,113$

Mouches mordantes ou symphoromies. $32,33,113$

Mouches noires ou simulies.5, 6, 7, 8, 9, 28, 112, 113

Mouches piquantes.

$6,20,21,32$

Mouches-poux des oiseaux ...

Moustiques ou maringouins..... $5,7,8,21,112,113$

Mouton, barbins (mélophages) du..8, 68, 70, 111,

Mouton, gale du

112,113

Mouton, larves des narines du.

$85,89,94,111$

Mouton, lucilie anglaise de la laine du .

57,58

62,67

Mouton, mites à gale du.

$85,89,94$

Mouton, oestre du.

$5,7,56,112$

Mouton, pou à tête rouge du

Mouton, poux broyeurs du.

Mouton, poux suceurs du.

Multiceps multiceps Leske.

Musca domestica $\mathrm{I}$

$79,82,83$

$76,82,111$

Myiase.

$35,61,52,64$

Myiase chez l'homme

35,64

Naphtaline.

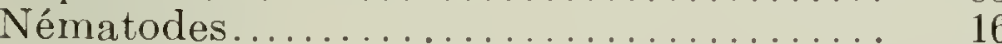

Nez coulant........................ $5{ }_{58}$

Nicotine.....................70, 82,94

Noir museau....................... 90,95

No-see-um (invisibles)

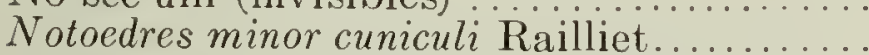

Notoedres minor Fürst. var. cati Hering.....

Edemagena tarandi $\mathrm{L}$

Estre de la gorge.
Estre du caribou.

PAGE

Estre du cheval.

Estre du mouton

$5,7,56,112$

du nez ou ostre hémorroidal $35,36,112,113$

Estre hémorroïdal ou oestre du nez 35, 36, 112, 113

(Estres.

$7,34,112$

Oestrus ovis $\mathrm{L}$

56

Oiseaux, mouches-poux des.............. 71

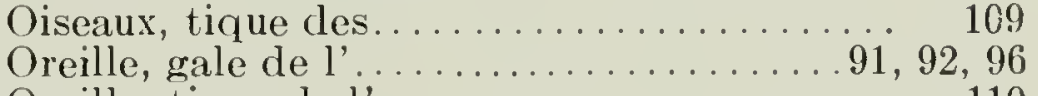

Oreille, tique de l'

Orignal, tique de l'............................... 106

Ornithodoros megnini Duges.............. 110

Ornithoica, esp

Otodectes cynotis Hering.

Paralysie agitante (Jiggers)

Paralysie à tique. .

$.102,103,108$

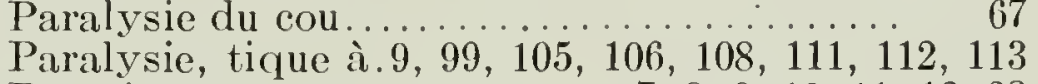

Parasites................7, 8, 9, 10,11, 12, 28

Parasites des tiques................... 106

Peaux endommagées ou "varromnées »....... 49

Peste bubonique..................... $\quad 72$

Petit pou des poulets.................. 81

Pétrole (huile de charbon) brut. . . 74, 83, 95, 96, 113

Phormia regina Mgn..................... 61, 63

Physoce phalus sexalatus (Molin) Diesing...... 13

Pied, gale du.................... 80, 90, 95

Piège à larves . ...................11, 12, 112

Pièges contre les mouches... . 8, 17, 28, 65, 112, 113

Pies..... 50

Plaies des chevaux......................... 15

Poison contre les rongeur's.............105, 111

Poll evil .

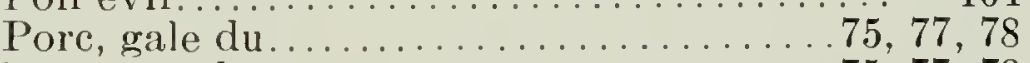

Porc, pou du.................... 75, 77, 78

Pore poux suceul's du .............. 75, 83, 113

Pore, puce du...................... 71, 72

Pou à large thorax................... $\quad 75$

Pou à nez court du bétail................ $\quad 75$

Pou à nez long du bétail.................... $\quad \begin{array}{r}75 \\ \text { Pou à tête }\end{array}$

Pou à tête louge du mouton.............. $\quad 79$

Pou commun des volailles.............79, 80, 81

Pou des volailles ou dermanysse des poulaillers.

Pou de tête des volailles.

Pou du corps des volailles.

Pou clu pied du mouton.

Pou du pore. .

Pou duveteux

Poule, pou variable de la

Poulets, petit pou des

Poussières contre les poux des volailles.

Pou variable de la poule

Poux broyeurs.

- bouf. .

- chat.

$112,113,114$

- cheval.

-chien.

80,81

- mouton.

80,84

- volailles.

- destruction des.

- vie et habitudes de

Poux suceurs $74,81,95,111,112,113,114$

—bœuf................. $8,75,81,85,111$

— cheval ou âne............. $8,76,82,85,111,113$

-chèvre ......................76, 81

— chien ..................... 77,84

-lapin................................... 77

-mouton..................76,82,111

-porc............ 75, 83, 113

- destruction des................. 81

- cycle évolutif et habitudes des.......... $\quad 77$

Préparations anti-mouches............ 7,51

Protecteurs contre les mouches...... . . 9, 10, 28, 37, 


\section{INDEX-fin}

Protecteurs mécaniques.....

Protecteurs mécaniques contre les mouches.

Protocalliphora avium Shann. \& Dobr

Protocalliphora hirudo cuprea Shann. \& Döbr.

Protocalliphora splendida Maca. .

Photophormia terrae novae Desv...

Psoroptes communis bovis Hering.

Psoroptes communis caprae.

Psoroptes communis equi Hering.

Psoroptes communis ovis Hering.

Psoroptes cuniculi Delafond.

Psoroptique, gale.

Puce du chat.

Puce du chien.

Puce européenne ordinaire des volailles.

Puce du lapin...

Puce du porc.

Puce du renard.

Puces.

Puces de l'homme

Pulex irritans

Pulvérisation de pyrèthre-huile de charbon. . 8, 18 $19,21,73,113$

Punaises communes comme fléau des volailles 73 Pyrèthre. . .......... 8, 70, 73, 83, 111

Queue, gale de la................. 87, 89

Refuges contre les inouches... $10,38,40,60,112,113$

Refuges de broussailles.

Renard, gale du

Renard, puce du.

Rongeurs, poison contre les

105,111

Rosier, hanneton $\mathrm{du}$

67,112

Rougeole

13

Sacs pour les oreilles.

$7,32,113,114$

42,96

Sarcophaga, esp

Sarcoptes scabici bovis Robin

Sarcoptes scabiei canis Gerlach.

Sarcoptes scabiei caprae Furstenburg

Sarcoptes scabiei cuniculi Gerlach.

Sareoptes scabiei equi Gerlach.

Sarcoptes scabiei ovis Megnin.

Sarcontes scabiei suis Gerlach.

Sarcoptes scabiei vulpis Railliet.

Sarcoptique, gale.

Sel contre les mouches.

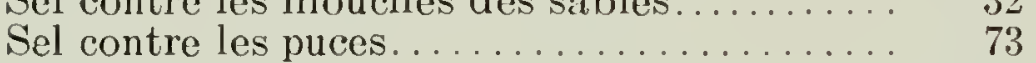

Sels d'Epsom ........................ 67

Simulie à bas blancs.

Simulies ou mouches noires. $5,6,7,8,9,28,112,113$

Simulium venustum Say..............29, 30, 32

Simuiium vittatum Zett.

Simullidés.

Soloneptes capillatus Enderlein.

Spilopsyllus cuniculi Dale.

$59,65,104,112$

Substances repoussantes contre les mouches. 7,9

$19,23,42,59$

Substances repoussantes contre les mouches

des étables.

Sulfate de cuivre.

Sulfate de nicotine.

Stomoxys calcitrans $\mathrm{I}$.

$8,84,97,112,113$
Strychnine.

PAGE

Symphoromies ou mouches mordantes. .32, 33, 113

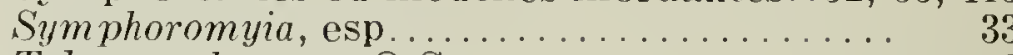

Tabanus phaenops O.S................ 28

Tabanus punctifer O.S ..............25, 27, 28

Taon des tanneurs ou hypoderme rayé...... . 43, 110

Taon ordinaire à tête verte............ 28

Taons des chevaux.... 5, 6, 7, 8, 9, 24, 26, 112, 113

Ténia à pores doubles du chien........... 72

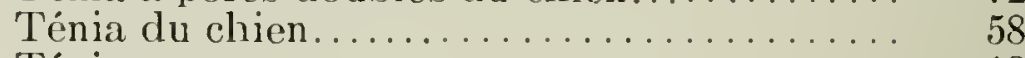

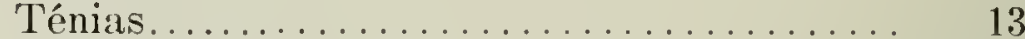

Ténias des volailles.................... 16

Térébenthine................. 59, 66

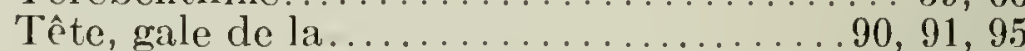

Tétrachlorure de carbone........... 8,66

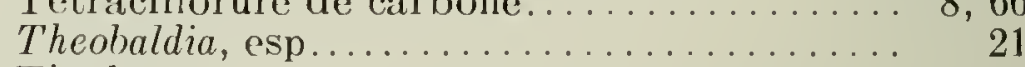

Tipules......................... 21

Tiques...5,6, 7,8,98, 111, 112

- à fièvre des Montagnes Rocheuses...... 99

-américaine du chien................ 108

-à paralysie....9, 99, 105, 106, 109, 111, 112, 113

-de l'oreille............... 110

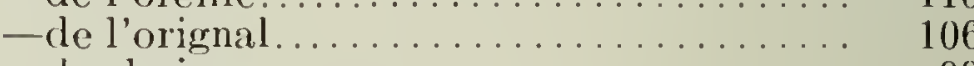

- des bois........................

-des oiseaux....................... 109

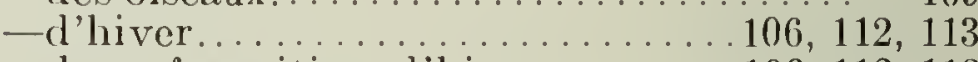

- lu cerf wapiti ou d'hiver..........106, 112, 113

-du cheval........................ 106

- du chien......................... 108, 109

- du lapin........................ 110

-du mouton............8,69, 70,111, 112, 113

¿étoilée...................... 110

-moyens répressifs et remèdes...... .8, 104, 108

Toile, capuchons, couvertures, pantalons, etc

Tournis

$7,8,19,40$

Trichodectes eanis DeGeer................ 80

Trichodectes caprae Gurlt................ 80

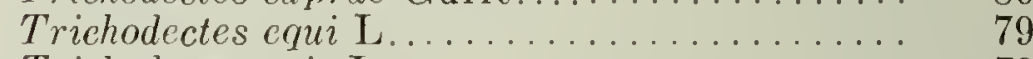

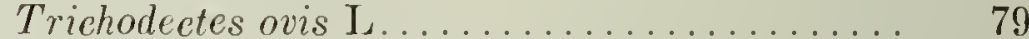

Trichodcetes parumpilosus Piaget........... 79

Trichodectes pilosus Giebel.............. 79

Trichodectes sealaris Nitzsch................. 79

Trichodectes subrostratus Nitzsch............ 80

Trichogramma minutum Riley.............. 28

Tuberculose....................... 12

Tularémie..............6, 25, 102, 108, 110

Varrons (larves d'hypodermes) ........ 8, 36, 88

Ver géant à tête épineuse............... 13

Vers ......................6, 13, 15, 63, 66

Vers de l'estomac des pores................ 13

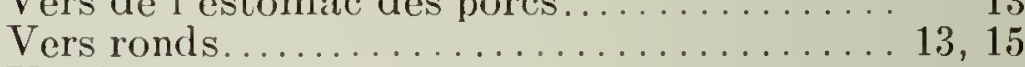

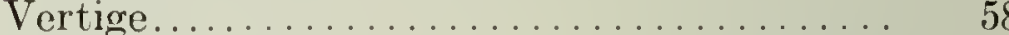

Volailles, gale des................ $92,96,98,113$

Volailles, mites des........96,97,98,112,113, 114

Volailles, pou commun des...........79, 80, 81

Volailles, pou de tête des............... 81

Volailles, pou du corps des................ 80, 81

Volailles, poussières contre les poux des...... 84

Volailles, poux broyeurs des...... 8 ,80, 82, 84, 96

Volailles, puce européenne ordinaire des..... 1112,71

Volailles, ténias des....................... 16

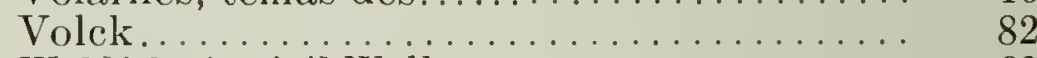

Wohlfahrtia vigil Walker....................... 62 




\section{LISTE DES PUBLICATIONS}

On peut se procurer les publications suivantes sur les insectes, toutes publiées par le Ministère de l'Agriculture, en en faisant la demande au Directeur de la publicité, Ministère de l'Agriculture, Ottawa:

La chenille à toile de la betterave............... Circulaire $\mathrm{n}^{\circ} 14$

La larve des pommes et moyens de la combattre dans la

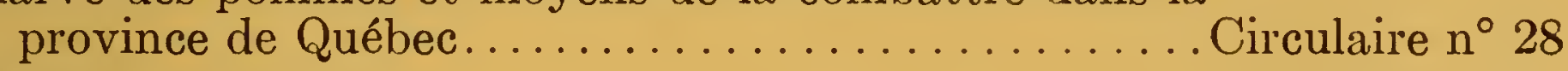

Le kermès Lecanium......................... Circulaire $\mathrm{n}^{\circ} 77$

Moyens de combattre la mouche importée de l'oignon... Circulaire $\mathrm{n}^{\circ} 88$

Le coupe-bouton du fraisier.....................

La mouche de Hesse dans les Provinces des Prairies.... Feuillet $n^{\circ} 30$

Les insectes nuisibles aux arbres d'ombrage dans les

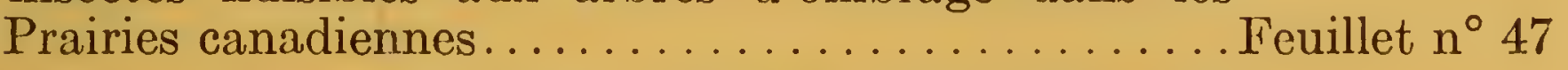

Maringouins, mouches noires, brûlots, etc.-Comment

$\mathrm{s}^{\prime}$ en protéger dans la forêt................... Feuillet $\mathrm{n}^{\circ} 55$

Criquets (sauterelles) comment les combattre au Canada,

à l'Est des Montagnes Rocheuses................Feuillet $n^{\circ} 146$

Moyens de combattre l'hypoderme au Canada.........Feuillet $\mathrm{n}^{\circ} 147$

Le thrips du glaïeul...................... Feuillet $n^{\circ} 151$

\section{PUBLICATIONS RÉCENTES-NOUVELLE CLASSIFICATION}

Insectes qui attaquent les pommes de terre...........Publication $\mathrm{n}^{\circ} 505$ Guide du collectionneur d'insectes................. Publication $n^{\circ} 520$

La pyrale du maïs........................ (Affiche colorée) 
J.-O. PATENAUDE, O.S.I. IMPRIMEUR DU ROI

OTTAWA, CANADA 